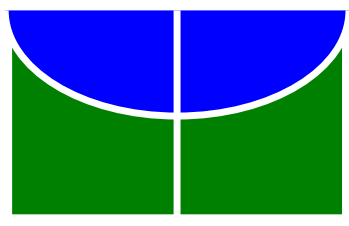

UNIVERSIDADE DE BRASÍLIA - UnB

INSTITUTO DE GEOCIÊNCIAS - IGD

PROGRAMA DE PÓS-GRADUAÇÃO EM GEOLOGIA

O POTENCIAL DE AGROMINERAIS SILICÁTICOS COMO FONTE DE NUTRIENTES NA AGRICULTURA TROPICAL

Fred Newton da Silva Souza

TESE DE DOUTORADO N 119

Orientador: Claudinei Gouveia de Oliveira

Co-orientador: Éder de Souza Martins 


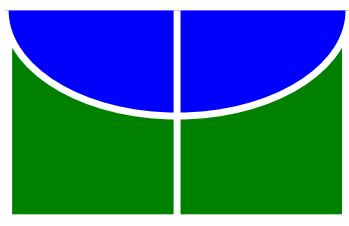

UNIVERSIDADE DE BRASÍLIA - UnB

INSTITUTO DE GEOCIÊNCIAS - IGD

PROGRAMA DE PÓS-GRADUAÇÃO EM GEOLOGIA

O POTENCIAL DE AGROMINERAIS SILICÁTICOS COMO FONTE DE NUTRIENTES NA AGRICULTURA TROPICAL

Fred Newton da Silva Souza

TESE DE DOUTORADO N 119

Orientador: Claudinei Gouveia de Oliveira

Co-orientador: Éder de Souza Martins 


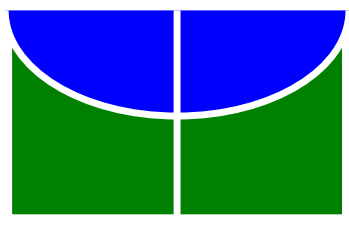

UNIVERSIDADE DE BRASÍLIA - UnB

INSTITUTO DE GEOCIÊNCIAS - IGD

PROGRAMA DE PÓS-GRADUAÇÃO EM GEOLOGIA

O POTENCIAL DE AGROMINERAIS SILICÁTICOS COMO FONTE DE NUTRIENTES NA AGRICULTURA TROPICAL

Fred Newton da Silva Souza

Tese de doutorado apresentada ao Curso de Pós-Graduação em Geologia - Área de Concentração Mineralogia e Petrologia, para obtenção do título de Doutor em Geologia.

Orientador: Claudinei Gouveia de Oliveira

Co-orientador: Éder de Souza Martins 
FOLHA DE JULGAMENTO

\section{O POTENCIAL DE AGROMINERAIS SILICÁTICOS COMO FONTE DE NUTRIENTES NA AGRICULTURA TROPICAL}

\section{Candidato: Fred Newton da Silva Souza}

Programa: Pós-Graduação em Geologia, Área de concentração Mineralogia e Petrologia, para obtenção do título de Doutor em Geologia.

Data da defesa: 04 de Dezembro de 2014

Banca Examinadora:

Prof $^{a}$.Dra . Edi Mendes Guimarães (UnB-IG)

Profa.Dra. Suzy H. Theodoro (UnB-CDS)

Prof. Dr. Antonio Carlos de Azevedo (ESALQ-LSO)

Prof. Dr. Jeremie Garnier (UnB-IG)

Prof. Dr. Claudinei Gouveia de Oliveira (UnB-IG) 
Dedico este trabalho,

e a trajetória desta conquista, a você,

se você aceitar que "a imaginação é mais importante que o conhecimento"

Albert Einstein

"Não há fatos eternos, como não há verdades absolutas"

Friedrich Nietzsche

À Juliana, minha admiração e companheira de todos os momentos,

Ao Otto e ao Munir por todas as alegrias, meus grandes amores,

À Fundação Universidade do Tocantins, pela oportunidade,

À Universidade de Brasília e ao Instituto de Geociências pelo apoio,

Ao orientador, Prof. Claudinei, pela confiança,

Ao co-orientador, Prof. Éder, pelas valorosas contribuições,

Ao Prof. D'Agostini, pela paciência,

À Claudia, por abrir a porta de sua casa sempre que precisei,

À Banca, pelas contribuições,

Aos amigos, por compreenderem minha ausência,

Ao Prof. Otton, pelo incentivo,

Ao Sr. Luis Carlos, da CooperSanto, pela abertura,

Aos colegas, pelas presenças,

A você, pela honra desta atenção,

Minha gratidão. 
Sumário

Lista de figuras

Lista de Tabelas

Abreviaturas, siglas e definições

Resumo

Abstract

\section{CAPÍTULO 1 \\ INTRODUÇÃO - IMPORTÂNCIA DO TEMA}

1.1. Introdução Geral.......................................................................................... 01

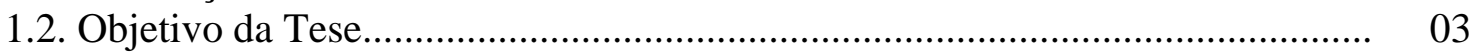

1.3. Fundamentação Teórica.................................................................................. 03

1.3.1. Dissolução mineral e liberação de nutrientes........................................... 03

1.3.1.1. Processos de intemperização química........................................... 03

1.3.1.2. Resistência mineral ao intemperismo............................................ 04

1.3.1.3. Cinética de dissolução mineral...................................................... 05

3.2. Ecofisiologia da produção vegetal......................................................... 08

1.3.2.1. Fatores de produção vegetal......................................................... 08

1.3.2.2. Nutrição mineral de plantas.......................................................... 09

1.3.2.3. Disponibilidade e dinâmica de nutrientes no solo......................... 11

1.3.3. Rochagem - remineralização de solos.................................................. 13

1.3.3.1. Agricultura tropical - particularidades e desafios........................ 13

1.3.2.2. Agrominerais silicáticos - pesquisas e rotas tecnológicas.............. 15

1.3.2.3. Regulamentação do usos de agrominerais silicáticos.................... 18

1.4. Síntese de uma proposição............................................................................. 19

\section{CAPÍTULO 2 \\ CARACTERIZAÇÃO DO AGROMINERAL SILICÁTICO}

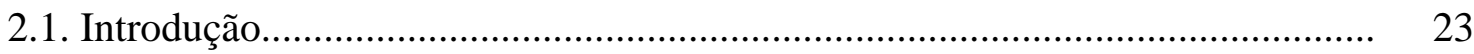

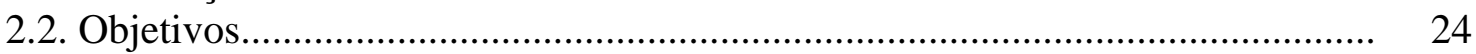

2.3. Material e Métodos.................................................................................. 24

2.3.1. Análises Físicas: Granulometria, Densidade Superfície Específica......... 25

2.3.2. Análises Petrográfica, Mineralógica e de Química Mineral.................... 25

2.3.3. Análise Geoquímica de elementos maiores, traços e ETRs...................... 26

2.3.4. Dissolução Parcial dos Minerais......................................................... 26

2.4. Resultados e Discussão..................................................................................... 26

2.4.1. Histórico e localização do Garimpo de Monte Santo-TO........................ 26

2.4.2. Aspectos fisiográficos da região............................................................. 27

2.4.2. Contexto geológico regional............................................................... 28

2.4.4. Caracterização do agromineral silicático............................................. 30

2.4.4.1. Petrologia e Mineralogia.......................................................... 30

2.4.4.2. Química Mineral .................................................................... 31

2.4.4.3. Geoquímica............................................................................ 36

2.4.4.4. Granulometria e Superfície Específica......................................... 38

2.4.4.5. Dissolução mineral por ataque sulfúrico...................................... 38

2.5. Considerações Complementares..................................................................... 39 


\section{CAPÍTULO 3 \\ DISSOLUÇÃO DO AGROMINERAL SILICÁTICO}

3.1. Introdução

3.2. Objetivos

42

3.3. Material e Métodos........................................................................................ 42

3.3.1. Características do agromineral silicático................................................ 42

3.3.2. Procedimento Experimental................................................................. 44

3.3.2.1. Dimensões das colunas de lixiviação............................................. 44

3.3.2.2. Composição dos tratamentos....................................................... 45

3.3.2.3. Características do solvente e taxas de fluxo................................... 46

3.3.4. Coleta e análise química do efluente..................................................... 47

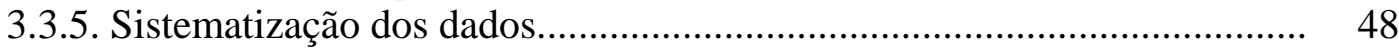

3.4. Resultados e Discussão...................................................................................... 49

3.4.1. Liberação dos elementos químicos do agromineral silicático................. 49

3.4.2. Dissolução mineral do agromineral silicático........................................ 50

3.4.3. Efeitos de diferentes solos na solubilização do agromineral silicático.... 52

3.5. Considerações Complementares...................................................................... 57

\section{CAPÍTULO 4 \\ EFICIÊNCIA NUTRICIONAL DO AGROMINERAL SILICÁTICO}

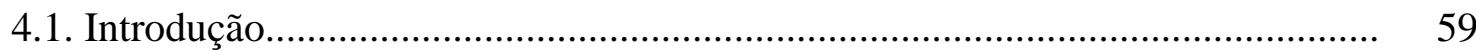

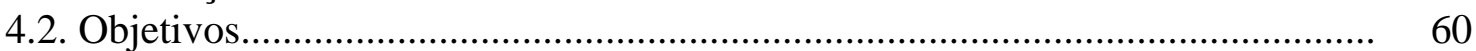

4.3. Material e Métodos........................................................................................ 60

4.3.1. Características do agromineral silicático e do solo.................................. 61

4.3.2. Composição dos tratamentos e condições de controle............................... 61

4.3.3. Parâmetros avaliados e sistematização dos resultados.............................. 63

4.4. Resultados e Discussão............................................................................... 64

4.4.1. Efeitos iniciais e de longo prazo sobre os atributos do solo.................... 64

4.4.2. Efeitos sobre o crescimento e a absorção de nutrientes pelas plantas..... 66

4.4.3. Eficiência relativa das fontes/doses........................................................ 73

4.5. Considerações Complementares...................................................................... $\quad 74$

\section{CAPÍTULO 5 \\ POTENCIAL DO AGROMINERAL SILICÁTICO NA CULTURA DA CANA-DE-AÇÚCAR}

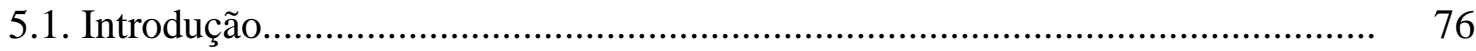

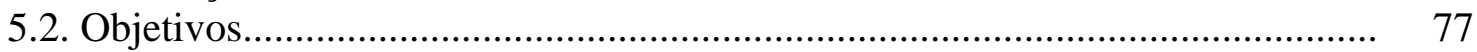

5.3. Material e Métodos............................................................................................ $\quad 77$

5.3.1. Condições edafoclimáticas do experimento.......................................... 78

5.3.2. Composição dos tratamentos e condições de controle............................ 79

5.3.3. Parâmetros avaliados.......................................................................... 80

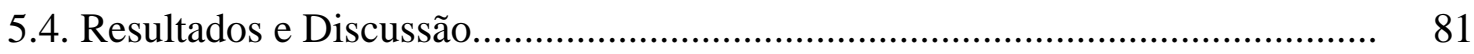

5.5. Considerações Complementares............................................................ 86 


\section{CAPÍTULO 6 \\ CONCLUSÕES, PERSPECTIVAS E CONSIDERAÇÕES FINAIS}

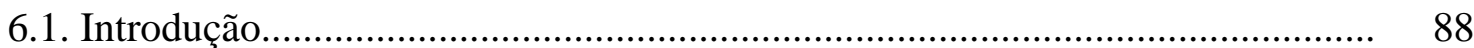

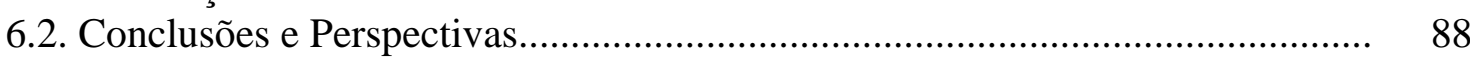

6.3. Considerações Finais...................................................................................... 91

CAPÍTULO 7

REFERÊNCIAS BIBLIOGRÁFICAS

7.1. Referência Bibliográficas..................................................................................... 93 


\section{Lista de Tabelas}

Tabela 2.1. Composição mineralógica modal e respectivas fórmulas estruturais.....

Tabela 2.2. Resultados dos teores dos elementos maiores totais (\% em massa)........

Tabela 2.3. Resultados dos teores dos elementos traços (ppm).

Tabela 2.4. Resultados dos teores dos elementos terras raras (ETR), Y e Sc (ppm).

Tabela 2.5. Teores dos elementos (\% em massa) extraídos por ataque sulfúrico.....

Tabela 3.1. Composição mineralógica modal e respectivas fórmulas estruturais.....

Tabela 3.2. Teores dos elementos maiores totais no agromineral (\% em massa)......

Tabela 3.3. Características físicas do agromineral......

Tabela 3.4. Características químicas e físicas dos solos e demais tratamentos avaliados no experimento.

Tabela 3.5. Tempo de percolação das lâminas aplicadas e acumuladas.

Tabela 3.6. Variações no pH e na concentração dos elementos nas soluções de reação do tratamento com agromineral (AS) nos diferentes momentos.

Tabela 3.7. Total dos elementos extraídos (mmoles) nos respectivos tratamentos...

Tabela 3.8. Liberação relativa dos elementos nos respectivos tratamentos.....

Tabela 4.1. Teores dos elementos maiores totais no agromineral (\% em massa)......

Tabela 4.2. Atributos físico-químicos originais do Neossolo Quartzarênico.

Tabela 4.3. Tratamentos de avaliação do potencial do agromineral silicático na disponibilidade de nutrientes no solo e na nutrição de plantas cultivadas.

Tabela 4.4. Médias para atributos químicos do solo após aplicação e incubação do agromineral e demais tratamentos por 30 dias

Tabela 4.5. Resumo das análises de variância conjunta para Matéria Seca (MS) e
Teores de Potássio (K), Cálcio (Ca) e Magnésio (Mg) para diferentes

Tabela 4.5. Resumo das análises de variância conjunta para Matéria Seca (MS) e
Teores de Potássio (K), Cálcio (Ca) e Magnésio (Mg) para diferentes Tratamentos (T) em dois ciclos de cultivo de milheto (C).....................

Tabela 4.6. Média de produção de matéria seca da parte aérea (MSPA
para os diferentes tratamentos, em dois ciclos de cultivo.

Tabela 4.7. Teores de macro e micronutrientes na parte aérea do milheto e respostas a alguns tratamentos.

Tabela 4.8. Acúmulo de macro e micronutrientes na parte aérea do milheto em

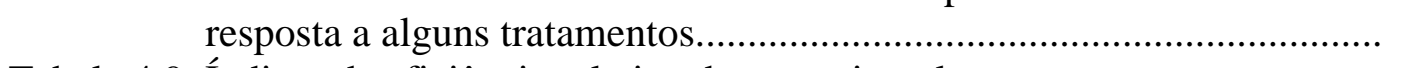

Tabela 4.9. Índices de eficiência relativa do agromineral........................................ 74

Tabela 5.1. Teores dos elementos maiores totais no agromineral (\% em massa)...... $\quad 78$

Tabela 5.2. Características físico-químicas do solo.................................................... $\quad 78$

Tabela 5.3. Descrição dos tratamentos avaliados no experimento............................. 80

Tabela 5.4. Análises de variância conjunta para Diâmetro do Colmo (DC), Número de Perfilhos (NP), Altura de Plantas (AP) e Produção de Colmo (PC), em 03 ciclos de produção (C) e cinco tratamentos (T)......

Tabela 5.5. Média para Altura de Planta AP $(\mathrm{cm})$ para os cinco tratamentos em três ciclos de cultivo da cana-de-açúcar.

Tabela 5.6. Média para Produção de Colmo $\left(\mathrm{t} \mathrm{ha}^{-1}\right)$ para os cinco tratamentos em três ciclos de cultivo da cana-de-açúcar.

Tabela 5.7. Teor de macronutrientes no tecido foliar da cana-de-açúcar.................. 84

Tabela 5.8. Teores de micronutrientes no tecido foliar da cana-de-açúcar. 


\section{Lista de Figuras}

Figura 1.1. Mecanismos e interações do sistema rocha-solo-planta-clima.

Figura 2.1. Contexto geológico da zona mineralizada do Garimpo de Esmeraldas de Monte Santo-TO

Figura 2.2. Fotomicrografias Litotipo A1 - biotita-gnaisse de textura granoblástica inequigranular fina, às vezes porfiroblástica, e estrutura foliada (composição $\mathrm{Pl}+\mathrm{BT}+\mathrm{GR}+\mathrm{FK}$ ).

Figura 2.3. Fotomicrografias Litotipo A4 - anfibolito de textura granoblástica inequigranular fina a média, e estrutura foliada (composição $\mathrm{HBL}+\mathrm{PL}+\mathrm{BT}+\mathrm{QZ}+\mathrm{CL})$

Figura 2.4. Diagrama de classificação dos feldspatos dos litotipos A1 (a) e A4 (b). $\quad 32$

Figura 2.5. Diferenciação das biotitas pelas relações $\mathrm{MgO}$ x $\mathrm{Al}_{2} \mathrm{O}_{3}$ e $\mathrm{FeO} \times \mathrm{Al}_{2} \mathrm{O}_{3} . \quad 33$

Figura 2.6. Diagrama de classificação e diferenciação das biotitas pelas relações proporcionais: a) $\mathrm{Fe} / \mathrm{Fe}+\mathrm{Mg} \times \mathrm{Al}^{\mathrm{IV}}$; e b) $\mathrm{Mg}-\mathrm{R}^{3+}-\mathrm{Fe}^{2+}$

Figura 2.7. Diagrama discriminante dos grandes grupos de anfibólios $(\mathrm{Na}+\mathrm{Ca}) \mathrm{B} \mathrm{x}$ (Na)B, e de classificatório dos anfibólios cálcicos.

Figura 2.8. Discriminação das granadas do biotita gnaisse: (A) Gr+And, Pir, Alm+Esp; (B) Gr, Esp, Alm

Figura 2.9. Gráficos (A) Si vs. $\mathrm{Fe} /(\mathrm{Fe}+\mathrm{Mg})$ de classificação das cloritas; (B) variação nas concentrações de $\mathrm{Fe} 2+$ e $\mathrm{Mg} 2+$ das cloritas analisadas.....

Figura 3.1. Dimensões da coluna de lixiviação utilizada no experimento................ 44

Figura 3.2. Dissolução do agromineral com base: a) na liberação de K e Si em solução (mmol L $\left.{ }^{-1}\right)$; b) na taxa de dissolução mineral $\left(\mathrm{mol} \mathrm{m}^{-2} \mathrm{~s}^{-1}\right) \ldots \ldots .$.

Figura 3.3. Reação da solução $(\mathrm{pH})$ nos respectivos tratamentos e momentos de

Figura 3.4. Concentrações de $\mathrm{K}$ em solução $\left(\mathrm{mmol} \mathrm{L}^{-1}\right)$ nos respectivos tratamentos

e momentos de coleta: a) agromineral e misturas com solos; b) solos isolados.

Figura 3.5. Concentrações de $\mathrm{Na}$ em solução $\left(\mathrm{mmol} \mathrm{L}^{-1}\right)$ nos respectivos tratamentos e momentos de coleta: a) agromineral e misturas com solos; b) solos isolados.

Figura 3.6. Concentrações de Ca em solução $\left(\mathrm{mmol}^{-1} \mathrm{~L}^{-1}\right)$ nos respectivos tratamentos e momentos de coleta: a) agromineral e misturas com solos; b) solos isolados.

Figura 3.7. Concentrações de $\mathrm{Mg}$ em solução (mmol L ${ }^{-1}$ ) nos respectivos tratamentos e momentos de coleta: a) agromineral e misturas com solos; b) solos isolados.

Figura 3.8. Concentrações de Fe em solução (mmol $\left.\mathrm{L}^{-1}\right)$ nos respectivos tratamentos e momentos de coleta: a) agromineral e misturas com solos; b) solos isolados.

Figura 3.9. Concentrações de $\mathrm{Mn}$ em solução (mmol L $\left.{ }^{-1}\right)$ nos respectivos tratamentos e momentos de coleta: a) agromineral e misturas com solos; b) solos isolados.

Figura 3.10. Concentrações de Si em solução (mmol $\mathrm{L}^{-1}$ ) nos respectivos tratamentos e momentos coleta: a) agromineral e misturas com solos; b) solos isolados.

Figura 4.1. Disponibilidade de potássio no solo (Mehlich 1) em função da aplicação e incubação de doses crescentes do agromineral silicático, depois de 30 dias 
Figura 4.2. Produção de matéria seca da parte aérea (MSPA), dos cultivos sequenciais e do acumulado, em função de doses crescentes de potássio aplicadas via agromineral.

Figura 4.3. Relação entre quantidade de potássio acumulada pelo milheto e produção de matéria seca da parte aérea do primeiro (A) e segundo cultivo (B).

Figura 4.4. Absorção de K nas plantas dos cultivos sequenciais e do acumulado, em função de doses crescentes de $\mathrm{K}$ aplicadas via agromineral.................................................................................... 73

Figura 5.1. Condições climáticas na área e período do experimento......................... 79

Figura 6.1. Curvas de resposta de produção $\left(\mathrm{t} \mathrm{ha}^{-1}\right)$ em função da dose $\left(\mathrm{kg} \mathrm{ha}^{-1} \mathrm{~K}\right)$. 


\section{Abreviaturas, siglas e definições}

ABNT

ABRACAL

ANDA

AS

BET

BT

CCA

CETEM

CL

COOPERGEMAS

COOPERSANTO

CPRM

CTC

DNPM

EDS

EMBRAPA

EPT

ETRs

FAN

FAO

FFC

FINEP

FK

FLL

GR

HBL

IBGE

ICP-AES

ICP-MS

IFA

IGD

IN

INMET

INPI

IPT

IQ

ISRIC

Ksat

LA

LABGEO

LASON

LMC

LMC

LO

LOI

MAPA

MCTI

MDIC
Associação Brasileira de Normas Técnicas

Associação Brasileira dos Produtores de Calcário Agrícola

Associação Nacional de Difusão de Adubos

Agromineral Silicático

Brunauer, Emmett, Teller

Biotita

Centro de Ciências Agrárias

Centro de Tecnologia Mineral

Clorita

Cooperativa dos Garimpeiros de Monte Santo

Cooperativa de Mineração dos Garimpeiros de Monte Santo

Serviço Geológico do Brasil

Capacidade de Troca de Catiônica

Departamento Nacional de Produção Mineral

Energy Dispersive Spectrometer

Emp resa Brasileira de Pesquisa Agropecuária

Elementos Potencialmente Tóxicos

Elementos Terras Raras

Fonte Alternativa de Nutriente

Food and Agriculture Organization

Plintossolo Pétrico Concrecionário

Financiadora de Estudos e Projetos

Feldspato Potássio

Fonte de Liberação Lenta

Granada

Hornblenda

Instituto Brasileiro de Geografia e Estatística

Inductively Coupled Plasma - Atomic Emission Spectrometry

Inductively Coupled Plasma Mass Spectrometry

International Fertilizer Industry Association

Instituto de Geociências

Instrução Normativa

Instituto Nacional de Meteorologia

Instituto Nacional de Propriedade Industrial

Instituto de Pesquisa Tecnológica

Instituto de Química

International Soil Reference and Information Centre

Condutividade Hidráulica

Latossolo Amarelo

Laboratório de Geoquímica

Laboratório de Microssonda Eletrônica

Lamoratório de Materiais e Combustíveis

Laboratório de Materiais e Combustíveis

Licença de Operação

Loss of Ignition

Ministério da Agricultura, Pecuária e Abastecimento

Ministério de Ciência, Tecnologia e Inovação

Ministério de Desenvolvimento, Industria e Comércio Exterior 


$\begin{array}{ll}\text { MME } & \text { Ministério de Minas e Energia } \\ \text { MOS } & \text { Matéria Orgânica do Solo } \\ \text { NATURATINS } & \text { Instituto Natureza do Tocantins } \\ \text { NBR } & \text { Norma Técnica } \\ \text { Pcm } & \text { Complexo Granítico-Gnáissico Campo Maior } \\ \text { PF } & \text { Perda ao Fogo } \\ \text { PI } & \text { Plagioclásio } \\ \text { PLG } & \text { Portaria de Lavra Garimpeira } \\ \text { PNM 2030 } & \text { Plano Nacional da Mineração } \\ \text { Prc } & \text { Sequência Metavulcano-Sedimentar Rio do Coco } \\ \text { PVC } & \text { Cloreto de Polivinita } \\ \text { RQ } & \text { Neossolo Quartzarênico } \\ \text { RT-ANF } & \text { Rocha Total - Anfibolito } \\ \text { RT-BT } & \text { Rocha Total - Biotita-Gnaisse } \\ \text { RT-AS } & \text { Rocha Total - Agromineral Silicático } \\ \text { SECEX } & \text { Secretaria de Comércio Exterior } \\ \text { TVD } & \text { Top Visible Dewlap } \\ \text { UnB } & \text { Universidade de Brasília } \\ \text { UNITINS } & \text { Fundação Universidade do Tocantins } \\ \text { WDS } & \text { Wavelength Dispersive Spectrometer }\end{array}$




\section{RESUMO}

Para uma sociedade cada vez mais consciente do grau das perturbações sistêmicas acarretadas ao meio físico decorrentes da crescente extração de recursos naturais, compreender os processos de intemperização e alteração dos minerais, e eventualmente afetar esses processos, torna-se relevante para a remineralização de solos agrícolas através da prática da rochagem. A agrogeologia, campo de estudos que envolve a interface entre as Geociências e as Ciências Agrárias, busca entender os processos de intemperismo na formação dos solos, e identificar possibilidades de aumentar as taxas de liberação de nutrientes minerais. Em regiões tropicais, onde o principal fator limitante do potencial agrícola é a baixa fertilidade natural dos solos, cujos fatores adversos são a alta acidez associada à toxidez por Al, e as baixas reservas de potássio$\mathrm{K}$, os agrominerais adquirem expressivo significado à viabilização da agricultura. No Brasil, esta situação preocupa uma vez que a exportação via colheitas são maiores do que a adição via fertilizantes, causando a exaustão de nutrientes e a degradação do solo, além do fato de mais de $60 \%$ do consumo de fertilizantes ser oriundo de importações. Assim, frente ao desafio da agricultura brasileira em melhorar a eficiência de uso dos fertilizantes e corretivos, qualquer estratégia possível implica necessariamente na adoção de técnicas produtivas baseadas em conhecimentos sobre as características e propriedades dos solos capazes de influenciar a disponibilidade e a absorção de nutrientes pelas plantas. Neste sentido, muitos estudos têm sido voltados à avaliação do potencial de uso de rochas silicáticas no suprimento de nutrientes em cultivos agrícolas. Os resultados das pesquisas indicam que a eficiência agronômica desses materiais depende da origem da rocha, da sua mineralogia e composição química, bem como de outros fatores associados a características do solo, do tempo de incubação do composto mineral, do tratamento prévio aplicado, e também, das espécies cultivadas. Todavia, as investigações sobre o potencial agrícola de minerais e rochas como fontes alternativas de nutrientes têm sido orientadas pela noção de fertilidade dominante nas ciências agrárias, restringindo-se à avaliação das alterações nos atributos químicos dos solos, ou aos efeitos na produção de plantas cultivadas. Como as rochas são de composição complexa e relativamente pouco conhecidas, especialmente quanto ao seu comportamento nos solos, além da adequada caracterização da composição das rochas selecionadas, e da avaliação da biodisponibilização dos elementos constituintes, tornase importante compreender como os fatores e efeitos conjugados decorrentes da interação rocha-solo-planta-clima influenciam a resposta das plantas cultivadas. O presente estudo avalia as possibilidades e limitações da prática da rochagem a partir dos resíduos minerais do Garimpo de Monte Santo-TO, adotando uma abordagem que permite avaliar: as propriedades físico-químicas determinantes da estabilidade e do comportamento do agromineral no meio; o modelo de aporte de nutrientes em comparação com outros produtos; e a efetividade do agromineral em cultivos específicos. Para tanto, além da necessidade de caracterizar física, mineralógica e geoquimicamente o agromineral, a avaliação envolveu a realização de experimentos com diferentes graus complexidade, cujos objetivos específicos são: i) estimar a taxa de dissolução do agromineral, e identificar os efeitos de sobreposição dos atributos dos 
solos na dinâmica de liberação de nutrientes; ii) avaliar os efeitos do agromineral no suprimento de nutrientes para cultivos sucessivos; iii) avaliar a viabilidade técnica do uso do agromineral em substituição e complementação às fontes convencionais de nutrientes. O agromineral silicático é formado por rochas vulcânicas máficoultramáficas da Sequência Metavulcano-Sedimentar Rio do Coco, caracterizadas como biotita-ganaisse e anfibolito. Após moagem dos resíduos minerais em indústria de calcário, o agromineral silicático apresenta 73\% das partículas com granulometria “fração areia” (0,06 a $2 \mathrm{~mm}$ ), e área de superfície específica de 0,562 $\mathrm{m}^{2} \mathrm{~g}^{-1}$ (BET). A composição geoquímica de rocha total revela 7,9\% de $\mathrm{CaO}, 9,8 \%$ de $\mathrm{MgO}, 2,2 \%$ de $\mathrm{K}_{2} \mathrm{O}$, além de vários outros elementos de nutrição de plantas. Os teores dos elementos potencialmente tóxicos (EPT) são muito baixos, e não oferecem riscos de contaminação ou ambiental. O estudo de dissolução mineral em colunas de lixiviação revelou uma taxa de liberação do $\mathrm{K}$ entre 2,68 e 2,04 $10^{-11} \mathrm{~mol} \mathrm{~m}^{-2} \mathrm{~s}^{-1}$, e do Si entre 1,55 e 1,18 $10^{-11}$ mol m $\mathrm{m}^{-2} \mathrm{~s}^{-1}$. A estabilidade das reações de dissolução foi atingida, com taxa (log $\mathrm{R}=$ $10,6 \mathrm{~mol} \mathrm{~m}^{-2} \mathrm{~s}^{-1}$ ) compatível às descritas na literatura sobre intemperismo dos silicatos. Os atributos e parâmetros dos solos potencializam a dissolução do agromineral em 2,5 a 3,8 vezes, principalmente, devido os efeitos do $\mathrm{pH}$, do teor de matéria orgânica e da capacidade de troca dos solos. O estudo de avaliação dos efeitos do agromineral no suprimento de nutrientes para cultivos sucessivos em casa de vegetação demonstrou que a produção de matéria seca e a absorção de K pelas plantas apresenta correlação linear com o aumento da dose do agromineral. Os resultados revelam que o ponto de equivalência em relação à fonte convencional do nutriente $(\mathrm{KCl})$ é obtido com a aplicação de $6 \mathrm{t} \mathrm{ha}^{-1}$ do agromineral. Os índices de eficiência do agromineral foram semelhantes ao registrado no tratamento referência com fonte solúvel de $K$, o que permite concluir que o agromineral constitui uma fonte eficiente no fornecimento de $\mathrm{K}$ para plantas cultivadas. Outros efeitos do agromineral foram observados sobre o $\mathrm{pH}$ do solo, e no aumento da eficiência dos fertilizantes convencionais. No estudo de avaliação da viabilidade técnica do uso do agromineral em substituição e complementação às fontes convencionais de nutrientes em três ciclos sucessivos de cultivo da cana-deaçúcar, obtiveram-se efeitos positivos no suprimento de nutrientes e no balanço nutricional, bem como no desenvolvimento fisiológico e no rendimento produtivo da cultura. Os resultados confirmam que agromineral pode ser utilizado como fonte alternativa de nutriente, e que a dose de resposta ótima situa-se entre 120 e $140 \mathrm{~kg} \mathrm{ha}^{-1}$ de $\mathrm{K}_{2} \mathrm{O}$, obtida com a aplicação de 5,5 a $6,5 \mathrm{t} \mathrm{ha}^{-1}$ do agromineral, com produtividade média de $112 \mathrm{t} \mathrm{ha}^{-1}$ de colmos. Por fim, acrescenta-se que o agromineral avaliado compreende uma fonte alternativa eficiente de nutrientes, e uma estratégia viável para equacionar a demanda regional por fertilizantes.

Palavras-chaves: rochas silicáticas; dissolução mineral; eficiência agronômica; 


\begin{abstract}
For a society increasingly aware of the degree of systemic disturbances brought about the physical environment posed by increased extraction of natural resources, understand the weathering processes and alteration minerals, and eventually affect these processes, it is relevant to the remineralization of agricultural soils through the practice of stonemeal. The agrogeologia, field studies involving the interface between Geosciences and Agricultural Sciences, seeks to understand the weathering processes in soil formation, and identify opportunities to increase the rates of release of nutrients. In tropical regions, where the main factor limiting agricultural potential is the low fertility of the soil, whose adverse factors are the high acidity associated with Al toxicity, and low reserves of potassium- $K$, the agrominerals acquire significant meaning to the viability of agriculture. In Brazil, this concern since the export via crops are larger than the addition via fertilizers, causing depletion of nutrients and soil degradation, besides the fact that over $60 \%$ of fertilizer consumption be from imports. Thus, given the challenge of Brazilian agriculture to improve the efficiency of use of fertilizers and any possible strategy necessarily implies the adoption of production techniques based on knowledge of the characteristics and soil properties can influence the availability and absorption of nutrients by plants. In this sense, many studies have addressed the evaluation of the potential use of silicate rocks in the supply of nutrients in crops. Research results indicate that the agronomic efficiency of these materials depends on the rock origin, their mineralogy and chemical composition, and other factors associated with soil characteristics, the incubation time of the mineral compound, the previous treatment applied, and also, the cultivated species. However, investigation of the agricultural potential of minerals and rocks as alternative sources of nutrients have been guided by the notion of dominant fertility in agricultural sciences, restricted to the evaluation of changes in chemical properties of the soil, or effects on production of cultivated plants. As the rocks are of complex composition and relatively little known, especially as to their behavior in the soil and the adequate characterization of the composition of selected rocks, and evaluating the bioavailability of the components, it is important to understand how factors and combined effects arising from the rock-soilplant-atmosphere interactions influence the response of cultivated plants. This study assesses the possibilities and limitations of the practice of stonemeal from mineral residues of panning of Monte Santo-TO, adopting an approach that evaluates: the determinants physicochemical properties of stability and agromineral behavior in the environment; nutrient intake model as compared to other products; and the effectiveness of agromineral in specific crops. Thus, besides the need to characterize physical, mineralogical and geochemical the agromineral, the evaluation involved performing experiments with varying degrees complexity, whose specific objectives are: i) to estimate the agromineral dissolution rate, and identify the overlap of soil attributes in the dynamics of nutrient release; ii) evaluate the effects of agromineral in the supply of nutrients to crop rotation; iii) evaluate the technical feasibility of using the agromineral to replace and complement to conventional sources of nutrients. The silicático agromineral consists of mafic-ultramafic volcanic rocks of sedimentary sequence
\end{abstract}


metavolcano-Rio Coco, characterized as biotite-amphibolite and ganaisse. After grinding the mineral waste lime industry, silicático agromineral has $73 \%$ of particles with a particle size "sand fraction" (0.06 to $2 \mathrm{~mm}$ ), and specific surface area of $0.562 \mathrm{~m}^{2}$ $\mathrm{g}^{-1}$ (BET). The geochemical composition of whole rock reveals $7.9 \% \mathrm{CaO}, 9.8 \% \mathrm{MgO}$, $2.2 \% \mathrm{~K} 2 \mathrm{O}$, and various other plant nutrition elements. The levels of potentially toxic elements (PTEs) are very low, and offer no risk of contamination or environmental. The study on the dissolution of mineral leaching columns showed a release rate $\mathrm{K}$ between 2.68 and $2.0410^{-11} \mathrm{~mol} \mathrm{~m}^{-2} \mathrm{~s}^{-1}$, and Si of 1.55 and $1.1810^{-11} \mathrm{~mol} \mathrm{~m}^{-2} \mathrm{~s}^{-1}$. The stability of the dissolution reactions was achieved, with a rate $\left(\log \mathrm{R}=-10.6 \mathrm{~mol} \mathrm{~m}^{-2} \mathrm{~s}^{-1}\right.$ ) compatible with those described in the literature weathering of silicate. The attributes and soil parameters potentiate the dissolution of agromineral 2.5 of 3.8 times, mainly due the effects of $\mathrm{pH}$, organic matter content and soil exchange capacity. The evaluation study of agromineral effects on the nutrient for successive crops in greenhouse showed that dry matter production and absorption of $\mathrm{K}$ by plants shows linear correlation with increasing agromineral dose. The results show that the equivalence point over conventional nutrient source $(\mathrm{KCl})$ is obtained by applying $6 \mathrm{t} \mathrm{ha}^{-1}$ agromineral. The agromineral efficiency indices were similar to that recorded in the treatment with soluble source of reference $\mathrm{K}$, which shows that the agromineral an efficient source provider of $\mathrm{K}$ for crops. Other agromineral effects were observed on the soil $\mathrm{pH}$, and increasing the efficiency of conventional fertilizers. In the study evaluating the technical feasibility of using the agromineral to replace and complement the conventional sources of nutrients in three successive cycles of cultivation of cane sugar, yielded positive effects on the nutrient and nutrient balance, as well as physiological development and production yield of the culture. The results confirm that agromineral can be used as an alternative nutrient source, and that the optimal response dose is between 120 and 140 kg ha- $1 \mathrm{~K}$, obtained by applying 5.5 to $6.5 \mathrm{t} \mathrm{ha}^{-1}$ agromineral, with an average yield of $112 \mathrm{t} \mathrm{ha}^{-1}$ stalk. Finally, it is added that the assessed agromineral comprises an effective alternative source of nutrients, and a viable strategy to equate the regional demand for fertilizers.

Keywords: silicate rocks; mineral dissolution; agronomic efficiency. 


\section{CAPÍTULO 1 \\ IMPORTÂNCIA DO TEMA}

\subsection{INTRODUÇÃO GERAL}

Em decorrência da crescente demanda por produtos de consumo de diversas naturezas, e da consequente intensificação de exploração de recursos naturais, em especial como ocorre na agricultura, esforços têm sido direcionados ao melhor entendimento dos processos que determinam a dinâmica mineralógica de nutrientes de plantas, sua disponibilidade e sua tendência ao esgotamento nos solos.

A presença e distribuição dos elementos nutrientes nos solos, bem como as estruturas mineralógicas que os contém, são fortemente condicionadas pela dinâmica de intemperismo das rochas (Harley e Gilkes, 2000). A taxa de dissolução dos minerais presentes nas rochas, por sua vez, determina a reposição de nutrientes em solução (Nahon, 1991; Blum e Stillings, 1995; Brantley e Chen, 1995; Nagy, 1995), e por consequência as possibilidades a partir da agricultura. Assim, na medida em que cresce o conhecimento referente ao ciclo geológico, e em especial sobre intemperismo, crescem as possibilidades à prática do manejo da fertilidade dos solos. Isso tudo é especialmente relevante em condições de clima tropical, onde a intensa lixiviação de íons torna os solos ácidos e os elementos de nutrição relativamente escassos.

Como a intemperização da maioria dos minerais primários e a formação de minerais secundários é um processo sempre muito lento em condições naturais, há quem diminua a relevância de se entender a dinâmica das reações que afetam as taxas de dissolução dos minerais para fins de produção agrícola (Rai e Kittrick, 1989). Entretanto, para uma sociedade também cada vez mais consciente do grau das perturbações sistêmicas acarretadas pela crescente extração de recursos naturais, compreender os processos de intemperização e alteração dos minerais, e eventualmente afetar esses processos, torna-se sim relevante, seja na identificação de materiais adequados para neutralizar a acidificação de solo em áreas mineradas (Jambor, 2000), na remediação de áreas contaminadas (Jackson, 1998), na contenção de resíduos radioativos (Curtis, 2000), ou no uso alternativo de rochas moídas como fonte de nutrientes para culturas agrícolas (Leonardos e Theodoro, 1999).

No texto seminal "Brot aus Steinen", de Julius Hensel (1898), a adição de compostos inorgânicos naturais na forma de pó de rochas como corretivos e fertilizantes é proposta como alternativa à restauração da fertilidade de solos degradados. A aplicação de rochas moídas ao solo é denominada "rochagem" ou "remineralização" (Leonardos et al., 1976; Campe et al., 1996).

A prática da "rochagem" na agricultura encontra fundamentação conceitual no que van Straaten (2002) refere como agrogeologia - abordagem que busca entender os processos de intemperismo na formação dos solos, e identificar possibilidades de aumentar as taxas de liberação de nutrientes de minerais. 
No Brasil, onde os fertilizantes consumidos na agricultura são em grande parte importados, cujos custos geram impactos consideráveis na balança comercial (ANDA, 2010), estudos têm sido voltados à avaliação do potencial de uso de rochas e rejeitos de mineração no suprimento de nutrientes em cultivos agrícolas. Exemplos são as ações da Rede Interinstitucional de Pesquisa de Rochas como Fonte Alternativa de Nutrientes AgriRocha (Embrapa/FINEP/MCTI); as pesquisas sobre rochas, minerais e rotas tecnológicas para produção de fertilizantes alternativos (CETEM/MCTI), e o projeto de identificação e localização geográfica de rochas e minerais como fonte alternativa de nutrientes na produção de biocombustíveis (CPRM/MME).

Os resultados das pesquisas indicam que a eficiência agronômica do processo da rochagem depende da origem da rocha, da sua mineralogia e composição química, bem como de outros fatores associados a características do solo, do tempo de incubação do composto mineral, do tratamento prévio aplicado, e também, das espécies cultivadas (Távora, 1982; Nascimento \& Loureiro, 2004). Importante ressaltar que, conforme apontado em Luz et al. (2010), a maioria das pesquisas de rochagem envolvem o aproveitamento de rejeitos de minas e de pedreiras, inclusive como interessante alternativa de redução do passivo ambiental.

Todavia, as investigações sobre o potencial agrícola de minerais e rochas como fontes alternativas de nutrientes têm sido orientadas pela noção de fertilidade dominante nas ciências agrárias, restringindo-se à avaliação das alterações nos atributos químicos dos solos, ou aos efeitos na produção de plantas cultivadas. Como as rochas são de composição complexa e relativamente pouco conhecidas, especialmente quanto ao seu comportamento nos solos, além da adequada caracterização da composição das rochas selecionadas, e da avaliação da biodisponibilização dos elementos constituintes, tornase importante compreender como os fatores e efeitos conjugados decorrentes da interação rocha-solo-planta-clima influenciam a resposta das plantas cultivadas.

Portanto, admitida a pertinência da rochagem como prática agronomicamente justificável, a questão central do presente estudo esta relacionada à dinâmica de solubilização de minerais e rochas, especialmente dos resíduos minerais do Garimpo de Esmeraldas de Monte Santo-TO. Assim, a partir de uma pesquisa bibliográfica de base sobre a temática, e de análises de caracterização dos resíduos minerais, foram geradas e organizadas as informações necessárias para os estudos experimentais complementares de avaliação: i) da taxa de dissolução mineral em laboratório; ii) da disponibilidade de nutrientes em casa de vegetação; iii) do potencial de uso agrícola em campo.

A racionalidade no uso da rochagem encontra fundamentação nos seguintes pressupostos: a intensidade das reações de dissolução são controladas pela taxa de eliminação de solutos, e consequente renovação de gradientes de concentração na solução (Toledo et al., 2008); o tratamento prévio das rochas possibilita suficiente extensão de superfície ativa que, em contado com água e substâncias nela dissolvidas, resulta na dissolução mineral e liberação de nutrientes (Casey \& Bunker, 1990); e o suprimento de determinados nutrientes às plantas não se restringe a íons em solução ou na forma trocável (Castilhos e Meurer, 2002). 
Por hipótese, a partir da determinação da taxa de dissolução do resíduo mineral é possível avaliar seu potencial no suprimento de nutrientes para plantas cultivadas.

\subsection{OBJETIVO DA TESE}

Avaliar as possibilidades e limitações da prática da rochagem a partir dos resíduos minerais do Garimpo de Monte Santo-TO.

\subsection{FUNDAMENTAÇÃO TEÓRICA}

\subsubsection{Dissolução mineral e liberação de nutrientes}

\subsubsection{Processos de intemperização química}

O processo de intemperismo compreende o conjunto de alterações que as rochas sofrem quando expostas às condições de elevada concentração de $\mathrm{O}_{2}, \mathrm{CO}_{2}$ e $\mathrm{H}_{2} \mathrm{O}$ existem na superfície do planeta. No intemperismo químico os minerais primários são dissolvidos via reações químicas, resultando na formação de novas fases minerais mais estáveis e em equilíbrio com as condições ambientais (Loughnan, 1969).

As alterações decorrentes do intemperismo químico, segundo Kampf et al. (2009), dependem da natureza da rocha, das características dos reagentes e das condições que controlam o equilíbrio das reações químicas. O intemperismo químico é produto da interação de diferentes processos - hidratação, solução, hidrólise, oxidaçãoredução e complexação, tornando difícil precisar quando se inicia e termina um ou outro processo (Nahon, 1991).

Em relação à dinâmica dos silicatos, Carvalho (1995) reconhece a hidrólise como a mais importante das reações de dissolução desses minerais. Para Casey e Bunker (1990), em condições ácidas o oxigênio torna-se protonação ao ligar-se com o íon $\mathrm{H}^{+}$, formando hidroxilas que enfraquecem as ligações oxigênio-metal da estrutura mineral. O resultado é a liberação dos íons alcalinos $\left(\mathrm{K}^{+}\right.$e $\left.\mathrm{Na}^{+}\right)$, alcalino-terrosos $\left(\mathrm{Ca}^{2+}\right.$ e $\mathrm{Mg}^{2+}$ ), além de Si na fase líquida.

A reação abaixo (1) exemplifica a alteração de um mineral primário, o feldspato microclínio, em um mineral secundário como a caulinita.

$$
2 \mathrm{KAlSi}_{3} \mathrm{O}_{8}+2 \mathrm{H}^{+}+9 \mathrm{H}_{2} \mathrm{O} \rightarrow \mathrm{Al}_{2} \mathrm{Si}_{2} \mathrm{O}_{5}(\mathrm{OH})_{4}+4 \mathrm{H}_{4} \mathrm{SiO}_{4}+2 \mathrm{~K}^{+}
$$

Nota-se que a solução de ataque (solvente) é ácida, pois contém excesso de prótons $\left(\mathrm{H}^{+}\right)$proveniente de diversas fontes, especialmente da dissociação do ácido carbônico $\left(\mathrm{H}_{2} \mathrm{CO}_{3} \rightarrow \mathrm{H}^{+}+\mathrm{HCO}_{3}{ }^{-}\right)$. A reação se completa pela reorganização dos componentes dissolvidos e formação de caulinita, e remoção dos outros compostos excedentes em solução $\left(\mathrm{H}_{4} \mathrm{SiO}_{4}\right.$ e íons $\left.\mathrm{K}^{+}\right)$por lixiviação. Caso a lixiviação não promova total remoção dos excedentes, as condições resultantes tendem a favorecer a formação de ilita conforme reação (2).

$$
3 \mathrm{KAlSi}_{3} \mathrm{O}_{8}+2 \mathrm{H}^{+}+12 \mathrm{H}_{2} \mathrm{O} \rightarrow \mathrm{KAl}_{2}\left(\mathrm{AlSi}_{3}\right) \mathrm{O}_{10}(\mathrm{OH})_{2}+6 \mathrm{H}_{4} \mathrm{SiO}_{4}+2 \mathrm{~K}^{+}
$$


Como bem apontam Stumm e Morgan (1996), as reações de dissolução de minerais podem ser distinguidas em congruentes e incongruentes. A dissolução congruente é caracterizada pela completa dissolução do mineral, sem resultar na formação de novas fases minerais, como ocorre na dissolução do quartzo (3). A dissolução incongruente consiste essencialmente de uma troca de ligantes da rede cristalina, resultando na formação de novas fases minerais e substâncias em solução, a exemplo da alteração de feldspato em muscovita (4).

$$
\begin{gathered}
\mathrm{SiO}_{2}+2 \mathrm{H}_{2} \mathrm{O} \rightarrow \mathrm{H}_{4} \mathrm{SiO}_{4} \\
3 \mathrm{KAlSi}_{3} \mathrm{O}_{8}+2 \mathrm{H}^{+}+12 \mathrm{H}_{2} \mathrm{O} \rightarrow \mathrm{KAl}_{3} \mathrm{Si}_{3} \mathrm{O}_{10}(\mathrm{OH})_{2}+6 \mathrm{H}_{4} \mathrm{SiO}_{4}+2 \mathrm{~K}^{+}
\end{gathered}
$$

Esta evidenciado que o intemperismo químico é determinantemente controlado pela presença de água, seja como agente físico, seja como solvente, ou como meio de transporte (Nahon, 1991). Para Toledo et al. (2008) enquanto forem mantidas as condições de renovação das soluções reagentes, as reações poderão progredir, sendo para tanto necessário que ocorra a eliminação dos componentes solúveis do sistema. $\mathrm{O}$ grau de eliminação dos elementos/substâncias dissolvidos pode assim determinar a intensidade da hidrólise, consequentemente, a intensidade da dissolução mineral.

Com base na intensidade do fluxo de água ou lixiviação através do perfil do solo, Pedro et al. (1969) descrevem três níveis de ação da hidrólise, os quais representam modelos de formação de minerais, a saber:

Bissialitização - fluxo de água pouco intenso, lixiviação fraca, e dessilicação limitada. O Si que permanece no sistema é suficiente para a neogênese de argilominerais 2:1, como na intemperização de feldspato-plagioclásio (albita) e formação de esmectita (5).

$$
\begin{gathered}
23 \mathrm{NaAlSi}_{3} \mathrm{O}_{8}+20 \mathrm{H}^{+}+64 \mathrm{H}_{2} \mathrm{O} \rightarrow \\
10 \mathrm{Na}_{0,3} \mathrm{Al}_{2}\left(\mathrm{Si}_{3,7} \mathrm{Al}_{0,3}\right) \mathrm{O}_{10}(\mathrm{OH})_{2}+32 \mathrm{H}_{4} \mathrm{SiO}_{4}+20 \mathrm{Na}^{+}
\end{gathered}
$$

Monossialitização - ocorre quando o fluxo de água é moderado, a lixiviação é mais acentuada, e a dessilicação moderada, permitindo a formação de argilominerais 1:1, como na intemperização de albita e formação de caulinita (6).

$$
2 \mathrm{NaAlSi}_{3} \mathrm{O}_{8}+2 \mathrm{H}^{+}+9 \mathrm{H}_{2} \mathrm{O} \rightarrow \mathrm{Al}_{2} \mathrm{Si}_{2} \mathrm{O}_{5}(\mathrm{OH})_{4}+4 \mathrm{H}_{4} \mathrm{SiO}_{4}+2 \mathrm{Na}^{+}
$$

Alitização - ocorre quando o fluxo de água é muito intenso, a lixiviação é muito forte e propicia a dessilicação completa, permanecendo apenas Al no sistema, como na intemperização de albita em gibbsita (7).

$$
\mathrm{NaAlSi}_{3} \mathrm{O}_{8}+\mathrm{H}^{+}+7 \mathrm{H}_{2} \mathrm{O} \rightarrow \mathrm{Al}(\mathrm{OH})_{3}+3 \mathrm{H}_{4} \mathrm{SiO}_{4}+\mathrm{Na}^{+}
$$

\subsubsection{Resistência mineral ao intemperismo}

Disso implica reconhecer que alguns minerais são alterados mais rapidamente do que outros, e que a estabilidade ou resistência de um mineral ao intemperismo depende de diversos fatores. Para Dana \& Hurlbut (1978) tais fatores incluem dureza, clivagem, coeficiente de expansão, extensão de superfícies reativas e das condições do ambiente. 
De acordo com Klein e Hurlbut (1993), a sequencia de reação de Bowen (1928) é similar à sequencia de estabilidade relativa definida por Goldich (1938), pois enquanto a primeira expressa a sequência de cristalização dos minerais, a outra expressa a susceptibilidade ao intemperismo dos minerais de silicato primários. Assim, minerais que se cristalizam primeiro (olivina $>$ hornblenda $>$ biotita $>$ microclinio) são mais facilmente intemperizados em condições de superfície.

Todavia, segundo Sticher e Bach (1966), a estabilidade intrínseca dos silicatos depende de fatores específicos dos próprios minerais, de modo que:

i) a estabilidade cresce com o aumento das ligações covalentes na estrutura do mineral (Si-O-Si e Si-O-M);

ii) a estabilidade cresce com o aumento do grau de condensação da estrutura pelo compartilhamento dos "O" entre tetraedros, e aumento da razão Si/O;

iii) a estabilidade decresce no grupo estrutural com o aumento da substituição do Si pelo Al (quartzo > albita > anortita);

iv) a estabilidade decresce no grupo estrutural com o decréscimo da eletronegatividade dos íons metálicos, reduzindo a resistência da ligação;

v) a estabilidade cresce com o aumento do tamanho e da carga dos íons na estrutura do poliedro que liga as unidades de silicatos $\left(\mathrm{Zr}^{4+}>\mathrm{Mg}^{2+}>\mathrm{K}^{+}\right)$, conferindo maior densidade de empacotamento dos átomos de "O".

Como o intemperismo químico é essencialmente controlado pela presença de água, é na fase aquosa, ou na solução do solo, onde ocorrem as reações de intemperização dos minerais. Portanto, da mesma forma que os processos de dissolução e precipitação de minerais afetam a composição química da solução do solo, os atributos químicos da solução do solo e a estabilidade intrínseca dos minerais determinam a ação de tais processos (Loughnan, 1969; Wieland et al., 1988; Casey e Bunker, 1990). Em decorrência, a análise da composição da solução do solo pode contribuir para o entendimento dos processos de intemperização química dos minerais no solo (McBride, 1994; Wolt, 1994; Karathanasis, 2002; Essington, 2004).

De acordo com Kampf et al (2008), os modelos de equilíbrio químico termodinâmico têm-se revelado ferramentas úteis na predição da intemperização de minerais no solo (dissolução e formação). Todavia, há diversas objeções quanto à aplicação de modelos termodinâmicos a sistemas abertos complexos como os solos, pois conforme destaca McBride (1994), no solo as transformações entre os componentes são impulsionadas por fluxos de matéria e energia com a vizinhança, resultando em estado de equilíbrio dinâmico (steady-state) apenas local.

\subsubsection{Cinética de dissolução mineral}

A cinética química pode ser definida como o estudo das taxas das reações químicas, e depende de vários fatores, incluindo concentração das substâncias, temperatura, presença de catalisadores entre outros (Drever, 1988). 
A cinética de dissolução da maioria dos minerais em ambientes naturais é controlada por reações heterogêneas que ocorrem na interface mineral-solução (Blum e Lasaga 1991). Para Casey e Bunker (1990), essas reações ocorrem de forma simultânea, porém, os sítios na estrutura de um mineral reagem de forma diferenciada durante o processo de intemperismo, de maneira que as reações de dissolução afetam e são afetadas pela composição química e pela estrutura da superfície mineral.

Desde há muito está entendido e tem sido demonstrado que a dissolução da maioria dos óxidos e minerais silicáticos em baixas temperaturas é controlada por fenômenos de superfície (Berner, 1978; Holdren e Berner, 1979; Stumm, 1987), preferencialmente em sítios de alta energia livre associados a deslocamentos ou microfraturas em planos e fraquezas, ou deformações nos cristais.

Conforme demonstrou Kalinowski (1997), à medida que a dissolução avança ocorre redução da energia livre no sistema, podendo um mineral dissolver-se uniformemente, reagir seletivamente em regiões com mais energia livre de superfície, ou formar uma camada alterada na interface solução-sólido.

Assim, a maioria das reações de dissolução de silicatos depende de interações entre íons na superfície do mineral. Essas interações de superfície envolvem grupos oxihidróxidos com $\mathrm{H}^{+}$e $\mathrm{OH}^{-}$(superfície de protonação) e ligantes como ânions e ácidos fracos que promovem as reações de dissolução (Carrol-Webb e Walther, 1988; Amrhein e Suarez, 1992; Oxburgh et al., 1994; Biber et al., 1994).

Berner (1978) descreve três mecanismos no processo de dissolução dos minerais: transporte de soluto do cristal dissolvido; desprendimento de íons ou moléculas da superfície do cristal (incluindo desorção, difusão na superfície, etc.); combinação simultânea dos dois processos anteriores:

- dissolução mais determinada pelo transporte: os íons são liberados da superfície do cristal para a solução muito rapidamente. Tão rapidamente que é formada uma solução saturada ao redor da superfície. A dissolução então se dá na medida em que ocorre difusão desses íons para regiões mais afastadas do cristal e com mais baixa concentração de solutos.

- dissolução mais determinada pela extensão de superficie sujeita a fenômenos de interação iônica: o desprendimento dos íons da superfície do cristal é tão lento que não acompanha a difusão. Na medida em que a dissolução supera a difusão, a concentração da solução próxima à superfície é a mesma que ao redor da solução, diminuindo assim a taxa de dissolução.

Para Wieland et al. (1988), a dissolução controlada pela superfície envolve uma série de etapas, tais como: transferência de massa de solutos $\left(\mathrm{H}^{+}, \mathrm{OH}^{-}\right.$, ligantes) para a superfície do mineral; ligações de solutos à superfície (adsorção ou formação de complexos de superfície); várias reações químicas de superfície (transferências inter estrutura cristalina, etc.); desprendimento de íons da superfície; difusão no interior do volume da solução. 
Portanto, como bem apontam Lelong et al. (1976), torna-se difícil estabelecer uma ordem de mobilidade dos elementos durante o intemperismo químico, pois são muitos os fatores envolvidos, e frequentemente contraditórios em seus efeitos sobre os processos de hidrólise, solubilização e formação de minerais secundários no solo.

De qualquer forma, mesmo com taxas e mecanismos de reação diversos, os cátions básicos e a sílica são progressivamente lixiviados do solo durante $\mathrm{o}$ intemperismo em um processo incongruente de transformação mineral. De acordo com Chesworth (1980), isso favorece o acúmulo de elementos de baixa solubilidade, como o $\mathrm{Al}$ e o $\mathrm{Fe}$, e a inexorável formação de um sistema residual empobrecido em nutrientes.

Na medida em que a dissolução de minerais envolve etapas de reações distintas, é claro que a reação de dissolução tem velocidade determinada pela etapa em que a reação é mais lenta. Para qualquer reação em que

$$
\mathrm{aA}+\mathrm{bB} \rightarrow \mathrm{cC}+\mathrm{dD}
$$

em que 'A', 'B', 'C' e 'D' são compostos químicos, e 'a', 'b', 'c', e 'd' são os respectivos números de moles. Se a velocidade da reação $\mathrm{R}$ é definida como o consumo dos reagentes com o tempo, então a reação pode ser escrita como

$$
\mathrm{R} \approx-1 / \mathrm{a} \cdot \mathrm{d}[\mathrm{A}] / \mathrm{dt}=-1 / \mathrm{b} \cdot \mathrm{d}[\mathrm{B}] / \mathrm{dt}=-1 / \mathrm{c} \cdot \mathrm{d}[\mathrm{C}] / \mathrm{dt}=-1 / \mathrm{d} \cdot \mathrm{d}[\mathrm{D}] / \mathrm{dt}
$$

Assim, a velocidade de reação corresponde à taxa com que os reagentes são consumidos, ou com que os produtos são produzidos, dividida pelo coeficiente estequiométrico (White et al., 1999). Portanto, a velocidade de reação em geral depende da concentração e propriedades dos reagentes, da concentração de hidrogênio e oxigênio, da constante de equilíbrio $\mathrm{K}$, da temperatura e das barreiras de energia.

A resistência dos minerais têm sido estudada através de experimentos que possibilitam o controle de parâmetros que afetam a cinética de dissolução mineral (Brady e Wather, 1989). Conforme sugere os autores, para inferir a intensidade dos processos de intemperismo, faz-se necessário antecipadamente conhecer e considerar os mecanismos que controlam a taxa de dissolução dos minerais.

$\mathrm{O}$ pH é um relevante fator dentre aqueles que afetam a taxa de dissolução de uma espécie mineral (Blum e Lasaga, 1988; Casey e Bunker, 1990; Brady, 1992; Drever, 1994; Stillings e Brantley, 1995; Malmström e Banwart, 1997). Os estudos experimentais de Casey e Sposito (1992) mostram que a energia de ativação para a dissolução dos silicatos é dependente da composição e do pH da solução reagente.

$\mathrm{O}$ efeito do $\mathrm{pH}$ está relacionado à adsorção de íons $\mathrm{H}^{+}$e $\mathrm{OH}^{-}$nas superfícies minerais (Blum e Lasaga, 1988), de maneira que a dissolução tende a ser lenta em condições de pH neutro, e rápidas em bases e ácidos fortes (Casey e Bunker, 1990). Segundo Drever (1994), a influência do pH na taxa de dissolução é fraca na faixa de 4 a 8 , principalmente para aluminossilicatos, indicando baixa solubilidade destes minerais. Para o autor, na ausência de ligantes orgânicos, a taxa de dissolução da maioria dos silicatos depende do $\mathrm{pH}$. 
O aumento da temperatura é outro fator que causa considerável acréscimo na taxa de dissolução mineral (Sparks, 1989), sendo seus efeitos sobre os silicatos experimentalmente bem conhecidos (Blum e Stillings, 1995; Dove, 1995). De acordo com White et al. (1999), a elevação da temperatura de 0 a $25^{\circ} \mathrm{C}$ resultou no aumento da taxa de dissolução em uma ordem de magnitude, sugerindo efeitos significativos das variações climáticas $\left(5-35^{\circ} \mathrm{C}\right)$ no intemperismo químico dos minerais de silicato.

Mas, além desses fatores, conforme aponta Berner (1978), a dissolução dos minerais depende, consideravelmente, da área de superfície reativa em contato com a água. Ainda segundo Berner, a superfície reativa do mineral é determinada por sua composição química, estrutura iônica e a microtopografia. Para Hendricks e Whittig (1968), o tamanho das partículas modifica a estabilidade dos minerais.

Portanto, a quantificação da relação entre estrutura mineral e taxa de dissolução torna-se de difícil determinação (Casey e Bunker, 1990). Assim, como os minerais são encontrados na natureza de forma impura, segundo Brady e Walther (1989) torna-se impossível generalizar uma série de estruturas para os estudos de dissolução mineral, e com isso comparar os resultados de diferentes experimentos.

\subsubsection{Ecofisiologia da produção agrícola}

\subsubsection{Fatores de produção vegetal}

A obtenção de máxima produção econômica associada à conservação ambiental compreende um dos principais desafios imposto a agricultura moderna. Para Castro et al. (1987), todas as estratégias possíveis implicam necessariamente em aliar técnicas produtivas a conhecimentos sobre os fatores de produção vegetal.

Isso esta evidenciado nas constatações de Lucchesi (1987), de que o crescimento e o desenvolvimento vegetal são resultantes de inúmeras inter-relações dos fatores de produção, as quais se manifestam em três níveis de controle: i) intracelular ou genético; ii) intercelular ou hormonal; e iii) extracelular ou ambiental.

De acordo com Tisdale et al, 1993, além das características intrínsecas das plantas, os fatores ambientais radiação solar, fotoperíodo, temperatura, água, aeração e os minerais do solo afetam consideravelmente a morfologia, o crescimento e a reprodução das plantas. Castro et al. (1987) acrescenta que os principais processos fisiológicos afetados pelos fatores ambientais são a atividade fotossintética, a respiração, o balanço hídrico e a absorção de nutrientes.

A água é sem dúvida um dos mais importantes fatores ambientais do crescimento e desenvolvimento das plantas, assim como a luminosidade e a temperatura. Por isso, nas regiões tropicais de latitudes menores, tais fatores favorecem grande produção biológica primária (biomassa), podendo chegar a $160 \mathrm{t}^{\mathrm{h}} \mathrm{ha}^{-1} \cdot \mathrm{ano}^{-1}$, em comparação com 30 t.ha ${ }^{-1}$. ano ${ }^{-1}$ nas regiões temperadas e frias (Sanchez (1976).

Com relação aos fatores edáficos, importa reconhecer que todos os elementos químicos de nutrição das plantas, com exceção do nitrogênio, provêm do solo 
(Malavolta, 1976). Desse modo, conforme descrevem Castro et al. (1987), além dos fatores climáticos, e da própria espécie vegetal, a utilização dos elementos de nutrição pelas plantas está condicionada a fatores físicos, químicos e biológicos do solo.

\subsubsection{Nutrição mineral de plantas}

Assim, conforme aponta Prado (2008), o estudo da nutrição de plantas possibilitou importantes conhecimentos sobre quais os elementos são essenciais para o ciclo de vida, como são absorvidos, translocados e acumulados, suas funções no metabolismo vegetal, bem como os distúrbios causados por deficiência ou toxidez.

Por nutriente entende-se o elemento químico considerado essencial às plantas, de maneira que sem ele a planta não vive (Nachtigall et al., 2007). Mas, para que um elemento químico seja considerado nutriente é preciso atender aos critérios de essencialidade (Arnon e Stout, 1939; Epstein e Bloom, 2006): compor uma molécula da estrutura ou do metabolismo da planta; e provocar anormalidades no crescimento, desenvolvimento e reprodução das plantas por consequência da sua insuficiência.

A composição química relativa dos nutrientes presentes na matéria seca das plantas é descrita por vários autores (Malavolta, 1976; Glass, 1983; Marschner, 1995; Epstein e Bloom, 2005; Nachtgall et al., 2007; Prado, 2008). De maneira geral as plantas apresentam: C, H e O (92 a 96\%); N (1,5 a 2\%); P (0,1 a 0,4\%); K (1 a 2,5\%); $\mathrm{Ca}(0,5$ a 1,5\%); $\mathrm{Mg}(0,2$ a 0,4\%); S (0,1 0,4\%); Fe, Mn, Zn, B, Cu, Mo (0,1 a 1\%).

Do ponto de vista nutricional, embora os nutrientes sejam igualmente importantes para a produção vegetal, os elementos essenciais são classificados de acordo com sua proporção na composição das plantas (Nachtigall et al., 2007; Prado, 2008) como: macronutrientes $\mathrm{N}, \mathrm{P}, \mathrm{K}, \mathrm{Ca}, \mathrm{Mg}$ e S ( $\mathrm{g}^{-\mathrm{Kg}^{-1}}$ de matéria seca); e micronutrientes $\mathrm{B}, \mathrm{Cu}, \mathrm{Fe}, \mathrm{Mn}, \mathrm{Mo}, \mathrm{Zn}$, e $\mathrm{Cl}$ ( $\mathrm{mg} . \mathrm{Kg}^{-1}$ de matéria seca).

O sistema de classificação dos nutrientes proposto por Mengel e Kirkby (1987) leva em conta o papel bioquímico que esses desempenham no metabolismo da planta: estruturais constituintes da matéria orgânica vegetal $(\mathrm{C}, \mathrm{H}, \mathrm{O}, \mathrm{N}$ e S); transferidores de energia (P e B); atividade enzimática, potencial osmótico e balanço de íons ( $\mathrm{K}, \mathrm{Ca}, \mathrm{Mg}$, $\mathrm{Mn}, \mathrm{Cl}$ e $\mathrm{Na}$ ); e os nutrientes que participam no transporte de elétrons para diversos sistemas bioquímicos ( $\mathrm{Fe}, \mathrm{Cu}, \mathrm{Zn}$ e $\mathrm{Mo}$ ).

Outros elementos são considerados benéficos para algumas plantas, ou seja, têm efeitos sobre o crescimento das mesmas, como Na, Se, Si e Co (Marschner, 1995). Estudos recentes propõem a inclusão de $\mathrm{Si}$ e $\mathrm{Na}$ entre os demais que compõem a lista dos nutrientes essenciais de plantas (Nachtigall et al., 2007; Malavolta, 2006). O Si também é considerado um elemento "quase essencial" (Epstein, 2006), e por isso tem recebido atenção de estudos de nutrição de plantas. Existem indicações da divisão das plantas quanto à capacidade de acumulação desse elemento (Marschner, 1995): plantas acumuladoras contêm teores de 10 a $15 \%$ de $\mathrm{SiO}_{2}$, a exemplo do arroz; plantas intermediárias contendo de 1 a $5 \%$ de $\mathrm{SiO}_{2}$, como a cana-de-açúcar; e plantas nãoacumuladoras com menos de $1 \%$ de $\mathrm{SiO}_{2}$, tais como as leguminosas. 
A absorção dos nutrientes pelas plantas ocorre no contato íon-raiz (Prado, 2008), seja pelo movimento do íon na solução do solo (difusão ou fluxo de massa), seja pelo próprio crescimento das raízes (interceptação radicular). Esse último apresenta menor contribuição relativa na absorção das plantas, pois as raízes ocupam apenas $1-2 \%$ do volume do solo. Portanto, os mecanismos de difusão e fluxo de massa contribuem de maneira mais expressiva para aumentar o contato íon-raíz e a absorção de nutrientes pelas plantas. Em síntese, o fluxo de massa é mais importante para a absorção de N, Ca, $\mathrm{Mg}, \mathrm{S}$ e alguns micronutrientes, enquanto que a difusão é o principal mecanismos para absorção de $\mathrm{P}, \mathrm{K}, \mathrm{Mn}$ e $\mathrm{Zn}$ pelas raízes das plantas.

O acúmulo de nutrientes nas plantas, via de regra, reflete sua exigência nutricional (Prado, 2008). De acordo com Fageria e Baligar (1993), existem vários mecanismos e processos nas plantas que determinam a absorção e contribuem para o uso eficiente de nutrientes, e estão relacionados com as características morfológicas e fisiológicas: sistema radicular; relação raízes e parte aérea; microorganismos simbióticos; e taxa fotossintética. Sendo assim, admite-se que a extração dos nutrientes do solo não ocorre de forma constante ao longo do ciclo de produção da cultura.

A extração de nutriente ao longo do tempo de cultivo, ou marcha de absorção, é explicada por uma "curva sigmoide" que acompanha a curva de crescimento da planta (Prado, 2008). Assim, os estudos de marcha de absorção de nutrientes pelas plantas revelam-se ferramentas úteis à melhoria da eficiência no uso dos fertilizantes, pois permitem definir a melhor época de aplicação para determinada cultura.

A eficiência no uso de nutrientes compreende a habilidade de uma espécie ou genótipo em promover altas produções mesmo em condições de baixa disponibilidade de determinado nutriente (Graham, 1984), ou ainda, a relação entre produção e concentração do nutriente no tecido (Lauchli, 1987).

A diagnose foliar realizada a partir da análise química das folhas compreende um método muito utilizado no monitoramento e avaliação do estado nutricional das plantas. Conforme descrito em Prado (2008), a utilização da análise foliar como critério diagnóstico do estado nutricional e da necessidade de fertilizantes, baseia-se na premissa de existir relação entre o suprimento de nutrientes, e os níveis dos elementos foliares, e que aumentos ou decréscimos nas concentrações de nutrientes resultam em produções mais altas ou mais baixas.

A partir da relação entre teor foliar e produção são definidas faixas ou zonas que representam os níveis de deficiência, de transição, de consumo de luxo e de toxidez do elemento na planta. Os resultados das análises químicas de tecido são utilizadas para definição dos níveis críticos e confecções das tabelas de teores adequados ou padrões. Em Raij et al. (1996) são descritos os teores de macro e micronutrientes considerados adequados para várias culturas.

Embora o processo de absorção de nutrientes seja específico e seletivo, a composição mineral das plantas é determinada por interações de natureza complexa envolvendo os diferentes elementos (Olsen, 1972). Para o autor, interação é a influência 
ou ação recíproca de um nutriente sobre o outro, podendo induzir desordem nutricional, seja por deficiência ou toxidez, e reflexos na produção das culturas.

A descrição dos conhecimentos dessas interações encontram-se em Malavolta et al. (1997), que as classifica em dois tipos fundamentais: efeitos interativos (antagonismo, inibição ou sinergismo) e efeitos não interativos.

Portanto, para se obter máxima eficiência no uso dos nutrientes, além dos fatores da própria planta, dentre os fatores ambientais torna-se relevante considerar a dinâmica de liberação dos nutrientes no solo.

\subsubsection{Disponibilidade e dinâmica de nutrientes no solo}

O crescimento e o desenvolvimento das plantas são afetados por fatores edáficos de natureza física, mineralógica, química e biológica. A disponibilidade engloba processos e reações pelos quais os elementos são liberados em solução e absorvidos pelas plantas, e envolve a capacidade do solo em fornecer os nutrientes e da planta em absorvê-lo e utilizá-lo eficientemente.

Para Meurer (2008), dentre os fatores químicos capazes de influenciar a disponibilidade e a absorção de nutrientes pelas plantas, destacam-se a composição mineralógica, o teor e a forma do elemento de nutrição, a reação do solo $(\mathrm{pH})$, o teor de matéria orgânica, e a presença de elementos potencialmente tóxicos.

O tipo e os teores de elementos minerais no solo são resultantes da intemperização do material de origem, de modo que a composição mineralógica determina a maior ou menor disponibilidade de elementos essenciais para as plantas. Assim, minerais primários como feldspato, micas e anfibólios, e minerais secundários, como vermiculita, esmectita, caulinita e óxidos de Fe e Al, têm acentuada importância no crescimento das plantas (Inda Junior et al., 2004; Meurer, 2008).

Os minerais da fração argila do solo (colóides) apresentam cargas positivas e negativas de superfície, que conferem ao solo capacidade de reter os íons na fase sólida, com efeitos sobre a maior ou menor disponibilidade para as plantas. De acordo com Lopes (1984), os solos sob cerrado apresentam fração argila formada, principalmente, por caulinita, gibbsita, goethita e quartzo, minerais de reduzida densidade de cargas negativas de superfície. E acrescenta, trata-se de solos altamente intemperizados, com baixa reserva de nutrientes para as plantas, fortemente sujeitos ao processo de lixiviação de cátions de bases, e com excessivo grau de permeabilidade.

As reservas de nutrientes do solo, especialmente de $\mathrm{K}, \mathrm{Ca}$ e $\mathrm{Mg}$, encontram-se nas formas estrutural, não-trocável, trocável e na solução do solo (Mengel e Kirkby, 1987; Tisdale e Nelson, 1993). Para Mengel e Kirkby (1987), essas formas estão em equilíbrio dinâmico, pois quando o teor na solução do solo diminui, por absorção pelas plantas ou por lixiviação, ocorre reposição da fase sólida (trocável e não-trocável) para a solução do solo. Portanto, quanto maior a depleção nos teores disponível para as plantas, maior a intensidade da liberação das reservas para restabelecer os equilíbrios. 
Os autores supõem que como todas as formas estão ligadas a este equilíbrio, todas podem ser liberadas, entretanto, reconhecem que a taxa de liberação dos elementos depende do tipo de reação envolvida e da composição mineralógica do solo.

De fato, além da maior parte dos nutrientes $\mathrm{K}, \mathrm{Ca}$ e $\mathrm{Mg}$ do solo encontrarem-se nas formas estrutural e não-trocável (Vahl et al., 1987), vários estudos revelam que o suprimento desses nutrientes para as plantas não é feito exclusivamente pela forma trocável (Rice e Kamprath, 1968; Crisóstomo e Castro, 1970; Oliveira et al., 1971; Christenson e Doll, 1973; Mielniczuk e Selbach, 1978; Raij e Quaggio, 1984; Nachtigall e Vahl, 1991; Meurer e Anghinoni, 1993; Rosolem et al., 1993; Simonete et al., 1998; Castilhos e Meurer, 2002).

Portanto, conforme descrito em Mello e Novais (2007), além do teor de nutrientes em solução, e da reserva desse na fase sólida, torna-se igualmente importante conhecer o poder de reposição da fase sólida para a solução do solo. Para os autores, a disponibilidade de nutrientes no solo é determinada por esses componentes, os quais denominam: (Q) fator quantidade representa a reserva do íon trocável na fase sólida; (I) fator intensidade é a concentração do íon na solução solo; (FC) fator capacidade ou poder tampão que compreende a relação $\Delta \mathrm{Q} / \Delta \mathrm{I}$. Assim, quanto maior o $\mathrm{FC}$, menor a concentração do íon em solução (I), e mais tamponado o solo.

Conforme mencionado, os teores de $\mathrm{K}, \mathrm{Ca}$ e $\mathrm{Mg}$ nos solos são provenientes do material de origem, mas cada elemento apresenta suas particularidades. Tisdale e Nelson (1993) destacam que a dinâmica de Ca e $\mathrm{Mg}$ em solução é menos complexa que a do $\mathrm{K}$, e que o Ca esta mais fortemente retido no complexo de troca do que o $\mathrm{Mg}$ em observação à série liotrópica $\left(\mathrm{Al}^{3+}>\mathrm{Ca}^{2+}>\mathrm{Mg}^{2+}>\mathrm{K}^{+}=\mathrm{NH}^{4+}>\mathrm{Na}^{+}\right)$, sendo o cátion predominante na CTC dos solos. Pelas mesmas razões explica-se a maior lixiviação de K em solos bem drenado, principalmente em solos de baixa CTC (Raij, 1991).

Para Lopes (1984), os teores extremamente baixos de $\mathrm{Ca}$ e $\mathrm{Mg}$, e a reduzida contribuição de K para o complexo de troca catiônica, tornam os valores relativos de Al trocável e das bases trocáveis as mais importantes limitações de uso dos solos de Cerrado. Conforme destacado por Schroeder (1984), os efeitos da acidez na disponibilidade dos nutrientes no solo são marcantes: a intemperização química dos minerais tende a diminuir em $\mathrm{pH}>5$; a formação de novos minerais é maior na faixa de $\mathrm{pH}$ entre 5,0 e 7,5; e a atividade do $\mathrm{Al}$ em solução é maior quando o $\mathrm{pH}<5,0$.

Em condições de elevada acidez a solubilidade dos minerais aumenta a concentração de determinados elementos em solução, podendo tornar-se tóxicos às plantas (Fageria, 1998), como o que ocorre com $\mathrm{Al}\left(\mathrm{Al}^{3+}\right), \mathrm{Mn}\left(\mathrm{Mn}^{2+}\right)$ e $\mathrm{Fe}\left(\mathrm{Fe}^{2+}\right)$, mesmo sendo esses últimos considerados micronutrientes (Valadares e Camargo, 1993).

A matéria orgânica do solo (MOS) é fonte de nutrientes, e apresenta alta capacidade de gerar cargas elétricas de superfície (Canellas et al., 1999), por isso, contribui de maneira significativa para o balanço de cargas no solo (Alleoni et al., 2009). Para os autores, em solos tropicais onde predominam argilominerais 1:1 e os 
óxidos de $\mathrm{Fe}$ e Al, a matéria orgânica torna-se a principal fração envolvida na formação de cargas negativas e troca de cátions.

Todavia, solos de Cerrado apresentam teores médios de matéria orgânica, mas reduzida CTC $\left(<4 \mathrm{meq} / 100 \mathrm{~cm}^{3}\right)$. Conforme aponta Lopes (1984), o pequeno efeito da fração orgânica sobre a CTC se deve a interações com óxidos de Fe e Al da fração argila, que em condições de baixo $\mathrm{pH}$ desenvolvem cargas positivas, reduzindo as cargas negativas líquidas. Outra possível explicação apontada é a de que, em condições de $\mathrm{pH}$ ácido, há diminuição da atividade microbiana e insuficiente ionização dos grupos funcionais da matéria orgânica (carboxílicos, fenólicos, enólicos e imídicos) para induzir a formação de significativo número de cargas negativas.

Os efeitos do pH na decomposição da matéria orgânica, e as implicações sobre a CTC do solo foram observados por Lopes (1984): em $\mathrm{pH}<5$ a CTC efetiva tende a diminuir com o aumento da matéria orgânica; entre $\mathrm{pH} 5$ e 5,5 há ligeiro aumento da CTC com o aumento da matéria orgânica; em $\mathrm{pH}>5,5$ houve aumento significativo na CTC efetiva com a variação no teor de matéria orgânica de 1 para $3 \%$.

\subsubsection{Rochagem - remineralização de solos}

\subsubsection{Agricultura tropical - particularidades e desafios}

O principal fator limitante do potencial produtivo agrícola brasileiro é a baixa fertilidade natural dos solos. Essa afirmativa sugere o entendimento de que "fertilidade" do solo refere-se ao crescimento e desenvolvimento, ou mesmo à produtividade das plantas. No entanto, como a produtividade é resultante da interação de vários fatores de solo, da planta e do clima, conceitualmente, é insuficiente associar fertilidade a produtividade das plantas.

Essa dificuldade de conceituação remete a outro equívoco, relacionar fertilidade do solo com a disponibilidade de nutrientes que a planta pode absorver durante seu ciclo (Raij, 1991; Novais et al., 2007). Para Cantarutti et al. (2007), conceituar fertilidade em associação a produtividade é simplista, pois o solo não se comporta passivamente (fonte) em relação às plantas (dreno).

De qualquer modo, e ainda que não estejam superadas as dificuldades conceituais, torna-se importante fazer inferência à capacidade dos solos suprirem os nutrientes demandados para o desenvolvimento das plantas. Neste sentido, conforme sugerem Novais et al. (2007), a avaliação deve pautar-se pela definição dos processos de amostragem e pela escolha dos métodos de análises, e dos modelos de interpretação dos resultados para recomendação de corretivos e fertilizantes.

Em condições de solos tropicais, como grande parte do território brasileiro, importa considerar a predominância de minerais de baixa reatividade (sesquióxidos e argilominerais 1:1) e carga variável dependente do $\mathrm{pH}$, com efeitos determinantes sobre a dinâmica e disponibilidade dos nutrientes para as plantas (Goedert e Oliveira, 2007). 
Estudos mostram que dentre os aspectos adversos da relação solo-planta, ou da "fertilidade dos solos" no mundo, merece destaque a alta acidez associada à toxidez por Al, e as baixas reservas de K (Wood et al., 2001; Bot et al., 2000). Para esses autores, mais de $50 \%$ dos solos $\left(750.10^{6}\right.$ ha) da América Tropical $\left(23^{\circ} \mathrm{N}-23^{\circ} \mathrm{S}\right)$ apresentam elevada acidez associada a valores de saturação de alumínio acima de $60 \%$, com efeitos sobre a deficiência de $\mathrm{Ca}$ e $\mathrm{Mg}$, toxidez de $\mathrm{Mn}$, e reflexos no crescimento das plantas.

Tal situação torna-se ainda mais preocupante com a exaustão de nutrientes do solo provocada pela exportação maior do que a adição via fertilizantes (Lopes e Guimarães, 2007). De acordo com levantamento realizado pelo World Soil Information, estima-se que o déficit anual médio de nutrientes na agricultura brasileira seja de 15 a $35 \mathrm{Kg} \cdot \mathrm{ha}^{-1}$ de NPK, podendo tornar os solos até então férteis, em solos improdutivos. Os mesmos estudos estimam que mais de 240 milhões de hectares de solos no mundo estejam comprometidos na sua integridade química, sendo que $30 \%$ desses localizam-se na América do Sul (Oldeman et al., 1991).

Os dados da Associação Industrial Internacional de Fertilizantes revelam que o consumo médio de nutrientes NPK no Brasil até os anos de 1990 foi de apenas 52 Kg.ha.ano ${ }^{-1}$, enquanto na China se consumiu $224 \mathrm{Kg}$.ha.ano ${ }^{-1}$ (IFA, 2005). Os dados mais recentes do IFA mostram que o Brasil aumentou o consumo médio para 154 Kg.ha.ano ${ }^{-1}$ de NPK no ano de 2004, com reflexos positivos na produção total das culturas agrícolas. Porém, com base na eficiência agronômica média dos fertilizantes, e na estimativa de remoção dos nutrientes pela produção das 16 principais culturas, Yamada e Lopes (1999) estimam que o déficit anual de nutrientes em 2002 atingiu 859 Mt de N, 514 de P, e 324 de K, tudo a custo do empobrecimento dos solos.

Paradoxalmente, o Brasil é o quarto maior consumidor mundial de fertilizantes, com mais de $60 \%$ do consumo oriundo de importações, o que gera um déficit de US\$ 5,1 bilhões na balança comercial (ANDA, 2010). A uma taxa de crescimento no consumo de 5,8\% ao ano nas últimas décadas, o consumo de fertilizantes passou de 70 para $155 \mathrm{~kg} \cdot \mathrm{ha}^{-1}$ (IBGE, 2012).

Em relação aos corretivos, a utilização de doses insuficientes explica a baixa produtividade média de grande parte das culturas (FAO, 2000). Mesmo assim, conforme apontam Raij e Quaggio (1984), dadas as condições de acidez e toxidez por Al dos solos brasileiros, o uso de corretivos promove resposta significativa em relação ao aumento na produção e ao custo-benefício.

De fato, como bem apontam Lopes e Guimarães (2007), os investimentos em corretivos e fertilizantes são altamente positivos, pois respondem por cerca de $50 \%$ dos aumentos de produtividade na agricultura brasileira. Todavia, o subconsumo de calcário se agravou quando comparado à evolução do consumo de fertilizantes, pois conforme dados da Associação Brasileira dos Produtores de Calcário, nos anos recentes a relação se estreitou para cerca de 1/1, quando o ideal seria entre 2,5 ou 3/1 (Abracal, 2005).

Com o aumento do consumo médio de nutrientes NPK por unidade de área cultivada (IFA, 2005), e a restrita disponibilidade primária de recursos agrominerais 
(Rodrigues et al., 2010), o Brasil torna-se ainda mais dependente das importações para suprir a demanda de fertilizantes básicos para a agricultura. Portanto, para uma agricultura que se revela a cada safra mais competitiva, os fertilizantes tornam-se insumos fundamentais, especialmente em condições de clima tropical onde os solos são em sua maioria ácidos e pobres em nutrientes.

Assim, dadas às particularidades das regiões tropicais, especialmente dos Cerrados, associadas aos altos custos dos fertilizantes e corretivos, o principal desafio da agricultura brasileira é melhorar a eficiência de uso desses insumos (Epstein e Bloom, 2006). Conforme apontado (Lopes, 1984; Castro et al., 1987; Meurer, 2008), todas as estratégias possíveis implicam necessariamente em aliar técnicas produtivas a conhecimentos sobre os fatores de produção vegetal, especialmente, das características e propriedades dos solos capazes de influenciar a disponibilidade e a absorção de nutrientes pelas plantas.

\subsubsection{Agrominerais silicáticos - pesquisas e rotas tecnológicas}

Os agrominerais são produtos da indústria extrativa mineral, e servem de matérias-primas para a indústria de fertilizantes ou para utilização direta na agricultura (Fernandes et al., 2010).

A limitada eficiência dos fertilizantes de síntese, altamente solúveis, nas condições de solos tropical (Baligar et al., 2001), associada aos altos custos das matérias-primas no mercado internacional, têm motivado o desenvolvimento de novos produtos pela indústria, menos solúveis e mais eficientes para as plantas. Conforme destaca por Jimenez (1992), a tendência são os "fertilizantes de liberação lenta", capazes de fornecer os nutrientes de acordo com as necessidades de cada fase dos cultivos, reduzindo-se as perdas por lixiviação e os custos econômicos.

Em contraste, alternativas têm sido propostas para a restauração da fertilidade de solos degradados. Entre elas, a adição de compostos inorgânicos naturais na forma de pó de rochas como corretivos e fertilizantes, apontada no texto seminal "Brot aus Steinen" de J. Hensel (1898). A aplicação de rochas moídas ao solo é denominada rochagem, sendo a calagem e a fosfatagem natural casos particulares (Leonaros et al., 1976), em muitos casos denominada como "remineralização" (Campe et al., 1996).

A prática da "rochagem" está conceitualmente fundamentada no que van Straaten (2002) refere como agrogeologia. Em seu livro "Rocks for crops", Straaten destaca os aspectos centrais das investigações agrogeológicas: o papel do material de origem do solo na disponibilidade de nutrientes, e os efeitos da aplicação de materiais geológicos na produtividade de culturas agrícolas. Assim, a abordagem agrogeologica tem contribuído para o melhor entendimento dos processos geológicos envolvidos na formação dos solos, na manutenção dos agroecossistemas, e na utilização de rochas e minerais como fonte de nutrientes para as plantas.

Dentre os vários materiais utilizados e pesquisados na rochagem, destacam-se as rochas silicáticas multinutrientes (Keller, 1948; Fyfe 198; Chesworth, 1982; van 
Straaten 2002; Gillman, 1980; Barak et al., 1983; Coroneos et al., 1996; Hinsinger et al., 1996; Harley e Gilkes, 2000). A utilização dessas rochas é atraente, pois apresentam potencial de fornecer uma grande variedade de nutrientes, diferente dos fertilizantes solúveis, que normalmente só fornecem os macronutrientes principais N, P e K (Fyfe et al., 1983; Leonardos et al., 1987). Essas rochas são compostas por minerais de maior solubilidade (biotita, flogopita, feldspatóides), além de teores razoáveis de $\mathrm{K}, \mathrm{Ca}, \mathrm{Mg}$ e micronutrientes (Nascimento e Lapido-Loureiro, 2004; Martins et al., 2008).

Para Luz et al. (2010), dependendo dos materiais utilizados (rochas e minerais) e dos fatores do solo e da planta, a prática da rochagem pode traduzir as seguintes funções: correção da acidez; fonte de nutrientes; e remineralização ou condicionamento do solo. Todavia, a literatura demonstra que o principal interesse da rochagem volta-se à obtenção de fontes alternativas de nutrientes, especialmente de $\mathrm{K}$, mediante processos de modificação física e/ou química de diferentes materiais.

Os primeiros estudos tecnológicos direcionados à produção de fertilizantes potássicos a partir de rochas silicáticas tiveram início no período da $1^{\mathrm{a}}$ Guerra Mundial, em países carentes de reservas convencionais de potássio (EUA, Inglaterra, França e Suécia). Conforme descrito em Almeida et al. (1978), dentre as várias rotas tecnológicas avaliadas, os melhores índices de recuperação do potássio foram obtidos via processos de fusão ou calcinação de silicatos-K com compostos de $\mathrm{Ca}$ e/ou outros aditivos $\left(\mathrm{SO}_{2}\right.$, $\mathrm{HCl}, \mathrm{H}_{2} \mathrm{SO}_{4}$ ), e recuperação dos voláteis e lixiviados.

No Brasil, os estudos sobre fontes não convencionais de potássio iniciaram-se na década de 1950 com os trabalhos de Ilchenko \& Guimarães (1953), envolvendo solubilização via ataque ácido em rochas silicáticas alcalinas (fonolito). Outros estudos dessas mesmas rochas avaliaram os efeitos da aplicação direta no solo após moagem (Catani e Gallo, 1960), mas sem resultados satisfatórios (Fujimori (1984).

$\mathrm{Na}$ década de 1970/80 as pesquisas de rochagem se intensificaram. Nesse período a atenção voltou-se às rochas silicáticas multi-nutrientes, devido a ampla ocorrência, e potencial de fornecimento de macro e micronutrientes (Fyfe et al., 1983). Nesse período, o Instituto de Pesquisas Tecnológicas (IPT) desenvolveu vários estudos sobre fontes alternativas de potássio para a indústria nacional de fertilizantes. De acordo com Almeida et al. (1978), as pesquisas do IPT envolveram o aproveitamento de rejeitos de lavras e de pedreiras, e de resíduos da retortagem de xisto, avaliados a partir de diferentes rotas tecnológicas.

Outros trabalhos importantes do período foram desenvolvidos pela Universidade de Brasília (UnB) com o objetivo de aumentar a fertilidade em solos lixiviados e arenosos sob condições de manejo da agricultura familiar (Leonardos et al., 1976).

No final da década de 1990, a Universidade de Brasília e a Embrapa Cerrados retomaram estudos sobre o uso de rochas como fonte alternativa de potássio em sistemas agropecuários (Melamed et al., 2007). As pesquisas coordenadas pelos Professores José Carlos Gaspar e Eduardo Delgado Assad, intitulada "carbonatitos como fonte alternativa para fertilização de solos", resultou em uma patente de 
propriedade intelectual (PI0102741-7 B1) registrada no Instituto Nacional de Propriedade Industrial - INPI.

Posteriormente, essas pesquisas foram ampliadas, passando a envolver outros materiais ou tipos de rochas (biotita-xisto, flogopitito, brecha vulcânica alcalina e carbonatito), todos rejeitos de mineração submetidos a moagem prévia, e avaliados em condições de casa de vegetação com diferentes culturas (Martins et al., 2008).

Desde então, a técnica da rochagem passou a compor a agenda de instituições de pesquisa e pesquisadores das diversas regiões do país, de maneira que em 2006 foi criada a Rede Interinstitucional de Pesquisa da Rochagem, a Rede AgriRocha, coordenada pela Embrapa Cerrados. A realização do I e II Congresso Brasileiro de Rochagem mostrou que as pesquisas de rochagem no Brasil envolvem diferentes abordagens metodológicas, tratamentos e delineamentos experimentais, além de uma variedade significativa de materiais (rochas e minerais) e culturas agrícolas.

Outras iniciativas igualmente importantes podem ser mencionadas, como as pesquisas sobre rochas, minerais e rotas tecnológicas para produção de fertilizantes alternativos (CETEM/MCTI), e também o projeto de identificação e localização geográfica de rochas e minerais como fonte alternativa de nutrientes na produção de biocombustíveis (CPRM/MME).

Os resultados das pesquisas indicam que a eficiência agronômica do processo da rochagem depende da origem da rocha, da sua mineralogia e composição química, bem como de outros fatores associados a características do solo, do tempo de incubação do composto mineral, do tratamento prévio aplicado, e também, das espécies cultivadas (Távora, 1982; Nascimento e Loureiro, 2004). Para Winiwarter e Blum (2006), isso dificulta a determinação das relações de causa-resposta e a definição das doses exatas a serem utilizadas, e de certo modo explicam os resultados pouco significantes de algumas experiências: materiais extremamente pobres associados a solos também muito deficientes em nutrientes; curto período de duração das experiências; e custos elevados.

Assim, o aspecto mais criticado da rochagem, a baixa solubilidade, na verdade compreende uma grande vantagem para agricultura tropical, onde a interação de fatores do solo (baixa capacidade de troca de cátions) e do clima (alta pluviosidade) tornam os fertilizantes solúveis facilmente lixiviados (Leonardos et al., 2000). Neste mesmo sentido, Martins (2010) aponta que a liberação lenta e gradual de nutrientes pela rochagem é positiva em função dos efeitos residuais sobre cultivos sucessivos, como é também a formação de minerais secundários sobre a elevação da CTC, com redução das perdas por lixiviação dos nutrientes na solução do solo.

Do ponto de vista econômico, o aspecto mais importante da viabilidade técnica da rochagem, é o custo associado ao transporte, visto que, para compensar a baixa solubilidade desses materiais e os reduzidos teores dos nutrientes, geralmente são recomendadas doses relativamente altas (Bolland e Baker, 2000). Com isso, a viabilidade econômica da rochagem esta limitada à distância entre o local de origem do 
agromineral e a área dos cultivos onde será aplicado, a exemplo do modelo adotado na indústria de calcário (Martins et al. 2008; Resende et al., 2006c).

Conforme já se apontou, a obtenção dos produtos usados na rochagem se dá especialmente por meio do aproveitamento dos resíduos de mineração, via de regra, considerados um passivo ambiental. Neste sentido, a rochagem representa importante ação frente ao objetivo estratégico "Produção Sustentável" do Plano Nacional de Mineração - PNM 2030 (MME, 2010), ou seja, incentivar a reciclagem, reuso e reaproveitamento de matérias provenientes de recursos minerais. Adicionalmente, a rochagem também corrobora com os preceitos da Lei $n^{0} 12.305 / 2010$, que institui a Política Nacional de Resíduos Sólidos.

O desafio principal da rochagem é fornecer os nutrientes no tempo certo e em quantidades requeridas pela cultura (Harley e Gilkes, 2000; Martins et al., 2008; Strateen, 2006). Uma recente contribuição à superação de tal desafio pode ser apresentada de forma indagativa, como o fez Peter van Straaten em palestra proferida no II Congresso de Rochagem realizado em 2013, na cidade de Poços de Caldas-MG, ao questionar: which rocks for which crops?

\subsubsection{Regulamentação do uso dos agrominerais silicáticos}

No Brasil, todos os insumos destinados à agricultura são inspecionados e fiscalizados pelo Ministério de Agricultura, Pecuária e Abastecimento - MAPA, conforme estabelece a Lei $n^{\circ} 6.894 / 1980$, regulamentada pelo Decreto $n^{\circ} 4.954 / 1980$.

Com base na Lei 6.894/1980, a Instrução Normativa $n^{0} 35 / 2006$, que estabelece as normas sobre especificações e garantias, tolerâncias, registro, embalagem e rotulagem dos insumos destinados à agricultura, enquadra os pós de rochas na categoria condicionador de solos, ou seja, um produto que promove a melhoria das propriedades físicas, físico-químicas ou atividade biológica do solo, podendo recuperar solos degradados ou desequilibrados nutricionalmente.

O exemplo é pó de rocha comercializado pela Mineradora Barreto SA, o MB-4, produzido a partir da mistura das rochas serpentinito e biotita-xisto, registrado junto ao MAPA como um condicionador de solos. Conforme estabelece a IN n $35 / 2006$, todos os condicionadores de solo devem apresentar no mínimo $60 \%$ de capacidade de retenção de água (CRA) e $200 \mathrm{mmolc} / \mathrm{Kg}$ de capacidade de troca catiônica (CTC).

Surge aqui a principal crítica aos critérios e parâmetros definidos dispostos no arcabouço legal que regulamenta a possível produção e comercialização de pós de rochas no Brasil. A questão suscitada é de que a grande maioria dos materiais estudados, inclusive os mais promissores para efeito da rochagem, não apresentam tais condições para enquadramento como condicionador de solo.

Diante de tal situação, esforços articulados por pesquisadores apoiados por suas respectivas instituições, conseguiram desencadear um processo de discussão que culminou com a revisão do referido arcabouço legal, e a publicação da Lei $\mathrm{n}^{\mathrm{o}}$ 
12.890/2013. A principal mudança promovida pela referida Lei foi a criação de uma nova categoria de insumo para a agricultura, os remineralizadores de solo, ou seja: material de origem mineral que tenha sofrido apenas redução e classificação de tamanho por processos mecânicos e que altere os indices de fertilidade do solo por meio da adição de macro e micronutrientes para as plantas, bem como promova a melhoria das propriedades físicas ou fisico-químicas ou da atividade biológica do solo.

Atualmente, um Grupo de Trabalho estuda os critérios e parâmetros a serem definidos para a normatização do uso de pós de rocha na agricultura, ou seja, as especificações para registro e comercialização dos remineralizadores de solo. A partir de informações socializadas via Rede AgriRocha, das primeiras oficinas de trabalho foram acolhidas propostas de especificações e garantias mínimas a serem observadas no enquadramento do pó de rocha como remineralizadores de solo: soma de bases (mínimo 9\%); pH de abrasão (mínimo 7); granulometria (filler, pó e farelado); teor de quartzo (máximo 20\%). Outros aspectos discutidos e que podem vir a compor as especificações para classificação e registro dos remineralizadores de solo:

- produto simples (um único material) ou misto (misturas de dois ou mais materiais);

- a mistura que compõem o produto deve apresentar soma de bases (mínimo 9\%);

- descrição do processo de obtenção e beneficiamento;

- laudo analítico da composição mineralógica, geoquímica e granulométrica;

- parecer de viabilidade agrícola de uso do produto.

\subsection{SINTESE DE UMA PROPOSIÇÃO}

A partir do que foi revisto sobre dissolução de minerais e rochas, e suas implicações na dinâmica de nutrientes no solo e na nutrição de plantas, bem como, sobre os fatores que determinam a eficiência da rochagem na agricultura tropical, algumas questões são levantadas em relação aos objetivos anunciados inicialmente:

- Os resíduos minerais gerados no Garimpo de Monte Santo-TO tem efeito como fonte alternativa de nutrientes em cultivos agrícolas sucessivos?

- A taxa de dissolução e liberação de $\mathrm{K}, \mathrm{Ca}$ e $\mathrm{Mg}$ do agromineral é compatível com as exigências nutricionais de plantas cultivadas?

- Qual a relação entre os atributos físico-químicos do solo e a solubilização do agromineral silicático?

- Quais os efeitos globais do agromineral sobre os atributos químicos do solo, e na nutrição e desenvolvimento de plantas cultivadas?

- Quais os efeitos do agromineral na nutrição e produção da cana-de-açúcar?

As investigações sobre minerais e rochas como fontes alternativas de nutrientes são em grande parte orientadas pela noção de fertilidade dominante nas ciências agrárias, pois abordam quase que exclusivamente as alterações nas características químicas dos solos, ou os efeitos sobre a produção das diferentes espécies cultivadas. 
Como bem apontam Cartagena e Diéz Lopes (1992), a avaliação de fontes de nutrientes de liberação lenta, como ocorre na rochagem, compreende um processo complexo, pois implica uma série de fatores intrínsecos e extrínsecos ao material. Essa complexidade está relacionada aos mecanismos envolvidos no sistema rocha-soloplanta-clima, resultantes de interações diversas entre parâmetros físico-químicos do próprio sistema (Melamed et al., 2007), mantidas e controladas pelo equilíbrio dinâmico das reações de troca de matéria e energia entre os componentes (Mello e Perez, 2009).

Assim, com o objetivo de avaliar as possibilidades e limitações da prática da rochagem a partir dos resíduos minerais do Garimpo de Monte Santo-TO, o presente estudo adota uma abordagem semelhante à preconizada por Jimenez (1992) na avaliação de fertilizantes de liberação lenta (FLL), onde se considera: i) as propriedades físico-químicas determinantes da estabilidade e do comportamento do produto no meio; ii) o modelo de aporte de nutrientes em comparação com outros produtos; iii) a efetividade do produto em cultivos específicos.

Para tanto, além da necessidade de caracterizar física, mineralógica e geoquimicamente o rejeito mineral gerado no Garimpo de Monte Santo-TO, conforme ilustrado na Figura 1.1, a avaliação das possibilidades e limitações da rochagem envolveu a realização de experimentos que caracterizam sistemas de diferentes graus de complexidade $(1<2<<3<4<<5)$.

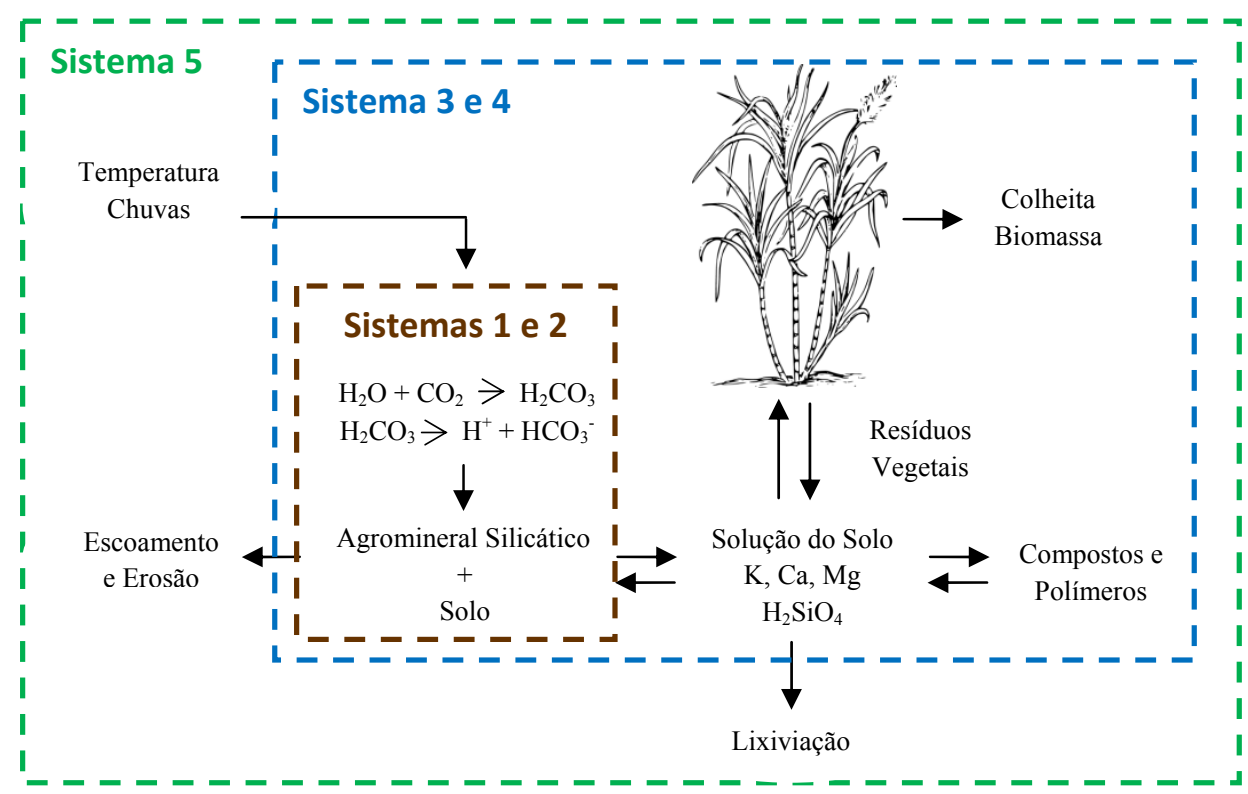

Figura 1.1. Mecanismos e interações do sistema rocha-solo-planta-clima.

Assim, a partir de um ensaio que considere as interações manifestadas nas relações mineral-solução (sistema 1) e mineral-solo-solução (sistema 2) é possível estimar a taxa de dissolução do rejeito mineral, e identificar os efeitos de sobreposição dos atributos dos solos na dinâmica de liberação de nutrientes do rejeito mineral. Os aspectos mais relevantes dessas interações remetem às características do próprio material, e aos fatores que interferem na dissolução mineral. 
Complementarmente, um ensaio em vasos com e sem plantas, em casa de vegetação, possibilita avaliar os efeitos do rejeito mineral no suprimento de nutrientes para cultivos sucessivos. Em se tratando de relações mineral-solo-solução (sistema 3) e mineral-solo-solução-planta (sistema 4), importa considerar os fatores que controlam e a dinâmica de nutrientes no solo, e a absorção e acúmulo de nutrientes nas plantas.

Por fim, um ensaio a campo, com uma cultura de ciclo semi-perene (cana-deaçúcar), permite avaliar a viabilidade técnica do uso do rejeito mineral em substituição e complementação às fontes convencionais de nutrientes. Nesse sistema mineral-solosolução-planta-clima tornam-se relevantes as características morfológicas e fisiológicas das plantas, os atributos do solo, as condições climáticas regionais, além da incidência de moléstias, erosão e lixiviação do solo, e exportação via colheita.

Adicionalmente, as informações geradas podem são fundamentais para o registro e comercialização deste tipo de agromineral como um remineralizador de solos, tornando-se úteis aos interesses das cooperativas de garimpeiros. 


\section{CAPÍTULO 2}

\section{CARACTERIZAÇÃO DO AGROMINERAL SILICÁTICO}

Resumo: O objetivo principal do estudo é caracterizar os aspectos geológicos, geoquímicos e mineralógicos dos rejeitos minerais do Garimpo de Esmeraldas de Monte Santo-TO. A zona mineralizada do garimpo é descrita como sendo formada por rochas vulcânicas máfico-ultramáficas da Sequência Metavulcano-Sedimentar Rio do Coco, e essa representada por duas unidades distintas: uma unidade basal composta de xistos magnesianos intercalados com metassedimentos; e uma unidade superior composta por anfibolito e metassedimentos. $\mathrm{O}$ pó de rocha obtido da moagem dos rejeitos minerais apresenta 73\% das partículas com granulometria "fração areia" (0,06 a $2 \mathrm{~mm})$, e área de superfície específica de $0,562 \mathrm{~m}^{2} \mathrm{~g}^{-1}$ (BET). A composição geoquímica de rocha total revelou que o pó de rocha apresenta 7,9\% de $\mathrm{CaO}, 9,8 \%$ de $\mathrm{MgO}, 2,2 \%$ de $\mathrm{K}_{2} \mathrm{O}$, além de vários outros elementos de nutrição de plantas. Os teores dos elementos potencialmente tóxicos (EPT) são muito baixos, e não oferecem riscos de contaminação ou ambiental. Os resultados dos testes de dissolução com ataque sulfúrico indicam que $50 \%$ do $\mathrm{K}_{2} \mathrm{O}$ presente no pó de rocha esta prontamente disponível para as plantas. Os teores extraídos de $\mathrm{CaO}$ e $\mathrm{MgO}(95 \%)$ mostra que o material também pode ser fonte desses nutrientes, com efeitos sobre a acidez dos solos agrícolas. Essas informações serão fundamentais nos estudos experimentais sobre a dissolução mineral e os efeitos potenciais do pó de rocha na nutrição de plantas, além de serem úteis ao registro e comercialização deste tipo de agromineral.

Palavras-chave: agromineral; rochas vulcânicas; mineralogia; geoquímica.

Abstract: The main objective of the study is to characterize the geological, geochemical and mineralogical minerals tailings panning Emeralds Holy Mount-TO aspects. The mineralized zone of the mine is described as being formed by maficultramafic volcanic rocks Metavulcano-Sedimentary Sequence of the Rio Coco, and that represented by two distinct units: a composite of magnesium schists intercalated with metasediments basal unit; and an upper unit composed of amphibolite and metasediments. The stone powder obtained by grinding the mineral tailings shows $73 \%$ of particles with a particle size "sand fraction" (0.06 to $2 \mathrm{~mm})$ and specific surface area of $0,486 \mathrm{~m} 2 \mathrm{~g}-1$ (BET). The whole rock geochemical composition revealed that the rock dust has $7.9 \% \mathrm{CaO}, 9.8 \% \mathrm{MgO}, 2.2 \% \mathrm{~K}_{2} \mathrm{O}$, and various other elements of plant nutrition. The levels of potentially toxic elements (EPT) are very low and do not provide or environmental contamination risks. The results of the dissolution tests with sulfuric acid attack indicate that $50 \%$ of $\mathrm{K}_{2} \mathrm{O}$ present in the rock dust (biotite-shale) is readily available to plants. The extracted contents of $\mathrm{CaO}$ and $\mathrm{MgO}$ contents $(95 \%)$ shows that the material can also be a source of these nutrients, with effects on the acidity of agricultural soils. This information will be fundamental in experimental studies of mineral dissolution and the potential effects of rock dust in plant nutrition, in addition to being useful to the registration and commercialization of this agromineral.

Keywords: agromineral; volcanic rocks; mineralogy; geochemistry. 


\subsection{INTRODUÇÃO}

Os agrominerais são produtos da indústria extrativa mineral, e servem de matérias-primas para a indústria de fertilizantes ou para utilização direta na agricultura (Fernandes et al., 2010). O Brasil é o quarto maior consumidor mundial de fertilizantes, com mais de $60 \%$ do consumo oriundo de importações (ANDA, 2010), o que gera um déficit de US\$ 5,1 bilhões na balança comercial (Kulaif, 2009).

Com o aumento do consumo médio de nutrientes NPK por unidade de área cultivada (IFA, 2005), e a restrita disponibilidade primária de recursos agrominerais (Rodrigues et al., 2010), o Brasil torna-se ainda mais dependente das importações para suprir a demanda de fertilizantes básicos para a agricultura. Portanto, para uma agricultura que se revela a cada safra mais competitiva, os fertilizantes tornam-se insumos fundamentais, especialmente em condições de clima tropical onde os solos são em sua maioria ácidos e pobres em nutrientes.

Essa situação têm motivado estudos voltados à avaliação do potencial de novas fontes de matérias-primas, ou mesmo de novos produtos, que possam suprir a demanda mais urgente da agricultura brasileira. Exemplos disso são as ações articuladas pela Rede Interinstitucional de Pesquisa de Rochas como Fonte Alternativa de Nutrientes para Sistemas Agropecuários - Rede AgriRocha, coordenada pela Embrapa Cerrados. Outras iniciativas de âmbito nacional são as pesquisas sobre rochas, minerais e rotas tecnológicas para produção de fertilizantes alternativos (CETEM/MCTI), e de identificação e localização geográfica de rochas e minerais como fonte alternativa de nutrientes na produção de biocombustíveis (CPRM/MME).

Os resultados das pesquisas indicam que a eficiência agronômica do processo da 'rochagem', definida como a aplicação de rochas moídas ao solo (Campe et al., 1996; Leonardos e Theodoro, 1999), depende da origem da rocha, da sua mineralogia e composição química, bem como de fatores associados às características do solo, do tempo de incubação do composto mineral, do tratamento prévio aplicado, e também, das espécies cultivadas (Távora, 1982; Nascimento \& Loureiro, 2004, Martins et al., 2008).

Todavia, ainda que sejam muitos os aspectos a serem considerados na escolha das rochas, em geral os resultados obtidos são pouco satisfatórios, sobretudo, devido a falta de conhecimento das características mineralógicas do material que se destina a aplicação direta ao solo (Nascimento e Loureiro, 2004). Para os autores, a efetividade da rochagem como fertilizante de liberação lenta esta condicionada ao entendimento da cinética de liberação dos íons em solução, e da dinâmica desses íons em função das características dos solos e das condições climáticas.

Os principais materiais utilizados como fontes alternativas são as rochas e minerais silicáticos, de ampla ocorrência regional (Távora, 1982; Nacimento e Loureiro, 2004; Martins et al., 2008). As pesquisas realizadas pela Embrapa Cerrados em conjunto com a Universidade de Brasília apontam alguns grupos de rochas com potencial de uso na agricultura (Martins et al., 2008): biotita-xisto e flogopitito; brecha vulcânica alcalina; carbonatito; e ultramáfica alcalina. 
Conforme apontado em Luz et al. (2010), a maioria das pesquisas de rochagem envolvem o aproveitamento de rejeitos de minas e de pedreiras, inclusive como interessante alternativa de redução do passivo ambiental. Por esta razão, tais iniciativas representam um importante contribuição ao objetivo estratégico "Produção Sustentável" definido no Plano Nacional de Mineração - PNM 2030 (MME, 2010), bem como aos preceitos da Lei n 12.305/2010, que institui a Política Nacional de Resíduos Sólidos.

Tendo em vista que as rochas silicáticas são de composição complexa e relativamente pouco conhecidas, diferente dos fertilizantes tradicionais, cuja pureza, concentração e solubilidade de nutrientes são bem estabelecidas (Resende et al, 2012), a avaliação do potencial agronômico da rochagem não pode prescindir de uma adequada caracterização da rocha selecionada.

O presente estudo utiliza de vários métodos e técnicas analíticas para descrever as características física, mineralógica e geoquímica dos resíduos do Garimpo de Esmeraldas de Monte Santo-TO.

\subsection{OBJETIVOS}

\section{Objetivo Geral}

Realizar estudos de caracterização física, mineralógica e geoquímica do agromineral.

\section{Objetivos Específicos}

- Descrever o contexto geológico regional da área que compreende a zona mineralizada do Garimpo de Esmeraldas de Monte Santo-TO;

- Analisar, quantificar e descrever as características físicas, químicas e mineralógicas das rochas constituintes e do próprio pó de rocha;

- Estimar a capacidade de liberação de nutrientes do pó de rocha em curto prazo mediante dissolução parcial com ataque sulfúrico.

\subsection{MATERIAL E MÉTODOS}

Os trabalhos iniciais consistiram em pesquisas bibliográficas com o objetivo de possibilitar suficiente entendimento do contexto geológico regional e, em especial, da área que compreende o Garimpo de Esmeraldas de Monte Santo-TO. A descrição apresentada baseia-se em informações obtidas no Programa Geologia do Brasil Tocantins - Folha SC.22 (Faraco et. al., 2004), e no Projeto Hidrogeologia do Tocantins - Palmas - Folha SD.22-Z-B (Frasca e Araújo, 2001).

Em visita à área foram coletadas 02 amostras consideradas representativas dos litotipos que constituem as unidades basal e superior da zona mineralizada do garimpo, as quais foram utilizadas nos estudos petrográficos, mineralógicos e geoquímicos. Uma amostra do próprio pó de rocha, obtida após a moagem de grande quantidade dos rejeitos em uma indústria de calcário da região, foi submetida às análises de composição geoquímica e granulométrica. 
Nos estudos de caracterização optou-se pela aplicação de diversas técnicas analíticas de minerais e rochas, cujos detalhes são descritos a seguir:

\subsubsection{Análises Físicas: Granulometria, Densidade Superfície Específica}

A superfície de reação é um dos fatores que determinam a taxa de liberação dos nutrientes de rochas moídas aplicadas in natura, mostrando sempre uma relação direta, ou seja, quanto mais fino o material, maior a dissolução mineral.

A análise granulométrica foi realizada a partir de uma amostra do pó de rocha obtida após a moagem dos rejeitos de mineração (Embrapa, 1997), a qual foi seca e fracionada com o auxílio de peneiras de malhas de diferentes aberturas $\left(\mathrm{N}^{\circ} 10<2,0\right.$ $\mathrm{mm} ; \mathrm{N}^{\circ} 20<0,84 \mathrm{~mm}$; $\left.\mathrm{N}^{\circ} 50<0,297 \mathrm{~mm}\right)$. Da menor fração $(<0,297 \mathrm{~mm})$ foi retirada uma amostra de peso conhecido, e com base no método da pipeta, calculou-se o percentual das frações silte $(<0,05 \mathrm{~mm})$ e argila $(<0,002 \mathrm{~mm})$.

A determinação da densidade aparente foi realizada pelo método direto da proveta (volume interno de $100 \mathrm{~mL}$ ), a partir de uma amostra do pó de rocha destorroada e peneirada $(<2,0 \mathrm{~mm})$.

A caracterização física foi complementada com a determinação da área de superfície específica do pó de rocha, realizada no Laboratório de Nanotecnologia da Embrapa Instrumentação. A área de superfície específica foi calculada a partir dos dados de adsorção de N2 obtidos em um equipamento Micrometrics ASAP-2000, e aplicação dos modelos BET e Langmuir.

\subsubsection{Análises Petrográfica, Mineralógica e de Química Mineral}

As amostras analisadas compreendem os litotipos (A1 e A4) que constituem a zona mineralizada do Garimpo de Monte Santo-TO, com os quais foram confeccionadas lâminas delgadas polidas de dimensões C x L x E (46 mm x 27 mm x 0,15”).

A análise petrográfica é o ponto de partida para praticamente todos os demais métodos analíticos em geologia. A caracterização mineralógica dos litotipos foi realizada no Laboratório de Microscopia do Instituto de Geociências da Universidade de Brasília - IGD/UnB, com o auxílio de microscópio petrográfico de luz refletida e invertida. Essas análises geraram informações mais precisas das relações texturais dos principais minerais constituintes, além de fotomicrografias convencionais que possibilitaram a contagem de pontos para estimativas modais.

As análises de determinação da composição química mineral foram realizadas no Laboratório de Microssonda Eletrônica (LASON-IGD/UnB). A microssonda eletrônica da JEOL, Modelo JXA-8230, conta com cinco espectrômetros e sete cristais analisadores TAPJ, LIF, LIFH, PETJ, PETH, LDE1 e LDE2. A utilização do equipamento se deu nas seguintes condições de operação: $15 \mathrm{KV}$; $20 \mathrm{~mA}$; feixe 0,5 a 1 mícron. Ao todo foram analisados 80 cristais considerados como representativos das duas rochas amostras, e gerados os seguintes produtos: i) análises pontuais quantitativas 
(WDS); ii) análises pontuais qualitativas (EDS); iii) imagens de varredura de raios-X (branco e preto); iv) espectros de raios-X; v) imagens de elétrons secundários (SE) e retroespalhados (BSE) por microscopia eletrônica de varredura.

\subsubsection{Análise Geoquímica de elementos maiores, traços e ETRs}

As amostras analisadas são as mesmas descritas anteriormente, ou seja, os litotipos biotita gnaisse (RT-BT) e anfibolito (RT-ANF), e também o rejeito de mineração na forma de pó de rocha (RT-PR).

Nas análises realizadas no Acme Analytical Laboratories Ltd foram empregados métodos de espectrometria de emissão atômica (ICP-AES) e espectrometria de massa (ICP-MS), ambos com fonte plasma acoplado indutivamente. O protocolo laboratorial do Acme prevê: a decomposição ou dissolução das amostras; a extração dos elementos desejados em uma solução; e a determinação por análise instrumental do elemento. No presente estudo foi utilizada a extração total para medir a abundância dos elementos de todos os minerais presentes na amostra.

A determinação de perda ao fogo (em inglês, loss on ignition, LOI) consiste na aferição da perda de massa representada pela água (adsorvida e estrutural) e pelos elementos voláteis presentes na rocha após aquecimento entre até cerca de $1000^{\circ} \mathrm{C}$. A determinação do carbono e do enxofre foram realizadas em um analisador LECO, o qual envolve combustão das amostras em um forno mantido sob fluxo de oxigênio e temperatura entre 1350 e $1500^{\circ} \mathrm{C}$, com detecção aferida por uma célula infravermelha.

\subsubsection{Dissolução Parcial dos Minerais}

A amostra utilizada compreende o próprio pó de rocha obtido após moagem, a qual foi encaminhada ao Laboratório de Solos da Embrapa Cerrados para determinação da dissolução parcial dos minerais constituintes.

O método aplicado consiste no tratamento da amostra com ácido sulfúrico $\mathrm{H}_{2} \mathrm{SO}_{4}$ 1:1 (densidade $1,47 \mathrm{~g} \mathrm{~cm}^{-3}$ ), e posterior diluição, filtração e determinação dos elementos ( $\mathrm{Fe}, \mathrm{Al}, \mathrm{K}, \mathrm{Ca}$ e $\mathrm{Mg}$ ) por espectrometria de emissão atômica com plasma de acoplamento induzido (ICP-AES). A sílica foi determinada no resíduo do extrato após dissolução com hidróxido de sódio $\mathrm{NaOH}$ a $30 \%$.

\subsection{RESULTADOS E DISCUSSÃO}

\subsubsection{Histórico e Localização do Garimpo de Monte Santo-TO}

A ocorrência de esmeraldas na porção centro-sul do Estado do Tocantins foi relatada em diversos trabalhos de pesquisa desenvolvidos a partir do final da década de 1980. A primeira delas foi a Verena Mineração Ltda (DNPM 860.686/90), que em 1990 iniciou intenso programa de exploração mineral na região, atraída especialmente pelas ocorrências de ouro e esmeralda associada a uma sequência do tipo Greestone Belt. 
Na segunda metade dos anos de 1990 a região se tornou alvo de interesse de garimpeiros e de diversas empresas de mineração. Em 1997, a descoberta de esmeralda na zona rural do município de Monte Santo, região central do Estado do Tocantins, ocasionou um grande fluxo de pessoas para a área denominada Garimpo de Monte Santo. Essa área localiza-se entre as coordenadas $10^{\circ} 03^{\prime 2} 23^{\prime}$ S e $49^{0} 00^{\prime} 06$ 'W, a $7 \mathrm{Km}$ ao Sul da sede do Município de Monte Santo, distante cerca de $83 \mathrm{Km}$ de Palmas e a 25 Km de Paraíso do Tocantins pela rodovia TO-080 (antiga GO-364).

As atividades de garimpagem e o grande fluxo de garimpeiros resultaram na criação de duas cooperativas, Coopersanto (864603/10) e Coopergemas (864602/10). As escavações de poços que variam de 1 a 11 metros de profundidade deram-se de forma mecanizada com auxílio de guinchos elétricos e bombas de sucção, e de forma manual com a utilização de sarrilhos. Hoje essas cooperativas dispõem de Permissão de Lavra Garimpeira (PLG) expedida pelo Departamento Nacional de Produção Mineral DNPM, e também de Licenças de Operação (LO) obtidas junto ao Instituto Natureza do Tocantins - Naturatins.

\subsubsection{Aspectos Fisiográficos da Região}

A área em questão apresenta clima tropical (Aw) segundo Köppen (1948), o qual caracteriza-se por uma estação seca bem acentuada (inverno), e outra chuvosa (verão). Os índices pluviométricos históricos situam-se em torno de $1750 \mathrm{~mm}$. Nos meses mais quentes do ano a temperatura supera os $38^{\circ} \mathrm{C}$, com valores médios anuais de $26^{\circ} \mathrm{C}$ e baixa amplitude térmica. A umidade relativa média anual é de $72 \%$, sendo registrados os maiores valores de umidade em janeiro (85\%) e em julho os menores (59\%).

A região do Garimpo de Monte Santo ocupa uma área de diferentes fitofisionomias do Cerrado distribuídas conforme o substrato rochoso: Campo Cerrado sobre os gnaisses; Cerradão sobre os cangarais instalados sobre as rochas máficas, ultramáficas e sedimentos paleozoicos; Matas de Galeria e Veredas de modo típico ao longo da rede de drenagem.

Geomorfologicamente, a região pertencente ao planalto do Interflúvio AraguaiaTocantins, divisor de águas entre os dois rios. As estruturas geológicas e as condições morfogenéticas definiram um relevo formado por encostas e serras de direção NW-SE com altitudes superiores a $450 \mathrm{~m}$. A morfologia da área é esculpida nos folhelhos e siltitos da Formação Pimenteiras, e xistos do Grupo Baixo Araguaia, representados principalmente pelas Serras das Cordilheiras (Frasca e Araújo, 2001).

Os corpos rochosos que constituem a Suíte Alcalina de Monte Santo acham-se arrasados, formando lajedos e blocos, e raras exceções de pequenos morrotes. Com isso não apresentam expressão topográfica ou morfológica marcante em relação às rochas do Complexo Goiano (Iwanuch, 1991).

Os solos estão intimamente relacionados às formas de relevo, às rochas e à vegetação, sendo comum a ocorrência de Latossolos, solos concrecionários 
(Plintossolos Pétricos concrecionários), solos arenosos (Neossolos Quartzarênicos), Neossolos Litólicos e Neossolos Flúvicos (Frasca e Araújo, 2001).

\subsubsection{Contexto Geológico Regional}

O material em estudo compreende os rejeitos do Garimpo de Esmeraldas de Monte Santo, região Centro-Oeste do Estado do Tocantins. O contexto geológico regional e local está bem caracterizado em vários estudos (Barreira, 1980; Barreira e Dardenne, 1981; Arcanjo et al., 2000), e também no Projeto Hidrogeologia no Tocantins - Palmas - Folha SD.22-Z-B (Frasca e Araújo, 2001), e Programa Geologia do Brasil - Tocantins - Folha SC.22 (Faraco et. al., 2004).

De acordo com os dados do Projeto Hidrogeologia no Tocantins - Folha Palmas - SD.22.Z.B-TO (Frasca e Araújo, 2001), do ponto de vista geológico a região abrange três segmentos crustais distintos: o Núcleo Cratônico; o Cinturão Araguaia; e a Bacia do Parnaíba. O Núcleo Cratônico compreende um terreno granito-gnáissico metamorfizado em médio-alto grau, associado a uma sequência metavulcano-sedimentar de fácies xisto verde. Apresenta duas unidades litoestratigráficas com arranjos e estilos estruturais similares: Complexo Granítico-Gnáissico Campo Maior (Pcm); e Sequência Metavulcano-Sedimentar Rio do Coco (Prc).

Conforme descrito em Frasca e Araújo (2001), a zona mineralizada do garimpo é composta por rochas vulcânicas máfico-ultramáficas da Sequência MetavulcanoSedimentar Rio do Coco (Prc), interpretada por Barreira e Dardenne (1981) como remanescentes do Greenstone Belt Arqueano (Figura 2.1). De acordo com Barreira (1980), trata-se de duas unidades distintas, ambas metamorfizadas à fácies xisto verde: a unidade basal composta por xistos magnesianos intercalados com metassedimentos químicos e pelíticos, serpentinitos e piroxenitos; e a sequência superior composta por anfibolito e metassedimentos.

Os contatos da Prc são discordantes e tectônicos (Frasca e Araújo, 2001): a sul e sudeste faz contato com o Complexo Granito-Gnaisse Campo Maior através de uma discordância litológica; a leste e a oeste faz contato tectônico com as formações do Grupo Baixo Araguaia através de uma zona de cisalhamento, e a nordeste é cortada pelo "stock" alcalino de Monte Santo. Ainda segundo os autores, a Prc foi submetida a uma sucessão de processos deformacionais e condições metamórficas, incluindo intenso hidrotermalismo. Regimes dúcteis, dúcteis-rúpteis e rúpteis obliteraram estruturas internas primárias e relações de contato originais, gerando acentuada foliação de transposição em todos os litotipos.

Estudos geocronológicos realizados por Arcanjo et al. (2000), utilizando o método $\mathrm{Pb} / \mathrm{Pb}$ em monocristais de zircão confirmaram seu posicionamento estratigráfico no Arqueano, com idade de $2.618 \pm 14$ Ma. Diferentemente, Frasca e Araújo (2001) sugerem idade paleoproterozóica baseada na relação de contato e similaridade estrutural da Prc com o Complexo Granito-Gnáissico Campo Maior (Pcm). 


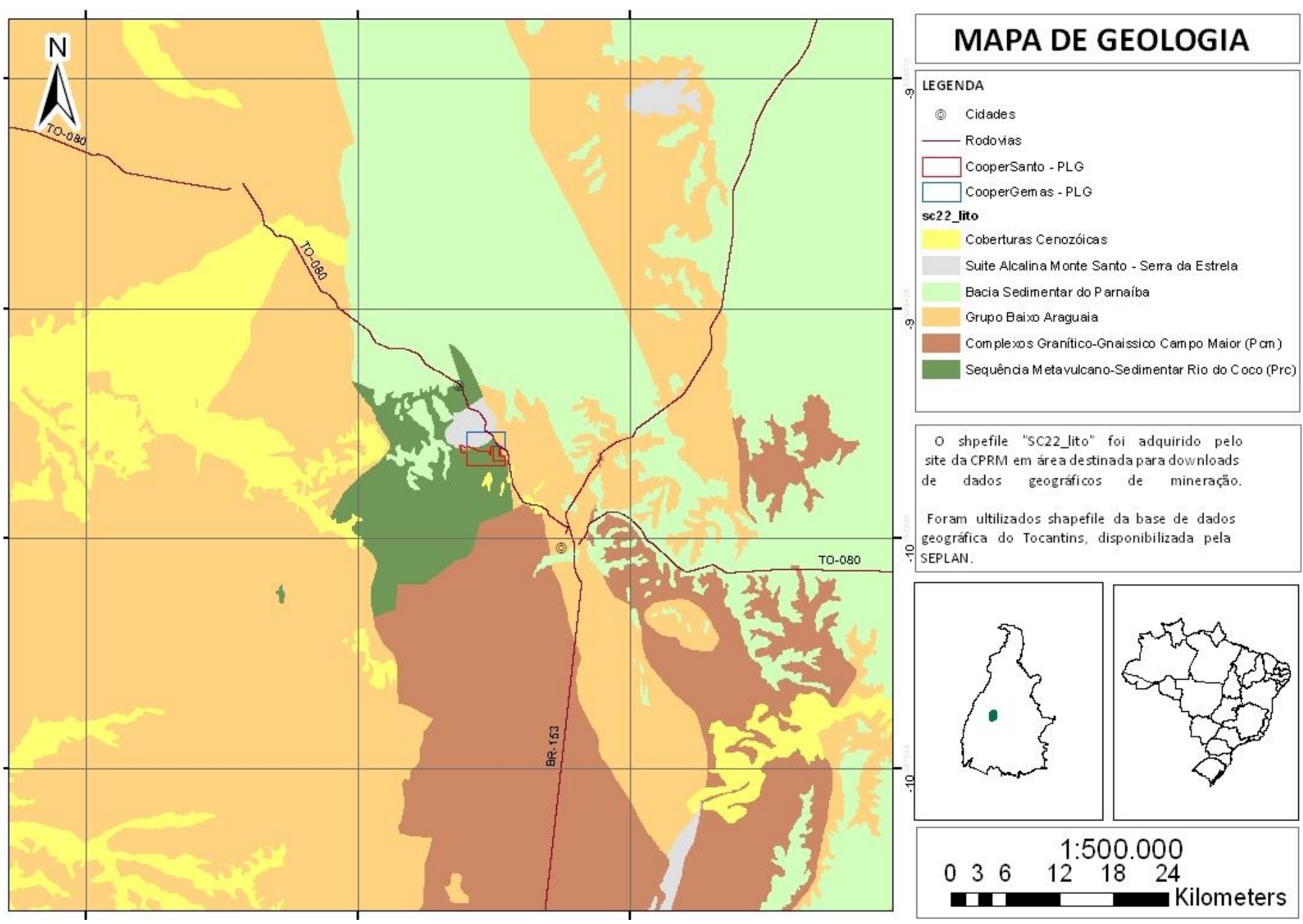

Figura 2.1 - Contexto geológico da zona mineralizada do Garimpo de Esmeraldas de Monte Santo-TO. 


\subsubsection{Caracterização do agromineral}

\subsubsection{Petrologia e Mineralogia}

O biotita gnaisse (A1) apresenta estrutura foliada, coloração cinza rosado, textura granoblástica inequigranular fina, às vezes porfiroblástica, cuja composição modal estimada apresenta plagioclásio $(70 \%)$, biotita $(17 \%)$, granada $(7 \%)$, microclínio (4\%), além de minerais acessórios como quartzo e calcita.

Neste litotipo (A1) todos os minerais apresentam contatos planares entre si, mostrando que estão em equilíbrio (Figura 2.2). O plagioclásio e a granada são subdiomórficos e pobremente geminados. A biotita ocorre em agregados lamelares orientados, caracterizada por xistosidade. O feldspato potássico é tabular xenomórfico, com geminação polissintética cruzada, típica do microclínio. O quartzo é intersticial aos feldspatos e forma mosaicos de cristais poligonizados.

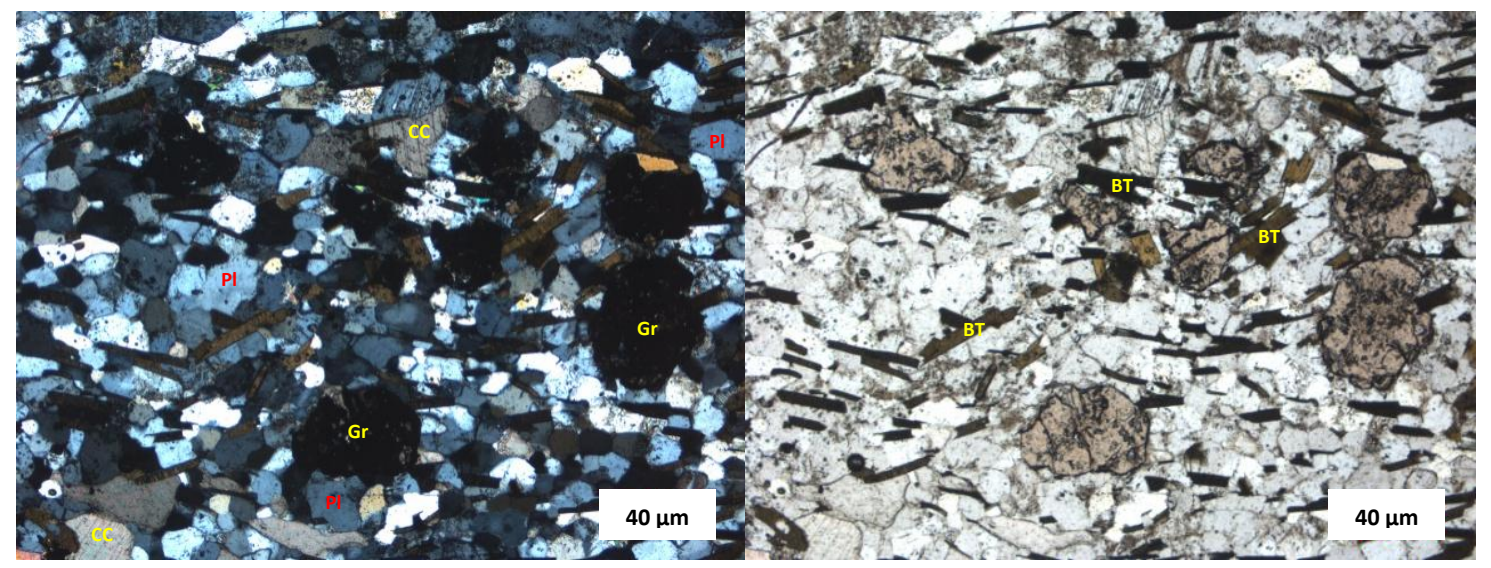

Figura 2.2. Fotomicrografias do Litotipo A1 - biotita-gnaisse de textura granoblástica inequigranular fina, às vezes porfiroblástica, e estrutura foliada (composição $\mathrm{Pl}+\mathrm{BT}+\mathrm{GR}+\mathrm{FK})$.

O anfibolito (A4) possui coloração esverdeada escuro, textura granoblástica inequigranular fina a média, e estrutura foliada, composta de hornblenda (65\%), biotita $(25 \%)$, plagioclásio (4\%), calcita (3\%), além de quartzo, clorita e óxidos de ferro como minerais acessórios.

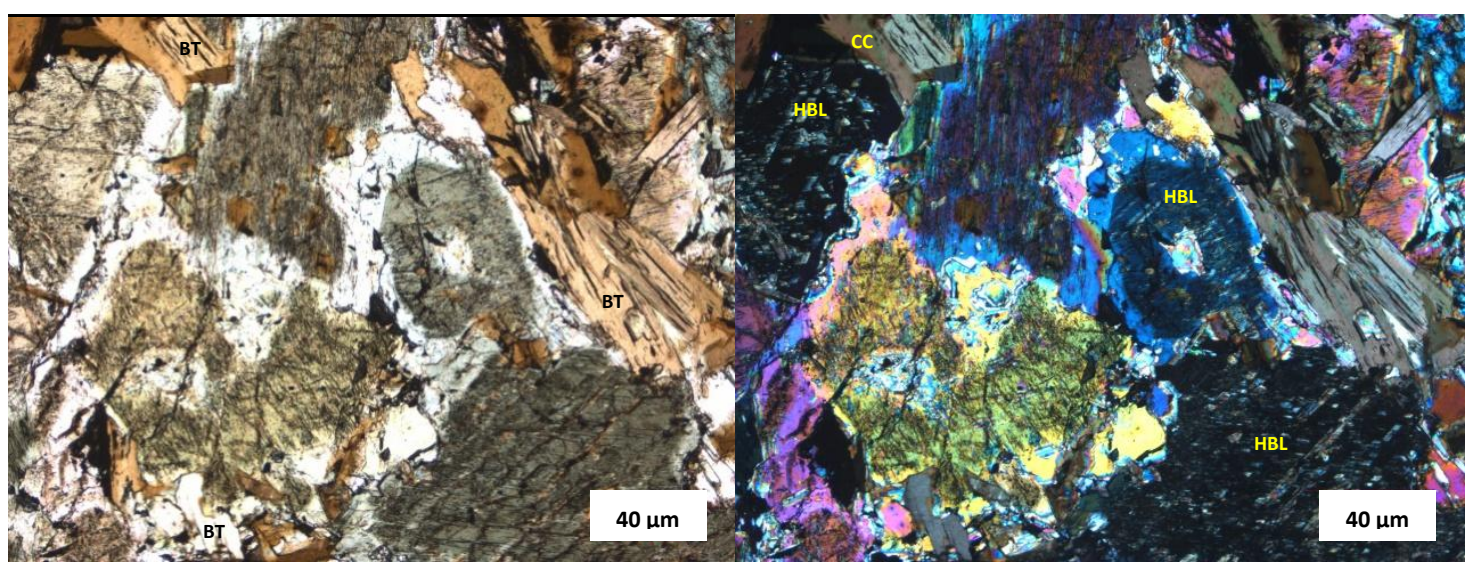

Figura 2.3. Fotomicrografias Litotipo A4 - anfibolito de textura granoblástica inequigranular fina a média, e estrutura foliada; composição HBL+PL+BT+QZ+CL. 
O litotipo A4 apresenta contatos planares entre os grãos, os quais mostram feições de estarem em equilíbrio entre si (Figura 2.3). A hornblenda é verde, tabular, idiomórfica a subidiomórfica, e esta orientada. O plagioclásio esta pobremente geminado, formando mosaicos de cristais poligonizados, intersticiais ao anfibólio, associado ao quartzo também poligonizado. A biotita é parda, e forma agregados lamelares. Os agregados lamelares de clorita estão associados ao anfibólio.

\subsubsection{Química Mineral}

Os litotipos descritos anteriormente foram analisados em microssonda eletrônica com feixe de elétrons. Com base nos resultados das análises pontuais quantitativas (WDS) foi realizada a normalização conforme o número de átomos de oxigênio previsto na estrutura dos respectivos minerais, e assim, calculada a composição química estrutural dos minerais. Na Tabela 2.1 são apresentados os resultados dos respectivos litotipos e fases minerais.

Tabela 2.1. Composição mineralógica modal e respectivas fórmulas estruturais.

\begin{tabular}{|c|c|c|}
\hline \multicolumn{2}{|c|}{ Composição mineralógica } & \multirow{2}{*}{$\begin{array}{l}\text { Fórmula estrutural } \\
\text { A1 (biotita gnaisse) }\end{array}$} \\
\hline$\%$ & & \\
\hline 70 & Plagioclásio & $\left(\mathrm{Na}_{0,767} \mathrm{Ca}_{0,195}\right) \mathrm{Al}_{1,176} \mathrm{Si}_{2,845} \mathrm{O}_{8}$ \\
\hline 17 & Biotita & $\left(\mathrm{K}_{1,857}\right)\left(\mathrm{Fe}_{3,916} \mathrm{Mg}_{0,731} \mathrm{Ti}_{0,305} \mathrm{Al}_{0,630}\right) \mathrm{Al}_{2,477} \mathrm{Si}_{5,523} \mathrm{O}_{20}(\mathrm{OH})_{4}$ \\
\hline 7 & Granada & $\left(\mathrm{Fe}_{1,8} \mathrm{Ca}_{0,9} \mathrm{Mn}_{0,2}\right)\left(\mathrm{Al}_{1,9} \mathrm{Fe}_{0,04}^{3+}\right) \mathrm{Al}_{0,08} \mathrm{Si}_{2,9} \mathrm{O}_{12}$ \\
\hline 4 & Microclínio & $\left(\mathrm{K}_{0,8}\right) \mathrm{AlSi}_{2,9} \mathrm{O}_{8}$ \\
\hline 2 & Calcita & $\mathrm{CaCO}_{3}$ \\
\hline$\%$ & & A4 (anfibolito) \\
\hline 65 & Hornblenda & $\left(\mathrm{Ca}_{1,8} \mathrm{Na}_{0,15}\right)\left(\mathrm{Mg}_{3,5} \mathrm{Fe}^{2+}{ }_{0,8} \mathrm{Al}_{0,3} \mathrm{Fe}^{3+}{ }_{0,09}\right)\left(\mathrm{Al}_{0,6} \mathrm{Si}_{7,4}\right) \mathrm{O}_{23}(\mathrm{OH})_{2}$ \\
\hline 25 & Biotita & $\left(\mathrm{K}_{1,743}\right)\left(\mathrm{Fe}_{1,441} \mathrm{Mg}_{3,824} \mathrm{Ti}_{0,125} \mathrm{Al}_{0,388}\right) \mathrm{Al}_{2,178} \mathrm{Si}_{5.822} \mathrm{O}_{20}(\mathrm{OH})_{4}$ \\
\hline 4 & Plagioclásio & $\left(\mathrm{Na}_{0,879} \mathrm{Ca}_{0,075}\right) \mathrm{Al}_{1,064} \mathrm{Si}_{2,971} \mathrm{O}_{8}$ \\
\hline 3 & Calcita & $\mathrm{CaCO}_{3}$ \\
\hline 3 & Clorita & $\left(\mathrm{Mg}_{7} \mathrm{Al}_{2,3} \mathrm{Fe}_{2} \mathrm{~K}_{0,2} \mathrm{Fe}_{0,1}\right)\left(\mathrm{Al}_{2,2} \mathrm{Si}_{5,8}\right) \mathrm{O}_{20}(\mathrm{OH})_{16}$ \\
\hline
\end{tabular}

Com base nos resultados das análises quantitativas WDS são descritas as principais características dos minerais de silicato constituintes dos litotipos estudados.

\section{- Feldspatos (microclínio e plagioclásio)}

As análises de microssonda eletrônica para os minerais de feldspatos envolveram ao todo 26 cristais, sendo 14 do litotipo A1 e 12 do litotipo A4. A nomenclatura utilizada considerou o membro final da molécula de anortita (An), calculada pela razão $\mathrm{Ca}^{+2} /\left(\mathrm{Ca}^{+2}+\mathrm{Na}^{+}+\mathrm{K}^{+}\right)$. Como não se verificou variações composicionais significativas de borda e núcleo, a inexistência de zonação composicional sistemática permitiu o tratamento em conjunto dos dados.

Os resultados mostram que os feldspatos são os constituintes mineralógicos mais abundantes do litotipo A1, representados por membros das séries calco-sódicos (70\%) e alcalinos (4\%). No litotipo A4 os feldspatos são representados apenas por membros da série calco-sódicos $(4 \%)$. 
No litotipo A1 os feldspatos são constituídos por microclínio e plagioclásiooligoclásio. No microclínio a proporção de albita é inferior a $10 \%$, enquanto no oligoclásio a proporção de albita é quase sempre igual a $80 \%$. No litotipo A4 os feldspatos constituem-se de albita quase pura (97\%), e oligoclásio com maior proporção de albita $(87 \%)$ em relação ao litotipo A1. A Figura 2.4 ilustra a distribuição dos feldspatos com base no diagrama de classificação proposto por Deer et al. (1992).

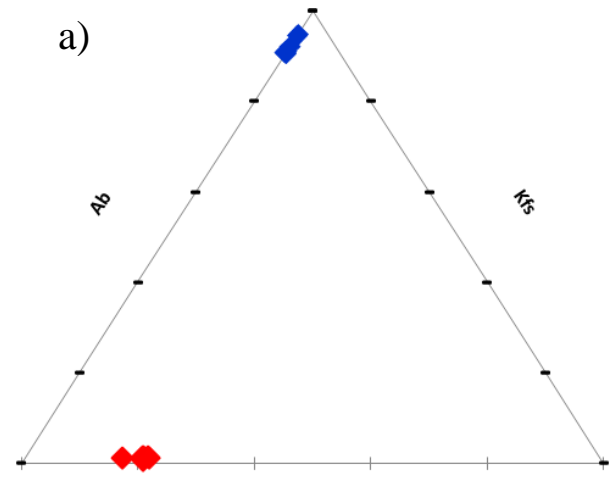

An

Microclínio

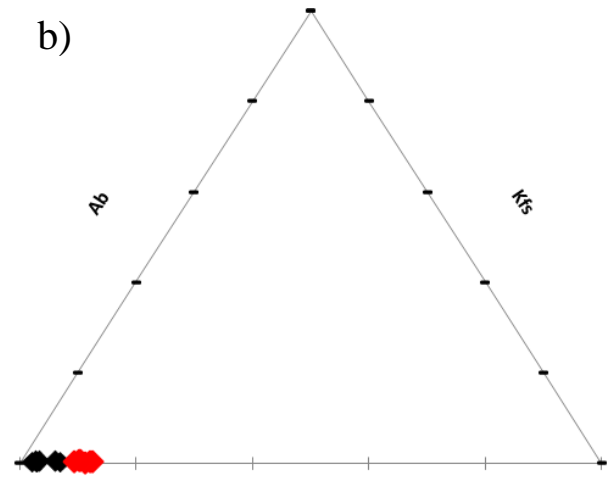

An

Oligoclásio

Figura 2.4. Diagramas de classificação dos feldspatos: a) litotipo A1; b) litotipo A4.

Os plagioclásios do litotipo A1 são fundamentalmente oligoclásios com valores de $X_{A n}$ que variam de ${ }_{0,16-0,21}\left(X_{A b}=0,77-0,82\right)$. Os feldspatos potássicos são em norma muito pobres em $\mathrm{Ca}\left(\mathrm{X}_{\mathrm{An}<0,01}\right)$, e nas composições mais albíticas os teores de $\mathrm{Na}$ também são baixos $\left(\mathrm{X}_{\mathrm{Ab}=0,093}\right)$.

Conforme descrito anteriormente os feldspatos do litotipo A4 são representados apenas por membros da série dos plagioclásios - albita e oligoclásio. Em comparação com o litotipo $\mathrm{A} 1$, os oligoclásios do litotipo A4 apresentam menor variação de

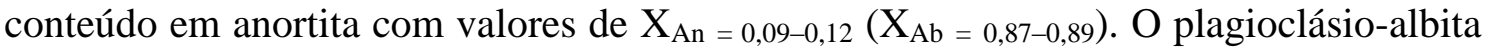
apresenta pequena variação no conteúdo de anortita $\left(X_{\mathrm{An}=0,02-0,06}\right)$ com teores de $\mathrm{X}_{\mathrm{Ab}}$ que variam de ${ }_{0,90-0,97}\left(\mathrm{X}_{\mathrm{Kfs}}<0,05\right)$.

Pelas variações observadas na composição da molécula de anortita $\left(\mathrm{X}_{\mathrm{An}}\right)$ nos respectivos litotipos, ou seja, $\mathrm{An}_{0,01-21,3}$ (A1) e $\mathrm{An}_{0,02-0,12}$ (A4), pode-se dizer que as mesmas são controladas principalmente pela natureza dos litotipos.

\section{- Mica (biotita)}

As análises envolveram ao todo 28 cristais, sendo 18 do litotipo A1 e 10 do litotipo A4. As biotitas analisadas apresentam grande variação nos teores de $\mathrm{MgO}$ entre os litotipos. No litotipo A1 os teores $\mathrm{X}_{\mathrm{Mg}}$ variam entre ${ }_{0,02-0,03}$, enquanto no litotipo A4 o teor $\mathrm{X}_{\mathrm{Mg}}=0,16-0,17$.

$\mathrm{O}$ conteúdo em $\mathrm{TiO}_{2}(\mathrm{Wt} \%)$ é relativamente diferente entre os litotipos, sendo maior no litotipo A1 $\left(\mathrm{TiO}_{2}=2,2-2,8\right)$ do que no litotipo A4 $\left(\mathrm{TiO}_{2}=0,9-1,3\right)$, em grande parte condicionado pela composição original dos protólitos. Da mesma forma, os teores de $\mathrm{FeO}$ das biotitas são bastante variados entre os litotipos, com substituição contínua de 
$\mathrm{MgO}$ pelo $\mathrm{FeO}$ (Figura 2.5). No litotipo $\mathrm{A} 1$ os teores de $\mathrm{X}_{\mathrm{Fe}}$ variam de $0,28-0,29$, com razão atômica $\mathrm{Fe} / \mathrm{Fe}+\mathrm{Mg}$ entre 0,81 e 0,85 , enquanto no litotipo $\mathrm{A} 4$ o teor de $\mathrm{X}_{\mathrm{Fe}}$ varia de $0,10-0,12$ e a razão $\mathrm{Fe} / \mathrm{Fe}+\mathrm{Mg}$ de 0,25 a 0,30 . De forma geral os dois litotipos apresentam biotitas pobres em Fe.
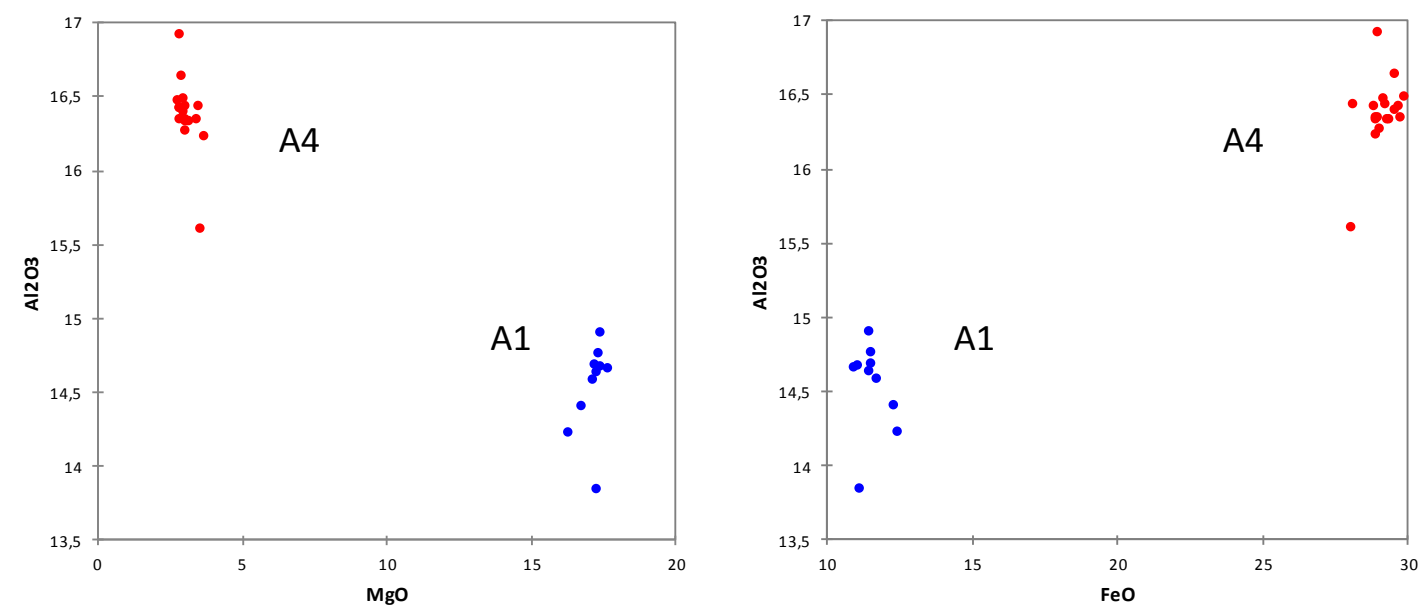

Figura 2.5. Diferenciação das biotitas pelas relações $\mathrm{MgO}$ x $\mathrm{Al}_{2} \mathrm{O}_{3}$ e $\mathrm{FeO}$ x $\mathrm{Al}_{2} \mathrm{O}_{3}$.

No diagrama $\mathrm{Mg} /(\mathrm{Mg}+\mathrm{Fe}) \times \mathrm{xAl}$ proposto por Deer et al. (1992), a biotita do litotipo A1 é nitidamente mais rica em $\mathrm{MgO}$ e $\mathrm{Al}_{2} \mathrm{O}_{3}$, e se posiciona em direção ao campo da flogopita com $\mathrm{Al}>3,1$ (Figura 2.6). No mesmo diagrama, a biotita do litotipo A4 apresenta razões $\mathrm{Mg} /(\mathrm{Mg}+\mathrm{Fe})$ mais baixas, e pequena variação nos teores de $\mathrm{Al}(2,4$ a 2,6), concentrando-se em posição intermediária, entre anita e flogopita.

Pela classificação de Foster (1960), a composição das biotitas quando plotadas no diagrama $\mathrm{Mg}-\mathrm{R}^{3+}-\mathrm{Fe}^{2+}$ (Figura 2.6), as biotitas do litotipo A1 são ferrosas, situam-se próximo ao limite da flogopita, confirmando a classificação de Deer et al. (1992), enquanto as biotitas do litotipo A4 são tipicamente magnesianas. O somatório do sítio octaédrico maior que 5,5 confirma a natureza trioctaédrica dessas micas.
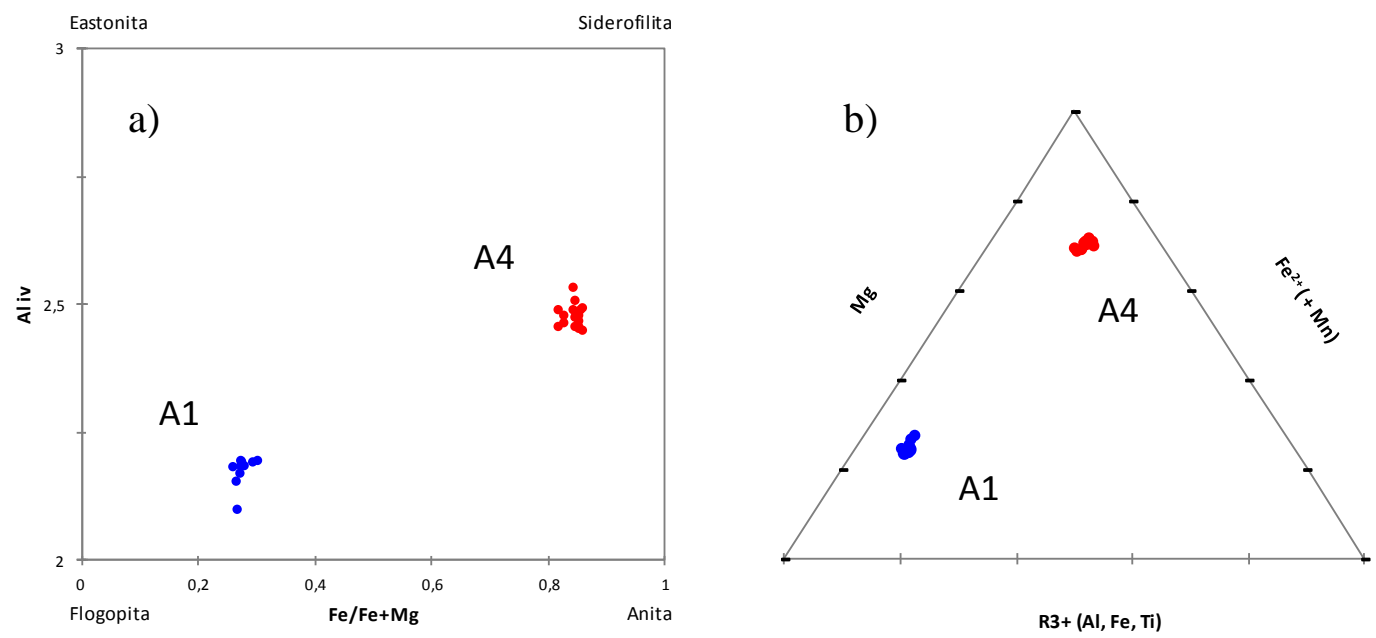

Figura 2.6. Diagramas de classificação e diferenciação das biotitas pelas relações proporcionais: a) $\mathrm{Fe} / \mathrm{Fe}+\mathrm{Mg}$ x Al ${ }^{\mathrm{IV}}$ (Deer et. al., 1992); e b) $\mathrm{Mg}^{-\mathrm{R}^{3+}-\mathrm{Fe}^{2+}}$ (Foster, 1960). 


\section{- Anfibólios (hornblenda)}

As análises dos anfibólios envolveram ao todo 12 cristais, todos do litotipo A4 (anfibolito). Os anfibólios são tipicamente hornblenda, actinolita e actinolitahornblenda. De forma geral a hornblenda apresenta percentagem em massa (Wt\%) de $\mathrm{X}_{\mathrm{Ca}}$ entre $0,11-0,12, \mathrm{X}_{\mathrm{Mg}=0,15-0,18}$, e XFe =0,06-0,09, razões $\mathrm{Mg} /(\mathrm{Mg}+\mathrm{Fe} 2)$ de 0,76 a 0,83, e baixos conteúdos de álcalis e $\mathrm{Al}_{\mathrm{t}}=0,33-1,36$.

$\mathrm{Na}$ atual nomenclatura dos anfibólios (Leake et al., 1997) os minerais analisados pertencem ao grupo dos anfibólios cálcicos, monoclínicos, que apresentam as seguintes características gerais: $(\mathrm{Ca}+\mathrm{Na}) \mathrm{B} \geq 1,0 ; 1,5 \geq \mathrm{CaB} \geq 0,5 ; \mathrm{CaB} \geq 1,5$ (Figura 2.7).
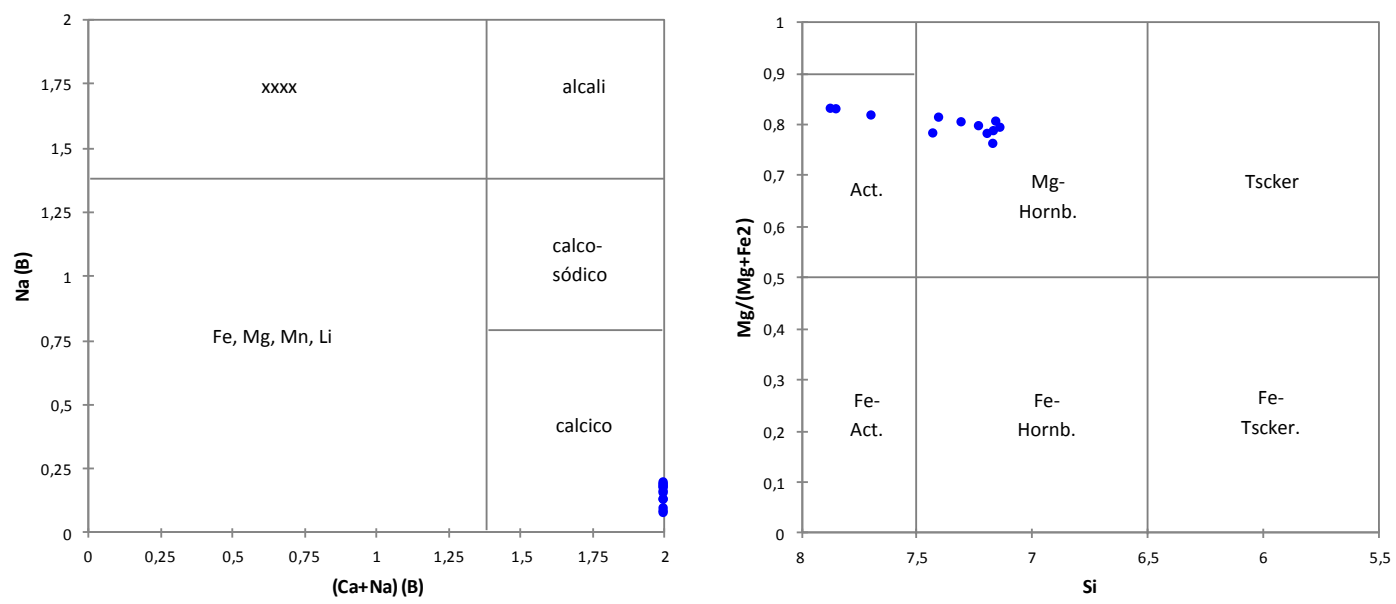

Figura 2.7. Diagrama discriminante dos grandes grupos de anfibólios $(\mathrm{Na}+\mathrm{Ca}) \mathrm{B} \times$ (Na)B, e classificatório dos anfibólios cálcicos (Leake et al., 1997).

Com base na fórmula estrutural dos anfibólios $\left(\mathrm{A}_{0-1} \mathrm{~B}_{2} \mathrm{C}_{5} \mathrm{~T}_{8} \mathrm{O}_{22}(\mathrm{OH})_{2}\right)$, descrita em Deer et al. (1992), a hornblenda apresenta a posição A ocupada em 68,7\% por átomos de $\mathrm{Na}$, enquanto a posição $\mathrm{B}$ é ocupada por $92,4 \%$ de $\mathrm{Ca}$. A posição $\mathrm{C}$ tem $71,2 \%$ de $\mathrm{Mg}, 17,7 \%$ de $\mathrm{Fe}^{2+}, 7,4 \%$ de $\mathrm{Al}$, e o restante átomos de $\mathrm{Fe}^{3+}, \mathrm{Cr}$, Ti e $\mathrm{Mn}$.

\section{- Granadas}

As análises de química mineral da granada envolveram ao todo 8 cristais, todos do litotipo A1 (biotita gnaisse). As granadas são tipicamente ricas em almandina, com $\mathrm{X}_{\mathrm{Alm}>0,50}$. Os resultados mostram que as granadas são ricas em moléculas de almandina e grossulária, onde predominam os elementos $\mathrm{Fe}$ e $\mathrm{Ca}$, respectivamente. Os teores de $\mathrm{X}_{\mathrm{Alm}}$ variam de $0,50-\mathrm{o}, 66$, com $\mathrm{X}_{\mathrm{Esp}=0,00-0,22}$ e $\mathrm{X}_{\mathrm{Gr}=0,25-0,35}$. Os teores das demais espécies são sempre baixos ou muito baixos, $\mathrm{X}_{\mathrm{And}<0,05}, \mathrm{X}_{\mathrm{Py}<0,01}$ e $\mathrm{X}_{\mathrm{Ura}}<0,002$.

O litotipo apresenta padrão de zonamento núcleo-borda que evidencia o enriquecimento de $\mathrm{Fe}$ e $\mathrm{Mn}$. As variações composicionais núcleo-borda para as principais espécies $-\mathrm{X}_{\mathrm{Alm}} 2-22 \%, \mathrm{X}_{\mathrm{Gr}} 8-10 \%$ e $\mathrm{X}_{\mathrm{Esp}} 10-77 \%$, demonstram que em geral ocorre substituição de $\mathrm{Mg}$ e $\mathrm{Mn}$ por Fe, e eventualmente por $\mathrm{Ca}$.

A proporção relativa dos membros extremos das granadas é representada nos diagramas discriminantes (Figura 2.8), e apesar de demonstrar ligeira variação composicional (A), a amplitude das variações descreve um único grupo de granadas (B). 

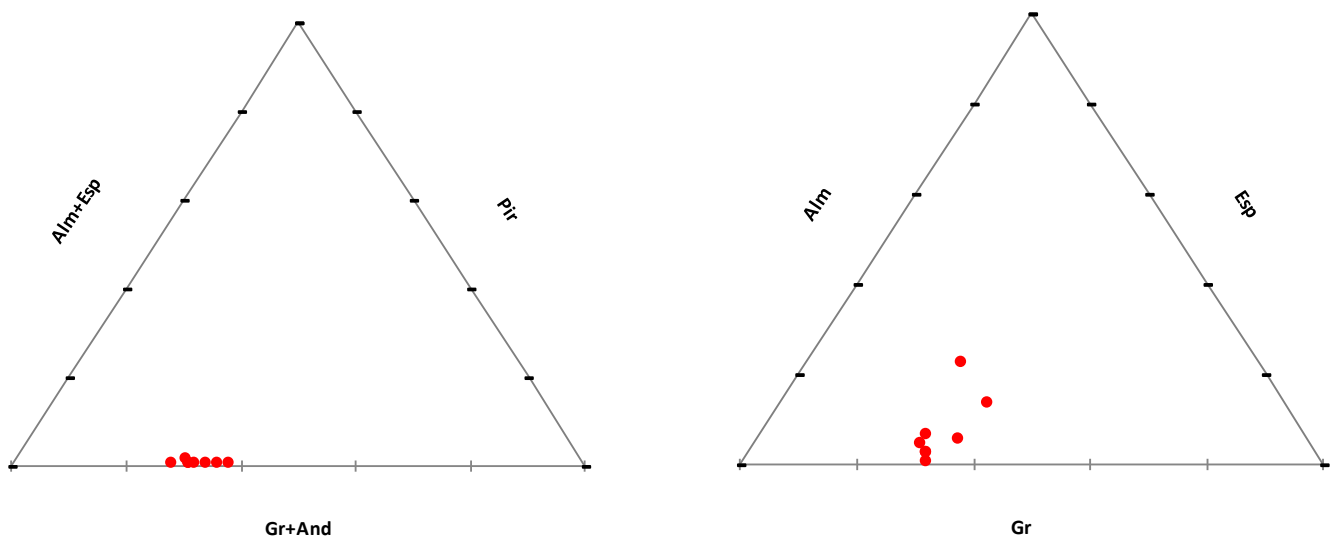

Gr

Figura 2.8. Discriminação das granadas: (A) Gr+And, Pir, Alm+Esp; (B) Gr, Esp, Alm.

Das variações composicionais observadas resulta uma granada cuja composição média da molécula é $\mathrm{X}_{\mathrm{Alm}=0,60}, \mathrm{X}_{\mathrm{Gr}=0,29}, \mathrm{X}_{\mathrm{Esp}=0,07}$ e $\mathrm{X}_{\mathrm{Py}+\mathrm{And}=0,03}$, ou seja, uma granada rica em Fe e Ca.

\section{- Cloritas (clinocloro)}

As análises das cloritas envolveram apenas 03 cristais, todos do litotipo A4 (anfibolito). As cloritas são todas tipicamente clinocloro, e de forma geral apresentam

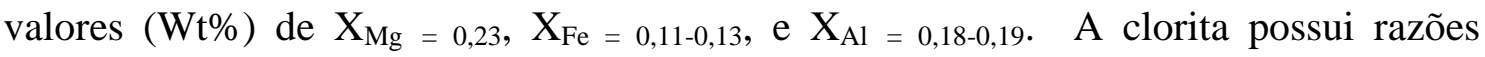
$\mathrm{Fe} /(\mathrm{Fe}+\mathrm{Mg}$ ) de 0,23, tratando-se de uma clorita rica em Mg (Bailey, 1980). O gráfico Si x Fe/(Fe+Mg) (Figura 2.9) comprova a classificação da clorita como do tipo clinocloro (Bayliss, 1975).
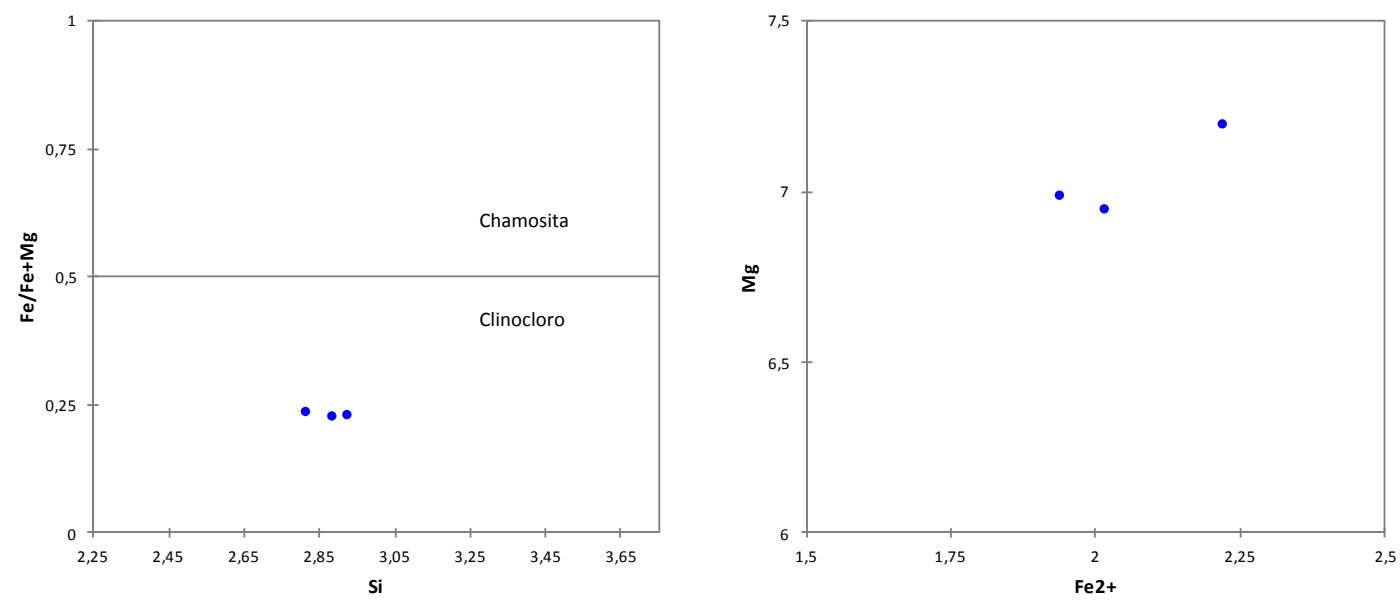

Figura 2.9. (A) $\mathrm{Si}$ vs. $\mathrm{Fe} /(\mathrm{Fe}+\mathrm{Mg}$ ) de classificação das cloritas (Bayliss, 1975); (B) variação nas concentrações de $\mathrm{Fe} 2+\mathrm{e} \mathrm{Mg} 2+$ das cloritas analisadas.

As substituições $\mathrm{Si}-\mathrm{Al}$ nos tetraedros e $\mathrm{Fe}-\mathrm{Mg}$ nos octaedros representam as principais modificações nas cloritas. A limitação de dados não permite diferenciar ou apontar qualquer tendência em termos de composição química das cloritas. 


\subsubsection{Geoquímica}

As análises geoquímicas realizadas no Acme Analytical Laboratories permitiram determinar a composição química da rocha total. Os resultados das análises são apresentados nas Tabelas 2.2, 2.3 e 2.4, e envolvem:

- elementos maiores - $\mathrm{SiO}_{2}, \mathrm{TiO}_{2}, \mathrm{Al}_{2} \mathrm{O}_{3}, \mathrm{Fe}_{2} \mathrm{O}_{3}, \mathrm{MnO}, \mathrm{CaO}, \mathrm{Na}_{2} \mathrm{O}, \mathrm{K}_{2} \mathrm{O}, \mathrm{P}_{2} \mathrm{O}_{5}$ e LOI;

- elementos traços - Ba, Rb, Sr, Cs, Ga, Tl, Ge, Ta, Nb, Hf, Zr, Ti, Y, Th, U, Cr, Ni, Co, $\mathrm{Sc}, \mathrm{V}, \mathrm{Cu}, \mathrm{Pb}, \mathrm{Zn}, \mathrm{Bi}, \mathrm{In}, \mathrm{Sn}, \mathrm{W}, \mathrm{Mo}, \mathrm{Be}, \mathrm{Ag}, \mathrm{As} \mathrm{e} \mathrm{Sb;} \mathrm{e}$

- elementos terras raras - La, Ce, Nb, Sm, Eu, Gd, Dy, Ho, Er, Yb e Lu.

Os resultados demonstram correlação positiva da sílica $\left(\mathrm{SiO}_{2}\right)$ com alguns elementos traços ( $\mathrm{Ba}, \mathrm{Ga}, \mathrm{Nb}, \mathrm{Hf}, \mathrm{Sn}, \mathrm{Sr}, \mathrm{Ta}, \mathrm{Th}, \mathrm{U}, \mathrm{W}, \mathrm{Zr}, \mathrm{Pb}, \mathrm{Cd}$ ), e negativa com outros (Be, Co, Cs, Rb, V, Mo, Cu, Zn, Ni, As, Sb, Bi, Ag, Hg, Tl, Se, B).

Importante destacar que alguns elementos traços são considerados micronutrientes ( $\mathrm{Co}, \mathrm{Cu}, \mathrm{Zn}$ e B), e exercem funções importantes na nutrição de plantas. Outros elementos traços considerados elementos potencialmente tóxicos (EPT), podem representar riscos ambientais ou de contaminação (como é o caso do $\mathrm{Cd}$ e do $\mathrm{Pb}$ ). Entretanto, os teores são muito baixos. Com base nos valores de referência desses elementos nos solos brasileiros (Fadigas et al., 2006), seriam necessárias 63 e 80 aplicações de $10 \mathrm{t} \mathrm{ha}^{-1}$ do pó de rocha para elevar os teores de $\mathrm{Pb}$ e $\mathrm{Cd}$ a níveis considerados preocupantes. Assim, o pó de rocha como insumo agrícola não oferece risco de contaminação ou ambiental. Todavia, admitida a possibilidade de aumento das taxas de liberação desses elementos no solo, tornam-se necessários estudos para avaliar a disponibilidade destes elementos e a absorção pelas plantas.

As concentrações em ETR da amostra do pó de rocha (RT-PR), a qual representa a composição média dos diferentes litotipos que forma a zona mineralizada do garimpo, podem ser consideradas elevadas quando comparadas às monazitas descritas por Lapido-Loureiro (1994).

Em termos médios o padrão de distribuição dos ETR é marcado por maior concentração de ETR leves (La, Ce, Pr e Nd) quando comparadas as ETR pesadas (Tb, Dy, Ho, Er, Tm, Yb e Lu). Em geral, o biotita gnaisse apresenta maiores teores de todos os ETR, exceto para escândio (Sc). 
Tabela 2.2. Resultados dos teores dos elementos maiores totais (\% em massa).

\begin{tabular}{|c|c|c|c|c|c|c|c|c|c|c|c|c|c|c|c|}
\hline Amostra & $\mathrm{SiO}_{2}$ & $\mathrm{Al}_{2} \mathrm{O}_{3}$ & $\mathrm{Fe}_{2} \mathrm{O}_{3}$ & $\mathrm{MgO}$ & $\mathrm{CaO}$ & $\mathrm{Na}_{2} \mathrm{O}$ & $\mathrm{K}_{2} \mathrm{O}$ & $\mathrm{TiO}_{2}$ & $\mathbf{P}_{2} \mathbf{O}_{5}$ & MnO & $\mathrm{Cr}_{2} \mathrm{O}_{3}$ & $\mathbf{P F}^{1}$ & $\mathrm{C}^{2}$ & $\mathbf{S}^{3}$ & Soma \\
\hline RT-PR & 50,94 & 13,00 & 8,58 & 9,79 & 7,96 & 3,05 & 2,21 & 0,51 & 0,14 & 0,16 & 0,09 & 3,2 & 0,52 & 0,09 & 99,66 \\
\hline RT. & 57,76 & 20,01 & 6,32 & 0,58 & 4,47 & 6 , & 2,0 & 0 & & U & 0 & 1 & 0.25 & 0,05 & 99,73 \\
\hline RT-ANF & 48,61 & 7,47 & 9,50 & 18,31 & 9,40 & 1,11 & 2,20 & 0,36 & 0,07 & 0,17 & 0,24 & 2,1 & 0,08 & 0,07 & 99,59 \\
\hline
\end{tabular}

${ }^{1} \mathrm{PF}$ - perda ao fogo, relativo ao teor total de voláteis $\left(\mathrm{CO}_{2}+\mathrm{SO}_{3}+\mathrm{H}_{2} \mathrm{O}\right)$;

${ }^{2} \mathrm{C}$ - carbono total medido pelo Leco;

${ }^{3} \mathrm{~S}$ - enxofre total medido pelo Leco;

${ }^{4}$ Soma relativa aos óxidos e à $\mathrm{PF}$.

Tabela 2.3. Resultados dos teores dos elementos traços (ppm).

\begin{tabular}{l|ccccccccccccccc}
\hline Amostra & Ba & Be & Co & Cs & Ga & Hf & Nb & Rb & Sn & Sr & Ta & Th & U & V & W \\
\hline RT-PR & 419 & 8 & 34,3 & 3,1 & 13,2 & 2,7 & 17,5 & 122,4 & 2 & 298,8 & 0,6 & 6,0 & 0,8 & 161 & 0,5 \\
RT-BT & 1016 & $<1$ & 4,0 & 1,6 & 18,2 & 9,2 & 106,0 & 64,7 & 3 & 340,2 & 6,2 & 12,2 & 2,4 & 16 & 1,8 \\
RT-ANF & 164 & $<1$ & 55,4 & 3,6 & 6,8 & 1,4 & 1,9 & 114,5 & 1 & 39,3 & 0,2 & 0,9 & 0,2 & 169 & $<0,5$ \\
\hline
\end{tabular}

Tabela 2.3. Continuação.....

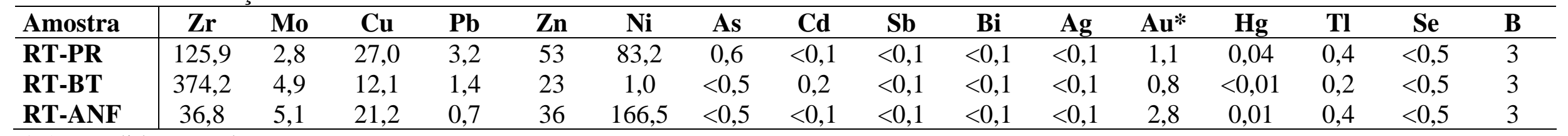

* Au medido em ppb

Tabela 2.4. Resultados dos teores dos elementos terras raras (ETR), Y e Sc (ppm).

\begin{tabular}{|c|c|c|c|c|c|c|c|c|c|c|c|c|c|c|c|c|}
\hline Amostra & $\mathbf{Y}$ & Sc & La & $\mathrm{Ce}$ & Pr & Nd & Sm & Eu & Gd & $\mathbf{T b}$ & Dy & Ho & $\mathbf{E r}$ & Tm & $\mathbf{Y b}$ & Lu \\
\hline RT-ANF & 11,1 & 41 & 10,0 & 17,6 & 2,47 & 10,9 & 2,70 & 0,63 & 2,74 & 0,35 & 2,30 & 0,47 & 1,21 & 0,18 & 1,00 & 0,15 \\
\hline
\end{tabular}




\subsubsection{Granulometria e Superfície Específica}

A dissolução dos silicatos é preferencialmente controlada por reações de superfície, e secundariamente pelas taxas de eliminação de solutos via lixiviação, de maneira que a área de superfície específica $\left(\mathrm{m}^{2} \mathrm{~g}^{-1}\right)$ e a distribuição granulométrica constituem variáveis fundamentais no estudo de dissolução mineral.

O resultado da composição granulométrica do material apresenta: 99,8\% de partículas < 0,8 mm; 85,6\% < 0,3 mm; 58\% < 0,15 mm; 21\% <0,06 mm; e 6\% <0,002 mm. De acordo com a Classificação da ABNT (ABNT/NBR 6502/95), o material (resíduo) apresenta 73\% das partículas com granulometria classificada como "fração areia" (0,06 a $2 \mathrm{~mm}), 21 \%$ como "fração silte" $(0,002$ a $0,06 \mathrm{~mm})$, e apenas $6 \%$ como "fração argila" $(<0,002 \mathrm{~mm})$.

A análise de superfície específica do pó de rocha $(<0,8 \mathrm{~mm})$, revela superfície de reação de $0,562 \mathrm{~m}^{2} \mathrm{~g}^{-1}$ (BET), com volume de poros de $3,5610^{-3} \mathrm{~cm}^{3} \mathrm{~g}^{-1}$ (\# $294 \AA$ ).

\subsubsection{Dissolução Mineral por Ataque Sulfúrico}

O método de extração parcial por ataque sulfúrico foi desenvolvido para caracterizar a mineralogia da fração argila de solos tropicais (Embrapa, 1997; Vettori, 1969) e como indicador do potencial de intemperismo na caracterização de minerais de rochas (Raij \& Valadares, 1974).

Os resultados obtidos a partir da dissolução parcial por ataque sulfúrico são apresentados na Tabela 2.5. Os resultados indicam o potencial de liberação de nutrientes destes materiais quando aplicado ao solo durante um ciclo anual.

Tabela 2.5. Teores dos elementos maiores (\% em massa) extraídos por ataque sulfúrico.

\begin{tabular}{cccccccc}
\hline Amostra & $\mathrm{Al}_{2} \mathrm{O}_{3}$ & $\mathrm{CaO}$ & $\mathrm{Fe}_{2} \mathrm{O}_{3}$ & $\mathrm{~K}_{2} \mathrm{O}$ & $\mathrm{MgO}$ & $\mathrm{SiO}_{2}$ & $\mathrm{TiO}_{2}$ \\
\hline & & \multicolumn{7}{c}{$\%$} & $\%$ & & & \\
\hline PR-MS & 7,1 & 7,6 & 8,3 & 1,2 & 8,9 & 48,6 & 0,5 \\
\hline
\end{tabular}

O teor de $\mathrm{K}_{2} \mathrm{O}$ extraível por ácido sulfúrico demonstra que $50 \%$ do potássio total do pó de rocha esta prontamente disponível para as plantas, podendo ser utilizado como referência para os cálculos de adubação em cultivos agrícolas. Uma dose de $100 \mathrm{~kg} \mathrm{ha}^{-1}$ de $\mathrm{K}_{2} \mathrm{O}$ é obtida com a aplicação de 8,5 toneladas de pó de rocha.

Importante destacar que, conforme a composição química das fases minerais constituintes do pó de rocha, o potássio extraível pelo ataque sulfúrico é relativo principalmente à biotita. Neste sentido, também vale lembrar que dentre os minerais que podem ser considerados fontes de potássio, a biotita é o mineral que apresenta o maior potencial como fonte deste nutriente. Como praticamente não há diferença nos teores de $\mathrm{K}_{2} \mathrm{O}$ das biotitas, os litotipos (biotita gnaisse e anfibolito) contribuem igualmente para os teores totais de potássio extraível. 
Os teores extraídos de $\mathrm{Ca}$ e $\mathrm{Mg}$ correspondem a 95\% do total presente no pó de rocha, o que sugere que o material pode ser fonte desses nutrientes, com efeitos sobre a acidez dos solos agrícolas.

Com base nos resultados estima-se que $73 \%$ do $\mathrm{CaO}$ e $97 \%$ do $\mathrm{MgO}$ sejam provenientes do anfibolito, principalmente devido a predominância de minerais ferromagnesianos (hornblenda). O biotita gnaisse contribui com $27 \%$ do $\mathrm{CaO}$, em grande parte devido aos minerais calco-sódicos (plagioclásios) e da calcita.

\subsection{CONSIDERAÇÕES COMPLEMENTARES}

A caracterização dos resíduos do Garimpo de Monte Santo-TO compreende etapa fundamental para outros estudos desenvolvidos nesta Tese: i) estimativa das taxas de dissolução mineral do pó de rocha; ii) avaliação da eficiência do pó de rocha como insumo agromineral; iii) avaliação do potencial de uso do pó de rocha como fonte alternativa de nutrientes na cultura da cana-de-açúcar.

Os resultados da caracterização e de dissolução traduzem informações que permitem pressupor que o pó de rocha apresenta potencial como agromineral silicático. A indicação do potencial do agromineral está na presença de: minerais mais intemperizáveis (biotita, anfibólio, plagioclásio e calcita); no teor total de bases $(\mathrm{CaO}$, $\mathrm{MgO}$ e $\mathrm{K}_{2} \mathrm{O}$ ) igual a $20 \%$, sendo grande parte (90\%) extraído com ataque sulfúrico; e baixos teores de elementos traços conferem ao pó de rocha a segurança desejada quanto aos riscos de contaminação de solos.

A caracterização petrográfica, geoquímica e mineralógica do pó de rocha é uma das etapas necessárias para os futuros registros e comercialização deste tipo de agromineral, tanto como condicionador (remineralizador) de solos, como também fornecedor de nutrientes. 


\section{CAPÍTULO 3}

\section{DISSOLUÇÃO DO AGROMINERAL SILICÁTICO}

Resumo: O estudo objetiva a determinação das taxas de reação e dissolução do agromineral silicático obtido pela moagem dos resíduos de mineração gerados pelo Garimpo de Esmeraldas de Monte Santo, Tocantins. O agromineral foi acondicionado em colunas de lixiviação, e aplicada água deionizada pura com taxa de fluxo constante $\left(6,5 \mathrm{~mm} \mathrm{~h}^{-1}\right)$ e lâminas que variaram de 42 a $195 \mathrm{~mm}$. O mesmo foi realizado com misturas do agromineral e diferentes solos na proporção de 2:1 (\% em massa), e com esses solos em particular, para verificar os efeitos dos atributos desses na dissolução do agromineral silicático. Periodicamente, alíquotas da solução foram extraídas para análise do $\mathrm{pH}$, condutividade elétrica e concentração iônica $\left(\mathrm{Na}^{2+}, \mathrm{K}^{+}, \mathrm{Ca}^{2+}, \mathrm{Mg}^{2+}, \mathrm{Fe}^{2+}\right.$, $\mathrm{Mn}^{2+}, \mathrm{Al}^{3+}$ e $\mathrm{Si}^{4+}$ ). A taxa de dissolução do agromineral com base no $\mathrm{K}$ situou entre 1,89 $10^{-13}$ e $1,6710^{-12} \mathrm{~mol} \mathrm{~m}^{-2} \mathrm{~s}^{-1}$, e do Si entre 1,50 e $9,6310^{-13} \mathrm{~mol} \mathrm{~m}^{-2} \mathrm{~s}^{-1}$. A dissolução foi predominantemente determinada por mecanismos de transporte e superfície durante a primeira metade do experimento (633 horas), e por mecanismos de superfície quando a concentração dos íons foi reduzida e estabilizada (633 até 1335 horas). A dissolução do agromineral silicático foi influenciada por características e parâmetros da solução reagente e dos solos, especialmente pelo teor de matéria orgânica e pela condutividade hidráulica. A estabilidade das reações de dissolução foi atingida, com taxa (log R = $10,6 \mathrm{~mol} \mathrm{~m}^{-2} \mathrm{~s}^{-1}$ ) compatível às descritas na literatura sobre intemperismo dos silicatos.

Palavras-chaves: agromineral silicático; dissolução mineral; sistema aberto.

Abstract: The study aims to determine the rates of reaction and dissolution of silicático agromineral obtained by grinding the waste generated by mining panning for emeralds Monte Santo, Tocantins. The agromineral was placed in the leaching column, pure deionized water and applied with constant flow rate $\left(6.5 \mathrm{~mm} \mathrm{~h}^{-1}\right)$ and blades ranging $42-$ $195 \mathrm{~mm}$. The same was done with mixtures of different soils and agromineral ratio of 2:1 (wt\%), with these soils in particular, to verify the effect of these attributes on the dissolution of silicático agromineral. Periodically, aliquots of the solution were taken for analysis of $\mathrm{pH}$, conductivity and ion concentration $\left(\mathrm{Na}^{2+}, \mathrm{K}^{+}, \mathrm{Ca}^{2+}, \mathrm{Mg}^{2+}, \mathrm{Fe}^{2+}\right.$, $\mathrm{Mn}^{2+}, \mathrm{Al}^{3+}$ and $\left.\mathrm{Si}^{4+}\right)$. The mineral dissolution rate based on $\mathrm{K}$ release ranged between $1,8910^{-13}$ and 1,67 $10^{-12} \mathrm{~mol} \mathrm{~m}^{-2} \mathrm{~s}^{-1}$, and based on Si between 1,50 and 9,63 $10^{-13} \mathrm{~mol} \mathrm{~m}^{-}$ ${ }^{2} \mathrm{~s}^{-1}$. The dissolution was determined predominantly by the transport and surface mechanisms during the first half of the experiment (633 hours) and surface mechanisms when the concentration of ions is reduced and stabilized (633 to 1335 hours). The dissolution of silicático agromineral was influenced by characteristics and parameters of the reagent solution and soils, especially the organic matter content and the hydraulic conductivity. The stability of the dissolution reactions was hit rate $\left(\log \mathrm{R}=-10,6 \mathrm{~mol} \mathrm{~m}^{-}\right.$ ${ }^{2} \mathrm{~s}^{-1}$ ) compatible with those described in the literature weathering of silicate.

Keywords: mineral dissolution; silicate agromineral; open system. 


\subsection{INTRODUÇÃO}

O processo de dissolução dos minerais silicáticos contribui para o consumo do $\mathrm{CO}_{2}$ atmosférico, para a liberação de cátions que influenciam na evolução da composição das águas subterrâneas e superficiais, bem como para o controle do pH nas águas e nos solos (Drever 1994). Neste último, a dissolução dos minerais proporciona disponibilização de macro e micronutrientes para as plantas, afetando diretamente as práticas agrícolas de fertilização dos solos.

A maioria dos solos tropicais, devido à intensa lixiviação das bases, são solos ácidos e de baixa fertilidade (Melfi et al. 1999). Medidas alternativas têm sido estudadas para diminuir danos ecológicos e econômicos da agricultura moderna e intensiva em insumos externos, especialmente em fertilizantes altamente solúveis. Nesta perspectiva, uma das medidas tem sido restaurar solos lixiviados ou degradados acrescentando agrominerais, que disponibilizariam os elementos perdidos na lixiviação.

Experimentos e dados sobre utilização de rochas moídas como fertilizante mostram que uma grande variedade de materiais pode ser utilizada (Kronberg et al. 1976, Leonardos et al. 1987) como alternativa de fertilização para os solos, com baixo custo e baixo impacto ambiental.

As rochas silicáticas apresentam composição mineralógica bastante diversa, algumas com teores médios significativos de $\mathrm{K}_{2} \mathrm{O}, \mathrm{CaO}$ e $\mathrm{MgO}$. Sua dissolução contribui como uma importante fonte desses cátions para o solo, e da sua alteração formam-se minerais secundários como os argilominerais (Fanning et al. 1989; Kalinowski e Schweda 1996). Vários autores propõem modelos matemáticos para quantificar e melhor entender a dinâmica dos processos que afetam a dissolução de minerais e rochas (Burns \& Barber, 1961; Martin \& Sparks, 1983; Havlin et al., 1985; Havlin \& Westfall, 1985). Tais modelos são aplicados a abordagens experimentais que se voltam à determinação das taxas de dissolução no laboratório e em campo.

Para Lasaga (1998), a abordagem experimental apresenta vantagens por permitir limitar as variações das condições físicas, químicas e biológicas do experimento, e com isso, possibilitar variações sistemáticas de parâmetros como composição mineral, temperatura, área de superfície e solutos para caracterizar os mecanismos envolvidos no processo de intemperismo.

Um importante aspecto no estudo de cinética é o método usado para medir as taxas de dissolução e outros parâmetros cinéticos. A escolha do método de estudo de cinética deve levar em conta os tipos de reações a serem estudadas e a escala de tempo relativa. De acordo com Sparks (1989), a obtenção de dados de cinética baseia-se fundamentalmente nos métodos do tipo batch (batelada) e métodos que envolvem fluxo.

Em geral, os métodos tipo batch são utilizados quando as reações de dissolução ocorrem em escala de tempo muito reduzidas. Esses métodos normalmente se baseiam em reações realizadas em ambiente fechado (Sparks, 1989). Os métodos de fluxo, assim como os métodos em batelada, se aplicam a reações de intemperismo consideradas lentas, tais como os processos controlados por difusão (Mello e Perez, 2009). Os 
métodos que envolvem fluxo caracterizam sistemas abertos por permitirem a constante entrada de reagentes e retirada de produtos (Chou e Wollast, 1984). Tais condições reduzem os gradientes de concentração nas fases aquosa e sólida, e a formação de precipitados, o que garante a manutenção das reações de dissolução mineral.

O presente estudo envolve a realização de um experimento em laboratório, onde colunas de lixiviação são utilizadas para determinação da taxa de dissolução do agromineral silicático obtido pela moagem das rochas que constituem os resíduos minerais do Garimpo de Esmeraldas de Monte Santo-TO.

\subsection{OBJETIVOS}

\section{Objetivo Geral}

Estimar a taxa de dissolução do agromineral silicático em determinadas condições de regime hídrico, e sob os efeitos de diferentes solos.

\section{Objetivos Específicos}

- Calcular a taxa de liberação dos elementos químicos do agromineral em função de lâminas d’água de percolação ao longo do tempo;

- Avaliar a solubilização do agromineral em diferentes tipos de solo, em função de diferentes lâminas d'água de percolação ao longo do tempo;

- Calcular as taxas de longo prazo e o tempo necessário para se atingir o estado de estabilidade das reações de dissolução do agromineral.

\subsection{MATERIAL E MÉTODOS}

Conforme proposto por White e Brantley (2003), a abordagem experimental adotada neste trabalho é baseada em técnicas de fluxo para a quantificação das taxas de dissolução do agromineral silicático. Trata-se de um experimento caracterizado como um sistema de fluxo, onde a água infiltrada reage progressivamente com as fases minerais.

A seguir é apresentada uma breve descrição das características do agromineral, e dos procedimentos envolvidos na montagem e condução dos experimentos: dimensões das colunas de lixiviação; composição dos tratamentos; características do solvente e taxas de fluxo; coleta e análise do efluente.

\subsubsection{Características do agromineral silicático}

As informações a seguir foram extraídas de um estudo mais amplo e detalhado de caracterização física, mineralógica e geoquímica do agromineral silicático.

Em síntese, o estudo de caracterização considerou os litotipos que constituem as unidades basal (biotita gnaisse) e superior (anfibolito) da zona mineralizada do garimpo, e também, uma amostra do agromineral após a moagem dos resíduos minerais. 
As análises petrográfica e de determinação da composição química mineral dos litotipos predominantes (A1 e A4) foram realizadas no Laboratório de Microscopia e no Laboratório de Microssonda Eletrônica, ambos do Instituto de Geociências da Universidade de Brasília (IGD/UnB). Na Tabela 3.1 são apresentados os resultados que expressam a composição química das fases minerais e respectivos litotipos que dão origem ao agromineral silicático.

Tabela 3.1. Composição mineralógica modal e respectivas fórmulas estruturais.

\begin{tabular}{|c|c|c|}
\hline \multicolumn{2}{|c|}{ Composição mineralógica } & \multirow{2}{*}{\begin{tabular}{|l} 
Fórmula estrutural \\
Litotipo A1 (biotita gnaisse)
\end{tabular}} \\
\hline$\%$ & & \\
\hline 70 & Plagioclásio & $\left(\mathrm{Na}_{0,767} \mathrm{Ca}_{0,195}\right) \mathrm{Al}_{1,176} \mathrm{Si}_{2,845} \mathrm{O}_{8}$ \\
\hline 17 & Biotita & $\left(\mathrm{K}_{1,857}\right)\left(\mathrm{Fe}_{3,916} \mathrm{Mg}_{0,731} \mathrm{Ti}_{0,305} \mathrm{Al}_{0,630}\right) \mathrm{Al}_{2,477} \mathrm{Si}_{5.523} \mathrm{O}_{20}(\mathrm{OH})_{4}$ \\
\hline 7 & Granada & $\left(\mathrm{Fe}_{1,8} \mathrm{Ca}_{0,9} \mathrm{Mn}_{0,2}\right)\left(\mathrm{Al}_{1,9} \mathrm{Fe}^{3+}{ }_{0,04}\right) \mathrm{Al}_{0,08} \mathrm{Si}_{2,9} \mathrm{O}_{12}$ \\
\hline 4 & Feldspato K & $\left(\mathrm{K}_{0,8}\right) \mathrm{AlSi}_{2,9} \mathrm{O}_{8}$ \\
\hline 2 & Calcita & $\mathrm{CaCO}_{3}$ \\
\hline$\%$ & & Litotipo A4 (anfibolito) \\
\hline 65 & Hornblenda & $\left(\mathrm{Ca}_{1,8} \mathrm{Na}_{0,15}\right)\left(\mathrm{Mg}_{3,5} \mathrm{Fe}^{2+}{ }_{0,8} \mathrm{Al}_{0,3} \mathrm{Fe}^{3+}{ }_{0,09}\right)\left(\mathrm{Al}_{0,6} \mathrm{Si}_{7,4}\right) \mathrm{O}_{23}(\mathrm{OH})_{2}$ \\
\hline 25 & Biotita & $\left(\mathrm{K}_{1,743}\right)\left(\mathrm{Fe}_{1,441} \mathrm{Mg}_{3,824} \mathrm{Ti}_{0,125} \mathrm{Al}_{0,388}\right) \mathrm{Al}_{2,178} \mathrm{Si}_{5,822} \mathrm{O}_{20}(\mathrm{OH})_{4}$ \\
\hline 4 & Plagioclásio & $\left(\mathrm{Na}_{0,879} \mathrm{Ca}_{0,075}\right) \mathrm{Al}_{1,064} \mathrm{Si}_{2,971} \mathrm{O}_{8}$ \\
\hline 3 & Calcita & $\mathrm{CaCO}_{3}$ \\
\hline 3 & Clorita & $\left(\mathrm{Mg}_{7} \mathrm{Al}_{2,3} \mathrm{Fe}^{2+}{ }_{2} \mathrm{~K}_{0,2} \mathrm{Fe}^{3+}{ }_{0,1}\right)\left(\mathrm{Al}_{2,2} \mathrm{Si}_{5,8}\right) \mathrm{O}_{20}(\mathrm{OH})_{16}$ \\
\hline
\end{tabular}

As análises da composição geoquímica realizadas no Acme Analytical Laboratories Ltd envolveram métodos de espectrometria de emissão atômica (ICP-AES) e espectrometria de massa (ICP-MS), ambos com fonte indutiva de plasma acoplada. Os resultados da composição geoquímica do agromineral para elementos maiores são apresentados na Tabela 3.2. Além desses, elementos considerados micronutrientes estão presentes em teores consideráveis (ppm): Mo (2,8); Cu (27,0); Zn (53,0); Co (34,3); B $(3,0)$. Já os teores de elementos traços deletérios a saúde humana são considerados baixos: As (0,6); Cd (<0,1); $\mathrm{Pb}(3,2)$; $\mathrm{Cr}(0,09)$; Ni $(83,2)$.

Tabela 3.2. Teores dos elementos maiores totais no agromineral (\% em massa).

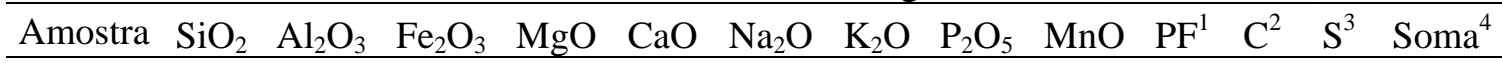

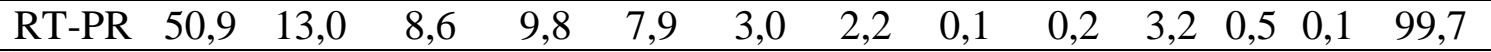

${ }^{1} \mathrm{PF}$ - perda ao fogo, relativo ao teor total de voláteis $\left(\mathrm{CO}_{2}+\mathrm{SO}_{3}+\mathrm{H}_{2} \mathrm{O}\right)$;

${ }^{2} \mathrm{C}$ - carbono total medido pelo Leco;

${ }^{3} \mathrm{~S}$ - enxofre total medido pelo Leco;

${ }^{4}$ Soma relativa aos óxidos e à PF.

A análise granulométrica do agromineral foi realizada a partir de uma amostra seca e fracionada com o auxílio de peneiras. A partir de uma amostra retirada da menor fração $(<0,297 \mathrm{~mm})$, pelo método da pipeta foram calculados o percentual das frações silte $(<0,05 \mathrm{~mm})$ e argila $(<0,002 \mathrm{~mm})$. A densidade aparente foi determinada pelo método direto da proveta, a partir de uma amostra destorroada e peneirada $(<2,0 \mathrm{~mm})$. A determinação da área de superfície específica, com base no método BET, foi realizada no Laboratório de Nanotecnologia da Embrapa Instrumentação. 
Tabela 3.3. Características físicas do agromineral (AS).

\begin{tabular}{|c|c|c|c|c|c|c|c|}
\hline Amostra & \multicolumn{5}{|c|}{ Granulometria (mm) } & ASE & Densidade \\
\hline & $<0,84$ & $<0,3$ & $<0,15$ & $<0,06$ & $<0,002$ & $m^{2} g^{-1}$ & $\mathrm{~g} \mathrm{dm}^{-3}$ \\
\hline AS & $99,8 \%$ & $88 \%$ & $76 \%$ & $27 \%$ & $6 \%$ & 0,562 & 1,46 \\
\hline
\end{tabular}

De acordo com a classificação da ABNT (ABNT/NBR 6502/95), e conforme as características físicas descritas na Tabela 3.3, o agromineral apresenta 73\% das partículas com granulometria classificada como “fração areia” (0,06 a 2 mm), 21\% como "silte” (0,002 a 0,06 mm), e 6\% como “argila” (<0,002 mm).

As análises de superfície específica do agromineral $(99,8 \%<0,8 \mathrm{~mm})$, revelam superfície de 0,562 $\mathrm{m}^{2} \mathrm{~g}^{-1}$ (BET), e volume de poros de $3,5610^{-3} \mathrm{~cm}^{3} \mathrm{~g}^{-1}$ (\# $294 \AA$ ).

\subsubsection{Procedimento Experimental}

\subsubsection{Dimensões das colunas de lixiviação}

As colunas de lixiviação foram confeccionadas com tubo PVC (cloreto de polivinila) rígido de 0,6 m de comprimento e $75 \mathrm{~mm}$ de diâmetro (Figura 3.1). Para evitar a deposição de partículas sólidas no efluente e não comprometer as análises químicas, no fundo da coluna foi colocada uma camada de quartzo (200 \pm 3g) depositada sobre papel filtro (0,1 mm), e por fim uma tela de nylon (\# 0,2 mm).

Na parte superior da coluna foi adaptado um sistema de controle do fluxo de água constituído basicamente de um balão-reservatório e um tubo capilar dosador. Na tampa inferior da coluna foi acoplado um tubo coletor ligando ao recipiente onde é depositado o efluente.

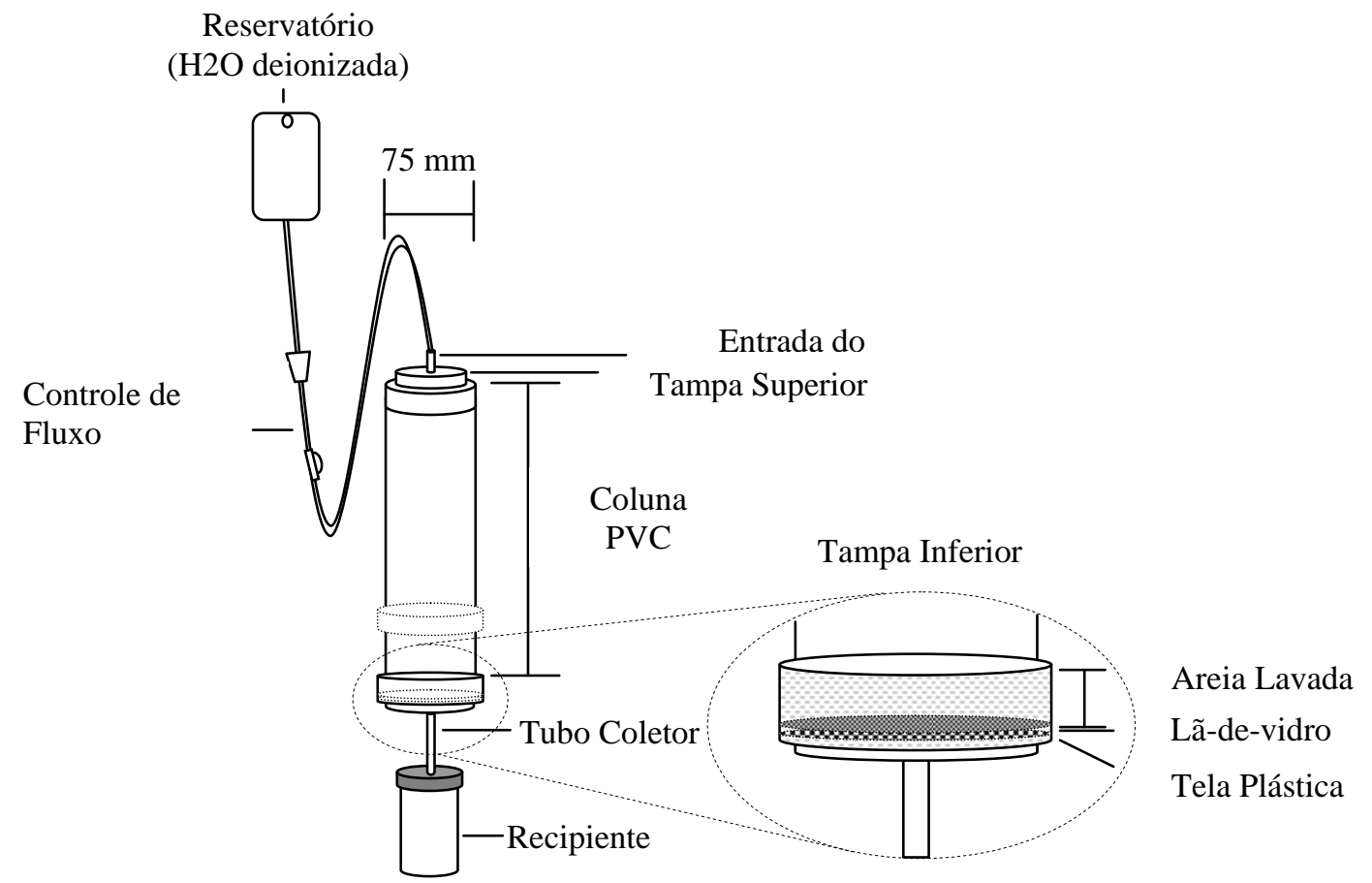

Figura 3.1. Dimensões da coluna de lixiviação utilizada no experimento. 


\subsubsection{Composição dos tratamentos}

O experimento foi composto por 07 tratamentos e 03 repetições, totalizando 21 colunas, com aplicação de fluxos simultaneamente. Os tratamentos envolvem o agromineral descrito anteriormente (AS), a combinação do agromineral e diferentes tipos de solos (AS+RQ, AS+LA, AS+FFc), e os solos isoladamente (RQ, LA, FFc).

Esses solos são representativos da região onde está localizado o Garimpo de Esmeraldas de Monte Santo-TO. Trata-se de solos pertencentes às classes Neossolo Quartzarênico, Latossolo Amarelo e Plintossolo Pétrico concrecionário, os quais cobrem quase $90 \%$ do território do Estado do Tocantins (Seplan, 2005), com as seguintes características (Embrapa, 2006):

- Neossolo Quartzarênico (RQ): solos constituídos por material mineral, com predomínio de características herdadas do material de origem formado fundamentalmente de quartzo, sendo definidos como solos pouco evoluídos e com horizonte $\mathrm{C}$ arenoso formado por grãos simples. Esses solos apresentam baixa saturação por bases (distróficos), elevada acidez e altos teores de alumínio trocável. Solos geralmente profundos e de alta permeabilidade. Abrangem diversos ambientes climáticos, com predomínio de áreas planas, sob a influência do lençol freático. Quanto ao material de origem, variam desde sedimentos aluviais até materiais provenientes da decomposição de quartzitos e arenitos no estado do Tocantins;

- Latossolo Amarelo (LA): solos constituídos por material mineral, originados a partir das mais diversas espécies de rochas e sedimentos, sob condições de clima e tipos de vegetação os mais diversos. Apresentam avançado estágio de intemperismo sobre o material de origem. Esses solos são destituídos de minerais primários ou secundários pouco resistentes ao intemperismo. Variam de fortemente a bem drenados. São normalmente muito profundos, fortemente ácidos, com baixa saturação por bases e altos teores de alumínio trocável. Ocorrem em áreas de depressão associados aos relevos plano a suave-ondulado no estado do Tocantins.

- Plintossolo Pétrico Concrecionário (FFc): solos constituídos por material mineral, e que se caracterizam fundamentalmente por apresentar horizonte petroplíntico concrecionário. Trata-se de solos fortemente ácidos, com predomínio de baixa saturação por bases. Solos com predomínio de horizonte concrecionário apresentam melhor drenagem e ocupam posições mais elevadas no relevo, normalmente em bordas de platô e áreas ligeiramente dissecadas de chapadas e chapadões das regiões Central e Norte..

Os solos foram coletados no horizonte de $0-20 \mathrm{~cm}$, sob vegetação de cerrado, nas proximidades de Palmas-TO. Em seguida os solos foram destorroados, peneirados ( $<2 \mathrm{~mm}$ ), secos ao ar, e então misturados ao agromineral na proporção 2:1 em massa, e acondicionados nas colunas. Amostras dos solos foram submetidas a análises físicas e químicas, conforme métodos de rotina empregados na avaliação da fertilidade de solos (Embrapa, 1997; Raij et al., 2001). Na Tabela 3.4 são apresentados os resultados que descrevem os atributos químicos, e a composição granulométrica dos solos. 
No final do experimento foi determinada a condutividade hidráulica dos tratamentos, a partir de amostras indeformadas coletadas no topo das colunas, e o auxílio de um permeâmetro de carga hidráulica constante de 2 cca (Libardi, 2005). A condutividade hidráulica dos respectivos tratamentos é apresentada na Tabela 4.

Tabela 3.4. Características químicas e físicas dos solos e demais tratamentos avaliados no experimento.

\begin{tabular}{|c|c|c|c|c|c|c|c|c|}
\hline \multirow{2}{*}{\multicolumn{2}{|c|}{ Parâmetros }} & \multicolumn{7}{|c|}{ Tratamentos } \\
\hline & & AS & $\mathrm{AS}+\mathrm{RQ}$ & $\mathrm{AS}+\mathrm{LA}$ & $\mathrm{AS}+\mathrm{FFC}$ & RQ & LA & FFC \\
\hline $\mathrm{pH}^{1}$ & $\left(\mathrm{H}_{2} \mathrm{O}\right)$ & 8,5 & 7,8 & 7,6 & 7,5 & 4,7 & 4,9 & 5,0 \\
\hline \multicolumn{9}{|c|}{ Atributos Químicos } \\
\hline $\mathrm{P}^{2}$ & $\mathrm{madm} \mathrm{dm}^{-3}$ & 21 & 107 & 93 & 53 & 4 & 3 & 4 \\
\hline $\mathrm{K}^{2}$ & Img um & 650 & 980 & 990 & 870 & 17 & 24 & 44 \\
\hline $\mathrm{Ca}^{3}$ & & 4,0 & 4,2 & 3,7 & 5,1 & 0,4 & 0,4 & 0,5 \\
\hline $\mathrm{Mg}^{3}$ & $\mathrm{cmol}_{\mathrm{C}} \mathrm{dm}^{-3}$ & 0,3 & 0,3 & 0,4 & 0,5 & 0,1 & 0,1 & 0,1 \\
\hline CTC & & 6,0 & 7,0 & 6,6 & 7,8 & 1,6 & 1,2 & 1,2 \\
\hline $\mathrm{V}$ & & 88,2 & 84,4 & 83,6 & 83 & 14,1 & 10,7 & 11,5 \\
\hline $\mathrm{m}$ & $\%$ & 0 & 0 & 0 & 0 & 67 & 52 & 41 \\
\hline $\mathrm{MO}^{4}$ & & 2,6 & 1,6 & 1,4 & 1,7 & 2,0 & 2,0 & 2,4 \\
\hline \multicolumn{9}{|c|}{ Composição Granulométrica } \\
\hline Areia & & 734 & 796 & 620 & 870 & 856 & 532 & 642 \\
\hline Silte & $\mathrm{g} \mathrm{dm}^{-3}$ & 206 & 144 & 200 & 10 & 24 & 228 & 158 \\
\hline Argila & & 60 & 60 & 180 & 120 & 120 & 240 & 200 \\
\hline \multicolumn{9}{|c|}{ Condutividade Hidráulica $^{5}$} \\
\hline Ksat & $\mathrm{mm} \mathrm{h}^{-1}$ & 23,1 & 58,7 & 41,5 & 48,9 & 73,2 & 54,9 & 60,1 \\
\hline
\end{tabular}

\subsubsection{Características do solvente e taxas de fluxo}

Depois de preenchidas as colunas com o material correspondente aos diferentes tratamentos, as mesmas foram pesadas e, em seguida, imersas em água deionizada até 2/3 da sua altura durante 48 horas para promover a saturação via ascensão capilar. Em seguida foram liberados os drenos e dado início ao processo de lixiviação e coleta dos efluentes, utilizando como solvente água deionizada ( $\mathrm{pH}$ 6,6 e CE $=0,06 \mu \mathrm{S} \mathrm{L}^{-1}$ a $25^{\circ} \mathrm{C}$ ).

A taxa de fluxo do solvente foi definida a partir de uma lâmina total correspondente ao regime pluviométrico (1865 mm ano ${ }^{-1}$ ) que caracteriza as condições climáticas da região do Garimpo de Esmeraldas de Monte Santo-TO.

Assim, a lâmina total de $1865 \mathrm{~mm}$ foi aplicada de maneira gradual, dividida em 12 momentos e 02 estágios (Tabela 3.5). O primeiro estágio envolve a aplicação de 07 lâminas crescentes (42 a 195 mm), e segundo estágio 05 lâminas uniformes (195mm).

O sistema de controle da taxa de fluxo, composto pelo conjunto capilar/dosador (Figura 3.1), foi ajustado para a menor vazão uniforme possível, ou seja, em $30 \mathrm{~mL} \mathrm{~h}^{-1}$, o que representa uma taxa de fluxo de $6,8 \mathrm{~mm} \mathrm{~h}^{-1}$. Portanto, em função da taxa de fluxo, o tempo das aplicações das respectivas lâminas variou e 6 a 29 horas. 
Como a condutividade hidráulica ( $\mathrm{K}_{\text {sat }}$ ) dos sistemas que caracterizam os tratamentos é 3 a 10 vezes maior que a taxa de fluxo aplicada $\left(6,8 \mathrm{~mm} \mathrm{~h}^{-1}\right)$, as reações entre o solvente e a fase sólida ocorreram sempre em condições não saturada. Isso porque em qualquer condição de umidade inferior àquela de saturação, e desde que a umidade no sistema seja uniforme, qualquer fluxo descendente inferior à condutividade será determinado pelo próprio fluxo aplicado.

Com base nas dimensões da coluna e na taxa de fluxo adotada foram estimados os tempos de percolação das lâminas aplicadas (horas), que no acumulado corresponde ao tempo total das reações do solvente com a fase sólida (Tabela 3.5).

Tabela 3.5. Tempo de percolação das lâminas aplicadas e acumuladas.

\begin{tabular}{|c|c|c|c|c|c|c|c|c|c|c|c|}
\hline \multicolumn{12}{|c|}{ Estágios/Momentos } \\
\hline \multicolumn{7}{|c|}{ Estágio 1} & \multicolumn{5}{|c|}{ Estágio 2} \\
\hline 1 & 2 & 3 & 4 & 5 & 6 & 7 & 8 & 9 & 10 & 11 & 12 \\
\hline \multicolumn{12}{|c|}{ Tempo de aplicação das lâminas (horas) } \\
\hline 6,2 & 10,3 & 14,3 & 20,4 & 24,6 & 26,5 & 28,7 & 28,7 & 28,7 & 28,7 & 28,7 & 28,7 \\
\hline \multicolumn{12}{|c|}{ Tempo total de percolação das lâminas aplicadas (horas) } \\
\hline 94 & 99 & 103 & 109 & 113 & 115 & 117 & 117 & 117 & 117 & 117 & 117 \\
\hline \multicolumn{12}{|c|}{ Tempo total de reação do solvente com a fase sólida (horas) } \\
\hline 94 & 193 & 296 & 405 & 518 & 633 & 750 & 867 & 984 & 1101 & 1218 & 1335 \\
\hline \multicolumn{12}{|c|}{ Tempo total de reação do solvente com a fase sólida (dias) } \\
\hline 4 & 8 & 12 & 17 & 22 & 26 & 31 & 36 & 41 & 46 & 51 & 56 \\
\hline
\end{tabular}

Importa reconhecer que, conforme a abordagem experimental adotada (sistema de fluxo), além da mineralogia e da composição química do agromineral e dos solos, a taxa de dissolução mineral é afetada pelo volume de infiltração e pelo tempo de reação da água com a superfície dos minerais.

Assim, dadas as condições dos sistemas que caracterizam os respectivos tratamentos, quanto maior for a condutividade, menor será o tempo de contato do solvente com o meio sólido, com efeitos sobre o grau de remoção de solutos, e consequentemente, na velocidade das reações de dissolução mineral.

\subsubsection{Coleta e análise química do efluente}

A coleta do efluente foi realizada continuamente através de um tubo coletor conectado à tampa inferior da coluna, e depositado em recipiente de polipropileno (1 L). A coleta do efluente foi realizada semanalmente durante todo o tempo necessário para a aplicação das taxas de fluxo e percolação das lâminas do solvente, sempre antes do início da aplicação da taxa de fluxo subsequente.

O volume coletado em cada momento foi quantificado pela massa (g) com o auxílio de uma balança eletrônica de bancada ( \pm 0,5 g), assegurando menor erro na mensuração e redução do risco de contaminação dos efluentes. Na sequência foram aferidos o pH e a condutividade elétrica com um peagâmetro digital (Modelo DM-2P).

No laboratório uma alíquota de $220 \mathrm{~mL}$ de cada efluente coletado foi filtrada em membrana de fibra de vidro (Millipore - $47 \mathrm{~mm}$ e $0,4 \mu \mathrm{m}$ ) com o auxílio de uma bomba 
de vácuo, e depositadas em um frasco de polipropileno (PP). Depois de eliminados os particulados, as alíquotas foram acidificadas com $\mathrm{HNO}_{3}$ concentrado (SYNTH/PA-ACS 65\%), e mantidas sob refrigeração para preservação das amostras conforme Standard Methods for the Examination of Water and Wastewater (APHA, 1992).

As análises químicas dos efluentes foram realizadas em um equipamento ICPMS Thermo Scientific X Series 2, no Laboratório de Materiais e Combustíveis (LMC), do Instituto de Química, da Universidade de Brasília (IQ/UnB). Na calibração do equipamento foram utilizadas soluções multielementos ( $\mathrm{Si}, \mathrm{Al}, \mathrm{Fe}, \mathrm{Mn}, \mathrm{Mg}, \mathrm{Ca}, \mathrm{Na}$ e K) com oito pontos de concentração (0, 0,5, 1, 3, 5, 10, 20, 100). Esse tipo de análise espectrométrica apresenta baixo limite de detecção, aspecto importante frente às baixas concentrações dos íons em solução nos efluentes.

\subsubsection{Sistematização dos dados}

A taxa de liberação dos principais elementos com o tempo foi calculada de acordo com a equação (Kalinowski e Schweda, 1996; Kalinowski, 1997):

$$
\mathrm{Rij}=\mathrm{Cij} \mathrm{Vj} / \mathrm{m} \mathrm{tj}
$$

onde, Rij é a taxa de liberação do cátion i durante o período de amostragem j em unidades de $\mathrm{mol} \mathrm{g}^{-1} \mathrm{~s}^{-1}$, Cij a concentração do elemento i (mol/l), $\mathrm{Vj}$ o volume em (l) da amostra coletada durante o período de amostragem j, m a massa (g) do mineral, e tj a duração (s) do período de amostragem j.

A taxa de intemperismo de um mineral de silicato, $\mathrm{R}\left(\mathrm{mol} \mathrm{m}^{-2} \mathrm{~s}^{-1}\right)$, é comumente definida pela relação entre a moles $\mathrm{Q}(\mathrm{mol})$ de um mineral que reagiu e a sua área de superfície específica $S\left(\mathrm{~m}^{2}\right)$ no tempo $\mathrm{t}(\mathrm{s})$ de duração da reação. Assim, a taxa de dissolução mineral foi calculada com base na área de superfície específica do agromineral, e no coeficiente estequiométrico do cátion $\mathrm{K}$ na fórmula química estrutural da biotita, uma vez que esse mineral contribui com $87 \%$ do K contido no agromineral. Portanto, a taxa de reação mineral $\left(\mathrm{mol} . \mathrm{m}^{-2} \cdot \mathrm{s}^{-1}\right)$ é calculada com base na equação (Kalinowski e Schweda, 1996):

$$
\mathrm{R}_{\mathrm{ij}}=\left(\mathrm{C}_{\mathrm{ij}} \mathrm{V}_{\mathrm{j}}\right) /\left(\mathrm{n}_{\mathrm{i}} \mathrm{m} \text { a } \mathrm{t}_{\mathrm{j}}\right)
$$

onde n é o número de cátions $\mathrm{K}$ por $\mathrm{O}_{20}(\mathrm{OH})_{4}$, e ‘a' área de superfície $\left(\mathrm{m}^{2} \mathrm{~g}^{-1}\right)$.

Diante dos resultados obtidos são estimadas as taxas de longo prazo, o tempo necessário para se atingir o estado de estabilidade das reações de dissolução do agromineral, e discutidas as taxas resultantes do presente experimento com aquelas descritas na literatura sobre intemperismo dos silicatos.

Adicionalmente, com base nos tratamentos com apenas solos, e nos tratamentos que envolvem esses solos em mistura com o agromineral, são discutidos os efeitos de "superposição" dos parâmetros do solo na dinâmica de liberação dos elementos químicos e dissolução do agromineral. 


\subsection{RESULTADOS E DISCUSSÃO}

\subsubsection{Liberação dos elementos químicos do agromineral silicático}

A dissolução da maioria dos minerais em ambientes naturais é controlada por reações heterogêneas que ocorrem na interface mineral-solução (Blum e Lasaga, 1991). Os estudos experimentais de Casey e Sposito (1992) mostram que a dissolução dos silicatos é dependente da composição e do pH da solução reagente.

Na Tabela 3.6 são apresentados os resultados referentes às mudanças no $\mathrm{pH}$ e nas concentrações dos elementos químicos em solução (mmol L ${ }^{-1}$ ) decorrentes da dissolução do agromineral silicático. $\mathrm{O}$ pH da solução após 94 horas do início da aplicação das lâminas de percolação $(6,54)$ não difere das condições iniciais do solvente $( \pm 6,6)$, mas eleva-se rapidamente até a $4^{\text {a }}$ coleta (405 horas) quando atinge o máximo de 8,33, mantendo-se acima de 8 no decorrer do experimento.

O rápido aumento do $\mathrm{pH}$ da solução deve-se, principalmente, à dissolução de carbonatos (calcita) presentes no agromineral silicático, pois com a elevação da concentração de Ca ocorre maior consumo dos íons $\mathrm{H}^{+}$da solução, os quais são responsáveis pelas reações de troca envolvidas na dissolução dos silicatos.

Tabela 3.6. Variações no pH e na concentração dos elementos nas soluções de reação do tratamento com agromineral (AS) nos diferentes momentos.

\begin{tabular}{ccccccccc}
\hline Tempo & \multicolumn{7}{c}{ Elementos $\left(\mathrm{mmol} \mathrm{L}^{-1}\right)$} \\
\hline (horas) & $\mathrm{pH}$ & $\mathrm{K}$ & $\mathrm{Ca}$ & $\mathrm{Na}$ & $\mathrm{Mg}$ & $\mathrm{Mn}$ & $\mathrm{Si}$ & $\mathrm{Fe}$ \\
\hline 94 & 6,54 & 0,28 & 0,48 & 0,09 & 0,04 & 0,004 & 0,23 & 0,003 \\
193 & 6,87 & 0,64 & 1,54 & 0,14 & 0,19 & 0,006 & 0,24 & 0,005 \\
296 & 8,31 & 2,28 & 4,99 & 0,76 & 0,60 & 0,033 & 0,26 & 0,007 \\
405 & 8,33 & 1,53 & 3,16 & 0,88 & 0,50 & 0,013 & 0,33 & 0,008 \\
518 & 8,27 & 1,00 & 2,20 & 0,12 & 0,23 & 0,005 & 0,54 & 0,009 \\
633 & 8,20 & 0,96 & 1,28 & 0,09 & 0,22 & 0,004 & 0,53 & 0,012 \\
750 & 8,18 & 0,88 & 1,16 & 0,09 & 0,20 & 0,002 & 0,50 & 0,009 \\
867 & 8,16 & 0,85 & 1,06 & 0,03 & 0,19 & 0,002 & 0,48 & 0,000 \\
984 & 8,14 & 0,80 & 0,99 & 0,02 & 0,17 & 0,001 & 0,46 & 0,000 \\
1101 & 8,11 & 0,76 & 0,97 & 0,02 & 0,15 & 0,001 & 0,41 & 0,000 \\
1218 & 8,09 & 0,65 & 0,91 & 0,02 & 0,14 & 0,001 & 0,38 & 0,000 \\
1335 & 8,06 & 0,65 & 0,84 & 0,01 & 0,13 & 0,000 & 0,37 & 0,000 \\
\hline Tx. Média & $\left(\mathrm{mol} \mathrm{g}^{-1} \mathrm{~s}^{-1}\right)$ & $2,32^{-11}$ & $1,22^{-11}$ & $3,04^{-12}$ & $1,73^{-12}$ & $1,69^{-12}$ & $8,23^{-13}$ & $3,29^{-14}$ \\
\hline Liberado & $(\%)$ & 0,65 & 0,37 & 0,06 & 0,03 & 0,09 & 0,02 & 0,001 \\
\hline
\end{tabular}

Os teores de Mn e Fe na solução foram bastante baixos. O Mn atinge o máximo (0,033 mmol L $\left.\mathrm{m}^{-1}\right)$ após 296 horas, com liberação de $60 \%$ do $\mathrm{Mn}$ em relação ao total. O Fe apresentou máxima concentração $\left(0,012 \mathrm{mmol} \mathrm{L}^{-1}\right)$ com 633 horas, com mais de $80 \%$ do Fe liberado. Com uma concentração em solução $<0,001 \mathrm{mmol} \mathrm{L}^{-1}$ ao final do experimento, a taxa média de liberação de Fe e Mn foi 3,29 $10^{-14}$ e $1,6910^{-12} \mathrm{~mol} \mathrm{~g}^{-1} \mathrm{~s}^{-1}$, respectivamente. 
As concentrações de $\mathrm{Na}, \mathrm{K}$, Ca e $\mathrm{Mg}$ foram crescentes no início, mas apresentaram particular redução até o final do experimento. A máxima concentração de Na em solução $\left(0,88 \mathrm{mmol} \mathrm{L}^{-1}\right)$ foi registrada depois de transcorridas as 405 horas iniciais, totalizando $82 \%$ do total do $\mathrm{Na}$ liberado durante todo o experimento. No momento final registrou-se baixa concentração de $\mathrm{Na}$ em solução $\left(0,01 \mathrm{mmol} \mathrm{L}^{-1}\right)$, e taxa média de liberação de $3,0410^{-12} \mathrm{~mol} \mathrm{~g}^{-1} \mathrm{~s}^{-1}$.

O Mg na solução foi máximo (0,6 mmol L-1) com 296 horas, momento em que apenas 30\% do elemento foi liberado. A partir desse momento ocorre rápida redução da concentração de $\mathrm{Mg}$ em solução, de maneira que ao final do experimento a concentração de $\mathrm{Mg}$ em solução foi próximo de $0,1 \mathrm{mmol} \mathrm{L}^{-1}$, e taxa média de liberação de $1,7310^{-12} \mathrm{~mol} \mathrm{~g}^{-1} \mathrm{~s}^{-1}$.

Os teores de Ca em solução foram os mais altos entre os elementos analisados. A máxima concentração de Ca (5,0 $\left.\mathrm{mmol} \mathrm{L}^{-1}\right)$ foi registrada com 296 horas, momento em que 36\% do Ca foi liberado. Em seguida há forte decréscimo na concentração de Ca em solução até as 633 horas, quando a liberação se torna uniforme $\left( \pm 1 \mathrm{mmol} \mathrm{L}^{-1}\right)$, e fecha 0 experimento com $0,84 \mathrm{mmol} \mathrm{L}^{-1}$, com taxa média de liberação de $1,2210^{-11} \mathrm{~mol} \mathrm{~g}^{-1} \mathrm{~s}^{-1}$.

A concentração do $\mathrm{K}$ em solução é a segunda maior dentre os elementos avaliados (Tabela 6), menor apenas que o Ca. O aumento durante as 296 horas iniciais do experimento é consistente $\left(0,28\right.$ a 2,28 $\left.\mathrm{mmol} \mathrm{L}^{-1}\right)$, mas apenas $28 \%$ do total de $\mathrm{K}$ foi liberado. A partir desse momento, a concentração de $\mathrm{K}$ em solução é reduzida linearmente, estabilizando em $0,65 \mathrm{mmol} \mathrm{L}^{-1}$ de $\mathrm{K}$ no final do experimento. A taxa média de liberação de $\mathrm{K}$ foi de 2,32 $10^{-11} \mathrm{~mol} \mathrm{~g}^{-1} \mathrm{~s}^{-1}$.

A liberação de Si em solução apresenta comportamento particular, de maneira que o aumento da concentração em solução se prolonga, e atinge a máxima somente depois de 518 horas $\left(0,54 \mathrm{mmol} \mathrm{L}^{-1}\right)$. A redução da concentração de Si é menos intensa que o observado nos demais elementos analisados, estabilizando-se em $0,37 \mathrm{mmol} \mathrm{L}^{-1}$ ao final do experimento, com taxa de liberação média calculada de $8,2310^{-13} \mathrm{~mol} \mathrm{~g}^{-1} \mathrm{~s}^{-1}$.

O Al não foi detectado em solução durante todo o experimento, apesar da sua significativa concentração na composição do agromineral $\left(\mathrm{Al}_{2} \mathrm{O}_{3}=13 \% \mathrm{wt}\right)$. Conforme apontou Wollast (1967), a distribuição de espécies de Al em solução é controlada pelo $\mathrm{pH}$ e pela solubilidade de amorfos de $\mathrm{Al}(\mathrm{OH})_{3}$, de modo que, na faixa de $\mathrm{pH}$ entre 4 e 8 , a solubilidade deste elemento torna-se muito baixa.

De maneira geral, consideradas as características do agromineral silicático e do solvente, as taxas de fluxo, e também o tempo, a taxa de liberação dos íons em solução apresenta a seguinte ordem: $\mathrm{K}>\mathrm{Ca}>>\mathrm{Na}>\mathrm{Mg}>\mathrm{Mn}>>\mathrm{Si}>>\mathrm{Fe}$.

\subsubsection{Dissolução mineral do agromineral silicático}

Como vários estudos sobre dissolução de micas têm demonstrado que a área de superfície específica não é alterada consideravelmente com o tempo (Kalinowski 1997), os cálculos levam em conta a área de superfície específica inicial do agromineral (BET 
$\left.0,562 \mathrm{~m}^{2} \mathrm{~g}^{-1}\right)$. Assim, entre o pH inicial $(6,54)$ e final $(8,06)$, a taxa de dissolução variou de 2,18 $10^{-13}$ a 1,93 $10^{-12} \mathrm{~mol} \mathrm{~m}^{-2} \mathrm{~s}^{-1}$ (BET), com taxa média de $2,6810^{-11} \mathrm{~mol} \mathrm{~m}^{-2} \mathrm{~s}^{-1}$.

A taxa de dissolução do agromineral calculada com base na liberação do íon $\mathrm{K}$ em solução foi semelhante aos obtidos em alguns estudos sobre dissolução de micas: 2,22 $10^{-13}$ a 2,75 $10^{-12} \mathrm{~mol} \mathrm{~m}^{-2} \mathrm{~s}^{-1}$ em biotita com pH entre 4-5 (Acker e Bricker, 1992); 1,0 a 4,0 $10^{-11} \mathrm{~mol} \mathrm{~m}^{-2} \mathrm{~s}^{-1}$ em flogopita e $\mathrm{pH} 4$ (Kalinowski e Schweda, 1996).

Com base na liberação de Si em solução a taxa de dissolução do agromineral foi pouco menor, com média de $1,2310^{-11} \mathrm{~mol} \mathrm{~m}^{-2} \mathrm{~s}^{-1}$ (BET). A Figura 3.2 ilustra o comportamento dos íons $\mathrm{K}$ e $\mathrm{Si}$ em solução e as taxas de dissolução mineral do agromineral ao longo do tempo.
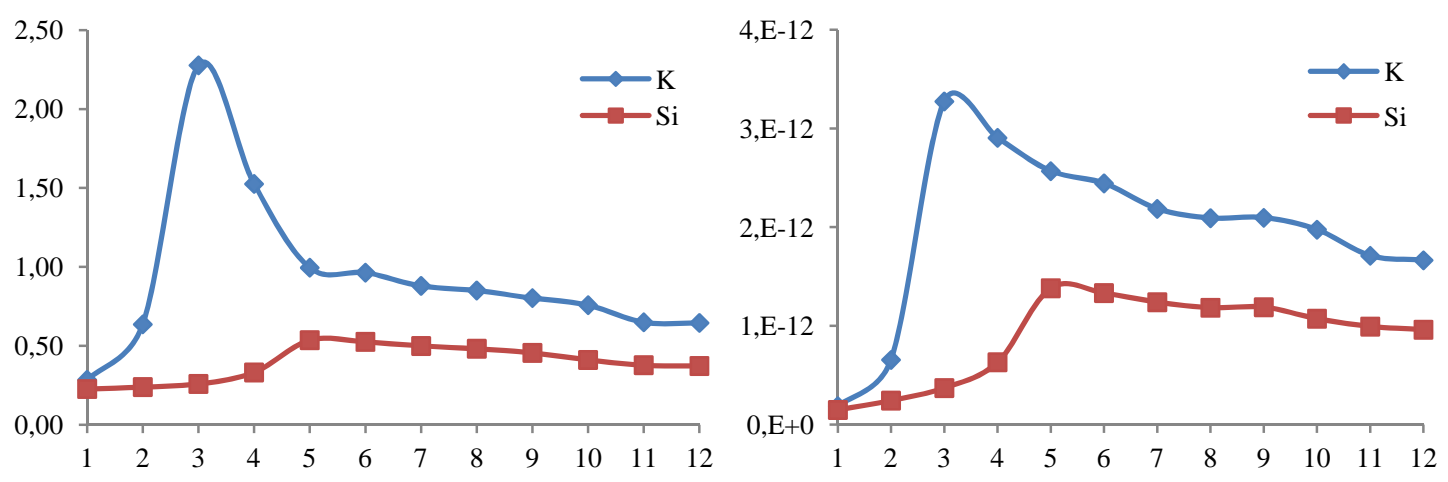

Figura 3.2. Dissolução do agromineral com base: a) na liberação de K e Si em solução $\left(\mathrm{mmol} \mathrm{L}^{-1}\right)$; b) na taxa de dissolução mineral (mol m $\mathrm{m}^{-2} \mathrm{~s}^{-1}$.

Os teores de K liberados em solução mostram que a dissolução do agromineral silicático caracteriza bem os mecanismos descritos por Berner (1978), ou seja: na fase inicial (0-296 horas) ocorre rápida liberação de K, e a dissolução é determinada pelo transporte do soluto do cristal em direção ao menor gradiente de concentração dos íons na solução reagente; na fase seguinte (296 até 633 horas) a liberação de K em solução é reduzida, mas a dissolução ainda é predominantemente determinada pelo transporte; na fase final (633 até 1335 horas) a concentração dos íons apresenta pequena redução e se estabiliza $\left(0,65 \mathrm{mmol} \mathrm{L}^{-1}\right)$, de maneira que a dissolução não acompanha a difusão, e portanto, passa a ser determinada pela extensão da superfície.

Com base nos dados da Tabela 3.6, calculou-se a liberação relativa dos elementos químicos do agromineral ao final do experimento (1335 horas): 0,65\% do K; 0,37\% do Ca; 0,09\% do Mn; 0,06\% do Na; 0,03\% do Mg; 0,02\% do Si; e 0,001\% do Fe. Isso significa que $1,22 \%$ do agromineral foram solubilizados durante o experimento.

Dentre os fatores que influenciaram a liberação dos íons em solução e a dissolução mineral, citam-se: a granulometria 'grosseira' do material (76\% > 0,15 mm) e a reduzida área de superfície de reação $\left(0,562 \mathrm{~m}^{2} \mathrm{~g}^{-1}\right)$; os teores de Ca liberados em solução, parte proveniente de carbonatos, o que contribuiu para rápida elevação do $\mathrm{pH}$; e as elevadas taxas de fluxo, com efeito sobre o tempo de reação rocha-solução. 


\subsubsection{Efeitos de diferentes solos na solubilização do agromineral silicático}

Os processos de dissolução mineral afetam a composição química da solução do solo, do mesmo modo que os atributos químicos da solução e a estabilidade intrínseca dos minerais determinam a ação dos processos de dissolução mineral (Loughnan, 1969; Wieland et al., 1988; Casey e Bunker, 1990).

Assim, a partir do comportamento dos íons em solução dos tratamentos que envolvem misturas de diferentes tipos de solos com o agromineral (AS+RQ, AS+LA, AS+FFc), distingue-se a "superposição" dos efeitos de alguns parâmetros da solução reagente e dos próprios solos na solubilização do agromineral.

Os resultados referentes ao pH inicial e final da solução, e aos teores totais extraídos dos elementos analisados para os respectivos tratamentos são resumidos na Tabela 3.7. Nota-se que todos os parâmetros apresentaram variação significativa entre os tratamentos avaliados no experimento.

Tabela 3.7. Total dos elementos extraídos (mmoles) nos respectivos tratamentos.

\begin{tabular}{|c|c|c|c|c|c|c|c|c|c|}
\hline \multirow{2}{*}{ Tratamento } & \multicolumn{2}{|c|}{$\mathrm{pH}$} & \multicolumn{7}{|c|}{ Total extraído em solução (mmoles) } \\
\hline & inicial & final & $\mathrm{Na}$ & K & $\mathrm{Fe}$ & $\mathrm{Mn}$ & $\mathrm{Ca}$ & $\mathrm{Mg}$ & Si \\
\hline AS & $6,5 \mathrm{c}$ & $8,1 \mathrm{a}$ & $1,2 \mathrm{a}$ & 7,6 a & $0,04 \mathrm{e}$ & $0,04 \mathrm{~d}$ & $12,4 \mathrm{~d}$ & $1,8 \mathrm{~b}$ & $3,5 \mathrm{a}$ \\
\hline $\mathrm{AS}+\mathrm{RQ}$ & $7,1 \mathrm{a}$ & $7,8 \mathrm{~b}$ & $0,6 \mathrm{~d}$ & $7,1 \mathrm{~b}$ & $0,16 \mathrm{~d}$ & $0,24 \mathrm{~b}$ & $16,6 \mathrm{c}$ & $1,7 \mathrm{~b}$ & $1,5 \mathrm{~d}$ \\
\hline $\mathrm{AS}+\mathrm{LA}$ & $7,2 \mathrm{a}$ & $7,4 \mathrm{c}$ & $0,7 \mathrm{~b}$ & $4,8 \mathrm{c}$ & $0,18 \mathrm{c}$ & $0,27 \mathrm{~b}$ & $18,1 \mathrm{~b}$ & $2,2 \mathrm{a}$ & $1,4 \mathrm{e}$ \\
\hline $\mathrm{AS}+\mathrm{FFC}$ & $7,2 \mathrm{a}$ & $7,3 \mathrm{c}$ & $0,6 \mathrm{c}$ & $7,2 \mathrm{~b}$ & $0,57 \mathrm{a}$ & $0,30 \mathrm{a}$ & 19,5 a & $2,1 \mathrm{a}$ & $1,8 \mathrm{c}$ \\
\hline RQ & $6,7 \mathrm{~b}$ & $5,3 \mathrm{~d}$ & $0,2 \mathrm{~g}$ & $0,2 \mathrm{e}$ & $0,14 \mathrm{~d}$ & $0,06 \mathrm{~d}$ & $0,4 \mathrm{e}$ & $0,1 \mathrm{e}$ & $1,3 \mathrm{e}$ \\
\hline LA & $6,0 \mathrm{~d}$ & $3,8 \mathrm{f}$ & $0,3 \mathrm{f}$ & $0,2 \mathrm{e}$ & 0,09 e & $0,09 \mathrm{~d}$ & 0,4 e & 0,2 c & $1,8 \mathrm{c}$ \\
\hline FFc & $6,9 \mathrm{~b}$ & $4,7 \mathrm{e}$ & $0,4 \mathrm{e}$ & $0,7 \mathrm{~d}$ & $0,30 \mathrm{~b}$ & $0,13 \mathrm{c}$ & $0,3 \mathrm{e}$ & $0,1 \mathrm{~d}$ & $2,0 \mathrm{~b}$ \\
\hline $\mathrm{CV}\left({ }^{\circ}\right.$ & 2,1 & 1,6 & 4,2 & 4,1 & 16,3 & 13,3 & 4,2 & 2,4 & 3,6 \\
\hline Média Geral & 6,7 & 6,3 & 0,6 & 4,0 & 0,2 & 0,2 & 9,7 & 1,2 & 1,9 \\
\hline
\end{tabular}

Médias seguidas pelas mesmas letras não diferem entre si, teste Scott \& Knott (1974), 5\% probabilidade;

O comportamento do $\mathrm{pH}$ entre os tratamentos agromineral (AS) e as misturas com solos (AS+RQ, AS+LA, AS+FFc) é bastante semelhante, marcado pelo aumento rápido até 296 horas, seguido de decréscimo quase uniforme até o final do experimento (Figura 3.3). Os pH’s finais apresentam relação com o pH de equilíbrio da fração mineral dos diferentes materiais - agromineral e solos.

Em parte, esse comportamento se deve à presença de carbonatos (calcita) no agromineral, os quais apresentam baixa estabilidade em condições ambientais, e liberação de bases que contribuem para a rápida elevação do $\mathrm{pH}$ da solução reagente. Complementarmente, os efeitos dos diferentes solos sobre as variações no pH das soluções lixiviadas podem ser distinguidos no teor de matéria orgânica: FFc > LA > RQ. Isso, pois à medida que a decomposição da matéria orgânica libera íons $\mathrm{H}+\mathrm{e}$ aumenta a acidez, ocorre dissolução mineral e liberação de bases, o que reduz a atividade do íon $\mathrm{H}^{+}$em solução e aumenta o pH.

Nos solos em particular, como esperado, os valores do pH da solução sempre foram menores comparados aos demais tratamentos. As variações observadas são 
decorrentes do próprio teor da matéria orgânica do solo (MOS), mas especialmente, do efeito dos distintos componentes ou grupos funcionais, conferindo potencial de tamponamento em ampla faixa de pH (Silva e Mendonça, 2007).

Os resultados demonstram forte interação da concentração iônica e do pH da solução, de modo que a dinâmica de liberação dos elementos químicos entre os tratamentos com o agromineral (AS) e com as misturas com solos (AS+RQ, AS+LA, AS+FFc) também apresentam grande semelhança. A concentração iônica da solução é marcada por aumento expressivo no inicio (296-405 horas), seguido de declínio acentuado (633 horas), e estabilização até o final do experimento.
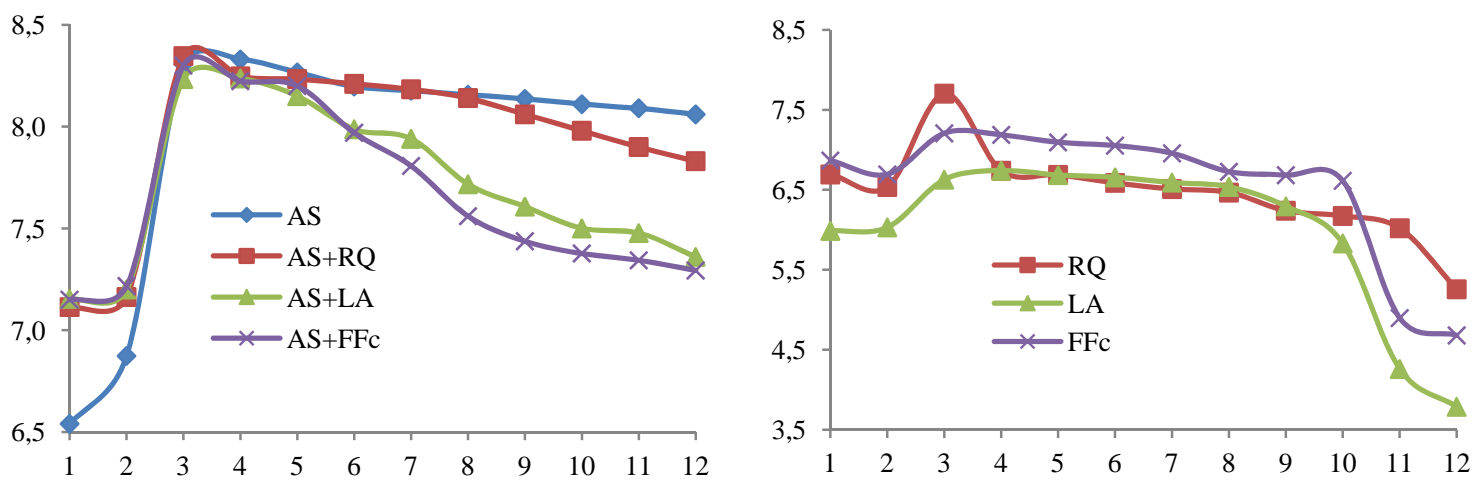

Figura 3.3. Reação da solução $(\mathrm{pH})$ nos respectivos tratamentos e momentos de coleta: a) agromineral e misturas com solos; b) solos isolados.

Na Figura 3.4 são ilustrados os efeitos dos diferentes tipos de solos na dinâmica de liberação de $\mathrm{K}$ do agromineral. Com base nos teores relativos de $\mathrm{K}$ liberados ao longo do experimento, constata-se que a "superposição" dos efeitos dos solos na dissolução do agromineral obedece a seguinte ordem: FFc > RQ > LA. Os efeitos mais significativos são influenciados em parte pelo menor $\mathrm{pH}$ e maior teor de matéria orgânica, conforme já apontado. Mas também, pela menor saturação de K no complexo de troca, o que favorece a liberação, aumento o potencial do íon K em solução.

Os solos em particular apresentam comportamento inicial semelhante, guardadas a ordem de grandezas da concentração de K em solução, cuja liberação relativa: RQ > FFc > LA. Tais resultados decorrem especialmente da maior condutividade hidráulica, que reduz o tempo de reação solução-solo, a dissolução e liberação de K em solução.
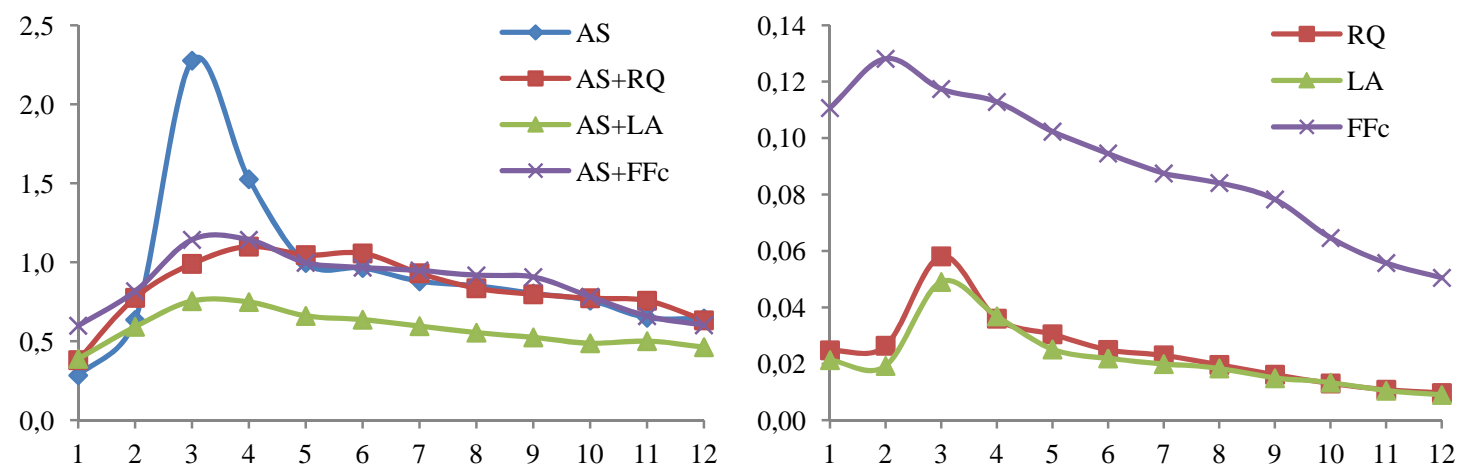

Figura 3.4. Concentrações de $\mathrm{K}$ em solução $\left(\mathrm{mmol} \mathrm{L}^{-1}\right)$ nos respectivos tratamentos e momentos de coleta: a) agromineral e misturas com solos; b) solos isolados. 
A liberação de Na é ilustrada na Figura 3.5, marcada por rápido aumento nos teores em solução, seguida de redução acentuada e estabilização final. A “superposição” dos efeitos dos solos (LA > FFc > RQ) na liberação de Na do agromineral são em grande parte influenciada pela maior condutividade hidráulica do sistema.

Entre os solos, comportamento diferenciado marcado pela redução inicial dos teores do íon Na em solução, aumento nos momentos seguintes, e declínio desuniforme ao longo do experimento: $\mathrm{FFc}>\mathrm{LA}>\mathrm{RQ}$. Tais resultados são decorrentes do aumento no tempo de reação solução-solo, favorecido pela menor condutividade hidráulica.
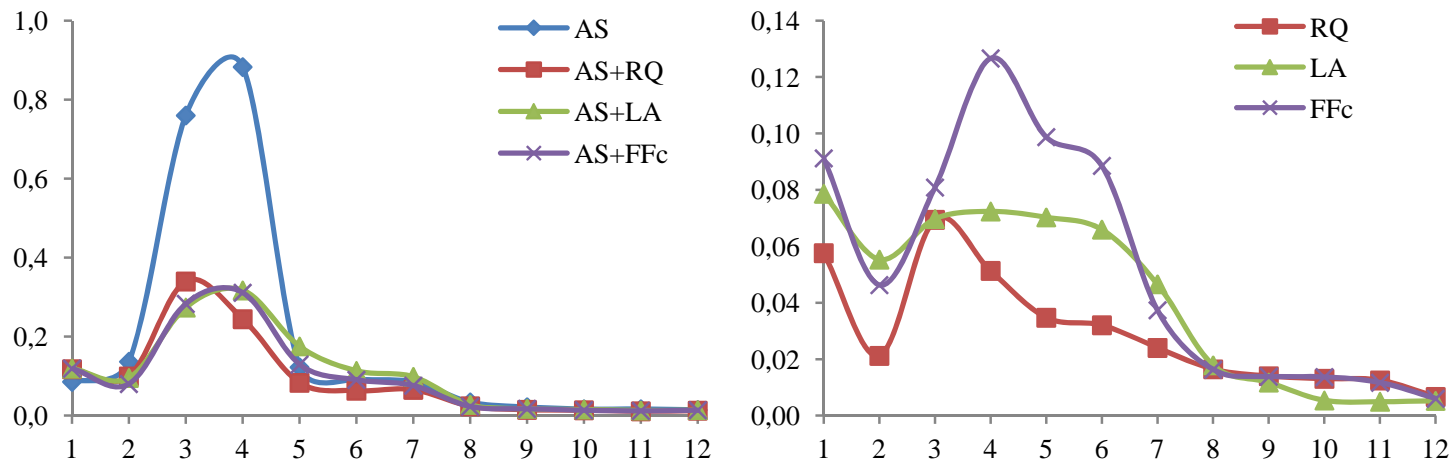

Figura 3.5. Concentrações de Na em solução ( $\mathrm{mmol} \mathrm{L}^{-1}$ ) nos respectivos tratamentos e momentos de coleta: a) agromineral e misturas com solos; b) solos isolados.

A dinâmica de liberação de Ca e Mg dos tratamentos avaliados são ilustrados nas Figuras 3.6 e 3.7. As concentrações de Ca em solução são as maiores dentre os elementos analisados, parte devido ao teor total de $\mathrm{CaO}$ presente em minerais de baixa estabilidade: plagioclásio (anortita) e carbonados (calcita). O teor total de MgO é maior que o de $\mathrm{CaO}$ no agromineral, mas suas concentrações em solução são menores. Isso se deve ao fato do Mg estar presente em minerais de biotita e anfibólio, os quais são um pouco mais estáveis e resistentes à dissolução mineral.

A "superposição" dos efeitos dos solos aumentou significativamente a dissolução do agromineral: FFc > LA > RQ. Esses efeitos estão associados especialmente, ao maior teor dos íons na fase sólida. Entre os tratamentos com solos, as concentrações de Ca e Mg em solução são muito baixas ( $\mathrm{LA}>\mathrm{FFc}>\mathrm{RQ}$ ), não havendo diferença na liberação de Ca, enquanto a liberação de Mg é pouco significativa.
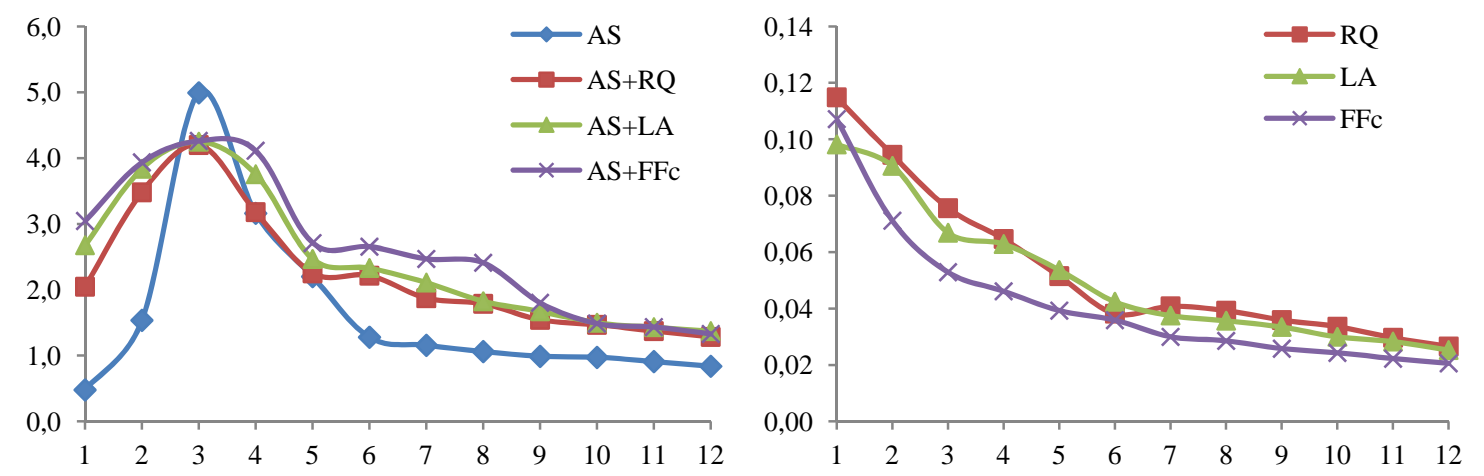

Figura 3.6. Concentrações de Ca em solução $\left(\mathrm{mmol}^{-1} \mathrm{~L}^{-1}\right)$ nos respectivos tratamentos e momentos de coleta: a) agromineral e misturas com solos; b) solos isolados. 

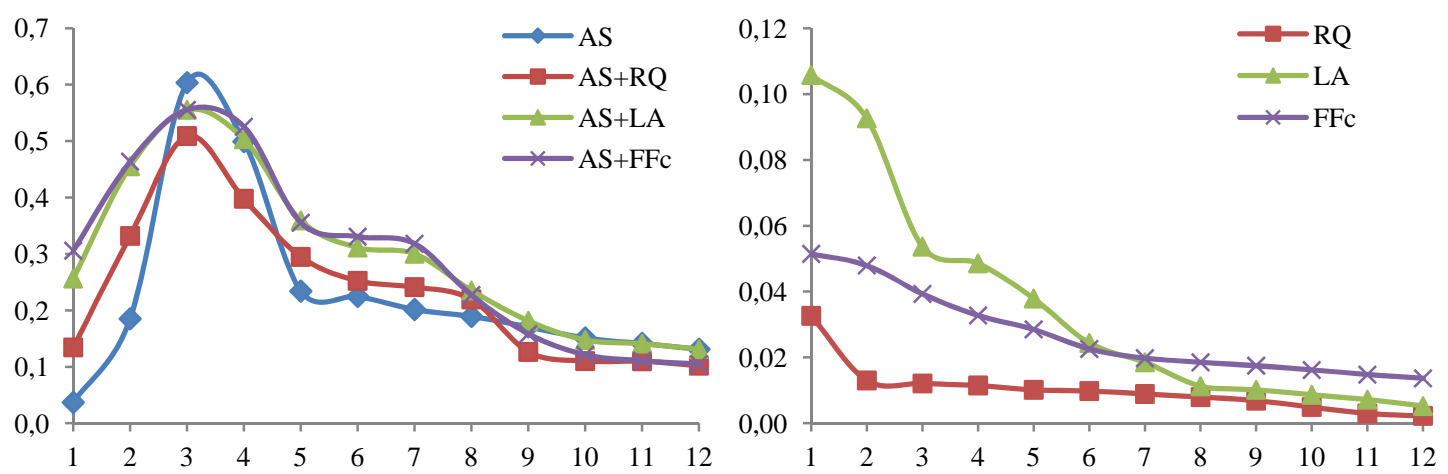

Figura 3.7. Concentrações de $\mathrm{Mg}$ em solução $\left(\mathrm{mmol} \mathrm{L}^{-1}\right)$ nos respectivos tratamentos e momentos de coleta: a) agromineral e misturas com solos; b) solos isolados.

A dinâmica de liberação de Fe e Mn apresenta comportamento semelhante aos íons descritos anteriormente, com rápido crescimento nos três momentos iniciais, seguido de redução, e estabilização no terço final do experimento (Figuras 3.8 e 3.9). A diferença significativa entre os tratamentos na primeira metade do experimento permite distinguir bem o efeito de "superposição" dos solos, na liberação relativa de Fe Mn do agromineral: $\mathrm{FFC}>\mathrm{LA}>\mathrm{RQ}$.

Nesses tratamentos, e entre os solos em particular, a maior liberação de Fe e Mn em solução ao longo do experimento esta relacionada ao teor total desses na composição dos solos.
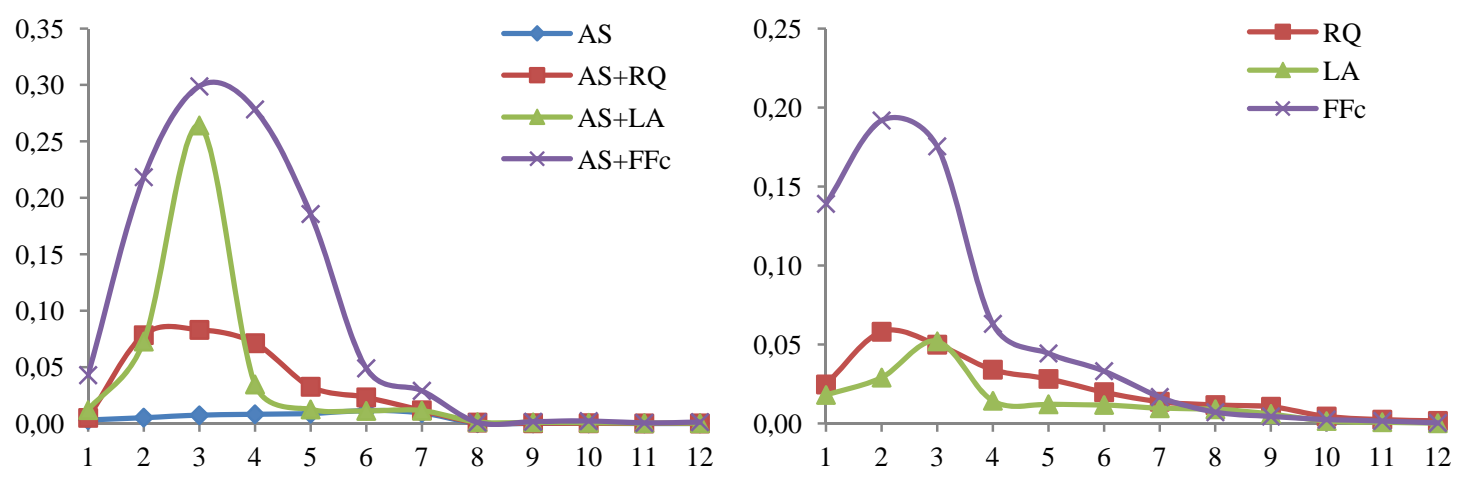

Figura 3.8. Concentrações de Fe em solução $\left(\mathrm{mmol} \mathrm{L}^{-1}\right)$ nos respectivos tratamentos e momentos de coleta: a) agromineral e misturas com solos; b) solos isolados.
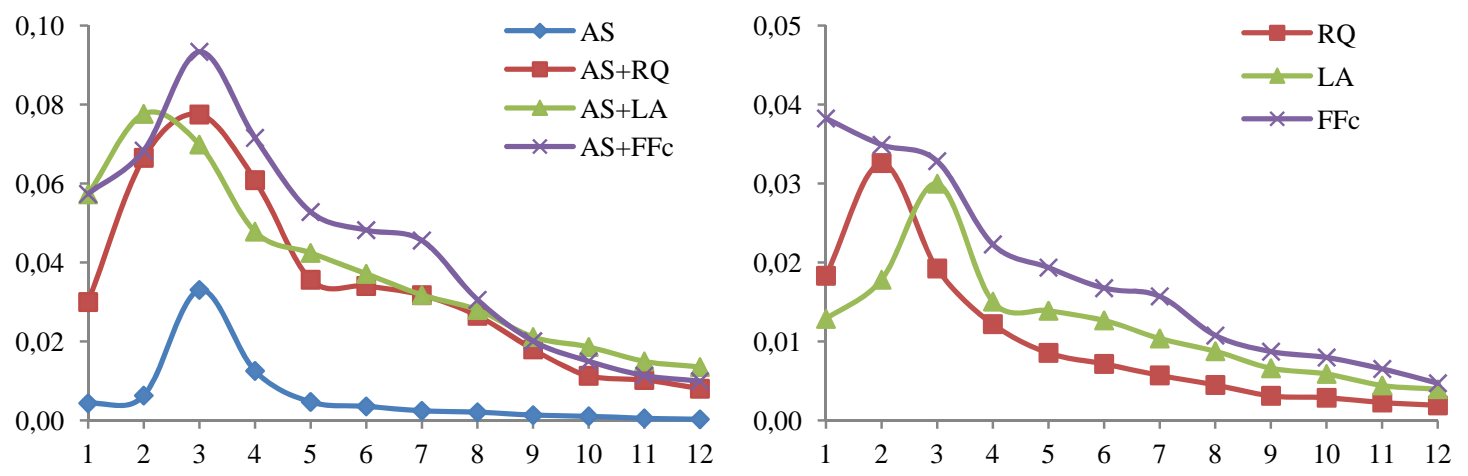

Figura 3.9. Concentrações de $\mathrm{Mn}$ em solução $\left(\mathrm{mmol} \mathrm{L}^{-1}\right)$ nos respectivos tratamentos e momentos de coleta: a) agromineral e misturas com solos; b) solos isolados. 
Na Figura 3.10 é apresentada a dinâmica de liberação de Si. Em todos os tratamentos o comportamento do Si em solução é semelhante, com pequeno aumento nos momentos iniciais, máxima concentração na quinta coleta (518 horas), e redução pronunciada seguida da estabilização até o final do experimento.

Nesses tratamentos os efeitos de "superposição” dos solos foram negativos, ou seja, reduziram a liberação de Si do agromineral, na seguinte ordem: RQ > LA > FFc. Esses efeitos decorrem do maior teor total de Si contido nos solos (\% wt).

Entre os solos isoladamente, o tratamento (LA) apresentou a maior liberação de Si em solução, maior também que sua mistura com o agromineral (AS+LA).
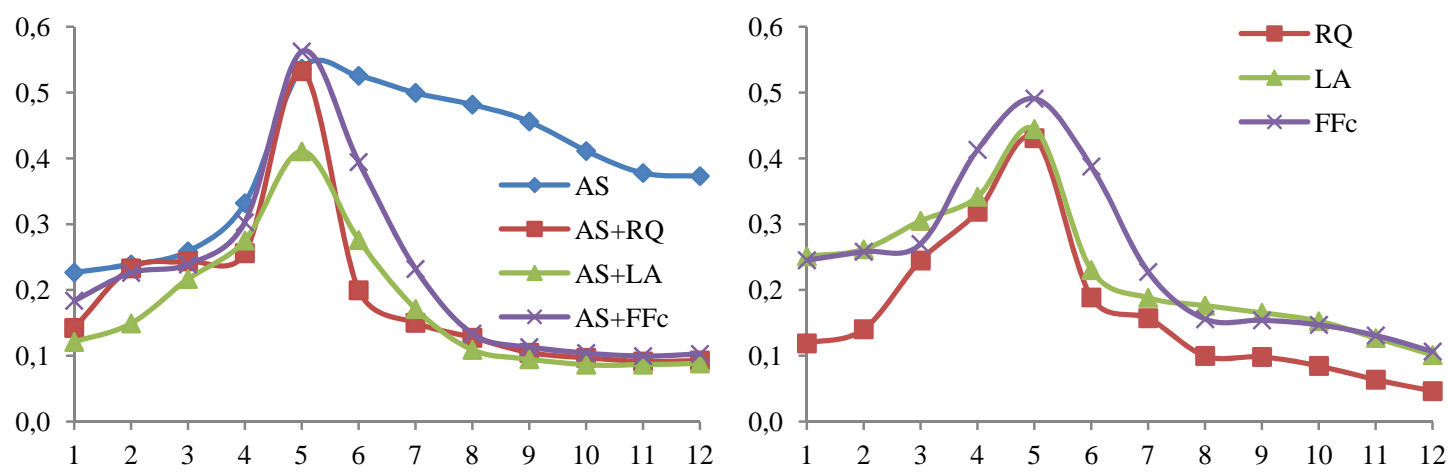

Figura 3.10. Concentrações de Si nas soluções lixiviadas $\left(\mathrm{mmol} \mathrm{L}^{-1}\right)$ nos respectivos tratamentos e momentos coleta: a) agromineral e misturas com solos; b) solos isolados.

Na Tabela 3.8 são apresentados os resultados em termos de liberação relativa dos elementos químicos nos respectivos tratamentos. Dada a proporção do agromineral nas misturas com solos (\%wt), constata-se que para todos os elementos analisados (Na, $\mathrm{K}, \mathrm{Ca}, \mathrm{Mg}$, Fe e Mn) ocorreram efeitos sinérgicos, ou seja, as características e atributos dos solos potencializaram a solubilização do agromineral.

Tabela 3.8. Liberação relativa dos elementos químicos nos respectivos tratamentos.

\begin{tabular}{lcccccccc}
\hline \multirow{2}{*}{ Tratamento } & \multicolumn{7}{c}{ Liberação relativa dos elementos químicos (\%) } \\
\cline { 2 - 9 } & $\mathrm{Na}$ & $\mathrm{K}$ & $\mathrm{Fe}$ & $\mathrm{Mn}$ & $\mathrm{Ca}$ & $\mathrm{Mg}$ & $\mathrm{Si}$ & Total \\
\hline AS & 0,06 & 0,6 & 0,001 & 0,1 & 0,4 & 0,03 & 0,021 & 1,2 \\
AS+RQ & 0,11 & 1,9 & 0,016 & 0,8 & 1,7 & 0,11 & 0,005 & 4,5 \\
AS+LA & 0,13 & 1,1 & 0,016 & 1,0 & 2,0 & 0,14 & 0,005 & 4,2 \\
AS+FFC & 0,12 & 2,1 & 0,017 & 1,1 & 2,2 & 0,14 & 0,008 & 5,7 \\
\hline
\end{tabular}

Os resultados mostram que os efeitos dos solos proporcionaram aumentos significativos (2,5 a 3,8 vezes) na solubilização do agromineral, na seguinte ordem: FFc $>$ RQ > LA. Tais efeitos foram mais expressivos na liberação de Ca (3 a 4,5 vezes), seguido do Mg (3 a 4 vezes) e do K (1 a 2,5 vezes). Em relação aos elementos, especificamente, constatou-se maior variação dos efeitos dos solos sobre a liberação do K (90\%), Ca (29\%) e Mg (27\%). 


\subsection{CONSIDERAÇÕES COMPLEMENTARES}

A ordem de grandeza da taxa de dissolução mineral do agromineral silicático é similar àquelas descritas na literatura. Todavia, a comparação direta não é apropriada, pois características dos materiais e condições experimentais são distintas.

De qualquer forma, os resultados de liberação dos íons em solução ao longo do experimento permite caracterizar bem o comportamento do agromineral frente as condições experimentais adotadas. Conforme esperado, a maior dissolução do agromineral no início é favorecida tanto pelas reações de superfície, quanto pelo transporte de solutos em favor do gradiente de concentração na solução reagente.

Ao final do experimento, dada a liberação relativa dos elementos analisados ( $\mathrm{Na}$, $\mathrm{K}, \mathrm{Fe}, \mathrm{Mn}, \mathrm{Ca}, \mathrm{Mg}$ e Si), obteve-se a solubilização de 1,22\% do agromineral. Os elementos com maior contribuição foram K (0,65\%), Ca (0,37\%) e Mg (0,03\%).

Dentre os fatores que mais influenciaram a liberação dos íons em solução e a dissolução do agromineral, a granulometria 'grosseira' do material e a reduzida área superficial específica adquirem maior significado.

Os atributos e parâmetros dos solos que favoreceram a dinâmica de liberação dos elementos químicos e a dissolução do agromineral foram: o $\mathrm{pH}$ da solução; o teor de matéria orgânica; a capacidade de troca; e a condutividade hidráulica.

Todos os solos potencializam a dissolução do agromineral, com semelhanças na dinâmica de liberação dos elementos químicos, porém, com diferenças significativas nos totais extraídos ao longo do experimento.

Os efeitos dos parâmetros físico-químicos dos solos na dinâmica de dissolução do agromineral foi maior no Plintossolo Pétrico Concrecionário ( $F F c$ ), seguido do Neossolo Quartzarênico (RQ), e do Latossolo Amarelo (LA). 


\section{CAPÍTULO 4}

\section{EFICIÊNCIA NUTRICIONAL DO AGROMINERAL SILICÁTICO}

Resumo: O presente trabalho avaliou os efeitos imediatos e residuais do uso de um agromineral silicático como fonte alternativa de nutrientes para plantas cultivadas. $\mathrm{O}$ agromineral avaliado compreende os resíduos minerais do Garimpo de Esmeraldas de Monte Santo-TO, cuja composição química apresenta 2,2\% $\mathrm{K}_{2} \mathrm{O}, 7,9 \% \mathrm{CaO}$ e 9,8\% $\mathrm{MgO}$, além de outros elementos considerados micronutrientes para plantas cultivadas, e granulometria $85,6 \%<0,3 \mathrm{~mm}$. O solo utilizado compreende um Neossolo Quartzarênico (RQ), de mineralogia simples e baixa fertilidade, típico de Cerrado. A avaliação dos diferentes tratamentos e doses crescentes de $\mathrm{K}$ aplicados via agromineral (50, 100, 150 e $300 \mathrm{mg} \mathrm{kg}^{-1}$ de K), levou em conta a produção de matéria seca da parte aérea de milheto (Pennisetum glaucum (L.) R. Br.), além das concentrações e acúmulo de macro e micronutrientes no tecido vegetal. Também foram avaliados os efeitos dos tratamentos sobre a disponibilidade de $\mathrm{K}$ no solo ao longo do tempo. Os resultados demonstraram que a produção de matéria seca e a absorção de $K$ pelas plantas foi crescente até a maior dose do agromineral (300 $\mathrm{mg} \mathrm{kg}^{-1}$ de $\mathrm{K}$ ), e que o ponto de equivalência em relação à fonte convencional do nutriente $(\mathrm{KCl})$ é obtido com a aplicação de $6 \mathrm{t} \mathrm{ha}^{-1}$ de agromineral (161 mg kg-1 de K). Os resultados obtidos mostraram que os índices de eficiência do agromineral foram semelhantes ao registrado no tratamento referência com fonte solúvel de $\mathrm{K}$, o que permite concluir que o agromineral constitui uma fonte eficiente no fornecimento de K para plantas cultivadas.

Palavras-chave: agromineral silicático; multinutriente; eficiência agronômica.

Abstract: This study evaluated the immediate and residual effects of using a silicático agromineral as an alternative source of nutrients for crops. The rated agromineral comprises mineral residues panning Emeralds Holy Mount-TO, whose chemical composition is 2,2\% $\mathrm{K} 2 \mathrm{O}, 7,9 \% \mathrm{CaO}$ and $9,8 \% \mathrm{MgO}$, and other elements considered micronutrients for plants grown and $85.6 \%$ particle size $<0,3 \mathrm{~mm}$. The soil comprises a Neossolo Quartzarênico (RQ), simple mineralogy and low fertility, typical of Cerrado. The evaluation of different treatments and increasing doses of $\mathrm{K}$ applied via agromineral (50, 100, 150 and $300 \mathrm{mg} \mathrm{kg}^{-1} \mathrm{~K}$ ), took into account the dry matter production of shoots of pearl millet (Pennisetum glaucum (L.) R. Br.), and the concentrations and accumulation of macro and micronutrients in plant tissue. We also evaluated the effects of treatments on $\mathrm{K}$ availability in the soil over time. The results showed that the dry matter yield and $\mathrm{K}$ uptake by plants were grown until the agromineral the highest dose (300 $\mathrm{mg} \mathrm{kg}^{-1} \mathrm{~K}$ ), and that the equivalence point over conventional nutrient source $(\mathrm{KCl})$ is obtained by applying $6 \mathrm{tha}^{-1}$ agromineral (161 mg $\left.\mathrm{kg}^{-1} \mathrm{~K}\right)$. The results showed that rates of efficiency agromineral were similar to that recorded in the reference treatment with soluble source of $\mathrm{K}$, which indicates that the agromineral constitutes an efficient source to supply K to crops.

Keywords: agromineral silicático; multinutrient; agronomic efficiency. 


\subsection{INTRODUÇÃO}

A agricultura moderna tem como principal desafio aliar a obtenção de máxima produção econômica à conservação ambiental. Dentre as estratégias possíveis, para Castro et al. (1987), todas implicam necessariamente na adoção de técnicas produtivas fundamentadas em conhecimentos sobre os fatores de produção vegetal.

Com relação aos fatores edáficos, importa reconhecer que todos os elementos químicos de nutrição das plantas, com exceção do nitrogênio, provêm do solo (Malavolta, 1979). Porém, conforme descrevem Castro et al. (1987), além dos fatores climáticos, e da própria espécie vegetal, a utilização dos elementos de nutrição pelas plantas está condicionada a fatores físicos, químicos e biológicos do solo.

Existem vários mecanismos e processos nas plantas que determinam a absorção e contribuem para o uso eficiente de nutrientes, que guardam relação estreita com as características fisiológicas e morfológicas (Fageria e Baligar, 1993). Fato é que, conforme descrito em Prado (2008), a extração dos nutrientes do solo acompanha a curva de crescimento da planta, e o acúmulo de nutrientes no tecido vegetal, via de regra, reflete sua exigência nutricional ao longo do cultivo.

Os estudos de absorção de nutrientes pelas plantas revelam-se úteis à melhoria da eficiência no uso dos fertilizantes e, por isso, tanto os fatores da própria planta (Lucchesi, 1987), quanto os fatores ambientais (Castro et al., 1987) são igualmente importantes na avaliação da dinâmica de liberação dos nutrientes no solo.

A eficiência no uso de nutrientes pode ser entendida como a habilidade de uma espécie ou genótipo em promover altas produções mesmo em condições de baixa disponibilidade de determinado nutriente (Graham, 1984), ou a relação entre produção e concentração do nutriente no tecido (Lauchli, 1987). A partir dessa compreensão sobre eficiência nutricional, muitos indicadores foram propostos a fim de expressar as relações entre o conteúdo de nutrientes na planta e a produção de matéria seca: eficiência de absorção (Swiader et al., 1994); eficiência de translocação (Li et al., 1991); eficiência de utilização (Siddiqi e Glass, 1981).

Todavia, embora o processo de absorção de nutrientes seja específico e seletivo, a composição mineral das plantas é determinada por interações de natureza complexa envolvendo os diferentes elementos (Olsen, 1972). Portanto, frente à busca da produção máxima das culturas, além de conhecer os teores adequados de nutrientes nas plantas, importa também considerar o balanceamento, ou o equilíbrio entre os nutrientes no sistema solo-planta (Malavolta et al., 1997). Inúmeras interações entre os elementos de nutrição são descritas na literatura, mas aos objetivos e condições experimentais do presente estudo, interessa os elementos $\mathrm{K}$, Ca e Mg.

Na avaliação de fontes alternativas de nutrientes, como são os materiais originados de rochas aplicados in natura, Resende et al. (2012) destacam a importância de buscar embasamento em informações e critérios resultantes da experimentação agronômica, conforme a natureza e constituição de cada material. Para os autores, uma vez determinada a composição química do material, estudos em casa de vegetação são 
necessários na determinação do potencial no suprimento imediato e residual de nutrientes para as plantas, complementados por estudos a campo para correto dimensionamento das recomendações de uso.

A Lei 12.890/2013 enquadra o agromineral silicático em uma nova categoria de insumo agrícola: remineralizadores - o material de origem mineral que tenha sofrido apenas redução e classificação de tamanho por processos mecânicos e que altere os índices de fertilidade do solo por meio da adição de macro e micronutrientes para as plantas, bem como promova a melhoria das propriedades físicas ou físico-químicas ou da atividade biológica do solo.

Dentre os critérios e parâmetros de especificação para registro e comercialização dos remineralizadores de solo, a exemplo dos demais insumos destinados à agricultura, além das características físicas e químicas do produto, discute-se a necessidade de pareceres de viabilidade do uso agrícola obtido mediante a experimentação agronômica, seja em condições controladas em casa de vegetação ou em condições de campo.

\subsection{OBJETIVOS}

\section{Objetivo Geral}

Avaliar a eficiência do agromineral silicático na disponibilidade de nutrientes (sistema mineral-solo-solução) e na nutrição de plantas ao longo do tempo (sistema mineral-solosolução-planta).

\section{Objetivos Específicos}

- Avaliar os efeitos iniciais e ao longo do tempo do agromineral sobre os atributos físico-químicos do solo, especialmente na disponibilidade $\mathrm{K}$, Ca e Mg;

- Avaliar o potencial de fornecimento de nutrientes pelo agromineral comparativamente a fontes minerais solúveis em ciclos sucessivos de cultivo;

- Estimar a dose do agromineral capaz de promover efeitos equivalentes às fontes solúveis de nutrientes (cloreto de potássio).

\subsection{MATERIAL E MÉTODOS}

A abordagem adotada segue as orientações propostas no Protocolo de Avaliação Agronômica de Rochas e Produtos Derivados como Fontes de Nutrientes ou Condicionadores de Solo (Resende et al., 2012). Assim, o presente trabalho compreende um experimento de incubação e cultivo de plantas em vasos, em casa de vegetação, realizado nas instalações do Centro de Ciências Agrárias (CCA/UNITINS).

Trata-se de um experimento personalizado, pois os tratamentos são definidos em função das características mineralógicas e químicas peculiares da fonte alternativa de nutrientes (FAN), no caso o agromineral silicático. 


\subsubsection{Características do agromineral silicático e do solo}

O material em estudo compreende os resíduos minerais do Garimpo de Esmeraldas de Monte Santo, Tocantins. Nos estudos de caracterização petrográfica e textural foram identificadas as rochas predominantes com a seguinte estimativa de composição modal (\% em massa): biotita gnaisse composto por plagioclásio (70\%), biotita (17\%), granada (7\%), ortoclásio (4\%), além de quartzo e calcita; e anfibolito composto de hornblenda (65\%), biotita (25\%), plagioclásio (4\%), calcita (3\%), além de quartzo, clorita e óxidos de ferro como minerais acessórios.

A composição química do agromineral (rocha total) é apresentada na Tabela 4.1 para elementos maiores e alguns elementos traços. Os elementos considerados micronutrientes ocorrem com consideráveis teores (ppm): Mo (2,8); Cu (27,0); Zn $(53,0)$; Co $(34,3)$; B $(3,0)$. Os teores de elementos traços deletérios a saúde humana são considerados baixos: As (0,6); Cd (<0,1); Pb $(3,2)$; $\mathrm{Cr}(0,09)$; Ni $(83,2)$.

Tabela 4.1. Teores dos elementos maiores totais no agromineral (\% em massa).

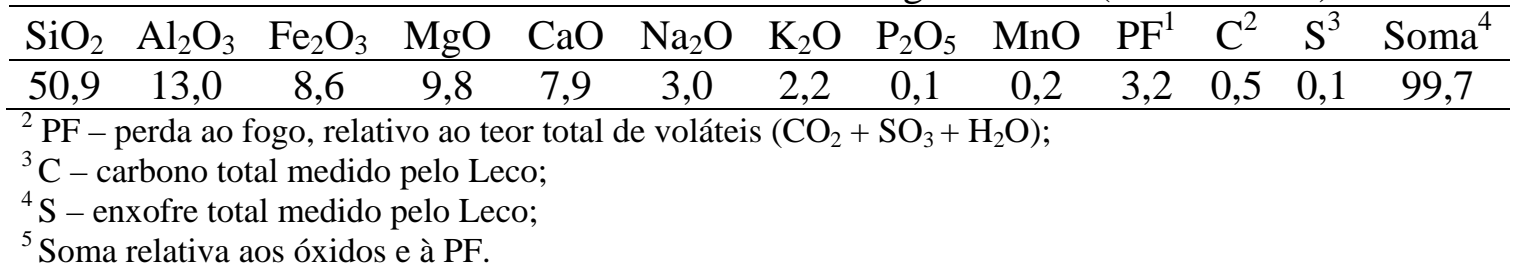

O agromineral foi obtido pela moagem dos resíduos em uma indústria de calcário, e conforme classificação da ABNT (ABNT/NBR 6502/95) apresenta 87\% das partículas na fração “areia” (0,06 a $2 \mathrm{~mm}), 21 \%$ na fração "silte” (0,002 a 0,06 mm), e $6 \%$ na fração "argila” $(<0,002 \mathrm{~mm})$.

O solo utilizado no experimento pode ser caracterizado como areia quartzosa (RADAMBRASIL, 1983), ou Neossolo Quartzarênico (Embrapa, 2006), com apenas $12 \%$ das partículas na fração “argila”. Os atributos físicos e químicos são apresentados na Tabela 4.2, com destaque para a elevada acidez ( $\mathrm{pH} 4,7)$, e baixa disponibilidade natural de potássio (12 $\mathrm{mg} \mathrm{dm}^{-3}$ ) (Sousa \& Lobato, 2004a).

A composição mineralógica do solo, aferida a partir da análise de difratometria de raios-X, no Laboratório de Raio-X do Instituto de Geociências da Universidade de Brasília - IGD/UnB, revelou a presença de caulinita, gibbsita e quartzo.

Tabela 4.2. Atributos físico-químicos originais do Neossolo Quartzarênico.

\begin{tabular}{cccccccc}
\hline $\mathrm{pH}$ & $\mathrm{P}$ & $\mathrm{K}$ & $\mathrm{Al}$ & $\mathrm{Ca}+\mathrm{Mg}$ & $\mathrm{Ca}^{++}$ & $\mathrm{H}+\mathrm{Al}$ & $\mathrm{MO}$ \\
\hline $\mathrm{CaC} 12$ & $\ldots \ldots \ldots . \mathrm{mg} / \mathrm{dm}^{3}$ & & $\ldots \ldots \ldots \ldots \ldots . \mathrm{m} . \mathrm{e} . / 100 \mathrm{cc} \ldots \ldots \ldots \ldots$. & $\%$ \\
\hline 4,7 & 4,0 & 17,0 & 1,1 & 0,5 & 0,4 & 3,3 & 2,0 \\
\hline
\end{tabular}

\subsubsection{Composição dos tratamentos e condições de controle}

O solo amostrado na profundidade $0-20 \mathrm{~cm}$ foi destorroado e dele retiradas raízes e demais fragmentos. Em seguida, o solo foi dividido em subamostras, e nessas aplicados os tratamentos, com os quais foram preenchidos os vasos de 8,3 kg de solo. 
Os tratamentos foram definidos em função das características mineralógicas e químicas do agromineral, com vistas a permitir suficientes evidências dos seus efeitos sobre os atributos do solo, e na nutrição e crescimento das plantas.

Seguindo um delineamento experimental de blocos casualizados, o experimento é composto de 14 tratamentos principais ( 1 a 14), e mais 05 tratamentos adicionais ( 15 a 19) conduzidos na ausência de plantas, todos com três repetições. Conforme se observa na Tabela 4.3, os tratamentos envolvem a utilização do agromineral como fonte de $\mathrm{K}$ em doses crescentes (50, 100, 150 e $300 \mathrm{mg} \mathrm{kg}^{-1}$ de $\mathrm{K}$ ), como potencial fonte de outros nutrientes (Ca, Mg e micronutrientes), e corretivo de acidez do solo.

No cálculo das quantidades do agromineral adicionada nos tratamentos foi considerado o teor total de $\mathrm{K}$, ou seja, 18,3 $\mathrm{g} \mathrm{kg}^{-1}\left(22,1 \mathrm{~g} \mathrm{~kg}^{-1}\right.$ de $\left.\mathrm{K}_{2} \mathrm{O}\right)$ Assim, as quantidades do agromineral calculadas para os tratamentos (doses de 50 a $300 \mathrm{mg} \mathrm{kg}^{-1}$ de $\mathrm{K}$ ) equivalem a aplicações que variam de 5,5 a $33 \mathrm{t} \mathrm{ha}^{-1}$ considerando uma incorporação a $20 \mathrm{~cm}$ de profundidade no solo. Dada a massa de solo dos vasos, as doses representam aplicações de 27,3 a 163,6 g vaso $^{-1}$ do agromineral.

Além desses, o experimento envolve tratamentos caracterizados pela utilização apenas de fontes solúveis (produtos p.a.) para permitirem contrastes ou servirem de referência para aferir a eficiência agronômica relativa do agromineral (Tabela 4.3).

Conforme descrito em Novais et al. (1991), a obtenção de adequadas condições ao cultivo em vasos são fundamentais para garantir efetividade na avaliação de fontes de nutrientes. Portanto, foi realizada adubação via reagentes p.a. nos tratamentos, ou seja, fornecido N, P, K, S, B, Cu, Mn, Zn e Mo nas quantidades de 325, 250, 150, 30, 0,5, 2, 3, 4 e 0,25 mg kg-1 respectivamente. A aplicação de corretivo de acidez do solo com uma mistura $\mathrm{CaCO}_{3}+\mathrm{MgO}$ p.a., na proporção Ca:Mg de 3:1, foi realizada para elevar a saturação por bases a $60 \%(\mathrm{~V})$.

Tabela 4.3. Tratamentos de avaliação do potencial do agromineral silicático na disponibilidade de nutrientes no solo e na nutrição de plantas cultivadas.

\begin{tabular}{|c|c|c|c|c|}
\hline Tratamento & Dose de K & Corretivo & $\mathrm{KCl}$ & Outros $^{1}$ \\
\hline \multicolumn{5}{|c|}{ Com plantas - efeitos na nutrição e produção de matéria seca } \\
\hline 1. Testemunha absoluta & & - & - & - \\
\hline 2. Testemunha + calagem & & + & - & - \\
\hline 3. Completo & & + & + & + \\
\hline 4. Completo - calagem & & - & + & + \\
\hline 5. Completo - potássio & & + & - & + \\
\hline 6. Completo - outros & & + & + & - \\
\hline 7. Agromineral $150 \mathrm{~K}$ & 150 & - & - & - \\
\hline 8. Agromineral $150 \mathrm{~K}+$ calagem + outros & 150 & + & + & + \\
\hline 9. Agromineral $150 \mathrm{~K}+$ calagem - outros & 150 & + & - & - \\
\hline 10. Agromineral $150 \mathrm{~K}$ - calagem + outros & 150 & - & + & + \\
\hline 11. Agromineral $50 \mathrm{~K}+$ calagem + outros & 50 & + & - & + \\
\hline 12. Agromineral $100 \mathrm{~K}+$ calagem + outros & 100 & + & - & + \\
\hline 13. Agromineral $150 \mathrm{~K}+$ calagem + outros & 150 & + & - & + \\
\hline 14. Agromineral $300 \mathrm{~K}+$ calagem + outros & 300 & + & - & + \\
\hline
\end{tabular}




\begin{tabular}{llccc}
\hline \multicolumn{5}{c}{ Sem plantas - efeitos nos atributos do solo } \\
\hline 15. & Testemunha absoluta & & & \\
\hline 16. & Completo & + & + & + \\
\hline 17. & Completo $-\mathrm{K}$ & + & - & + \\
\hline 18. & Agromineral 150 & - & - & - \\
\hline 19. & Agromineral $150+$ outros & + & + & + \\
\hline
\end{tabular}

${ }^{1}$ Outros: Nitrogênio (N); Fósforo $\left(\mathrm{P}_{2} \mathrm{O}_{5}\right)$; Micros (Zn, Mn, Co, Cu e Mo).

Depois da aplicação dos tratamentos, o solo de cada vaso foi umedecido, e assim mantido incubado por 30 dias. Após esse período foram coletadas amostras para caracterização inicial do efeito dos tratamentos nos atributos químicos do solo. As análises dos atributos químicos do solo seguiram os procedimentos metodológicos descritos em Silva (1999).

Como planta teste foi utilizado o milheto (Pennisetum glaucum (L.) R. Br.), especialmente por tratar-se de uma espécie que apresenta elevada capacidade de absorção e ciclagem de nutrientes (Sanzonowicz \& Mielniczuk, 1985; Rosolem et al., 2005; Torres \& Pereira, 2008).

A semeadura do primeiro cultivo do milheto foi realizada no dia 09/12/2013, mantendo-se 15 plantas por vaso após o desbaste. As irrigações diárias com água deionizada mantiveram a umidade do solo a $80 \%$ da capacidade de campo.

A adubação de cobertura com nitrogênio $(\mathrm{N})$, na forma de nitrato de amônio, foi fracionada em três etapas: aos 15 dias após a semeadura $50 \mathrm{mg} \mathrm{kg}^{-1}$ de $\mathrm{N}$; aos 30 dias mais $100 \mathrm{mg} . \mathrm{kg}^{-1}$ de $\mathrm{N}$; e aos 45 dias mais $50 \mathrm{mg} \mathrm{kg}^{-1}$ de $\mathrm{N}$.

\subsubsection{Parâmetros avaliados e sistematização dos resultados}

O corte do milheto foi realizado aos 60 dias após o plantio, momento em que pelo menos 50\% das plantas apresentava florescimento. A parte aérea das plantas foi pesada e o material submetido à secagem em uma estufa de circulação de ar forçada $\left(60^{\circ} \mathrm{C}\right)$ por 72 horas. Em seguida, amostras de cada tratamento foram submetidas à análise química de tecido vegetal (Malavolta et al., 1997) para quantificação dos teores de nutrientes acumulados nas plantas de milheto em resposta aos diversos tratamentos.

O segundo cultivo de milheto foi iniciado no dia 21/02/2014, visando avaliar o efeito residual dos tratamentos. Nessa fase não foi feita nenhuma adubação de semeadura, e apenas uma adubação de cobertura aos 20 dias após o plantio ( $\mathrm{mg} \mathrm{kg}^{-1}$ de $\mathrm{N})$. Todos os demais procedimentos de condução do experimento seguiram aqueles descritos para o cultivo anterior. A parte aérea foi colhida aos 55 dias, da qual determinou-se a produção de matéria seca e a concentração de nutrientes.

A partir dos dados de absorção de nutrientes, especialmente $K$, produção de matéria seca, e teores de nutrientes no solo, conforme descrito em Moll et al. (1982), Goedert e Lopes (1987), e Novais e Smyth (1999), foram determinados os índices de eficiência de absorção (EA), eficiência de utilização (EU), eficiência do fertilizante (EF), eficiência agronômica relativa (ER) e o índice eficiência agronômica (IEA). 


$$
\begin{aligned}
& \mathrm{EA}=\left(\mathrm{K} \text { acumuladoPlantaTeste } / \mathrm{K} \text { aplicado }{ }_{\text {Tratamento }}\right) \\
& \mathrm{EU}=\text { (Massa secaplantaTeste } / \mathrm{K} \text { acumulado } \text { PlantaTeste }) \\
& \mathrm{EF}=\left(\text { Massa seca }{ }_{\text {PlantaTeste }} / \mathrm{K} \text { aplicado } \text { Tratamento }\right) \\
& \mathrm{ER}=100 *\left(\mathrm{~K} \text { acumulado } \text { Tratamento } / \mathrm{K} \text { acumulado }_{\mathrm{KCl}}\right)
\end{aligned}
$$

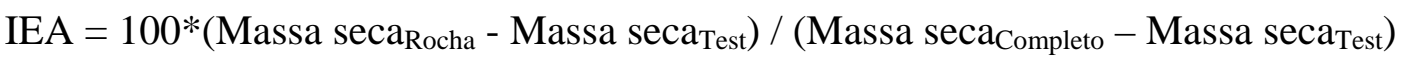

Todos os resultados foram testados estatisticamente, variância e teste de média a $1 \%$ e $5 \%$ de probabilidade. As respostas às doses do agromineral silicático foram avaliadas por regressão, considerando-se o teor de potássio disponível no solo, a produção de matéria seca, e a absorção de potássio pelas plantas.

Nos tratamentos sem plantas (Tabela 3), amostras foram coletadas e analisadas periodicamente ao longo de 150 dias com o propósito de avaliar os efeitos do agromineral sobre os atributos do solo. As análises de macro e micronutrientes foram realizadas conforme metodologias descritas em Silva (1999).

\subsection{RESULTADOS E DISCUSSÃO}

\subsubsection{Efeitos iniciais e de longo prazo sobre os atributos do solo}

Os efeitos iniciais da aplicação dos tratamentos no solo, decorrentes da incubação por 30 dias, são avaliados pela análise dos parâmetros de fertilidade do solo (Tabela 4.4). De maneira geral, as alterações promovidas são coerentes com os tratamentos aplicados.

No que diz respeito aos efeitos particulares do agromineral (Tabela 4.4), conforme esperado, observa-se que a omissão do fornecimento de $\mathrm{K}$ no tratamento (Completo-K) resultou em baixa disponibilidade do elemento no solo, permitindo evidenciar o efeito do agromineral como fonte desse nutriente. Nota-se ainda efeitos positivos sobre os teores de Ca e Mg, com aumento do $\mathrm{pH}$ e da CTC, porém, menores que os incrementos registrados no tratamento testemunha+calagem.

A análise da Figura 4.1 mostra que a liberação inicial de $\mathrm{K}$ do agromineral é proporcional à dose aplicada, pois houve aumento linear na disponibilidade de $\mathrm{K}$ com as doses crescentes do agromineral. O mesmo foi verificado por Resende et al. (2006), porém, para conforme Machado et al. (2005) a solução ácida do extrator Mehlich 1 promove a solubilização das rochas, superestimando a disponibilidade do nutriente.

Ainda assim, mesmo na maior dose aplicada (300 mg $\mathrm{kg}^{-1}$ de K) a disponibilidade de $\mathrm{K}$ foi menor que a registrada com a aplicação do nutriente via fonte solúvel (150 mg kg ${ }^{-1}$ ). Mas como a dissolução do agromineral se prolonga com o tempo de reação com o solo, a dinâmica de liberação torna-se gradual, com efeitos positivos sobre a redução das perdas de $\mathrm{K}$ por lixiviação. Conforme apresentado e discutido sequencialmente, a eficiência do agromineral no suprimento de K não foi comprometida pela moderada solubilidade dos minerais silicáticos. 
Tabela 4.4. Médias dos atributos químicos do solo após aplicação e incubação do agromineral e demais tratamentos por 30 dias.

\begin{tabular}{|c|c|c|c|c|c|}
\hline Tratamento & $\mathrm{pH}$ & $\mathrm{K}$ & $\mathrm{Ca}$ & $\mathrm{Mg}$ & CTC \\
\hline & & \multicolumn{4}{|c|}{----------- $\mathrm{cmol}_{\mathrm{C}} \mathrm{dm}^{-3}$------------ } \\
\hline 1. Testemunha absoluta & $4,3 \mathrm{~h}$ & $0,03 \mathrm{~d}$ & $0,1 \mathrm{~d}$ & $0,0 \mathrm{~d}$ & $2,4 \mathrm{e}$ \\
\hline 2. Testemunha + calagem & $7,0 \mathrm{a}$ & $0,07 \mathrm{~d}$ & $2,4 \mathrm{c}$ & $0,8 \mathrm{~b}$ & $3,6 \mathrm{e}$ \\
\hline 3. Completo & $6,4 \mathrm{c}$ & $0,52 \mathrm{~b}$ & $4,1 \mathrm{~b}$ & $0,7 \mathrm{~b}$ & $5,9 \mathrm{c}$ \\
\hline 4. Completo - calagem & $4,9 \mathrm{~g}$ & $0,75 \mathrm{a}$ & $2,3 \mathrm{c}$ & $0,2 \mathrm{~d}$ & $6,4 \mathrm{c}$ \\
\hline 5. Completo - potássio & $6,0 \mathrm{~d}$ & $0,06 \mathrm{~d}$ & $6,9 \mathrm{a}$ & $1,1 \mathrm{a}$ & $9,3 \mathrm{a}$ \\
\hline 6. Completo - outros & $7,0 \mathrm{a}$ & $0,53 \mathrm{~b}$ & $2,1 \mathrm{c}$ & $0,7 \mathrm{~b}$ & $3,7 \mathrm{~d}$ \\
\hline 7. Agromineral 150K & $6,0 \mathrm{~d}$ & $0,22 \mathrm{c}$ & $1,4 \mathrm{c}$ & $0,3 \mathrm{~d}$ & $3,9 \mathrm{~d}$ \\
\hline 8. Agromineral 150K+calagem+outros & $6,3 \mathrm{c}$ & $0,52 \mathrm{~b}$ & $7,1 \mathrm{a}$ & $1,0 \mathrm{a}$ & $9,7 \mathrm{a}$ \\
\hline 9. Agromineral 150K+calagem-outros & $7,2 \mathrm{a}$ & $0,27 \mathrm{c}$ & $2,8 \mathrm{c}$ & $0,5 \mathrm{c}$ & $3,9 \mathrm{~d}$ \\
\hline 10. Agromineral $150 \mathrm{~K}$-calagem+outros & $5,7 \mathrm{e}$ & $0,26 \mathrm{c}$ & $4,6 \mathrm{~b}$ & $0,3 \mathrm{c}$ & $7,5 \mathrm{~b}$ \\
\hline 11. Agromineral 50K+calagem+outros & $5,4 \mathrm{f}$ & $0,06 \mathrm{~d}$ & $5,0 \mathrm{~b}$ & $0,4 \mathrm{c}$ & $7,7 \mathrm{~b}$ \\
\hline 12. Agromineral $100 \mathrm{~K}+$ calagem+outros & $6,1 \mathrm{~d}$ & $0,07 \mathrm{~d}$ & $6,4 \mathrm{a}$ & $1,1 \mathrm{a}$ & $10,0 \mathrm{a}$ \\
\hline 13. Agromineral $150 \mathrm{~K}+$ calagem+outros & $6,4 \mathrm{c}$ & $0,08 \mathrm{~d}$ & $6,5 \mathrm{a}$ & $0,8 \mathrm{~b}$ & $9,0 \mathrm{a}$ \\
\hline 14. Agromineral 300K+calagem+outros & $6,6 \mathrm{~b}$ & $0,16 \mathrm{~d}$ & $6,7 \mathrm{a}$ & $0,9 \mathrm{~b}$ & $9,5 \mathrm{a}$ \\
\hline $\mathrm{CV}(\%)$ & 1,9 & 21,8 & 20,0 & 19,9 & 13,5 \\
\hline Média Geral & 6,1 & 5,0 & 4,4 & 0,6 & 6,8 \\
\hline
\end{tabular}

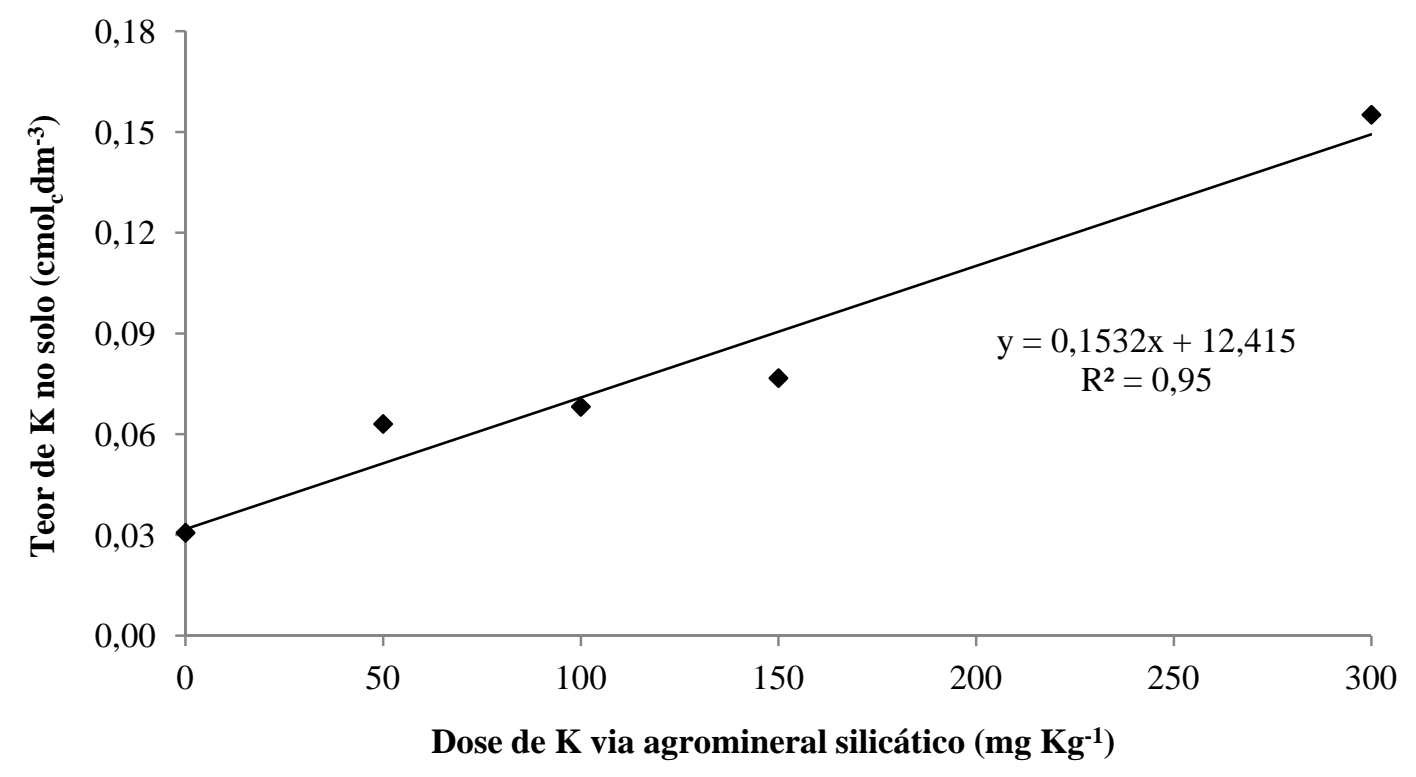

Figura 4.1. Disponibilidade de potássio no solo (Mehlich 1) em função da aplicação e incubação de doses crescentes do agromineral silicático, depois de 30 dias.

Os efeitos dos diferentes tratamentos resultaram em pequena variação nos teores de K disponível ao longo do tempo. Nos tratamentos que receberam aplicação do agromineral silicático, isoladamente e em associação a outros nutrientes, a liberação de $\mathrm{K}$ se deu de forma imediata, porém, a disponibilidade de K obtida foi 32\% menor que a registrada com a mesma dose da fonte solúvel ( $\mathrm{KCl})$. 
A máxima disponibilidade de $\mathrm{K}$ obtida com o agromineral foi de $150 \mathrm{mg} \mathrm{dm}^{-3}$, dos quais $25 \mathrm{mg} \mathrm{dm}^{-3}$ correspondentes à reserva prontamente disponível do solo sob o efeito da aplicação de corretivo e outros nutrientes (Completo-K). Os resultados da aplicação do agromineral, quando comparados aos valores de referência para a recomendação de adubação (Raij et al., 1996; Sousa \& Lobato, 2004a), revelam seu potencial no suprimento da demanda nutricional de muitas culturas.

Em se tratando de um sistema fechado, sem lixiviação ou exportação via colheitas, a liberação do K é limitada pela saturação de diferentes espécies iônicas em solução, em grande parte resultantes das reações de dissolução do próprio agromineral. Conforme será demonstrado a seguir, na presença de plantas atuando como dreno de K as reações de dissolução do agromineral são favorecidas, com incremento na quantidade total de K disponibilizado ao longo dos ciclos de cultivo.

\subsubsection{Efeitos sobre o crescimento e a absorção de nutrientes pelas plantas}

Os efeitos do agromineral enquanto fonte alternativa de nutrientes são demonstrados no desenvolvimento das plantas, e na absorção e acúmulo de nutrientes no tecido vegetal. Na Tabela 4.5 são resumidos os resultados obtidos pelas análises de variância conjunta para os 12 tratamentos e os 02 ciclos de cultivo, e respectivos aspectos avaliados. Todos os parâmetros analisados apresentaram variação significativa entre os tratamentos e os ciclos de cultivo, e também para a interação desses.

Tabela 4.5. Resumo das análises de variância conjunta para Matéria Seca (MS) e Teores de Potássio (K), Cálcio (Ca) e Magnésio (Mg) para diferentes Tratamentos (T) em dois ciclos de cultivo de milheto (C).

\begin{tabular}{lccccc}
\hline \multirow{2}{*}{ Fontes de Variação } & \multicolumn{5}{c}{ Quadrados Médios } \\
\cline { 2 - 6 } & GL & MS & K & Ca & Mg \\
\hline Tratamentos (T) & 11 & $1795,54^{*}$ & $255,71^{*}$ & $34,74^{*}$ & $44,95^{*}$ \\
Ciclos (C) & 1 & $5133,04^{*}$ & $318,48^{*}$ & $13,82^{*}$ & $56,97^{*}$ \\
Interação (TxC) & 11 & $343,73^{*}$ & $11,08^{*}$ & $8,71^{*}$ & $11,86^{*}$ \\
Bloco & 2 & 1,49 & 2,45 & 6,62 & 6,49 \\
Resíduo & 46 & 5,42 & 2,39 & 2,28 & 1,72 \\
\hline CV (\%) & 8,34 & 10,91 & 14,45 & 25,71 \\
\hline Médias & 27,92 & 14,18 & 10,44 & 5,10 \\
\hline * significativo a 5\% de probabilidade pelo teste F.
\end{tabular}

Os dados de produção de matéria seca da parte aérea do milheto em ambos os cultivos são apresentados na Tabela 4.6. Os resultados demonstram que os principais fatores limitantes da fertilidade do solo utilizado no experimento obedecem à seguinte ordem decrescente de restrição ao desenvolvimento das plantas: acidez do solo (tratamento 4); em menor intensidade pela deficiência de potássio (tratamento 5); e na sequencia pela deficiência dos outros nutrientes (tratamento 6). 
Tabela 4.6. Média de produção de matéria seca da parte aérea (MSPA) do milheto para os diferentes tratamentos, em dois ciclos de cultivo.

\begin{tabular}{|c|c|c|c|}
\hline Tratamento & Ciclo 1 & Ciclo & \\
\hline & \multicolumn{3}{|c|}{ Matéria Seca $\left(\right.$ g vaso $^{-1}$ ) } \\
\hline 1. Testemunha absoluta & $0,2 \quad--$ & 0,2 & -- \\
\hline 2. Testemunha + calagem & $10,8 \mathrm{~g}$ & 7,0 & $\mathrm{~d}$ \\
\hline 3. Completo & $52,2 \mathrm{~d}$ & 20,3 & $\mathrm{C}$ \\
\hline 4. Completo - calagem & $0,0 \quad--$ & 0,0 & -- \\
\hline 5. Completo - potássio & $11,2 \mathrm{~g}$ & 7,0 & $\mathrm{~d}$ \\
\hline 6. Completo - outros & $15,4 \mathrm{~g}$ & 9,7 & $\mathrm{~d}$ \\
\hline 7. Agromineral $150 \mathrm{~K}$ & $12,4 \mathrm{~g}$ & 7,1 & $\mathrm{~d}$ \\
\hline 8. Agromineral $150 \mathrm{~K}+$ calagem + outros & 75,4 a & 26,0 & $\mathrm{~b}$ \\
\hline 9. Agromineral $150 \mathrm{~K}+$ calagem - outros & $13,0 \mathrm{~g}$ & 6,9 & $\mathrm{~d}$ \\
\hline 10. Agromineral 150K - calagem + outros & $64,5 \mathrm{~b}$ & 34,9 & $\mathrm{a}$ \\
\hline 11. Agromineral 50K + calagem + outros & $25,2 \mathrm{f}$ & 24,9 & $\mathrm{~b}$ \\
\hline 12. Agromineral $100 \mathrm{~K}+$ calagem + outros & $42,8 \mathrm{e}$ & 24,3 & $\mathrm{~b}$ \\
\hline 13. Agromineral $150 \mathrm{~K}+$ calagem + outros & $48,6 \mathrm{e}$ & 27,0 & $\mathrm{~b}$ \\
\hline 14. Agromineral 300K + calagem + outros & $60,0 \quad \mathrm{c}$ & 38,7 & $\mathrm{a}$ \\
\hline
\end{tabular}

No segundo cultivo a produção de matéria seca foi sensivelmente reduzida em relação ao cultivo inicial (Tabela 4.6). A redução na produção resulta da menor disponibilidade de nutrientes em decorrência da substancial remoção dos mesmos pelo primeiro cultivo. De qualquer modo, a comparação dos resultados obtidos nos tratamentos 11, 12, 13 e 14 (doses de agromineral correspondentes a 50, 100, 150 e 300 $\mathrm{mg} \mathrm{kg}^{-1}$ de $\mathrm{K}$ ) com aqueles do tratamento 5 (completo-K), sugere que o agromineral silicático têm efeito potencial no suprimento de K para as plantas, com significativo efeito residual em cultivos sucessivos.

Os resultados comparativos dos tratamentos 7 e 2 revelam os efeitos do agromineral como corretivo de acidez, e fonte de cálcio e magnésio. Tais efeitos são ainda evidentes pelos resultados obtidos no tratamento 10, o qual apresentou a segunda melhor resposta de produção de matéria seca no acumulado dos dois ciclos de cultivo. A melhor resposta foi obtida no tratamento 8, demonstrando não ter ocorrido interações negativas que pudessem limitar a disponibilidade de nutrientes ao ponto de comprometer o crescimento e desenvolvimento das plantas.

Outra importante constatação foi o incremento da produção de matéria seca em resposta às doses crescentes de agromineral, havendo incremento de produção até a maior dose (300 mg kg-1 de K). Na Figura 4.2 são representas as respostas das plantas às doses de agromineral, e o ponto de equivalência em relação ao tratamento referência (completo), obtido com a aplicação de $6 \mathrm{t} \mathrm{ha}^{-1}$ de agromineral (161 $\mathrm{mg} \mathrm{kg}^{-1}$ de K).

Esses resultados demonstram que o agromineral têm efeitos potenciais como fonte de potássio, de cálcio e de magnésio. Mas, em se tratando de um material de composição multimineral e multinutriente, os efeitos positivos do agromineral também podem estar relacionados a outros elementos de nutrição das plantas. 


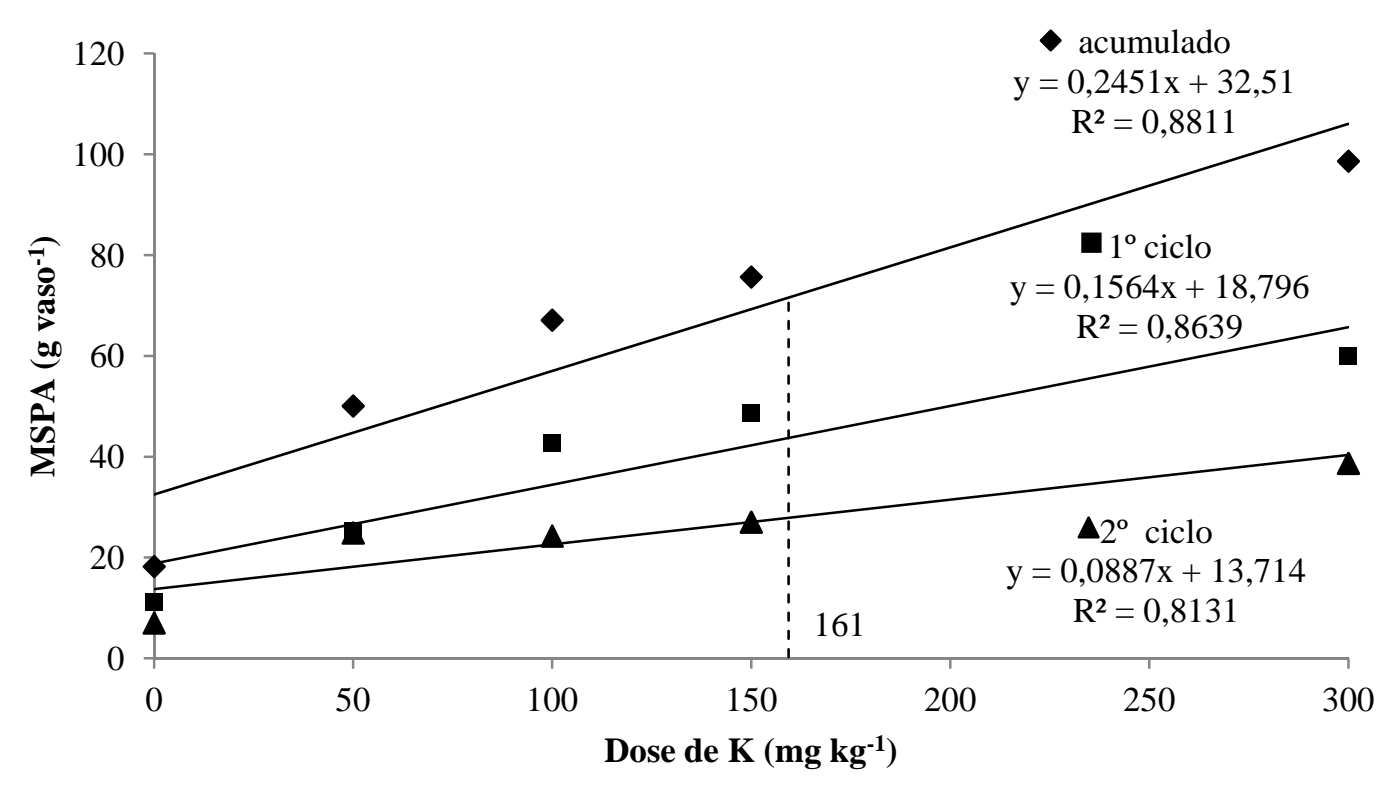

Figura 4.2. Produção de matéria seca da parte aérea (MSPA), dos cultivos sequenciais e do acumulado, em função de doses crescentes de potássio aplicadas via agromineral.

De qualquer maneira, reconhece-se que os efeitos do agromineral extrapolam as respostas normalmente observadas com os fertilizantes solúveis, especialmente pelos benefícios aditivos, como o melhor equilíbrio nutricional e o condicionamento do solo.

Os teores e o acúmulo de nutrientes na matéria seca do milheto (Tabelas 4.7 e 4.8), referentes ao primeiro e segundo cultivos, confirmam as tendências relatadas para os efeitos dos tratamentos em relação à disponibilidade de nutrientes no solo e ao desenvolvimento das plantas. 
Tabela 4.7. Teores de macro e micronutrientes na parte aérea do milheto em resposta a alguns tratamentos.

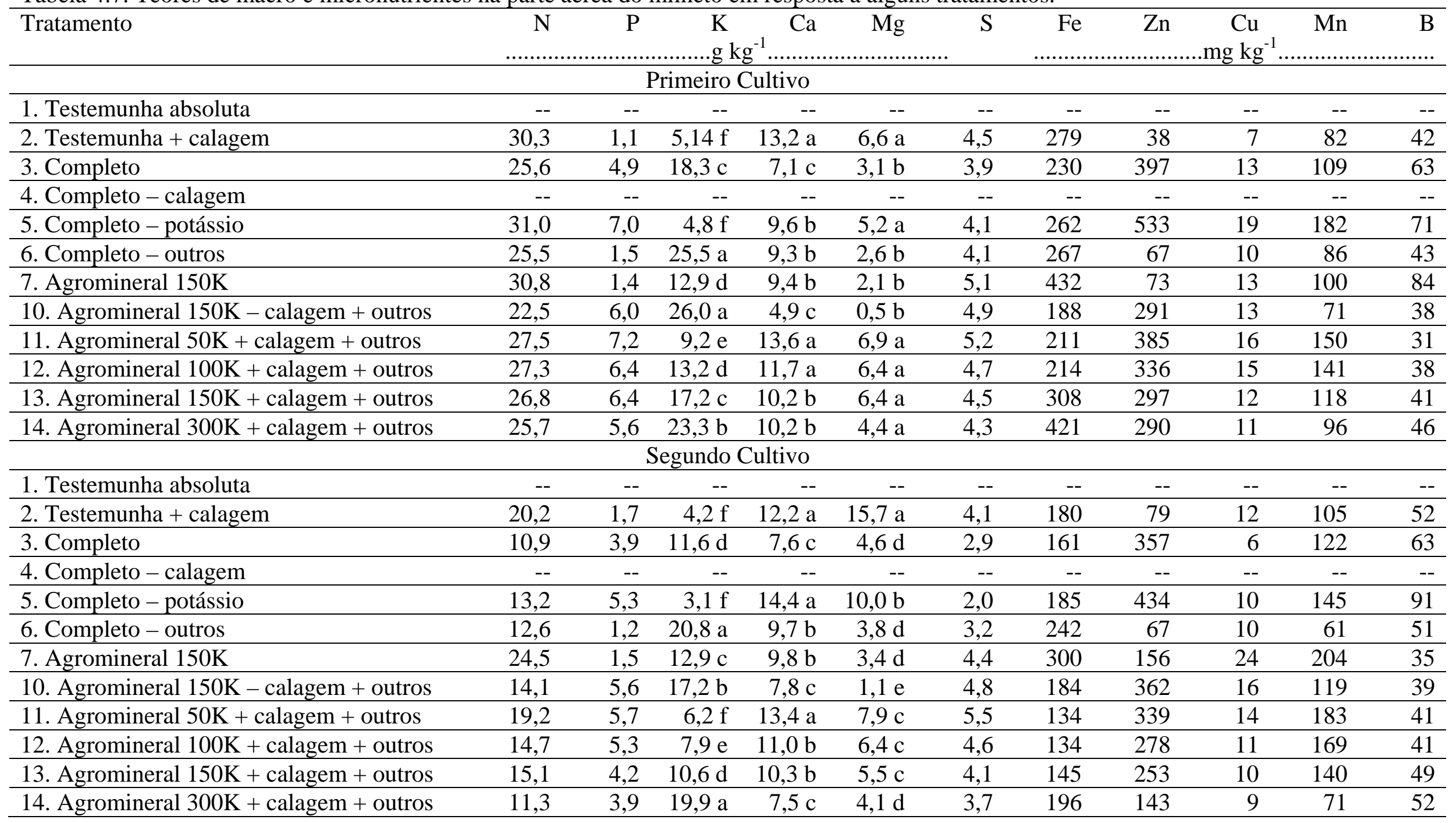


Tabela 4.8. Acúmulo de macro e micronutrientes na parte aérea do milheto em resposta a alguns tratamentos.

\begin{tabular}{|c|c|c|c|c|c|c|c|c|c|c|c|}
\hline Tratamento & $\mathrm{N}$ & $\mathrm{P}$ & $\mathrm{K}$ & $\mathrm{Ca}$ & $\mathrm{Mg}$ & $S$ & $\mathrm{Fe}$ & $\mathrm{Zn}$ & $\mathrm{Cu}$ & $\mathrm{Mn}$ & B \\
\hline & & & ng vas & & & & & & 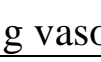 & & \\
\hline 1. Testemunha absoluta & -- & -- & -- & -- & -- & -- & -- & -- & -- & -- & -- \\
\hline 3. Completo & 1338 & 256 & 958 & 371 & 160 & 204 & 12046 & 20750 & 696 & 5710 & 3292 \\
\hline 4. Completo - calagem & -- & -- & -- & -- & -- & -- & -- & -- & -- & -- & -- \\
\hline 5. Completo - potássio & 348 & 79 & 54 & 108 & 58 & 46 & 2939 & 5987 & 221 & 2042 & 796 \\
\hline 10. Agromineral 150K-calagem+outros & 1450 & 385 & 1680 & 318 & 34 & 313 & 12173 & 18775 & 839 & 4602 & 2454 \\
\hline 11. Agromineral $50 \mathrm{~K}+$ calagem+outros & 692 & 181 & 231 & 344 & 173 & 130 & 5313 & 9695 & 420 & 3786 & 802 \\
\hline 12. Agromineral $100 \mathrm{~K}+$ calagem+outros & 1168 & 276 & 564 & 501 & 275 & 201 & 9180 & 14405 & 668 & 6052 & 1649 \\
\hline 13. Agromineral $150 \mathrm{~K}+$ calagem+outros & 1306 & 312 & 839 & 497 & 311 & 219 & 14981 & 14480 & 589 & 5740 & 2010 \\
\hline 14. Agromineral 300K+calagem+outros & 1540 & 333 & 1399 & 612 & 264 & 258 & 25242 & 17388 & 660 & 5798 & 2758 \\
\hline \multicolumn{12}{|c|}{ Segundo Cultivo } \\
\hline 5. Completo - potássio & 93 & 38 & 22 & 101 & 71 & 14 & 1305 & 3056 & 76 & 1025 & 644 \\
\hline 6. Completo - outros & 123 & 12 & 203 & 94 & 37 & 31 & 2354 & 660 & 101 & 597 & 503 \\
\hline 7. Agromineral $150 \mathrm{~K}$ & 174 & 11 & 92 & 70 & 24 & 31 & 2140 & 1113 & 176 & 1452 & 249 \\
\hline 10. Agromineral 150K-calagem+outros & 490 & 196 & 599 & 271 & 38 & 167 & 6426 & 12642 & 558 & 4160 & 1359 \\
\hline 11. Agromineral $50 \mathrm{~K}+$ calagem+outros & 478 & 141 & 154 & 333 & 196 & 137 & 3343 & 8450 & 365 & 4571 & 1030 \\
\hline 12. Agromineral $100 \mathrm{~K}+$ calagem+outros & 356 & 129 & 191 & 267 & 155 & 112 & 3266 & 6757 & 267 & 4099 & 1006 \\
\hline 13. Agromineral $150 \mathrm{~K}+$ calagem+outros & 408 & 113 & 287 & 278 & 149 & 111 & 3917 & 6843 & 270 & 3782 & 1326 \\
\hline 14. Agromineral $300 \mathrm{~K}+$ calagem+outros & 435 & 150 & 771 & 291 & 157 & 143 & 7604 & 5542 & 348 & 2758 & 2011 \\
\hline
\end{tabular}


Com base nos resultados apresentados na Tabela 4.7, nota-se que os efeitos resultantes do agromineral sobre o crescimento das plantas também são refletidos na absorção de nutrientes, e em níveis correspondentes ao tratamento completo. Os resultados mostram que o agromineral libera $\mathrm{K}, \mathrm{Ca}, \mathrm{Mg}$ e micronutrientes em formas assimiláveis pelas plantas.

Mas a absorção de nutrientes pelas plantas é um processo específico e seletivo, caracterizado por muitas interações que determinam sua composição mineral. A interação é a influência ou ação recíproca de um nutriente sobre o outro (Olsen, 1972), cujos efeitos podem ser antagônicos ou sinérgicos em razão da proporção, das espécies iônicas, da planta e seu estádio de desenvolvimento (Gama, 1977).

A relação entre os elementos na nutrição de plantas e na produção das culturas é bem conhecida (Malavolta et al., 1997). Para Rosolem (2006), dadas as condições de elevada acidez e baixa capacidade de troca de cátions da grande maioria dos solos brasileiros, as interações mais importantes envolvem $\mathrm{K}$, Ca e Mg. Conforme descrito em Prado (2008), o incremento nos teores foliares de K reduzem a absorção de Ca e Mg, mas ainda assim asseguram níveis de produção satisfatórios.

Os resultados obtidos nos diferentes tratamentos com o agromineral mostram que a maior absorção de $\mathrm{K}$, em função das doses crescentes do agromineral, inibiu a absorção e concentração de $\mathrm{Ca}$ e $\mathrm{Mg}$ no tecido vegetal do milheto. Todavia, a concentração desses nutrientes situa-se próxima aos valores de referência encontrados na literatura (Calegari, 1985; Braz et al., 2004; Prado e Vidal, 2008): N (12 a 36); P (0,4 a 3,3); K (14 a 38); Ca (3 a 10,8); Mg (0,7 a 5,1).

Isso confirma que a capacidade de suprimento de $\mathrm{K}$ pelo agromineral não caracterizou consumo de luxo pelas plantas (Malavolta et al., 1997; Rosolem et al., 2003). Conforme já reconhecido, isso decorre do melhor equilíbrio nutricional favorecido pelos efeitos positivos do agromineral.

Os resultados descritos anteriormente são ilustrados na Figura 4.3. Os coeficientes de determinação denotam que a produção de matéria seca em ambos os cultivos foi estritamente condicionada à absorção de K pelas plantas.

No primeiro cultivo, comparativamente à resposta obtida no tratamento 3 (completo), o qual envolve utilização da fonte solúvel KCl (150 mg kg-1 de K), a dose correspondente de K aplicado via agromineral (tratamento 13) acumulou 12\% menos K, e produziu $7 \%$ menos matéria seca. No segundo cultivo, o tratamento com agromineral produziu 33\% mais matéria seca, e acumulou 22\% mais $\mathrm{K}$ do que o tratamento de referência com $\mathrm{KCl}$. 

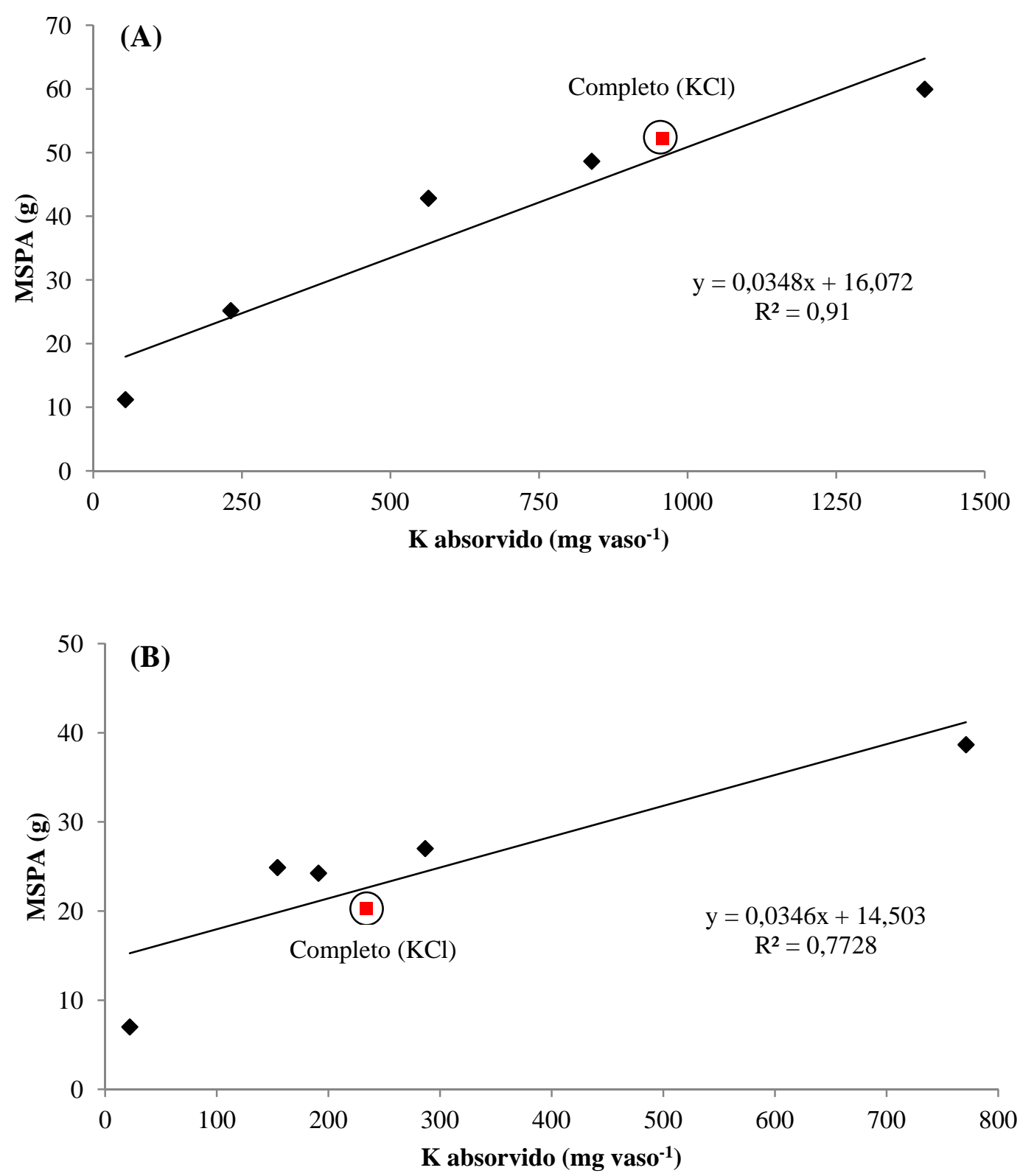

Figura 4.3. Relação entre quantidade de potássio acumulada pelo milheto e produção de matéria seca da parte aérea do primeiro (A) e segundo cultivo (B).

No balanço geral, ou seja, considerando os cultivos sequenciais, o agromineral produziu $9 \%$ mais biomassa, e acumulou apenas $6 \%$ menos $\mathrm{K}$ do que o tratamento de referência com fonte solúvel.

Na Figura 4.4 são representados os resultados que expressam a resposta das plantas frente às doses agromineral (50 a $300 \mathrm{mg} \mathrm{kg}^{-1}$ de $\mathrm{K}$ ) em relação à absorção de $\mathrm{K}$ em cada ciclo de cultivo e o somatório dos efeitos inicial e residual dos tratamentos. $\mathrm{O}$ ponto de equivalência em relação ao tratamento referência (completo) corresponderia à aplicação de $161 \mathrm{mg} \mathrm{kg}^{-1}$ de $\mathrm{K}$ via agromineral. Isso significa que seria necessário aplicar $6 \mathrm{t} \mathrm{ha}^{-1}$ de agromineral para obter os mesmos efeitos da fonte solúvel. 


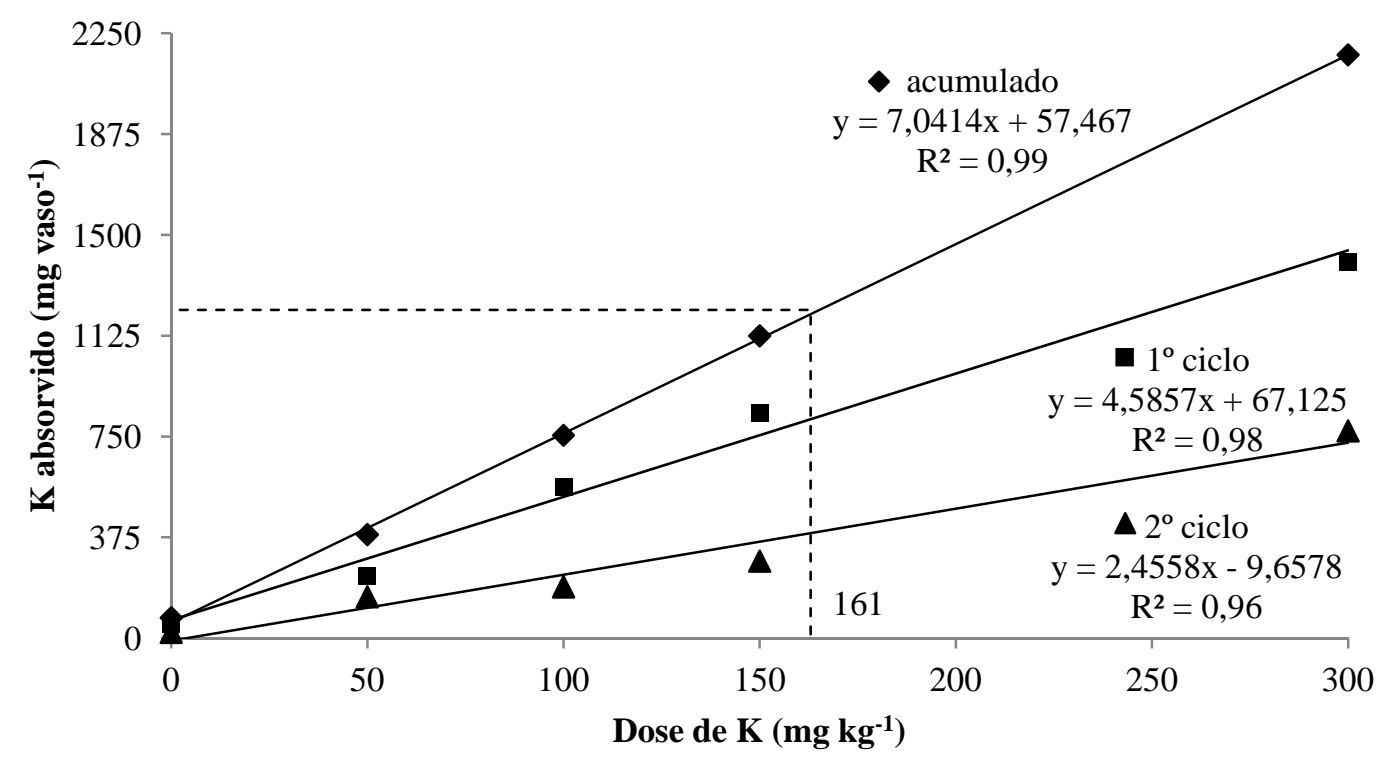

Figura 4.4. Absorção de $\mathrm{K}$ nas plantas dos cultivos sequenciais e do acumulado, em função de doses crescentes de $\mathrm{K}$ aplicadas via agromineral.

Os resultados apresentados permitem algumas constatações: i) em ambos os cultivos a absorção de $\mathrm{K}$ liberado do agromineral apresenta estreita relação com a produção de matéria seca; ii) os efeitos residuais do agromineral são expressivos, pois, em comparação com a fonte solúvel, apresentou maior produção de matéria seca; iii) embora a quantidade de K liberado do agromineral e aproveitado pelas plantas seja considerável, os teores acumulados na parte área das plantas são inferiores aos obtidos no tratamento referência com fonte solúvel.

Diante dos resultados obtidos, considerando que o requerimento de nutrientes para o crescimento de plantas com sistema radicular confinado (vasos) é muito maior que o exigido nos sistemas abertos em condições de campo (Novais et al., 1991), constata-se que os efeitos do agromineral vão além do simples fornecimento de K. Além disso, o fato do agromineral favorecer a absorção de outros nutrientes, os efeitos observados decorrem do estabelecimento de uma condição de equilíbrio nutricional mais favorável ao crescimento das plantas.

\subsubsection{Eficiência relativa das fontes/doses}

Os resultados de acúmulo de nutrientes na matéria seca, frente às doses de agromineral aplicadas, permite comparar os índices de eficiência dos tratamentos com doses crescentes do agromineral e o tratamento completo, e com isso estimar a recuperação dos nutrientes aplicados via agromineral, e sua eficiência agronômica.

A partir da adubação realizada e da extração do $\mathrm{K}$ oriundo das reservas originais do solo (tratamento 3), a qual foi da ordem de $235,6 \mathrm{mg} \mathrm{kg}^{-1} \cdot \mathrm{vaso}^{-1}$, a recuperação do nutriente aplicado via agromineral após dois cultivos do milheto foi de 75, 82, 84 e 85\% 
nos tratamentos equivalentes a 50, 100, 150 e $300 \mathrm{mg} \mathrm{kg}^{-1}$ de $\mathrm{K}$, respectivamente. Esses efeitos estão relacionados à melhoria geral do ambiente de exploração radicular, com reflexos no desenvolvimento das plantas e na absorção de nutrientes.

Na Tabela 4.9 são resumidos os índices de eficiência dos tratamentos com doses crescentes de agromineral e do tratamento referência com fonte solúvel de K. Os índices de eficiência de absorção revelam que a liberação de K do agromineral (tratamento 13) foi pouco menor que a inferida no tratamento referência (tratamento 2), porém, com maior eficiência de utilização do nutriente.

Tabela 4.9. Índices de eficiência relativa do agromineral.

\begin{tabular}{lcccc}
\hline \multirow{2}{*}{ Tratamento } & \multicolumn{4}{c}{ Índices de Eficiência de } \\
\cline { 2 - 5 } & Absorção & Utilização & Fertilizante & Agronômica \\
\hline 3. Completo & 0,96 & 61 & 58 & 100 \\
\hline 11. Agromineral 50K+calagem+ & 0,93 & 130 & 121 & 69 \\
\hline 12. Agromineral 100K+calagem+ & 0,91 & 89 & 81 & 93 \\
\hline 13. Agromineral 150K+calagem+ & 0,90 & 67 & 61 & 104 \\
\hline 14. Agromineral 300K+calagem+ & 0,89 & 45 & 40 & 136 \\
\hline
\end{tabular}

Ainda com base nos índices da Tabela 4.9, nota-se maior eficiência do fertilizante e agronômica do tratamento com agromineral (tratamento 13), em grande parte resultante do fornecimento de $\mathrm{K}$, mas também de outros benefícios adicionais na nutrição das plantas. A eficiência agronômica crescente até a maior dose de agromineral sugere que a aplicação de doses elevadas pode ser vantajosa devido aos efeitos globais sobre os atributos do solo, nutrição das plantas e produção vegetal.

\subsection{CONSIDERAÇÕES COMPLEMENTARES}

Os resultados apresentados demonstram que o agromineral silicático obtido dos resíduos minerais do Garimpo de Esmeraldas de Monte Santo-TO apresenta viabilidade técnica para uso como fonte de potássio (K); libera outros nutrientes como cálcio (Ca) e magnésio (Mg) com efeitos sobre o pH do solo e no desenvolvimento das plantas; e melhora a eficiência dos fertilizantes convencionais.

De qualquer forma, estima-se que a aplicação de $6 \mathrm{t} \mathrm{ha}^{-1}$ de agromineral pode proporcionar ganhos de produtividade, melhoria na fertilidade do solo e redução da necessidade de fertilizantes convencionais para adubação das culturas agrícolas.

A constatação do efeito residual do agromineral em cultivos sucessivos sugere que o uso eficiente do mesmo deve levar em conta o período de tempo ou número de safras em que são verificados incrementos de produtividade, bem como o prazo de amortização dos custos associados a aplicação do agromineral. Para isso são necessários experimentos de média/longa duração, com vários cultivos em condições de campo.

Portanto, para que seja feita recomendação de uso do agromineral silicático fazse necessário a realização de experimentos em condições de campo, mediante o qual serão aferidos os efeitos agronômicos de forma conclusiva. 


\section{CAPÍTULO 5}

\section{POTENCIAL DO AGROMINERAL SILICÁTICO NA CULTURA DA CANA-DE-AÇÚCAR}

Resumo: A rochagem compreende uma técnica de remineralização do solo pela aplicação direta de rochas moídas ao solo, sobretudo daquelas pertencentes ao grupo das rochas silicáticas multinutrientes. O presente trabalho teve como objetivo avaliar o uso de resíduo de mineração como fonte alternativa de nutrientes na produção da cultura da cana-de-açúcar em três ciclos sucessivos de cultivo, a partir dos efeitos sobre aspectos fisiológicos, nutricionais e produtivos da cultura. O agromineral apresenta em sua composição 2,2\% $\mathrm{K}_{2} \mathrm{O}, 7,9 \% \mathrm{CaO}$ e 9,8\% MgO, além de outros elementos considerados micronutrientes para plantas cultivadas, e granulometria $85 \%<0,3 \mathrm{~mm}$. O estudo experimental foi realizado em solo de Cerrado (Neossolo Quartzarênico), na região central do Estado do Tocantins, e considerou duas estratégias de uso do agromineral, em substituição com doses crescentes de agromineral (60, 120 e $240 \mathrm{~kg} \mathrm{ha}^{-1}$ de $\mathrm{K}_{2} \mathrm{O}$ ), e em complementação à fonte convencional de potássio $(\mathrm{KCl})$. Os resultados confirmam que o agromineral pode ser utilizado como fonte alternativa de nutriente, pois seus efeitos mostraram-se iguais aos obtidos com a fonte convencional. Os resultados demonstraram ainda que a dose de resposta ótima situa-se entre 120 e $140 \mathrm{~kg} \mathrm{ha}^{-1}$ de $\mathrm{K}_{2} \mathrm{O}$, obtida com a aplicação de 5,5 a 6,5 t ha ${ }^{-1}$ do agromineral, cujas produtividades foram de 112, $130 \mathrm{e}$ $97 \mathrm{t} \mathrm{ha}^{-1}$ de colmos nos respectivos cultivos. Cabe destacar que a produtividade média dos diferentes tratamentos foi maior que a média $\left(72 \mathrm{t} \mathrm{ha}^{-1}\right.$ ) registrada no Estado do Tocantins, safra 2011/2012.

Palavras-chave: rochagem; agromineral silicático; cana-de-açúcar; cerrado.

Abstract: The stonemeal comprises a remineralization technique soil by direct application of rock crushed to the ground, especially those belonging to the group of silicate rocks multinutrient. This study aimed to evaluate the use of mining waste as an alternative source of nutrients in crop production of cane sugar in three successive cycles of cultivation, from the effects of physiological, nutritional and productive culture. The agromineral presents in its composition $2.2 \% \mathrm{~K}_{2} \mathrm{O}, 7.9 \% \mathrm{CaO}$ and $9.8 \%$ $\mathrm{MgO}$, and other elements considered micronutrients for crops, and 85\% particle size $<0.3 \mathrm{~mm}$. The experimental study was conducted in soil Cerrado (Quartzipsamment), the central region of the State of Tocantins, and considered two agromineral the use of strategies in place with increasing doses of agromineral (60, 120 and $240 \mathrm{~kg} \mathrm{ha}^{-1} \mathrm{~K}_{2} \mathrm{O}$ ), and as a complement to conventional source of potassium $(\mathrm{KCl})$. The results confirm that the agromineral can be used as an alternative nutrient source, because its effects were equal to those obtained with the conventional source. The results also showed that the optimal response dose is between 120 and $140 \mathrm{Kg} \mathrm{ha}^{-1} \mathrm{~K}_{2} \mathrm{O}$, obtained by applying 5.5 to $6.5 \mathrm{t} \mathrm{ha}^{-1}$ agromineral whose yields were 112,130 and $97 \mathrm{tha}^{-1}$ of stems in their crops. It should be noted that the average yield of the different treatments was higher than average $\left(72 \mathrm{t} \mathrm{ha}^{-1}\right)$ registered in the State of Tocantins, 2011/2012.

Keywords: stonemeal; agromineral silicático; sugar cane; cerrado. 


\subsection{INTRODUÇÃO}

A importância socioeconômica da cana-de-açúcar é destacada devido à sua múltipla utilidade, seja como forragem para alimentação animal, ou como matéria-prima para a fabricação de inúmeros produtos. Atualmente, a cana-de-açúcar constitui a principal fonte energética alternativa do Brasil.

De acordo com o Ministério da Agricultura, Pecuária e Abastecimento (MAPA, 2007) a cana-de-açúcar (Saccharum officinarum) é cultivada em todas as regiões, e em extensa área territorial do país, ocupando o terceiro lugar em área plantada, atrás apenas da soja e do milho. Entre 1990 e 2008 a área plantada de cana-de-açúcar no Brasil cresceu 100\%, e a produção 150\% (AGRIANUAL, 2009). Em 2010, a área plantada de cana-de-açúcar no Estado do Tocantins foi de 10,8 mil ha, com produtividade média de 73 ton.ha ${ }^{-1}$, resultando em uma produção de mais de 780 mil toneladas.

Vários estudos comprovam o potencial para a expansão das lavouras canavieiras no Estado do Tocantins (Granja, 2010), especialmente devido às altas temperaturas, luminosidade, e período chuvoso definido. No entanto, como bem aponta Capone et al. (2011) a fertilidade dos solos compreende o principal fator limitante à cultura. Dentre os aspectos adversos ligados à baixa fertilidade dos solos tropicais, merecem destaque a alta acidez, frequentemente associada à toxidez relativa ao alumínio (Al) que afeta cerca de 63\% dos solos (Bot et al., 2000), e as baixas reservas de potássio (Wood et al., 2001), segundo elemento mais consumido na agricultura brasileira (DNPM, 2009).

O elemento potássio (K) é o nutriente mais consumido e exportado pela cana-deaçúcar (Orlando Filho, 1993), e por isso exigido em grandes quantidades. No entanto, além dos solos tropicais serem pobres em minerais contendo K, também apresentam baixa capacidade de retenção de cátions, o que favorece perdas por lixiviação do K oriundo dos fertilizantes (Curi et al., 2005).

Nas últimas décadas a taxa de crescimento do consumo de fertilizantes no Brasil foi de 5,8\% ao ano (ANDA, 2012), que em relação à área plantada representa um aumento de 70 para $155 \mathrm{~kg} \mathrm{ha}^{-1}$ (IBGE, 2012). Nesse contexto, apesar de responder por menos de $1 \%$ do mercado nacional de fertilizantes, o Tocantins apresentou crescimento médio anual da ordem de 15\%, superior ao maior consumidor nacional, o Mato Grosso (12\%), e a estados de maior tradição agrícola como Paraná (5,7\%) e Rio Grande do Sul (3,9\%). Entre 2011 e 2012 o consumo de matérias-primas fertilizantes no Tocantins aumentou 30\% (ANDA, 2012), cujos produtos representaram 73\% do volume total das importações, com destaque para o cloreto de potássio (25\%) que movimentou cerca de US\$ 95 milhões (MDIC/SECEX, 2012).

Mas se o uso de fertilizantes e corretivos no Brasil tem proporcionado aumentos consideráveis de produtividade das principais culturas agrícolas (ANDA, 2003; IBGE, 2005), por outro lado, o International Soil Reference and Information (ISRIC) estima um déficit anual médio de nutrientes de 25 a $35 \mathrm{~kg} \mathrm{ha}^{-1}$ de NPK na agricultura brasileira. Ainda assim, o Brasil ocupa posição de destaque em um cenário global 
marcado por forte aumento da demanda por alimentos acompanhada do crescimento populacional (FAO, 2005).

Neste sentido, além de aumentar a área plantada e a produtividade dos cultivos agrícolas, torna-se igualmente importante e estratégico para o país, reduzir a dependência pelos fertilizantes consumidos na agricultura. Essa situação motivou a articulação e criação da Rede AgriRocha de pesquisa sobre rochas brasileiras como fonte alternativa de nutrientes em sistemas agropecuários.

O presente trabalho compreende parte dos esforços da Rede AgriRocha no Estado do Tocantins, que através de ações compartilhadas no âmbito do Projeto ROCKBIOCOM, volta-se ao desenvolvimento de novas fontes e rotas tecnológicas de agrominerais para a produção de biocombustíveis líquidos.

\subsection{OBJETIVOS}

\section{Objetivo Geral}

Avaliar potencial de uso do agromineral silicático aplicado in natura como fonte alternativa de nutrientes na cultura da cana-de-açúcar.

\section{Objetivos Específicos}

- Avaliar os efeitos comparativos do agromineral em relação ao cloreto de potássio sobre os aspectos fisiológicos, nutricionais e produtivos da cana-de-açúcar;

- Avaliar os efeitos imediatos (cana-planta) e residuais (cana-soca) do agromineral na cultura da cana-de-açúcar;

- Avaliar a viabilidade técnico-econômica do uso do agromineral no manejo da cultura da cana-de-açúcar.

\subsection{MATERIAL E MÉTODOS}

De acordo com Resende et al. (2012), além dos ensaios discriminatórios, a viabilidade técnica para fontes alternativas de nutrientes deve ser complementada com testes em sistema aberto, ou seja, em condições edafoclimáticas mais próximas possível da realidade de manejo agrícola da região potencialmente consumidora.

O material em estudo compreende os resíduos minerais do Garimpo de Esmeraldas de Monte Santo, região Centro-Oeste do Estado do Tocantins. Nos estudos de caracterização petrográfica e textural foram identificados dois litotipos predominantes: o biotita gnaisse cuja composição modal estimada apresenta plagioclásio (70\%), biotita (17\%), granada (7\%), ortoclásio (4\%), além de quartzo e calcita; e o anfibolito composto de hornblenda (65\%), biotita (25\%), plagioclásio (4\%), calcita (3\%), além de quartzo, clorita e óxidos de ferro como minerais acessórios.

A composição química do agromineral (rocha total) é apresentada na Tabela 5.1 para elementos maiores e alguns elementos traços. Os elementos considerados micronutrientes revelam consideráveis teores (ppm): Mo (2,8); Cu (27,0); Zn (53,0); Co 
$(34,3)$; B $(3,0)$. Os teores de elementos traços deletérios a saúde humana são considerados baixos: As (0,6); Cd $(<0,1)$; $\mathrm{Pb}(3,2)$; $\mathrm{Cr}(0,09)$; $\mathrm{Ni}(83,2)$.

Tabela 5.1. Teores dos elementos maiores totais no agromineral (\% em massa).

\begin{tabular}{|c|c|c|c|c|c|c|c|c|c|c|}
\hline $\mathrm{SiO}_{2}$ & $\mathrm{Al}_{2} \mathrm{O}_{3}$ & $\mathrm{Fe}_{2} \mathrm{O}_{3}$ & $\mathrm{MgO}$ & $\mathrm{CaO}$ & $\mathrm{Na}_{2} \mathrm{O}$ & $\mathrm{K}_{2} \mathrm{O}$ & $\mathrm{P}_{2} \mathrm{O}_{5}$ & $\mathrm{MnO}$ & $\mathrm{PF}^{1}$ & Soma $^{2}$ \\
\hline 50,9 & 13,0 & 8,6 & 9,8 & 7,9 & 3,0 & 2,2 & 0,1 & 0,2 & 3,2 & 99,7 \\
\hline
\end{tabular}

O agromineral foi obtido por moagem em uma indústria de calcário da região e apresenta a seguinte distribuição granulométrica: 99,8\% de partículas $<0,8 \mathrm{~mm}$; $88 \%<$ $0,3 \mathrm{~mm} ; 76 \%<0,15 \mathrm{~mm} ; 27 \%<0,06 \mathrm{~mm}$; e $6 \%<0,002$. De acordo com a ABNT (ABNT/NBR 6502/95), o agromineral apresenta 77\% das partículas com granulometria classificada como fração "areia” (<2 mm, > 0,06 mm), 21\% fração "silte" (>0,002 mm, $<0,06 \mathrm{~mm})$, e apenas $6 \%$ como fração "argila” $(<0,002 \mathrm{~mm})$.

\subsubsection{Condições edafoclimáticas do experimento}

O experimento foi conduzido em uma área antes ocupada por uma pastagem (Andropogon gayanus Kunth) formada a cerca de 10 anos, e em estádio avançado de degradação (Centro de Ciências Agrárias/UNITINS, em Palmas-TO). O solo é caracterizado como Neossolo Quartzarênico (RQ), com apenas 12\% de argila, cuja mineralogia é composta basicamente de gibsita, caulinita e quartzo, o que implica baixa fertilidade natural (Tabela 5.2).

Tabela 5.2. Características físico-químicas do solo.

\begin{tabular}{cccccccc}
\hline $\mathrm{pH}$ & $\mathrm{P}$ & $\mathrm{K}$ & $\mathrm{Al}$ & $\mathrm{Ca}+\mathrm{Mg}$ & $\mathrm{Ca}^{++}$ & $\mathrm{H}+\mathrm{Al}$ & $\mathrm{MO}$ \\
\hline $\mathrm{CaC} 12$ & $\ldots \ldots \ldots . \mathrm{mg} / \mathrm{dm}^{3}$ & & $\ldots \ldots \ldots \ldots \ldots \ldots . \mathrm{m} . \mathrm{e} . / 100 \mathrm{cc} \ldots \ldots \ldots \ldots .$. & $\%$ \\
\hline 4,7 & 4,0 & 17,0 & 1,1 & 0,5 & 0,4 & 3,3 & 2,0 \\
\hline
\end{tabular}

Conforme destacado por Resende et al. (2012) em ambientes desse tipo costuma haver diferenças marcantes nas respostas às fontes alternativas de nutrientes (FAN), decorrentes da melhoria na fertilidade do solo e no aumento da produtividade, especialmente na comparação com corretivos e fertilizantes convencionais.

O clima na região é caracterizado como úmido/sub-úmido (C2WA Thornthwaite) com precipitação média anual de 1350 mm e pequena deficiência hídrica. Na Figura 5.1 são sistematizados dados climatológicos do Instituto Nacional de Meteorologia - INMET, obtidos na Estação Automática de Palmas-TO, correspondente ao período de condução do experimento, o qual se estendeu de 17/12/2010 a 06/11/2013, envolvendo 03 ciclos completos de cultivo da cana-de-açúcar.

Com base nesses dados são descritas algumas características gerais das condições climáticas da região. A temperatura apresenta menor variação entre máximas e mínimas durante o período chuvoso (verão) do que na seca (inverno). As máximas $\left(39^{\circ} \mathrm{C}\right)$ são registradas nos meses de setembro e outubro, em grande parte devido a proximidade do início do período chuvoso, e as mínimas $\left(11^{\circ} \mathrm{C}\right)$ em agosto. As maiores médias situam-se próximas de $31^{\circ}$ (chuvas) e as menores de $23^{\circ} \mathrm{C}$ (estiagem). 


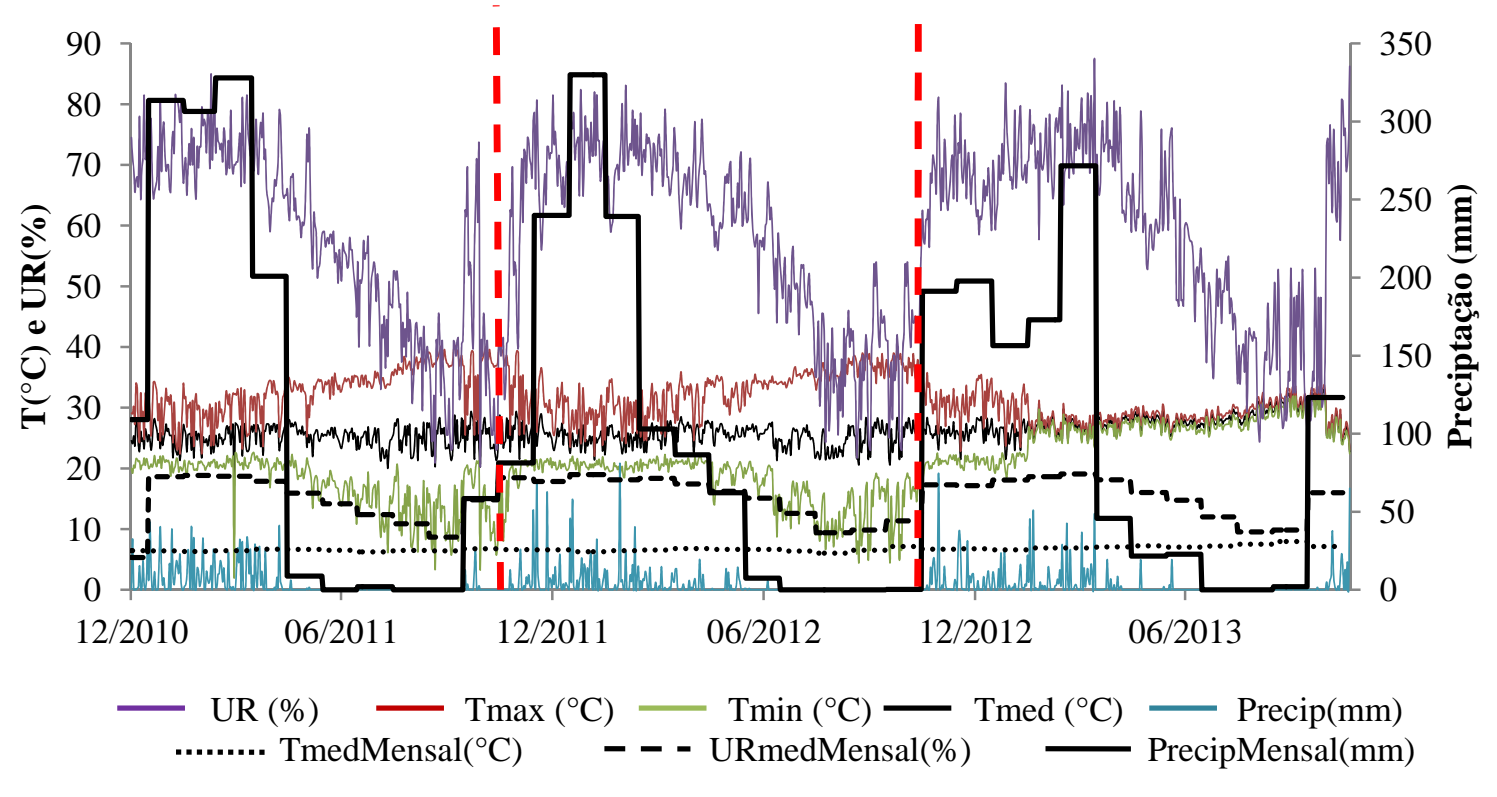

Figura 5.1. Condições climáticas na área e período do experimento.

De maneira geral o período chuvoso inicia-se em outubro, mas as chuvas se tornam mais frequentes na segunda metade de novembro. No primeiro ciclo choveu $1330 \mathrm{~mm}$, com preciptação máxima de $43 \mathrm{~mm}$. As chuvas tiveram início logo após o plantio, com 85 dias de chuva bem distribuídos, favorecendo um bom desenvolvimento as plantas. No segundo ciclo as chuvas iniciaram-se somente depois de 21 dias da colheita da cana-planta. A preciptação total foi de $1150 \mathrm{~mm}$ registrados em 100 dias de chuva, alguns de elevada intensidade, máxima de $81 \mathrm{~mm}$. No terceiro ciclo foram 104 dias de chuva, máxima de $74 \mathrm{~mm}$, e um total $1300 \mathrm{~mm}$ de chuva.

\subsubsection{Composição dos tratamentos e condições controle}

Do ponto de vista operacional os experimentos a campo exigem alguns cuidados adicionais àqueles conduzidos em casa de vegetação. $\mathrm{O}$ aumento da complexidade, em grande parte decorrente de variáveis independentes, remete à opção por um experimento de reduzido número de tratamentos.

O desenho experimental em faixa é constituído por uma variedade, cinco tratamentos e três repetições. As parcelas com dimensões de 16 x 7m, apresentam área útil (AUP) de $74 \mathrm{~m}^{2}$. O espaçamento de plantio seguiu o padrão da região, ou seja, $1 \mathrm{~m}$ entre linhas com 12 a 15 gemas $\mathrm{m}^{-1}$.

De acordo com Resende et al. (2012) a definição dos contrastes da validação pretendida implica na inclusão de tratamentos-controles. Como as FAN não são prontamente solubilizadas como os fertilizantes convencionais, e apresentam baixa concentração em nutrientes, em geral, sua aplicação baseia-se no teor total e não no teor solúvel do nutriente de interesse. No presente trabalho priorizou-se tratamentos que representam: i) manejo tradicional da adubação com fontes convencionais (controle positivo); ii) associação das fontes convencionais com a fonte alternativa; iii) variação de doses da fonte alternativa. 
A Tabela 5.3 resume a composição dos tratamentos, onde todos os tratamentos receberam calagem (2 $\mathrm{Mg} \mathrm{ha}^{-1}$ na forma de calcário filler para elevar a saturação de bases para $\mathrm{V}=60 \%$ (Raij et al., 1996), além de adubação com nitrogênio (150 kg ha ${ }^{-1}$ na forma de sulfato de amônio), fósforo (90 $\mathrm{kg} \mathrm{ha}^{-1}$ na forma de superfosfato simples), e micronutrientes (150 kg ha ${ }^{-1}$ na forma de FTE-BR12).

Tabela 5.3. Descrição dos tratamentos avaliados no experimento.

\begin{tabular}{lccc}
\hline Tratamentos & Fonte de $\mathrm{K}$ & Dose $\left(\mathrm{kg} \mathrm{ha}^{-1} \mathrm{~K}_{2} \mathrm{O}\right)$ & Outros nutrientes \\
\hline 1.KCl & $\mathrm{KCl}$ & 60 & + \\
$2 . \mathrm{KCl}+\mathrm{AS}$ & KCl+Agromineral & $30+30$ & + \\
\hline 3.ASI & Agromineral & 60 & + \\
\hline 4.ASII & Agromineral & 120 & + \\
\hline 5.ASIII & Agromineral & 240 & + \\
\hline
\end{tabular}

O agromineral silicático (AS) foi aplicado no sulco de plantio em doses correspondentes a 30, 60, 120 e $240 \mathrm{~kg} \mathrm{ha}^{-1}$ de K. Após a aplicação dos tratamentos, o plantio da cana-de-açúcar (variedade RB83-5486) foi realizado no dia 17/12/2010.

Durante o primeiro ciclo (cana-planta) todos os tratamentos receberam os mesmos tratos culturais, ou seja, duas adubações de cobertura, aos 45 e 90 dias após o plantio, envolvendo nitrogênio (60 $\mathrm{kg} \mathrm{ha}^{-1}$ de $\mathrm{N}$ na forma de sulfato de amônio).

Após as colheitas da cana-planta e da cana-soca, no início do ciclo de cultivo subsequente, todos os tratamentos receberam adubações de manutenção em cobertura: $100 \mathrm{~kg} \mathrm{ha}^{-1}$ de $\mathrm{N}$ (sulfato de amônia); $50 \mathrm{~kg} \mathrm{ha}^{-1}$ de $\mathrm{P}_{2} \mathrm{O}_{5}$ (superfosfato simples); $150 \mathrm{~kg}$ $\mathrm{ha}^{-1}$ de micronutrientes (FTE BR-12); $150 \mathrm{~kg} \mathrm{ha}^{-1}$ de $\mathrm{K}$ (conforme as fontes). No tratamento-controle o $\mathrm{K}$ foi fracionado em duas aplicações com intervalo de 30 dias.

\subsubsection{Parâmetros avaliados}

As avaliações envolveram a mensuração dos aspectos produtivo, fisiológico e nutricional, tecnológicos e as alterações nos atributos físico-químicos do solo:

a) aspecto produtivo: a colheita e aferição da produção de colmos ( $\mathrm{t} \mathrm{ha}^{-1}$ ) foram realizadas depois de completados os ciclos produtivos; primeiro com 315; segundo com 376; e terceiro com 372 dias.

b) aspecto fisiológico: realizado ao final de cada ciclo produtivo, sempre antes da colheita; a amostragem levou em conta 05 segmentos de $1 \mathrm{~m}$ de linha, num total de 05 amostras por repetição e 15 por tratamento; a avaliação considerou dados de diâmetro do colmo (DC), perfilhamento (PF) e altura da planta sem a ponteira (AP).

c) aspecto nutricional: a avaliação do estado nutricional da cultura foi realizada ao final do $2^{\circ}$ ciclo de produção, e envolveu seguintes elementos (N, P, K, Ca, Mg, S, B, Cu, $\mathrm{Fe}, \mathrm{Mn}, \mathrm{Zn}$ e $\mathrm{Si}$ ); as amostras foram obtidas a partir da folha TVD (Top Visible Dewlap) ou folha+1 do sistema Kuijper, com segmentação dos $20 \mathrm{~cm}$ centrais e exclusão da nervura central (Malavolta et al., 1989). 
Todos os resultados obtidos foram analisados estatisticamente pela variância e teste de médias (Scott \& Knott, 1974). Adicionalmente, foram definidas as equações de resposta produtiva ( $\left(\mathrm{ha}^{-1}\right)$ em função da dose $\left(\mathrm{kg} \mathrm{ha}^{-1} \mathrm{de} \mathrm{K}\right)$.

\subsection{RESULTADOS E DISCUSSÃO}

O potencial de uso do agromineral como fonte alternativa de nutrientes na cultura da cana-de-açúcar revela-se nos efeitos sobre o desenvolvimento e produção das plantas, qualidade do produto, atributos físico-químicos do solo, e custos associados.

Na Tabela 5.4 são resumidos os resultados obtidos pelas análises de variância conjunta para os 03 ciclos de produção, 05 tratamentos avaliados, e respectivos aspectos avaliados. Todos os parâmetros analisados apresentaram variação significativa entre os ciclos de produção. O diâmetro do colmo (DC) apresenta redução linear com os cultivos sucessivos (CV=5,69\%), mas é no número de perfilhos (NP) que tal redução é mais expressiva $(\mathrm{CV}=17,9 \%)$. Ainda com base nos resultados da Tabela 5, nota-se que os efeitos dos tratamentos foram manifestados nos parâmetros altura de plantas (AP) e produção de colmo (PC), e que estatisticamente não houve interação entre os efeitos dos tratamentos e os ciclos de produção.

Tabela 5.4. Análises de variância conjunta para Diâmetro do Colmo (DC), Número de Perfilhos (NP), Altura de Plantas (AP) e Produção de Colmo (PC), em 03 ciclos de produção (C) e cinco tratamentos (T).

\begin{tabular}{lccccc}
\hline \multirow{2}{*}{ Fontes de Variação } & \multicolumn{5}{c}{ Quadrados Médios } \\
\cline { 2 - 6 } & GL & DC & NP & AP & PC \\
\hline Ciclos (C) & 2 & $43,54^{*}$ & $31,11^{*}$ & $47559,80^{*}$ & $4646,61^{*}$ \\
Tratamentos (T) & 4 & 2,42 & 1,22 & $1091,62^{*}$ & $905,88^{*}$ \\
Interação (CxT) & 8 & 2,14 & 4,28 & 661,58 & 66,75 \\
Bloco & 2 & 0,44 & 0,74 & $1559,95^{*}$ & $378,12^{*}$ \\
Resíduo & 22 & 2,98 & 1,94 & 238,08 & 47,28 \\
\hline CV (\%) & 5,69 & 17,93 & 5,96 & 6,92 \\
\hline Médias & 30,36 & 7,78 & 292,10 & 99,44 \\
\hline * significativo a 5\% de probabilidade pelo teste F.
\end{tabular}

A análise do desdobramento dos efeitos dos tratamentos sobre o parâmetro altura de plantas (AP) é apresentada na Tabela 5.5. Com base nos resultados do teste de médias a 5\% pp. (Scott \& Knott, 1974), nota-se que apenas no $2^{\circ}$ ciclo houve diferença significativa na AP, com efeito do tratamento-controle $(\mathrm{KCl})$ inferior aos demais. Tais efeitos são reforçados quando observadas as médias gerais dos tratamentos.

Por outro lado, quando comparados os efeitos dos tratamentos entre os ciclos de produção, apenas o tratamento-controle $(\mathrm{KCl})$ não apresentou diferenças significativas. Todos os demais tratamentos tiveram efeitos sensíveis no aumento da AP do $1^{\circ}$ para o $2^{\circ}$ ciclo, mas expressiva redução para o $3^{\circ}$ ciclo. 
Tabela 5.5. Média para Altura de Planta AP (cm) para os cinco tratamentos em três ciclos de cultivo da cana-de-açúcar, em Palmas-TO.

\begin{tabular}{ccccccccc}
\hline \multirow{2}{*}{ Tratamentos } & \multicolumn{4}{c}{ Teste F } & \multirow{2}{*}{ Média } \\
\cline { 2 - 7 } & \multicolumn{3}{c}{ Ciclo 1} & \multicolumn{1}{c}{ Ciclo 2} & Ciclo 3 & & \\
\hline KCl & 281,30 & Aa & 274,33 & Ba & 269,33 & Aa & 275,00 & b \\
AS+KCl & 303,80 & Aa & 323,66 & Aa & 258,66 & Ab & 295,40 & a \\
ASI & 302,30 & Aa & 325,00 & Aa & 250,33 & Ab & 292,50 & a \\
ASII & 307,70 & Aa & 322,00 & Aa & 247,00 & Ab & 292,20 & a \\
ASIII & 314,70 & Aa & 327,67 & Aa & 274,33 & Ab & 305,60 & a \\
\hline Médias & 301,20 & A & 314,53 & A & 259,93 & B & 292,10 & \\
\hline
\end{tabular}

Médias seguidas pelas mesmas letras maiúsculas ${ }^{1}$ na linha ou minúsculas ${ }^{2}$ na coluna não diferem entre si, pelo teste de Scott \& Knott (1974), a 5\% de probabilidade;

${ }^{1}$ desdobramento dos tratamentos dentro das épocas;

2 épocas dentro dos tratamentos.

Os resultados de produção de colmo (PC) apresentados na Tabela 5.6 mostram os efeitos dos tratamentos nos respectivos ciclos de produção da cana-de-açúcar. As diferenças são maiores no $1^{\circ}$ ciclo, onde o tratamento-controle $(\mathrm{KCl})$ e o tratamento ASI, os quais envolvem a mesma dose de $\mathrm{K}_{2} \mathrm{O}\left(60 \mathrm{~kg} \mathrm{ha}^{-1}\right)$, apresentaram efeitos semelhantes na produção. $\mathrm{O}$ tratamento $\mathrm{AS}+\mathrm{KCl}$, que envolve associação das fontes avaliadas, diferiu dos tratamentos anteriores, com efeito $20 \%$ superior e produção média de $95 \mathrm{t} \mathrm{ha}^{-1}$. Os tratamentos ASII e ASIII apresentaram produção média de $106 \mathrm{t} \mathrm{ha}^{-1}$.

No $2^{\circ}$ ciclo observa-se um aumento significativo dos efeitos dos tratamentos na produção da cana-de-açúcar, e a redução nas diferenças entre os mesmos. Os resultados confirmam os efeitos observados no ciclo anterior para os tratamentos $\mathrm{KCl}$ e ASI. Os demais tratamentos apresentaram efeitos diferentes dos anteriores, mas semelhantes entre si. O tratamento $\mathrm{AS}+\mathrm{KCl}$, mesmo com menor dose de $\mathrm{K}_{2} \mathrm{O}\left(60 \mathrm{~kg} \mathrm{ha}^{-1}\right)$, não diferiu dos tratamentos ASII e ASIII que receberam doses maiores (120 e $240 \mathrm{~kg} \mathrm{ha}^{-1}$ ).

No $3^{0}$ ciclo os efeitos dos tratamentos apresentam uma redução geral. Apenas o tratamento ASI diferiu dos demais, com uma produção de apenas 69 t.ha $^{-1}$. Dentre os tratamentos que resultaram com efeitos estatisticamente semelhantes, nota-se similaridade entre os tratamentos $\mathrm{KCl}$ e $\mathrm{AS}+\mathrm{KCl}$, e desempenho superior dos tratamentos ASII e ASIII.

Tabela 5.6. Média para Produção de Colmo ( $\mathrm{t} \mathrm{ha}^{-1}$ ) para os cinco tratamentos em três ciclos de cultivo da cana-de-açúcar, em Palmas-TO.

\begin{tabular}{|c|c|c|c|c|c|}
\hline \multirow{2}{*}{ Tratamentos } & \multicolumn{3}{|c|}{ Teste F } & \multirow{2}{*}{\multicolumn{2}{|c|}{ Média }} \\
\hline & Ciclo 1 & Ciclo 2 & Ciclo 3 & & \\
\hline $\mathrm{KCl}$ & $80,10 \quad \mathrm{Cb}$ & $110,14 \mathrm{Ba}$ & $85,78 \quad \mathrm{Ab}$ & 92,01 & C \\
\hline $\mathrm{AS}+\mathrm{KCl}$ & $94,94 \quad \mathrm{Bb}$ & $122,25 \mathrm{Aa}$ & 82,22 Ac & 99,80 & $\mathrm{~b}$ \\
\hline ASI & $83,60 \quad \mathrm{Cb}$ & $108,23 \mathrm{Ba}$ & $69,04 \quad \mathrm{Bc}$ & 86,96 & C \\
\hline ASII & $106,63 \mathrm{Ab}$ & $127,30 \mathrm{Aa}$ & 91,80 Ac & 108,58 & $\mathrm{a}$ \\
\hline ASIII & $106,86 \mathrm{Ab}$ & $127,07 \quad \mathrm{Aa}$ & $95,57 \mathrm{Ab}$ & 109,83 & $\mathrm{a}$ \\
\hline Médias & $94,42 \quad \mathrm{~B}$ & $119,00 \quad \mathrm{~A}$ & $84,88 \quad C$ & 99,44 & \\
\hline
\end{tabular}

Médias seguidas pelas mesmas letras maiúsculas ${ }^{1}$ na linha ou minúsculas ${ }^{2}$ na coluna não diferem entre si, pelo teste de Scott \& Knott (1974), a 5\% de probabilidade;

${ }^{1}$ desdobramento dos tratamentos dentro das épocas; ${ }^{2}$ épocas dentro dos tratamentos. 
A partir das médias gerais dos tratamentos, constata-se que os efeitos dos tratamentos $\mathrm{KCl}$ e ASI são estatisticamente iguais, o que comprova a eficiência da estratégia de substituição da fonte convencional $(\mathrm{KCl})$ pela fonte alternativa (ASI). Da mesma maneira, confirma a eficiência da estratégia de associação das fontes, pois os efeitos do tratamento AS+KCl foram diferentes e superiores aos anteriores.

A análise de regressão mostra que os resultados de produção em função das doses de agromineral aplicadas $\left(60,120\right.$ e $240 \mathrm{~kg} \mathrm{ha}^{-1}$ de $\left.\mathrm{K}_{2} \mathrm{O}\right)$ ajustaram-se melhor à equação de $2^{\circ}$ grau (Figura 5.2). Mesmo não havendo diferença estatística significativa entre as doses mais elevadas do agromineral, as curvas de respostas descritas pelas equações apontam que a dose ótima situa-se entre 120 e $140 \mathrm{~kg} \mathrm{ha}^{-1}$ de $\mathrm{K}_{2} \mathrm{O}$, obtida com a aplicação de 5,5 a 6,5 t ha ${ }^{-1}$ do agromineral, as quais resultam na produção de 112 , 130 e $97 \mathrm{t} \mathrm{ha}^{-1}$ de colmos nos respectivos cultivos.

De acordo com Korndörfer et al. (1999), os efeitos da adubação potássica são mais favoráveis na cana-soca do que na cana-planta, e acrescentam que a dose de K para obtenção de níveis adequados (100\% da máxima produção esperada) é de cerca de 140 $\mathrm{kg} \mathrm{ha}^{-1}$ de $\mathrm{K}_{2} \mathrm{O}$.

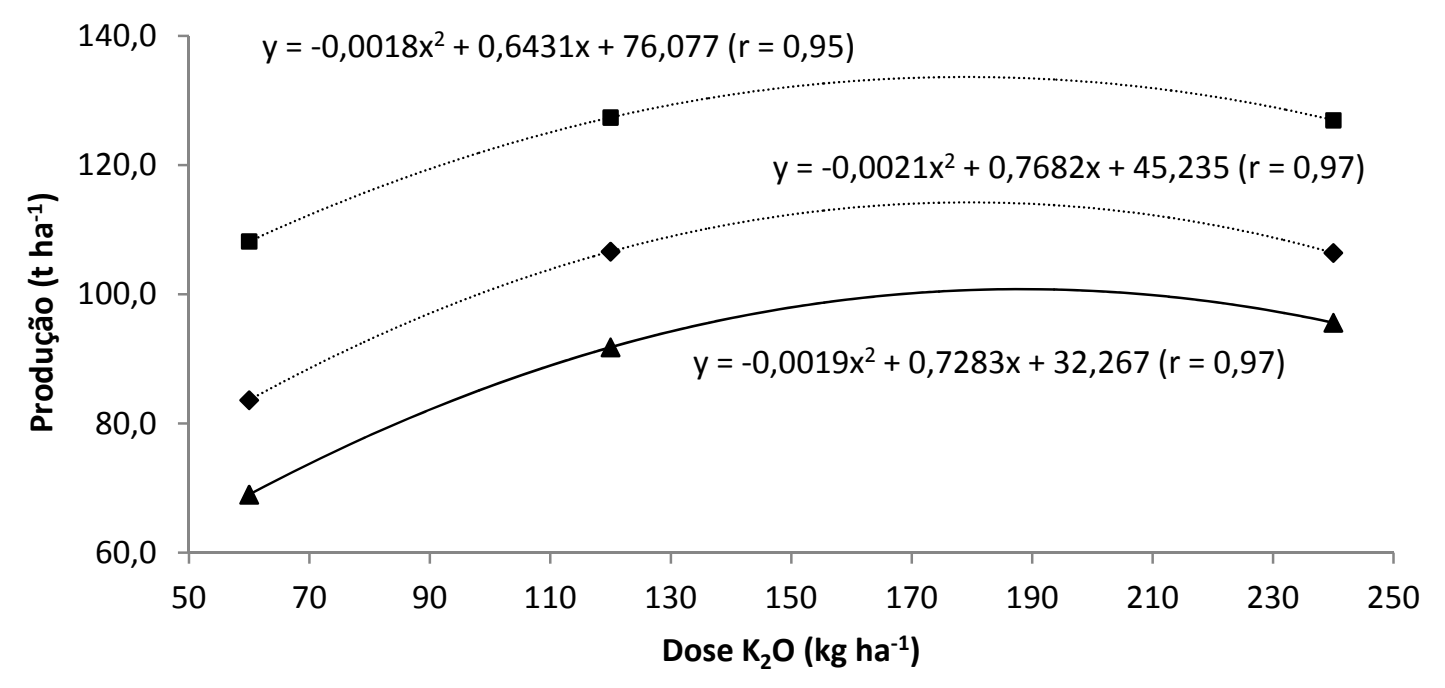

- Ano 1 -Ano $2 \Delta$ Ano 3

Figura 5.2. Curvas de resposta de produção $\left(\mathrm{t} \mathrm{ha}^{-1}\right)$ em função da dose $\left(\mathrm{kg} \mathrm{ha}^{-1} \mathrm{~K}_{2} \mathrm{O}\right)$.

A diagnose foliar parte da premissa de que existe relação direta entre o suprimento de nutrientes pelo solo (ou tratamentos) e os níveis dos elementos foliares, e que acréscimos ou decréscimos nas concentrações desses resultam em produções mais altas ou mais baixas (Prado, 2008). No final do $2^{\circ}$ ciclo de produção (cana-soca) foi realizada uma análise de tecido foliar, a partir da qual torna-se possível não apenas avaliar o estado nutricional das plantas, mas distinguir os efeitos dos tratamentos no suprimento de nutrientes e no incremento da produção.

Na Tabela 5.7 são apresentados os resultados das análises do tecido vegetal para os teores de macronutrientes $\left(\mathrm{g} \mathrm{kg}^{-1}\right)$. $\mathrm{O}$ teste de médias revela que não houve diferença no efeito dos tratamentos sobre o acúmulo dos elementos. Por outro lado, ao comparar 
os teores mensurados com as faixas de teores considerados adequados para a cultura da cana-de-açúcar (Raij et al., 1996), nota-se que:

a) os teores dos elementos $\mathrm{N}$, Ca e $\mathrm{S}$ estão abaixo do limite inferior da faixa considerada adequada, mas em uma zona considerada de transição entre o adequado e o deficiente, uma vez que não se constatou sintomas visíveis de deficiência; nessa fase mantêm-se a relação direta entre teor foliar e produção;

b) os teores de $\mathrm{K}, \mathrm{P}$ e Mg estão adequados, e refletirá uma produção que situa-se entre o nível critico (80 a 90\%) e a máxima produção (100\%).

Assim como observado no presente estudo, Orlando Filho et al. (1993a) constataram que teores de $12 \mathrm{~g} \mathrm{~kg}^{-1}$ são considerados adequados tanto para cana-planta quanto para cana-soca, e que a cultura responde melhor a adubação potássica em solos pobres em K.

A absorção de nutrientes pelas plantas é um processo específico e seletivo, caracterizado por muitas interações, as quais determinam sua composição mineral. A interação é a influência ou ação recíproca de um nutriente sobre o outro (Olsen, 1972), cujos efeitos podem ser antagônicos ou sinérgicos em razão da proporção, das espécies iônicas, e da planta e seu estádio de desenvolvimento (Gama, 1977).

A relação entre os elementos na nutrição de plantas e na produção das culturas é bem conhecida (Malavolta et al., 1997). Os nutrientes N e K apresentam uma interação bem característica, pois a aplicação de maiores doses de $\mathrm{N}$ somente promoverão incremento de produção se acompanhadas de doses proporcionais de K (Dibb e Thompson, 1985). Os resultados obtidos nos diferentes tratamentos mostram uma relação K/N (0,9 a 1,2), cujos valores são muito próximos daqueles descritas na literatura, os quais variam de 1,5 (Raij et al., 1996) a 2,4 (Anderson e Bowen, 1992).

Tendo em vista as condições de elevada acidez e baixa capacidade de troca de cátions da grande maioria dos solos brasileiros, as interações mais importantes envolvem K, Ca e Mg (Rosolem, 2005). Mas segundo os autores, o insuficiente entendimento dessas interações não permite generalizar recomendações de adubação potássica a partir dos níveis de Ca e Mg.

Tabela 5.7. Teor de macronutrientes no tecido foliar da cana-de-açúcar.

\begin{tabular}{|c|c|c|c|c|c|c|}
\hline \multirow{2}{*}{ Tratamento } & \multicolumn{6}{|c|}{ Macronutrientes $\left(\mathrm{g} \mathrm{kg}^{-1}\right)$} \\
\hline & $\mathrm{N}$ & $\mathrm{Ca}$ & $\mathrm{K}$ & $\mathrm{P}$ & Mg & $S$ \\
\hline $\mathrm{KCl}$ & $12,0 \mathrm{a}$ & $0,7 \mathrm{a}$ & 12,9 a & $1,7 \mathrm{a}$ & $1,8 \mathrm{a}$ & $1,0 \mathrm{a}$ \\
\hline $\mathrm{AS}+\mathrm{KCl}$ & $12,2 \mathrm{a}$ & 0,6 a & 12,6 a & 1,6 a & $1,4 \mathrm{a}$ & $0,8 \mathrm{a}$ \\
\hline ASI & $12,5 \mathrm{a}$ & 0,5 a & 11,3 a & $1,4 \mathrm{a}$ & $1,6 \mathrm{a}$ & $0,8 \mathrm{a}$ \\
\hline ASII & $11,8 \mathrm{a}$ & 0,6 a & 11,9 а & $1,8 \mathrm{a}$ & $1,7 \mathrm{a}$ & $0,9 \mathrm{a}$ \\
\hline ASIII & $11,2 \mathrm{a}$ & $0,7 \quad \mathrm{a}$ & 13,2 a & $1,7 \mathrm{a}$ & $1,9 \mathrm{a}$ & $0,9 \mathrm{a}$ \\
\hline $\mathrm{CV}(\%)$ & 5,6 & 28,3 & 16,6 & 19,9 & 12,8 & 15,0 \\
\hline Médias & 11,9 & 0,6 & 12,4 & 1,6 & 1,7 & 0,9 \\
\hline$(*)$ & $18-25$ & $2,0-8,0$ & $10-16$ & $1,5-3,0$ & $1,0-3,0$ & $1,5-3,0$ \\
\hline$(* *)$ & $15-27$ & $1,8-7,6$ & $6,2-20,0$ & $0,8-3,5$ & $0,8-3,5$ & $0,3-10,0$ \\
\hline
\end{tabular}

Médias seguidas das mesmas letras na coluna não diferem significativamente,pelo teste de Scott \& Knott (1974), a 5\% de probabilidade; $\left(^{*}\right)$ teores médios no Brasil (Raij et al., 1996); ${ }^{* *}$ ) teores médios em várias regiões do globo (Anderson e Bowen, 1992). 
Como aponta Moore (1961), o incremento nas doses de K causa decréscimo nos teores de Ca e Mg na planta, e que esses últimos são antagônicos na solução do solo, ou seja, o excesso de um prejudica a absorção do outro. De acordo com Prado (2008), teores de $\mathrm{K}$ foliares próximos de $18 \mathrm{~g} \mathrm{~kg}^{-1}$ reduzem a absorção de $\mathrm{Ca}$ e $\mathrm{Mg}$, mas asseguram níveis de produção satisfatórios. Por outro lado, o aumento da concentração de Mg na solução do solo não afeta a obsorção de K pela planta (Fonseca e Meurer, 1997), por se tratar de um íon monovalente, de menor grau de hidratação, e de mais fácil absorção que os cátions divalentes.

Os teores de micronutrientes acumulados na parte aérea das plantas são apresentados na Tabela 5.8. O teste de médias mostra que houve diferença significativa nos teores de Boro (B) e Ferro (Fe) acumulados nas folhas das plantas em função dos tratamentos avaliados. Nota-se que os tratamentos que receberam maiores doses do agromineral (PRII e PRIII) apresentam efeitos semelhantes no fornecimento desses nutrientes para a cultura da cana-de-açúcar, distinguindo-se dos demais tratamentos.

Os resultados mostram correlação positiva entre estes micronutrientes (B/Fe), pois seus teores aumentam consideravelmente no tecido vegetal com o aumento da dose do agromineral. O mesmo verifica-se nos teores de $\mathrm{Zn}$, apesar dos resultados não apresentarem diferenças estatísticas entre os tratamentos avaliados.

A comparação com os valores de referência (Raij et al., 1996) revela que o acúmulo dos elementos micronutrientes no tecido vegetal resultou bastante diferente:

a) os elementos Fe, Mn e Zn estão adequados, e sugere possibilidade de máxima produção (100\%);

b) o B apresenta teores acima do limite superior da faixa considerada adequada, em uma zona considerada de "consumo de luxo", onde o acúmulo do elemento no tecido não resulta em toxidez, mas o aumento da concentração também não resulta em aumento da produção;

c) o $\mathrm{Cu}$ apresenta teores abaixo da faixa adequada, mas como não foram observados sintomas visíveis de deficiência, manteve-se a relação direta entre teor foliar e produção;

Tabela 5.8. Teores de micronutrientes no tecido foliar da cana-de-açúcar.

\begin{tabular}{|c|c|c|c|c|c|c|}
\hline \multirow{2}{*}{ Tratamento } & \multicolumn{6}{|c|}{ Micronutrientes $\left(\mathrm{mg} \mathrm{kg}^{-1}\right.$ ) } \\
\hline & B & $\mathrm{Cu}$ & $\mathrm{Fe}$ & $\mathrm{Mn}$ & $\mathrm{Zn}$ & Si (\%) \\
\hline $\mathrm{KCl}$ & $32,44 \mathrm{~b}$ & $1,93 \mathrm{a}$ & $45,39 \mathrm{~b}$ & 29,56 a & 25,27 a & $0,07 \mathrm{a}$ \\
\hline $\mathrm{AS}+\mathrm{KCl}$ & $28,39 \mathrm{~b}$ & 2,13 a & $33,29 b$ & 23,55 a & 16,71 a & $0,07 \mathrm{a}$ \\
\hline ASI & $30,35 \mathrm{~b}$ & 2,01 a & $36,17 \mathrm{~b}$ & 24,02 a & 18,38 a & $0,07 \mathrm{a}$ \\
\hline ASII & 50,95 a & 1,68 a & 39,33 a & 28,95 a & 21,21 a & 0,08 a \\
\hline ASIII & 59,43 a & $1,21 \mathrm{a}$ & 45,67 a & 27,38 a & 27,32 a & $0,12 \mathrm{a}$ \\
\hline $\mathrm{CV}(\%)$ & 25,4 & 35,2 & 10,2 & 19,2 & 18,7 & 23,9 \\
\hline Médias & 40,3 & 1,8 & 39,9 & 26,7 & 21,8 & 0,08 \\
\hline$(*)$ & $10-30$ & $6-15$ & $40-250$ & $25-250$ & $10-50$ & $1-5$ \\
\hline$(* *)$ & $1-30$ & $3-100$ & $20-600$ & $12-400$ & $15-50$ & -- \\
\hline
\end{tabular}

Médias seguidas das mesmas letras na coluna não diferem significativamente, pelo teste de Scott \& Knott (1974), a 5\% de probabilidade; $(*)$ teores médios no Brasil (Raij et al., 1996); $\left(^{* *}\right)$ teores médios em várias regiões do globo (Anderson e Bowen, 1992). 
A causa fisiológica para a interação de $\mathrm{K}$ e micronutrientes não é tão clara quanto àquelas observadas para os macronutrientes, assim como seus efeitos aditivos ou secundários. No entanto, algumas interações são sugeridas (Dibb e Thompson, 1985), como aumento da absorção de Mn e Zn. Para Ramani e Kannan (1974) a presença de K desempenha importante papel na regulação da absorção de Mn, ou seja, maior absorção de Mn quando este apresentar baixa concentração no solo, e ao contrário, frente altas concentrações de Mn no solo.

Outro elemento benéfico é o Si (Epstein, 2002), o qual merece atenção pelo fato do estudo envolver rochas silicáticas como fonte alternativa de nutrientes. Os resultados de acumulação de Si no tecido vegetal (Tabela-9), apesar de não apresentaram diferenças significativas, mostra que o aumento das doses da fonte alternativa (agromineral) contribuiu para o aumento do teor desse elemento nas plantas.

Os teores acumulados comprovam tratar-se de uma 'planta intermediária' na acumulação de Si (Marschner, 1995), onde o elemento exerce efeitos na rigidez das células, na arquitetura foliar, na taxa fotossintética, e na redução da transpiração excessiva das plantas, além de contribuir para melhorar a eficiência do P, e minimizar a toxicidade de $\mathrm{Al}$, Fe e Mn em solos com altos teores desses elementos.

Estudos com a aplicação de escória siderúrgica comprovaram os efeitos benéficos do Si na produção de colmos (Prado e Fernandes, 2001; Prado et al., 2003; Korndörfer, 2001), e sugerem que a resposta das plantas ao Si é mais significativa em condições de estresse - doenças/pragas, $\mathrm{pH}$ baixo, excesso de $\mathrm{Al}$ ou déficit hídrico. Para Gaspar (2007) os efeitos do Si na produtividade da cana-de-açúcar são mais expressivos em solos arenosos, constituindo atualmente uma realidade em muitas usinas do Estado de São Paulo.

Outros trabalhos têm demonstrado o aumento na produção de colmo da cana-deaçúcar decorrente da aplicação de Si (Savant et al., 1999; Korndörfer e Lepsch, 2001). Da mesma forma, Silveira et al. (2003) observaram incrementos significativos na produção de cana-de-açúcar com a aplicação de silicato de cálcio.

De qualquer forma, os resultados apresentados corroboram para afirmar algumas constatações a cerca da nutrição mineral na cultura da cana-de-açúcar (Prado, 2008): maior exigência em $\mathrm{K}$ do que em $\mathrm{N}$; inversão na ordem-padrão de extração entre Zn e B; e acúmulo de Si, com reflexos no crescimento das plantas e na produção da cultura.

\subsection{CONSIDERAÇÕES COMPLEMENTARES}

As discussões apresentadas anteriormente descrevem bem os efeitos do agromineral silicático derivado de resíduos de mineração como fonte de nutriente na cultura da cana-de-açúcar. Os resultados demonstram os efeitos de diferentes estratégias de uso do agromineral como fonte de K, ou seja, em substituição e complementação da fonte convencional $(\mathrm{KCl})$, bem como os efeitos associados ao aumento da dose do agromineral silicático estudado. 
Frente às condições de solo e clima em que se desenvolveram os sucessivos ciclos de cultivo da cana-de-açúcar, constatou-se que o agromineral silicático teve efeito positivo no suprimento de nutrientes e no balanço nutricional das plantas, e consequentemente, no desenvolvimento fisiológico e no rendimento produtivo da cultura.

Por fim, conclui-se que o agromineral silicático avaliado compreende uma importante fonte alternativa de nutrientes para a cultura da cana-de-açúcar, constituindo um recurso frente à crescente demanda por nutrientes na agricultura regional. 


\subsection{INTRODUÇÃO}

A literatura relativamente extensa sobre agrominerais silicáticos como fonte de nutrientes, condicionadores ou remineralizadores de solos, revela que seu potencial é determinado por inúmeras reações de intemperismo químico responsáveis pelo controle do fluxo de nutrientes no sistema mineral-solo-planta-clima.

Além da intensidade da hidrólise, a qual determina a taxa de eliminação de solutos, e consequente renovação dos gradientes de concentração em solução, a liberação de nutrientes da estrutura mineral para a solução do solo é influenciada por vários fatores: origem, composição química, mineralógica e granulométrica das rochas moídas; aspectos relacionados às características dos solos; ciclo produtivo e exigências nutricionais das plantas; tratamento prévio aplicado à rocha; e tempo de incubação do agromineral no solo.

Assim, considerando que as rochas silicáticas multinutrientes são de composição mineralógica diversa, e que seu comportamento nos solos revela-se extremamente complexo, o presente estudo adota abordagem semelhante à utilizada na avaliação de fertilizantes de liberação lenta (FLL), onde são consideradas: as propriedades físicoquímicas determinantes da estabilidade e do comportamento do produto no meio; o modelo de aporte de nutrientes em comparação com outros produtos; e a efetividade do produto em cultivos específicos.

Desse modo, além da adequada caracterização física, mineralógica e geoquímica, o agromineral obtido do beneficiamento (moagem) dos resíduos minerais gerados no Garimpo de Monte Santo-TO, a avaliação envolveu a realização de experimentos que caracterizam sistemas de diferentes graus de complexidade, cujos objetivos específicos foram:

i) Estimar a taxa de dissolução do agromineral, e identificar os efeitos de sobreposição dos atributos dos solos na dinâmica de liberação de nutrientes;

ii) Avaliar os efeitos do agromineral no suprimento de nutrientes para cultivos sucessivos;

iii) Avaliar a viabilidade técnica do uso do agromineral em substituição e complementação às fontes convencionais de nutrientes.

\subsection{CONCLUSÕES E PERSPECTIVAS}

Com base nos estudos desenvolvidos e resultados obtidos, conclui-se que os resíduos minerais do Garimpo de Esmeraldas de Monte Santo-TO apresentam comprovada eficiência e viabilidade de uso na rochagem, seja como fonte de nutrientes, ou como remineralizador de solos, o que permite denominá-lo um agromineral, ou melhor, um agromineral silicático. 
No universo da investigação é ainda possível concluir que:

(1) Sistema Mineral-Solução:

- As taxas de dissolução registradas são semelhantes às descritas na literatura, e caracterizam bem o comportamento do agromineral nas condições experimentais.

- A dissolução do agromineral no início é favorecida por reações de transporte, mas a estabilização na fase final indica predomínio de reações de superfície.

- A solubilização do agromineral foi de apenas 1,22\%, sobretudo devido a contribuição do K (0,65\%), do Ca (0,37\%) e do Mg (0,03\%).

(2) Sistema Mineral-Solo-Solução:

- A solubilização do agromineral é fortemente influenciada pelos parâmetros: pH da solução; teor de matéria orgânica; capacidade de troca; e condutividade hidráulica.

- A solubilização do agromineral foi 2,5 a 3,8 vezes maior na presença dos solos: Plintossolo Pétrico (FFc) > Neossolo Quartzarênico (RQ) > Latossolo Amarelo (LA).

- A dinâmica de liberação dos elementos químicos por efeito dos solos apresenta variação significativa nos teores totais extraídos: 90\% para K e 30\% para Ca e Mg.

(3) Sistema Mineral-Solo-Solução:

- O aumento linear na disponibilidade de $\mathrm{K}$ com as doses crescentes do agromineral indica que a liberação de $\mathrm{K}$ é proporcional à dose aplicada.

- O agromineral silicático apresenta efeito como fonte de nutrientes ( $\mathrm{K}$, Ca e $\mathrm{Mg}$ ), e como remineralizador de solos devido os efeitos sobre o $\mathrm{pH}$ e a CTC do solo.

- A disponibilidade de $\mathrm{K}$ obtida com a aplicação do agromineral foi apenas 32\% menor que a registrada com a mesma dose da fonte convencional (KCl).

(4) Sistema Mineral-Solo-Solução-Planta:

- A aplicação de $6 \mathrm{t}$ ha ${ }^{-1}$ do agromineral silicático proporciona efeitos compatíveis aos obtidos com a fonte convencional de potássio ( $\mathrm{KCl})$.

- A eficiência do agromineral no suprimento de $K$ não foi comprometida pela moderada solubilidade dos minerais silicáticos.

- A aplicação do agromineral apresenta efeito residual em cultivos sucessivos, de modo que a dissolução do agromineral foi 15 vezes maior na presença de plantas, resultando na recuperação de 75 a 85\% do K aplicado.

(5) Sistema Mineral-Solo-Solução-Planta-Clima:

- O uso do agromineral silicático tem efeito positivo no balanço nutricional, bem como no desenvolvimento fisiológico e no rendimento produtivo da cana-de-açúcar.

- O agromineral apresenta viabilidade técnica em diferentes estratégias de uso, seja em substituição ou em complementação à fonte convencional (KCl).

- As curvas de dose-resposta sugerem que a aplicação de $6 \mathrm{t} \mathrm{ha}^{-1}$ do agromineral resulta na produção média de $112 \mathrm{t} \mathrm{ha}^{-1}$ de colmos em três ciclos de cultivos sucessivos. 
Os resultados permitiram ainda constatar a manifestação de algumas relações com especial significado para a dinâmica de nutrientes no solo, as quais contribuem para o entendimento dos fatores e mecanismos que determinam o potencial do agromineral silicático em condições de clima tropical.

1. a acidez do solo, caracterizada pela presença do íon $\mathrm{H}^{+}$, favorece a solubilização dos minerais e liberação dos íons na solução do solo;

2. com o aumento da solubilização dos minerais a concentração dos íons $\mathrm{K}^{+}, \mathrm{Ca}^{2+} \mathrm{e}$ $\mathrm{Mg}^{2+}$ tornam-se mais elevadas, e também o $\mathrm{pH}$, o que favorece a CTC visto que os solos tropicais apresentam carga variável dependente do $\mathrm{pH}$;

3. o complexo de troca é mantido em equilíbrio dinâmico com a solução do solo, e à medida que os íons são absorvidos pelas plantas, ocorre reposição para a solução, reduzindo a lixiviação desses no perfil do solo;

4. o consumo dos íons em solução, seja via absorção pela planta, complexação ou lixiviação, provoca o estabelecimento de um novo equilíbrio, via de regra obtido com o aumento da solubilização dos minerais;

5. o aumento excessivo da concentração iônica na solução, acima dos produtos de solubilização, podem resultar na formação de precipitados, e alterar o equilíbrio dinâmico entre as fases sólida e líquida do solo.

Diante do exposto, e com base em relevantes informações disponíveis na literatura, constata-se que em certas condições específicas os efeitos dos agrominerais silicáticos podem ser potencializados, seja como fonte de nutrientes ou remineralizadores de solos:

i) solos altamente intemperizados compostos de argilominerais 1:1 e óxihridróxidos de Fe e Al favorecem a lixiviação dos nutrientes no perfil do solo, com efeitos expressivos na dinâmica de dissolução dos agrominerais;

ii) maior extensão das superfícies de reação obtida pelo tratamento prévio (moagem) das rochas que aumentam a taxa de dissolução mineral e reposição dos nutrientes na solução do solo;

iii) intensa atividade biológica devido às plantas e aos microorganismos que promove mudanças temporais nas concentrações dos íons em solução e nos níveis de $\mathrm{CO}_{2}$ e $\mathrm{O}_{2}$ do solo, com efeitos sobre as reações de superfície e nas taxas de dissolução mineral;

Diante das constatações obtidas, os estudos futuros deverão levar em conta: os aspectos do solo capazes de influenciar a dissolução mineral e a dinâmica de nutrientes na solução do solo; a extensão de superfícies reativas após processo de beneficiamento (moagem) e a taxa de dissolução do agromineral; as características morfológicas do sistema radicular e as interações que ocorrem rizosfera capazes de influenciar a liberação e a absorção de nutrientes pelas plantas; o momento (pré ou pós-plantio) e o local (lanço ou sulco ou cova) adequado para a aplicação do agromineral silicático ao solo; os efeitos globais do manejo de agrominerais silicáticos em solos tropicais, 
especialmente em relação à formação de novas fases minerais, ao aumento da capacidade de troca, à elevação e manutenção da acidez do solo em níveis adequados, à atividade microbiana e ao consumo e fixação de $\mathrm{CO}_{2}$ no solo.

\subsection{CONSIDERAÇÕES FINAIS}

O pensamento científico contemporâneo reforçou a tendência de valorização dos preceitos da observação, da experiência e da busca cada vez maior de utilidade para o saber. Mas com as reflexões epistemológicas decorrentes das contribuições dadas pela física ao conhecimento da natureza, emergiram-se novas abordagens metodológicas, e a incorporação da perspectiva sistêmica ao pensamento científico.

Assim, a partir da revolução científico-tecnológica iniciada na segunda metade do século passado, pautada em uma abordagem interdisciplinar, avanços significativos foram obtidos em várias áreas do conhecimento, com reflexos em diversos setores produtivos. Com isso, a Ciência adquiriu papel estratégico no contexto atual de enormes desafios para compatibilizar desenvolvimento econômico e equilíbrio do meio físico.

No decorrer desta Tese evidenciou-se a contribuição da Pesquisa Agrogeológica, campo de estudos de interface das Geociências com as Ciências Agrárias, para a estratégia de utilização de rochas e minerais como fonte de nutrientes para as plantas.

A abordagem metodológica revelou-se apropriada, comprovando a hipótese de que a partir da determinação da taxa de dissolução do resíduo mineral é possível avaliar seu potencial no suprimento de nutrientes para plantas cultivadas. Do mesmo modo, o melhor entendimento das interações rocha-solo-solução-planta-clima, e dos mecanismos que controlam as reações de dissolução mineral, revelam-se informações determinantes ao manejo adequado dos agrominerais silicáticos em solos tropicais.

Os resultados constituem informações úteis na parametrização dos efeitos de outras rochas silicáticas, uma vez que o potencial dos agrominerais silicáticos é resultante de efeitos e fatores conjugados: tipo de rocha e sua composição química e mineralógica; pH, composição da solução e condutividade hidráulica do solo; e exigência nutricional, sistema radicular e ciclo produtivo das plantas cultivadas.

Em resumo, o potencial do agromineral silicático obtido dos resíduos minerais do Garimpo de Monte Santo-TO não decorre exclusivamente da sua capacidade de fornecer nutrientes para as plantas cultivadas, mas também, em função dos feitos associados à melhoria das propriedades físicas, químicas e microbiológicas dos solos. Assim, a utilização deste agromineral silicático compreende uma alternativa para o suprimento da demanda regional de fertilizantes na agricultura, com reflexos importantes sobre os custos de produção associados, e também, na redução do passivo ambiental decorrente da mineração.

Acrescenta-se ainda, que as informações geradas na Tese são úteis à Cooperativa de Garimpeiros de Monte Santo, caso ela venha requerer o registro do agromineral silicático como um “remineralizador de solos” junto ao Ministério da Agricultura. 
Por fim, sem a presunção de querer encerrar a discussão acerca da complexidade que envolve a temática dos agrominerais e seu potencial para a agricultura tropical, a questão anunciada por van Straaten, “que rochas para quais culturas?”, pode ser reformulada: quais rochas, em que solos, e para quais plantas?

"A verdadeira cura para um solo desgastado consiste em administrar-lhe rochas trituradas. Desta maneira, as plantas recebem novamente o que elas por natureza necessitam. Prova disso pode observar-se na milenar fertilidade das terras do Egito; o lodo do Nilo as nutre quase que exclusivamente de rochas finamente trituradas, junto com ingredientes orgânicos nitrogenados”

Julius Hensel, 1898 


\section{CAPÍTULO 7}

\section{REFERÊNCIAS BIBLIOGRAFICAS}

ANDA - ASSOCIAÇÃO NACIONAL DE DIFUSÃO DE ADUBOS. (2003). Anuário estatístico do setor de fertilizantes. ANDA, São Paulo-SP.

ANDA - ASSOCIAÇÃO NACIONAL DE DIFUSÃO DE ADUBOS. (2010). Anuário estatístico do setor de fertilizantes. ANDA, São Paulo-SP.

ANDA - ASSOCIAÇÃO NACIONAL DE DIFUSÃO DE ADUBOS. (2012). Anuário estatístico do setor de fertilizantes. ANDA, São Paulo-SP.

ACKER, J.G. \& BRICKER, O.P. (1992). The influence of $\mathrm{pH}$ on biotite dissolution and alteration kinetics at low temperature. Geochimica et Cosmochimica Acta, v.56, p.30733092 .

AGRIANUAL. (2009). Anuário da Agricultura Brasileira. AGRA FNP Ltda. São Paulo.

ALMEIDA, E.B.; FARJALLAT, J.E.S.; VALARELLI, J.V.; YOSHIDA, R. (1978). Fontes alternativas de potássio (Projeto IPT). XXX Congresso Brasileiro de Geologia. Recife, Anais 4. p.1696-1705.

AMRHEIN, C. \& SUAREZ, D.L. (1992). Some factors affeting the dissolution kinetics of anorthite at $25^{\circ}$ C. Geochimica et Cosmochimica Acta, v.56, p.1815-1826.

ANDERSON, D.L.; BOWEN, J.E. (1992). Nutrição da cana-de-açúcar. Piracicaba: Associação Brasileira para Pesquisa da Potassa e do Fosfato. 40 p.

ANDERSSON, A.; WIKLANDER, L. (1975). Release of crystal constituents by chemical weathering of some soil minerals. Soil Science, 120:13-19.

APHA - AMERICAN PUBLIC HEALTH ASSOCIATION. (1992). Standard Methods for the Examination of Water and Wastewater.Washington, DC: APHA. 1992.

ARCANJO, S.H.S.; MOURA, C.A.V.; ABREU, F.A.M.; GORAYEB, P.S.S. (2000). Rio do Coco volcano-sedimentary sequence: 2.6 exotic terrain in the Paleoproterozoic Tocantins Shear Belt, Central Brazil. In: $31^{\circ}$ Congresso Internacional de Geologia SBG. Rio de Janeiro-RJ. CD-ROM.

ARNON, D. I.; STOUT, P. R. (1939). The essentiality of certain elements in minute quantity for plants with special reference to copper. Journal of Plant Physiology. V. 14, p. 371-375.

ABNT - ASSOCIAÇÃO BRASILEIRA DE NORMAS TÉCNICAS. (1995). Rochas e solos: terminologia, NBR 6502/95. Rio de Janeiro. 18p.

ABRACAL - ASSOCIAÇÃO BRASILEIRA DOS PRODUTORES DE CALCÁRIO AGRÍCOLA. (2005). Calcário agrícola - Consumo aparente no Brasil 1984-2004.

BAILEY, S.W. Classification and structures of the micas. (1984). In: Micas; Reviews in mineralogy. Blacksburg: Mineralogical Society of America, v.13. p.1-12.

BALIGAR , V.C.; FAGERIA, N.K. \& HE, Z.L. (2001). Nutrient use efficiency in plants. Comm. Soil Sci. Plant Anal., 32:921-950. 
BARREIRA, C.F. \& DARDENNE, M.A. (1981). A Seqüência Vulcano-Sedimentar Rio do Coco. In: IMPÓSIO DE GEOLOGIA DO CENTRO-OESTE, 1. Goiânia.1991, Soc. Bras. Geol. p. 241-264.

BARREIRA, C.F. (1980). Geologia e prospecção geoquímica da área do Rio do Coco, Paraíso do Norte - GO. Dissertação de Mestrado. Universidade de Brasília. Brasília-DF.

BAYLISS, P. (1975). Nomenclature of the trioctahedral chlorite. Can. Mineral: 13. p. 178-180.

BERNER, R.A. (1978). Rate control of mineral dissolution under earth surface conditions. American Journal of Science, v.278, p.1235-1252.

BIBER, M.V., AFONSO, M.S. \& STUMM, W. (1994). The coordination chemistry of weathering: IV. Inhibition of the dissolution of oxide minerals. Geochimica et Cosmochimica Acta, v.58, p.1999-2010.

BLUM, A. \& LASAGA, A.C. (1988). Role of surface speciation in low-temperature dissolution of minerals. Nature, n.331, p.431-433.

BLUM, A. \& LASAGA, A.C. (1991). The role surface of speciation in the dissolution of albite. Geochimica et Cosmochimica Acta, v.55, p.2193-2201.

BLUM, A.E. \& STILLINGS, L.L. (1995). Feldspar dissolution kinetics. In: WHITE, A.F. \& BRANTLEY, S.L., eds., Chemical Wheathering Rates of Silicate Minerals. Washington: Mineralogical Society of America. Review in Mineralogy, v. 31, p.29146.

BOLLAND, M.D.A.; BAKER, M.J. (2000). Powdered granite is not an effective fertilizer for clover and wheat in sandy soils from Western Australia. Nutrient Cycling in Agroecosystems, v.56, p 59-68.

BOT, A. J.; NACHTERGAELE, F.O.; YOUNG, A. (2000). Land resource potential and constraints at regional and country levels. Land and Water Development Division, Food and Agriculture Organization, U.N., Rome. 114p.

BOWEN, N.L. (1928). The evolution of igneous rocks. New Jersey, Princeton University Press. 334p.

BRADY, P.V. \& WALTHER, J.V. (1989). Controls on silicate dissolutin rates in neutral and basic $\mathrm{pH}$ solutions at $25^{\circ} \mathrm{C}$. Geochimica et Cosmochimica Acta, v.53, p.2823-2830.

BRADY, P.V. (1992). Silicate surface chemistry elevated temperatures. Geochimica et Cosmochimica Acta, v.56, p.2941-12946.

BRASIL - Decreto Federal no 4.954, de 14 de janeiro de 2004. Aprova o regulamento da Lei $n^{\circ}$ 6.894, de 16 de dezembro de 1980, que dispõe sobre a inspeção e fiscalização da produção e do comércio de fertilizantes, corretivos, inoculantes ou biofertilizantes destinados à agricultura, e dá outras providências. Diário Oficial da União: República Federativa do Brasil, Poder Executivo, Brasília, DF, 15 jan. 2004. Disponível em: https://www.planalto.gov.br/ccivil_03/_Ato2004-2006/2004/Decreto/D4954.htm

BRASIL - Lei $\mathrm{n}^{\circ}$ 12.305, de 02 de agosto de 2010. Política Nacional de Resíduos Sólidos. $2^{\mathrm{a}}$ Ed. Brasília: Câmara dos Deputados - Edições Câmara - Série Legislação no 81, 2012.73p. Disponível em: 
BRASIL - Lei $\mathrm{n}^{\circ}$ 12.305, de 02 de agosto de 2010. Política Nacional de Resíduos Sólidos. $2^{a}$ Ed. Brasília: Câmara dos Deputados - Edições Câmara - Série Legislação $n^{\circ}$ 81, 2012.73p.

BRASIL - Lei $\mathrm{n}^{\circ} 12.890$, de 10 de Dezembro de 2013. Inclui os remineralizadores como uma categoria de insumo destinado a agricultura. Diário Oficial da União: República Federativa do Brasil, Poder Executivo, Brasília-DF, 11 de Dezembro de 2013. Disponível em: $\quad$ http://www.planalto.gov.br/ccivil_03/_Ato20112014/2013/Lei/L12890.htm

BRASIL - Lei n ${ }^{\circ} 6894$, de 16 de dezembro 1980. Dispõe sobre a inspeção e fiscalização da produção e comércio de fertilizantes, corretivos, inoculantes ou biofertilizantes destinados à agricultura e dá outras providências, Diário Oficial da União: República Federativa do Brasil, Poder Executivo, Brasília, DF, 17 dez.1980. Disponível em: https://www.planalto.gov.br/ccivil_03/Leis/1980-1988/L6894.htm

BRAZ，A.J.B.P.; SILVEIRA， P.M.; KLIEMANN， H.J.; ZIMMERMANN， F.J.P. (2004). Acumulação de nutrients em folhas de milheto e dos capins braquiária e mombaça. Revista Brasileira Tropical. Goiânia-GO, v.34, n.2. p. 83-87.

BURNS, A.F. \& BARBER, S.A. (1961). Effect of temperature and moisture on exchangeable potassium. Soil Sci. Soc. Am. Proc., 25:349-352.

CALEGARI, A. (1985). Guia de plantas para adubação verde de inverno. Documentos, 9. Londrina-PR: IAPAR.

CAMPE, J., O'BRIEN, T.A. \& BARKER, A.V. (1996). Soil remineralization for sustainable agriculture. Remineralise the Earth, Spring. p.141-164.

CANTARUTTI, R.B.; BARROS, N.F.; MARTINEZ, H.E.P.; NOVAIS, R.F. (2007). Avaliação da fertilidade do solo e recomendação de fertilizantes. In: NOVAIS, R.F.; ALVAREZ, V.H.; BARROS, N.F.; FONTES, R.L.F.; CANTARUTTI, R.B.; NEVES, J.C.L. Fertilidade do solo. Viçosa, Sociedade Brasileira de Ciência do Solo. p.769-850.

CAPONE, A.; LUI, J.J.; SILVA, T.R.; DIAS, M.A.R.; MELO, A.V. (2011). Avaliação do comportamento de quinze cultivares de cana-de-açúcar na Região Sul do Tocantins. J. Biotec. Biodivers. v. 2, N.3: pp. 70-78, Agosto.

CARROLL-WEBB, S.A. \& WALTHER, J.V. (1988). A surface complex reaction model for the $\mathrm{pH}$-dependence of corundun and kaolinite dissolution rates. Geochimica et Cosmochimica Acta, v.52, p.2609-2623.

CARTAGENA, C.C. \& DÍEZ LOPEZ, M. (1992). Evaluación de lós fertilizantes de liberación lenta - ensayos de laboratório. In. JIMENEZ GÓMEZ, S. Fertilizantes de Liberación Lenta. Mundi-Prensa. Madrid. p.83-110.

CARVALHO, I.G. (1995). Fundamentos da geoquímica dos processos exógenos. Universidade Federal da Bahia/Instituto de Geociências. 213p.

CASEY, W. H. \& SPOSITO, G. (1992). On the temperature dependence of mineral dissolution rates. Geochimica et Cosmochimica Acta, v.56, p.3825-3830.

CASEY, W.H. \& BUNKER, B. (1990). The leaching of mineral and glass surfaces during dissolution. In: HOCLELLA JR.,M.F.; WHITE, A.(ed.) Mineral-Water Interface Geochemistry. Washington: Mineralogical Society of American. Reviews in Mineralogy, v.13, p.397-426. 
CASTILHOS, R.M.V. \& MEURER, E.J. (2002). Suprimento de potássio de solos do Rio Grande do Sul para arroz irrigado por alagamento. R. Bras. Ci. Solo, 26:977-982.

CASTRO, P.R.C.; FERREIRA, S.O.; YAMADA, T. (1987). Ecofisiologia da produção agrícola. Piracicaba: Associação Brasileira para Pesquisa da Potassa e do Fosfato POTAFOS. 249p.

CATANI, R.A.; GALLO, J.R. (1960). A disponibilidade do potássio da "Leucita de Poços de Caldas", estudada por meio do arroz. Anais da Escola Superior de Agricultura "Luiz de Queiroz", vol. 17, 30-35.

CHERSWORTH, W. (1973). The residual system of chemical weathering: a model for the chemical breakdown of silicate rocks at the surface of earth. J. Soil Sci. 24(1):68-81.

CHESWORTH, W. (1980). The haplosoil systems. Am. J. Sci., 280:969-985.

CHOU, L. \& WOLLAST, R. (1984). Study of the weathering of albite at room temperature and pressure with a fluidized bed reactor. Geochimica et Cosmochimica Acta, v.48, p.2205-2217.

CHRISTENSON, D.R. \& DOLL, E.C. (1973) Release of magnesium from soil clay and silt fractions during cropping. Soil Sci., 116:56-63.

CORONEOS, C.; HINSINGER, P.; GILKES, R. J. (1996). Granite powder as a source of potassium for plants: a glasshouse bioassay comparing two pasture species. Nutrient Cycling in Agroecosystems, Dordrecht, v. 45, n. 2, p. 143-152.

CRISÓSTOMO, L.A. \& CASTRO, A.F. (1970). Poder de suprimento de potássio de solos da zona fisiográfica de Baturité, Ceará, Brasil. Turrialba, 20:425-433.

CURI, N.; KÄMPF, N.; MARQUES, J.J. (2005). Mineralogia e Formas de Potássio em Solos Brasileiros. IN: YAMADA, T. \& ROBERTS, T.L. (ED.). Potássio na agricultura brasileira. Piracicaba: Instituto da Potassa \& Fosfato, Instituto Internacional da Potassa. p.91-122.

DANA, J.D. e HURLBUT, C.S. (1984). Manual de mineralogia. Livros Técnicos e Científicos - LTC. Editora S.A., Rio de Janeiro. 642 p.

DEER, W.A.; HOWIE, R.A.; ZUSSMAN, J. (1992). Minerais Constituintes das Rochas - uma introdução. Traduzido por Luís E. Nabais Conde. Fundação Gulbenkian, Lisboa. $558 \mathrm{p}$.

DIBB, D.W.; THOMPSON JUNIOR, W.R. (1985). Interaction of potassium with other nutrients. In: MUNSON, R.D. (Ed.). Potassium en agriculture. Madison: ASA. p.513533.

DNPM - DEPARTAMENTO NACIONAL DE PRODUÇÃO MINERAL. (2009). Potássio. In: Economia Mineral do Brasil - 2009. Brasília: DNPM/Cidade Gráfica e Editora Ltda. p.569-576.

DOVE, C.M. (1995). Kinetics and thermodynamic controls on silica reactivity in weathering enviroments. In: WHITE, A.F.; BRANTLEY, S.L. (ed.). Chemical Wheathering Rates of Silicate Minerals. Washington: Mineralogical Society of America. Reviews in Mineralogy, v.31, p.235-282.

DREVER, J.I. (1988). The geochemistry of natural waters. New Jersey: Prentice Hall. 202p. 
DREVER, J.I. (1994). The effect of land plants on weathering rates of silicate minerals. Geochimica et Cosmochimica Acta, v.58, p.2325-2332.

EMBRAPA - EMPRESA BRASILEIRA DE PESQUISA AGROPECUÁRIA. (1997). Manual de métodos de análise de solo. 2.ed. - Rio de Janeiro, Embrapa-CNPS. 212p.

EMBRAPA - EMPRESA BRASILEIRA DE PESQUISA AGROPECUÁRIA. (2006). Sistema Brasileiro de Classificação de Solos. 2 ed. - Rio de Janeiro: Embrapa-SPI. 306p.

EMBRAPA - EMPRESA BRASILEIRA DE PESQUISA AGROPECUÁRIA. (1999). Sistema Brasileiro de Classificação de Solos. Brasília-DF. 412p.

EPSTEIN, E. (2002). Silicon in plant nutrition. In: Second Silicon in Agriculture Conference. Japanese Society of Soil Science and Plant Nutrition, Tsuruoka, Yamagata. p.1-5.

EPSTEIN, E.; BLOOM, A.J. (2006). Nutrição mineral de plantas: princípios e perspectivas. Londrina: Editora Planta. 403p.

ESSINGTON, M.E. (2004). Soil and water chemistry. Boca Raton, CRC Press, 523p.

FADIGAS, F.S.; AMARAL SOBRINHO, N.M.B.; MAZUR, N.; ANJOS, L.H.C. \& FREIXO, A.A. (2006). Proposição de valores de referência para a concentração natural de metais pesados em solos brasileiros. Rev. Bras. Eng. Agrícola e Ambiental, vol. 10, n.3, p. 699-705.

FAGERIA, N.K.; BALIGAR, V.C. (1993). Screening crop genotypes for mineral stresses. In: WORKSHOP ON ADAPTATION OF PLANTS TO SOIL STRESSES, 1993, Lincoln. Proceedings. Lincoln: University of Nebraska. p.142-159. (Intsormil Publication, 94-2).

FANNING, D.S., KERAMIDAS, V.Z. \& EL-DOSOKY, M.A. (1989). Micas. In: DIXON, J.; WEED, S. (eds). Mineral in soil environments. Wisconsin: Soil Science Society of America. p. 551-634.

FAO. Food and Agriculture Organization of the United Nations. (2005). Statistical Databases. Agriculture. Disponível em: http://www.fao.org/corp/statistics/en/.

FARACO, M.T.L., et al. (2004). Folha SC.22-Tocantins. In: Carta Geológica do Brasil ao Milionésimo, Sistema de Informações Geográficas. Programa Geologia do Brasil. CPRM, Brasília. CD-Rom.

FERNANDES, B.; RESENDE, M. \& REZENDE, S.B. (1978). Caracterização de alguns solos sob cerrado e disponibilidade de água para as culturas. Experientiae, 24:209-260.

FERNANDES, F.R.C.; LUZ, A.B.; CASTILHOS, Z.C. (2010). Agrominerais para o Brasil. 1ed. Rio de Janeiro, RJ: CETEM, v. 1. 380 p.

FONSECA, J.A. \& MEURER, E.J. (1997). Inibição da absorção de magnésio pelo potássio em plântulas de milho em solução nutritiva. R.Bras.Ci.Solo, 21:47-50.

FOSTER, M. D. (1960). Layer charge relations in the dioctahedral and trioctahedral micas. In: The American Mineralogist. v.45. p.383-398.

FRASCA, A.A. \& ARAÚJO, V.A. (2001). Projeto Hidrogeologia no Tocantins - Folha Palmas (TO) - SD.22-Z-B. Goiânia: CPRM. 52 p. 
FUJIMORI, K. (1984). Desenvolvimento da tecnologia de produção do fertilizante potássico tipo kalsilita, próprio para agricultura tropical a partir das rochas potássicas. Anais do XXXIII Congresso Brasileiro de Geologia, Rio de Janeiro - p. 4892-4902.

FYFE, W.S., KRONBERG, B.I., LEONARDOS, O.H. \& OLORUFEMI, N. (1983). Global tectonics and agriculture: a geochemical perspective. Agr Ecosyst Env 9: p.383399.

GAMA, M.V. (1977). Efeitos do azoto e do potássio na composição mineral do trigo e do tomate. Agronomia Lusitana, v.38. p.111-121.

GILLMAN, G.P. (1980). The effect of crushed basalt scoria on the cation exchange properties of a highly weathered soil. Soil Sci. Soc. Am. J. 44:465-468.

GOEDERT, W. J.; LOPES, A. S. (1987). Eficiência agronômica de fertilizantes fosfatados para culturas anuais, perenes, pastagens e reflorestamento. In: SEMINÁRIO SOBRE RECUPERAÇÃO DE FÓSFORO, São Paulo. Anais... São Paulo: Ibrafos. p. 24-49.

GOLDICH, S.S. (1938). A study in rock weathering. Jornal of Geology, v.46, p.11-58.

GRAHAM, R. D. (1984). Breeding for nutritional characterístics in cereal. In: TINKER, P. B; LANCHLI, A. (Ed). Advances in plant nutrition. New York: Praeger Publishers. p.57-102.

GRANJA, J.R.M. (2010). Expansão da Atividade Canavieira em Goiás e Tocantins: condicionantes e componentes principais. Universidade Federal do Tocantins - UFT. Palmas. Dissertação de Mestrado.

HARLEY, A.D.; GILKES, R.J. (2000). Factors influencing the release of plant nutrient elements from silicate rock powders: a geochemical overview. Nutrient Cycling in Agroecosystems, Dordrecht, v. 56, n. 1, p. 11-36.

HAVLIN, J.L., \& WESTFALL, D.G. (1985). Potassium kinetics and plant response in calcareous soils. Soil Sci. Soc. Am. J., 49:366-370.

HAVLIN, J.L., WESTFALL, D.G., \& OLSEN, S.R. (1985). Mathematical models for potassium release kinetics in calcareous soils. Soil Sci. Soc. Am. J., 49:371-376.

HENDRICKS, D.M. \& WHITTIG, L.D. (1968). Andesite weathering. I. Mineralogical transformation from andesite to saprolite. J. Soil Sci., 19:135-146.

HENSEL, J. (1989) Brout und Stein. Tradução Sebastião Pinheiro - Pães de Pedra. Porto Alegre, Fundação Juquira Candiru, 2003.

HINSINGER, P.; BOLLAND, M. D. A.; GILKES, R. J. (1996). Silicate rock powder: effect on selected chemical properties of a range of soils from Western Australia and on plant growth as assessed in a glasshouse experiment. Nutrient Cycling in Agroecosystems, Dordrecht, v. 45, n. 1, p. 69-79.

HOLDREN, G.R. \& BERNER, R.A. (1979). Mechanism of feldspar weathering: I. Experimental Studies. Geochimica et Cosmochimica Acta, v.43, p.1161-1171.

IBGE - INSTITUTO BRASILEIRO DE GEOGRAFIA E ESTATÍSTICA. (2005). Levantamento sistemático da produção agrícola. Disponível em: http://www.ibge.gov.br/home/estatistica/indicadores 
IBGE - INSTITUTO BRASILEIRO DE GEOGRAFIA E ESTATÍSTICA. (2012). Indicadores de Desenvolvimento Sustentável. Disponível em: http://www.ibge.gov.br/home/estatistica/indicadores

ILCHENKO, W \& GUIMARÃES, D. (1953). Sobre a utilização agrícola dos sienitos nefelínicos do Planalto de Poços de Caldas. MG. Inst. Tecn. Avulso. 15. 16p.

INDA JUNIOR, A.V.; KLANT, E.; NASCIMENTO, P.C. (2004). Composição da fase sólida mineral do solo. In.: MEURER, E.J. (Ed.). Fundamentos de química de solo. 2 ed. Porto Alegre, Gêneses. 290p.

INTERNATIONAL FERTILIZER INDUSTRY ASSOCIATION - IFA. (2005). Fertilizer consumption statistics from 1970/71 to 2005/06. http://www.fertilizer.org/ifa/statistics.asp

IWANUCH, W. (1991). Geologia dos Complexos Alcalinos Proterozóicos do Centro do Estado do Tocantins. IG/USP. Tese de Doutoramento.

JAMBOR, J.L. (2000). The relationship of mineralogy to acid-and neutralization potential. In: COTTER-HOWELS, J.D.; CAMPBELL, L.S.; VALSAMI-JONES, E. \& BATCHELDER, M., eds. Environmental mineralogy: Microbial interactions, anthropogenic influences, contaminated land and waste management. London, Mineralogical Society of Great Britain \& Ireland. p.141-159.

JIMENEZ GÓMEZ, S. (1992). Fertilizantes de Liberación Lenta. Mundi-Prensa. Madrid. 126 p.

KALINOWSKI, B.E. \& SCHWEDA, P. (1996). Kinetics of muscovite, phlogopite, and biotite dissolution and alteration at $\mathrm{pH} 1-4$, room temperature. Geochimica et Cosmochimica Acta, v.60, p.367-385.

KALINOWSKI, B.E. (1997). Dissolution kinetics and alteration products of micas and epidote in acidic solutions at room temperature. Doctoral thesis. Stockholm: Stockolm University. $62 \mathrm{p}$.

KÄMPF, N., CURI, N. \& MARQUES, J.J. (2009). Intemperismo e ocorrência de minerais no ambiente do solo. In: MELO, V.F. \& ALLEONI, R.F., eds. Química e Mineralogia do Solo. SBCS, Viçosa. p.334-371.

KARATHANASIS, A.D. (2002). Mineral equilibria in environmental soil systems. In: DIXON, J.B. \& SCHULZE, D.G., eds. Soil mineralogy with environmental applications. Madison, Soil Scince Society of America, p.109-151.

KELLER, W.D. (1948). Native rocks and minerals as fertilizers. Sci. Monthly 66:122-130.

KLEIN, C. \& HURLBUT, S. (1993). Manual of Mineralogy. 21ed. John Wiley \& Sons.

KÖPPEN, W. (1948). Climatologia: Com un estudio de los climas de La tierra. Fondo de Cultura Econômico, México. 478p.

KORNDÖRFER, G.H. \& I. LEPSCH. (2001). Effect of silicon on plant growth and yield. In: DATNOFF, L.E.; KORNDÖRFER, H.K. \& SNYDER, G.H. (coord.) Silicon in Agriculture. 1. p.. Elsevier Science B.V., Amsterdam, The Netherlands.

KORNDÖRFER, G.H.; RIBEIRO, A.C.; ANDRADE, L.A.B. (1999). Cana-de-açúcar. In: RIBEIRO, A.C.; GUIMARÃES, P.T.G.; ALVAREZ, V.H. Recomendações para uso de corretivos e fertilizantes em Minas Gerais - $5^{\text {a }}$ aproximação. Viçosa: Comissão de Fertilidade do Solo do Estado de Minas Gerais. p.285-288. 
KRONBERG, B. I.; LEONARDOS, O. H.; FYFE, W. S.; MATTOSO, S.Q.; SANTOS, A. M. (1976). Alguns dados geoquímicos sobre solos no Brasil. Uso Potencial do pó de pedreira como fonte de nutrientes críticos em solos altamente lixiviados- com atenção à geoquímica de alguns solos da Amazônia. In: CONGRESSO BRASILEIRO DE GEOLOGIA, 29., 1976, Ouro Preto. Anais... Ouro Preto: Sociedade Brasileira de Geologia, 1976. p147-169.

LANCHLI, A. (1987). Soil scienci in the next. Twenty five years, does a biotecnology play a role. Soil Sci. Soc. Am J. Madison, 54.

LAPIDO- LOUREIRO, F.E.V. (1994). Terras Raras no Brasil - Depósitos, recursos identificados, reservas. Rio de Janeiro, CETEM.

LASAGA, A.C. (1998). Kinetic Theory in the Earth Sciences. Princeton Univ. Press, Princeton, NJ. 781p.

LAUCHLI, A. (1987). Soil science in the next twenty-five years: does a biotechnology play a role? Soil Science Society of American Journal, v.51. p.1405-9.

LEAKE B. E. et al. (1997). Nomenclature of Amphiboles. The Canadian Mineralogist: 35. p. $219-246$

LELONG, F., TARDY, Y., GRANDIN, G., TRESCASES, J.J. \& BOULAMGE, B. (1976). Pedogenesis, chemical weathering and processes of formation of some supergene ore deposits. In: WOLF, K.H., ed.. Handbook of strata-bound and stratiform ore deposits, I - Principles and general studies. Amsterdam, Elsevier. v.3. p.93-173.

LEONARDOS, O.H.; FYFE, W.S.; KROMBERG, B. (1976). Rochagem: método de aumento de fertilidades em solos lixiviados e arenosos. Congr. Bras. Geol. Ouro Preto. Anais. SBG. p. 137-145.

LEONARDOS, O. H.; FYFE, W. S.; KROMBERG, B. I. (1987). The use of ground rocks in laterite systems: an improvement to the use of conventional soluble fertilizers? Chemical Geology, v.60, p.361-370.

LEONARDOS, O.H. \& THEODORO, S.H. (1999). Fertilinzing tropical soils for sustainable development. In: Workshop on Topical Soils. Rio de Janeiro: Academia Brasileira de Ciências. p.143-153.

LEONARDOS, O.H.; THEODORO, S.H.; ASSAD, M.L. (2000). Remineralization for sustainable agriculture: A tropical perspective from a Brazilian viewpoint. Nutrient Cycling in Agroecosystems, 56:3-9.

LI, B.; McKEAND, S. E.; ALLEN, H. L. (1991). Genetic variation in nitrogen use efficiency of loblolly pine seedlings. Forest Science, Bethesda, v. 37, n. 2, p. 613-626.

LIBARDI, P.L. (2005). Dinâmica da água no solo. São Paulo: EDUSP. 335p.

LOPES, A.S. \& GUIMARÃES, L.R.G. (2007). Fertilidade do solo e produtividade agrícola. In.: Fertilidade do Solo, eds. NOVAIS, R.F., ALVAREZ V., V.H., BARROS, N.F., FONTES, R.L.F., CANTARUTTI, R.B. \& NEVES, J.C.L.. SBCS, Viçosa. 1017p.

LOPES, A.S. (1984). Solos sob "cerrado": características, propriedades e manejo. 2a edição Piracicaba, Assoc. Bras. para Pesq. da Potassa e do Fosfato. 162p.

LOUGHNAN, F.C. (1969). Chemical wheathering of the silicate minerals. New York: Elsevier. 146p. 
LUCCHESI, A. A. (1987). Fatores da produção vegetal. In: Castro, P. R. C.; Ferreira, S. O.; Yamada, T. Ecofisiologia da produção agrícola. Piracicaba: Associação Brasileira para Pesquisa da Potassa e do Fosfato. p. 1-11.

LUZ, A.B., LAPIDO-LOUREIRO, F.E., SAMPAIO, J.A., CASTILHOS, Z.C., BEZERRA, M.S. (2010). Rochas, minerais e rotas tecnológicas para produção de fertilizantes alternativos. In. Agrominerais para o Brasil. Rio de Janeiro: CETEM/MCT. p. 61-89.

MACHADO, C.T.T.; RESENDE, A.V.; MARTINS, E.S.; SOBRINHO, D.A.S.; NASCIMENTO, M.T.; FALEIRO, A.S.G.; LINHARES, N.W.; SOUZA, A.L. \& CORAZZA, E.J. (2005) Potencial de rochas silicáticas no fornecimento de potássio para culturas anuais: II. Fertilidade do solo e suprimento de outros nutrientes. In: Congresso Brasileiro de Ciência do Solo, 30. Recife, Anais. Recife: UFRPE/SBCS. (CD-rom).

MALAVOLTA, E. (1976). Manual de química agrícola. São Paulo: Agronômica Ceres. 528p.

MALAVOLTA, E. (1979). ABC da Adubação. $4^{\mathrm{a}}$ edição. São Paulo SP, Editora Agronomia Ceres. 255 p.

MALAVOLTA, E. (1985). Nutrição de plantas. In: FERRI, M.G. (org.) Fisiologia vegetal. São Paulo : EDUSP, Vol.1. 400p.

MALAVOLTA, E. (2006). Manual de nutrição mineral de plantas. São Paulo: Editora Agronômica Ceres. 638p.

MALAVOLTA, E., VITTI, G.C. \& OLIVEIRA, S.A. (1997). Avaliação do estado nutricional das plantas: princípios e aplicações. 2. ed. Piracicaba: Potafos. 319p.

MALAVOLTA, E., VITTI, G.C., OLIVEIRA, S.A.de. (1989). Avaliação do estado nutricional das plantas; princípios e aplicações. Piracicaba: POTAFOS. 201p.

MALMSTRÖM, M. \& BANWART, S. (1997). Biotite dissolution at $25^{\circ} \mathrm{C}$ : The pH dependence rate and stoichiometry. Geochimica et Cosmochimica Acta, v.61, p.27792799.

MAPA - MINISTÉRIO DA AGRICULTURA, PECUÁRIA E ABASTECIMENTO. (2004). Decreto Federal $n^{\circ} 4.954$, de 14 de janeiro de 2004. Aprova o regulamento da Lei ${ }^{\circ}$ 6.894, de 16 de dezembro de 1980, que dispõe sobre a inspeção e fiscalização da produção e do comércio de fertilizantes, corretivos, inoculantes ou biofertilizantes destinados à agricultura, e dá outras providências. Diário Oficial da União: República Federativa do Brasil, Poder Executivo, Brasília, DF, 15 jan. 2004. Disponível em: https://www.planalto.gov.br/ccivil_03/_Ato2004-2006/2004/Decreto/D4954.htm

MAPA - MINISTÉRIO DA AGRICULTURA, PECUÁRIA E ABASTECIMENTO. (2007). Balanço nacional da cultura da cana-de-açúcar e agroenergia. Secretaria de Produção e Agroenergia-SPAE. Brasília-DF.

MARSCHNER, H. (1995). Mineral nutrition of higher plants. 2 ed. London: Academic Press. 889 p.

MARTIN, H.W. \& SPARKS, D.L. (1983). Kinetics of non-exchangeable potassium release from two costal plan soils. Soil Sc. Soc. Am. J., 47:883-887.

MARTINS, E.S., OLIVEIRA, C.G., RESENDE, A.V.; MATOS, M.S.F. (2008). Agrominerais - Rochas Silicáticas como Fontes Minerais Alternativas de Potássio para 
a Agricultura. In: Adão B. Luz e Fernando Lins (eds.), Rochas e Minerais Industriais Usos e Especificações, Rio de Janeiro: CETEM, p. 205-221

MARTINS, E.S.; RESENDE, A.V.; OLIVEIRA, C.G.; FURTINI NETO, A.E. (2010). Materiais Silicáticos como Fontes Regionais de Nutrientes e Condicionadores de Solos. In: F. R. C. Fernandes; A. B. da Luz; Z. C. Castilhos. (Org.). Agrominerais para o Brasil. 1ed. Rio de Janeiro, RJ: CETEM, v. 1, p. 89-104.

McBRIDE, M.B. (1994). Environmental chemistry of soils. New York, Oxford University Press. 406p.

MELAMED, R.; GASPAR, J.; MIEKELEY, N. (2007). Pó-de-rocha como fertilizante alternativo para sistemas de produção sustentáveis em solos tropicais. Rio de Janeiro: CETEM. 24 p. (Série Estudos e Documentos. Versão Provisória, SED-72).

MELFI, A.; CERRI, C. C.; FRITSCH, E.; FORMOSO, M. L. L. (1999). Tropical soils: genesis, distribuition and degradation of lateritic pedological systems. In: Workshop on Topical Soils. Rio de Janeiro: Academia Brasileira de Ciências. p.9-30 .

MELLO, J.W.V. \& PEREZ, D.V. (2009). Equilíbrio químico das reações no solo. In: Melo, V.F. \& Alleoni, R.F., eds., Química e Mineralogia do Solo. SBCS, Viçosa, 2009. p.152-244.

MENGEl, K.; KIRKBY, E. A. (1987). Principles of plant nutrition. Bern: International Potash Institute.

MEURER, E.J. \& ANGHINONI, I. (1993). Disponibilidade de potássio e sua relação com parâmetros de solo. R. Bras. Ci. Solo, 17:377-382.

MEURER, E.J. (2008). Fundamentos de química do solo. Porto Alegre: Gênesis, 3 ed. 290p.

MEURER, E.J.; KAMPF, N. \& ANGHINONI, I. (1996). Fontes potenciais de potássio em alguns solos do Rio Grande do Sul. R. Bras. Ci. Solo, 20:41-47.

MIELNICZUK, J. \& SELBACH, P.A. (1978). Capacidade de suprimento de potássio de seis solos do Rio Grande do Sul. R. Bras. Ci. Solo, 2:115-120.

MDIC - MINISTÉRIO DO DESENVOLVIMENTO, INDÚSTRIA E COMÉRCIO EXTERIOR. (2012). Balança comercial brasileira: unidades da federação. SECEX. Disponível em: http://mdic.gov.br.

MME - MINISTÉRIO DE MINAS E ENERGIA. PLANO NACIONAL DE MINERAÇÃO - PNM 2030. (2010). Geologia, Mineração e Transformação Mineral. Brasília-DF. 178p.

MOLL, R. H.; KAMPRATH, E. J.; JACKSON, W. A. (1982). Analysis and interpretation of factors which contribute to efficiency of nitrogen utilization. Agronomy Journal, New York, v. 74, p. 562-564.

MOORE, D.P. (1961). Uptake of magnesium and its interactions with calcium in excised barley roots. Plant Physiology, v.36, n.3. p.291-295.

NACHTIGALL, G.R. \& VAHL, L.C. (1991). Capacidade de suprimento de potássio dos solos da região Sul do Rio Grande do Sul. R.Bras. Ci. Solo, 15:37-42.

NACHTIGALL, P.E.; MOONEY, T.A.; TAYLOR, K.A.; YUEN, M.M.L. (2007). Hearing and auditory evoked potential methods applied to odontocete cetaceans. Aquat. Mamm. 33, 6-13. 
NAHON, D.B. (1991). Introduction to the Petrology of Soils and Chemical Weathering: New York, John Wiley \& Sons, 313 p.

NASCIMENTO, M. \& LOUREIRO, F.E.L. (2004). Fertilizantes e sustentabilidade: o potássio na agricultura brasileira, fontes e rotas alternativas. Rio de Janeiro: CETEM/MCT. Série Estudos e Documentos, 61. 66p.

NOVAIS, R. F.; NEVES, J. C. L.; BARROS, N. F. (1991). Ensaio em ambiente controlado. In: OLIVEIRA, A. J.; GARRIDO, W. E.; ARAÚJO, J. D.; LOURENÇO, S. (Coord.). Métodos de pesquisa em fertilidade do solo. Brasília: EMBRAPA-SEA. p.190-253. (EMBRAPA-SEA. Documentos, 3).

NOVAIS, R.F. \& SMYTH, T.J. (1999). Fósforo em solo e planta em condições tropicais. Viçosa: UFV. 399p.

NOVAIS, R.F. \& MELLO, J.W.V. Relação de solo-planta. (2007). In: NOVAIS, R.F.; ALVAREZ V., VH; BARROS, NF; FONTES, RLF; CANTARUTTI, R.B.; NEVES, J.C.L. Fertilidade do Solo. Viçosa, MG, Sociedade Brasileira de Ciência do Solo. p.276374.

NOVAIS, R.F.; ALVAREZ V., V.H.; BARROS, N.F.; FONTES, R.L.F.; CANTARUTTI, R.B.; NEVES, J.C.L. (Eds.). (2007). Fertilidade do solo. Viçosa: SBCS. 1017p.

OGASAWARA, E.; KULAIF, Y.; FERNANDES, F.R.C. (2010). A industria brasileira de fertilizantes (cadeia NPK) - projeções de 2010 a 2030. In.: Agrominerais para o Brasil. FERNANDES, F.R.C.; LUZ, A.B.; CASTILHOS, Z.C. (Eds.). Rio de Janeiro: CETEM/MCT. p. 145-168.

OLDEMAN, L. R.; HAKKELING, R. T. A.; SOMBROEK, W. G. (1991). World map of the status of human-induced soil degradation: an explanatory note. 2. ed. Wageningen: International Soil Reference and Information Centre. 34 p.

OLIVEIRA, O., LUDWICK, A.E. \& BEATTY, M.T. (1971). Potassium removed from some southerm Brazilian soils by exhaustive cropping and chemical extraction methods. Soil Sci. Soc. Am. Proc., 35:763-767.

OLSEN, S.R. (1972). Micronutrients interactions. In: MONTVERDT, J.J.; GIORDANO, P.M.; LINDSAY, W.L. (Ed.) Micronutrients in agriculture. Soil Science of America Monographs. Madison (Wisconsin). p.243-288.

ORLANDO FILHO, J.; MACEDO, N.; TAKESHI, H. (1994). Seja o doutor do seu canavial. Piracicaba: POTAFOS. 17 p. (Arquivo do Agrônomo, 6)

OXBURGH, R., DREVER, J.L. \& SUN, Y.T. (1994). Mechanism of plagioclase dissolution in acid solutions at $25^{\circ}$ C. Geochimica et Cosmochimica Acta, v.58, p.6661669.

PEDRO, C., JAMAGNE, M. \& BEGON, J.C. (1969). Mineral interactions and transformations in relation to pedogenesis during the Quaternary. Soil Sci., 107:462469.

PRADO, R.M.; FERNANDES, F.M. (2001). Resposta da cana-de-açúcar a aplicação da escória siderúrgica como corretivo de acidez do solo. Revista Brasileira de Ciência do Solo, v.25, n.1. p. 199-207. 
PRADO, R.M. (2003). Efeito residual da escória siderúrgica como corretivo de acidez do solo na soqueira da cana-de-açúcar. Revista Brasileira de Ciência do Solo, v.27, n.2. p.287-296.

PRADO, R.M. e VIDAL, A.A. (2008). Efeitos da omissão de macronutrientes em solução nutritiva sobre o crescimento e a nutrição do milheto. Revista Agropecuária Tropical. Goiânia-GO, v.38, n.3, jul/set. p. 208-214

PRADO, R. M. (2008). Nutrição de Plantas. 1.ed. São Paulo: Editora UNESP, v.1. 407p

RADAMBRASIL. (1983). Levantamento dos recursos naturais: geologia, geomorfologia, pedologia, vegetação e uso potencial da terra. Folhas SF. 23 / 24, Rio de Janeiro/Vitória. Rio de Janeiro, Ministério das Minas e Energia. 780p.

RAI, D. \& KITTRICK, J.A. (1989). Mineral equilibria and the soil system. In: DIXON, J.B. \& WEED, S.B. eds. Minerals in soil environments. Madison, Soil Science Society America. p.161-198.

RAIJ, B. \& VALADARES, J.M.A.S. (1974). Análise dos elementos maiores de rochas, argilas e solos. Campinas, Instituto Agronômico de Campinas. 23p. (IAC. Boletim Técnico, 16).

RAIJ, B. \& QUAGGIO, J.A. (1984). Disponibilidade de potássio em solos para capim braquiária cultivado em vasos. Bragantia, 43:531-539.

RAIJ, B. van. (1991). Fertilidade do solo e adubação. Editora agronômica Ceres Ltda. Piracicaba, SP. 343p.

RAIJ, B. van; CANTAREllA, H.; QUAGGIO, J. A.; FURLANI, A. M. C. (1996). Recomendações de adubação e calagem para o Estado de São Paulo. 2a. ed. Campinas: Instituto Agronômico e Fundação IAC. p. 237-239. (Boletim Técnico, 100)

RAIJ, B. van; ANDRADE, J.C.; CANTARELLA, H.; QUAGGIO, J.A. (2001). Análise química para avaliação da fertilidade de solos tropicais. Campinas Instituto Agronômico. 285p.

RAMANI, S.; KANNAN, S. (1974). Effects of certain cations on manganese absorption by excised rice roots. Communications in Soil Science and Plant Analysis, New York, v.5. p.435-442.

RESENDE, A.V.; FURTINI NETO, A.E.; MARTINS, E.S.; HURTADO, S.S.C.; OLIVEIRA, C.G; SENA, M.C. (2012). Protocolo de avaliação agronômica de rochas e produtos derivados como fontes de nutrientes às plantas ou condicionadores de solo. Embrapa Milho e Sorgo. Documentos 143. 30p.

RESENDE, A.V.; MARTINS, E.S.; OLIVEIRA, C.G.; SENA, M.C.; MACHADO, C.T.T.; KINPARA, D.I.; OLIVEIRA FILHO, E.C. (2006). Suprimento de Potássio e Pesquisa de Uso de Rochas in natura na Agricultura Brasileira. Espaço e Geografia (UnB), v. 9, p. 19-42.

RICE, H.B. \& KAMPRATH, E.J. (1968). Avaliability of exchangeable and nonexchangeable Mg in sandy Coastal Plain soil. Soil Sci. Soc. Am. Proc., 32:386-388.

RODRIGUES, A.F.S. (2010). Mineração para o Agronegócio. In: Economia Mineral do Brasil, Brasília: DNPM, cap. 7, p. 532-595.

RODRIGUES, A.F.S.; FONSECA, D.S.; HIDER, M.; PARAHYBA, R.E.; CAVALCANTE, V.M.M. (2010). Agrominerais - recursos e reservas. In.: 
Agrominerais para o Brasil. FERNANDES, F.R.C.; LUZ, A.B.; CASTILHOS, Z.C. (Eds.). Rio de Janeiro: CETEM/MCT. p. 23-44.

ROSOLEM, C. A.; CALONEGO, J. C.; FOLONI, J. S. S. (2005). Potassium leaching from millet straw as affected by rainfall and potassium rates. Communications in Soil Science and Plant Analysis, New York, v. 36, p. 1063-1074.

ROSOLEM, C.C.A., BESSA, A. \& PEREIRA, H.F.M. (1993). Dinâmica do potássio no solo e nutrição potássica da soja. Pesq. Agropec. Bras., 28:1045-1054.

SANCHEZ, P.A., (1976). Properties and Management of Soils in the Tropics. Wiley, New York.

SANZONOWICZ, C.; MIELNICZUK, J. (1985). Potassium distribution in the soil profile as affected by crop, fertilizers and fertilizer management. Revista Brasileira de Ciência do Solo, Campinas, v. 9, n. 1, p. 45-50.

SAVANT, N.K.; KORNDÖRFER, G.H.; SNYDER, G.H.; DATNOFF, L.E.. (1999). Silicon Nutrition and Sugarcane Production: A review. J.Plant Nutri. New York, NY.12(22):1853-903.

SEPLAN - Secretaria de Planejamento e Meio Ambiente. (2005). Atlas do Tocantins: subsídios ao planejamento e a gestão territorial. $3^{\circ}$ ed. - Palmas-TO, Seplan/DZE.

SIDDIQI, M.Y.; GLASS, A.D.M. (1981). Utilisation index: a modified approach to the estimation and comparison of nutrient utilization efficiency in plants. Journal of Plant Nutrition, v.4. p. 289-302.

SILVA, F. C. (Org.). (1999). Manual de análises químicas de solos, plantas e fertilizantes. Brasília: Embrapa Comunicação para Transferência de Tecnologia. 370 p.

SILVA, I.R. \& MENDONÇA, E.S. (2007). Matéria orgânica do solo. In. Fertilidade do Solo. NOVAIS et. al. Eds. Viçosa-MG; Sociedade Brasileira de Ciência do Solo. p.275376.

SILVEIRA JR, E.G.; PENATTI, C.; KORNDORFER, G.H.; CAMARGO, M.S. (2003).

Silicato de cálcio e calcário na produção e qualidade da cana-de-açúcar - Usina Catanduva. In: Cong. Bras. Ciê. do Solo - Solo: Alicerce dos Sistemas de Produção XXIX. CD ROM. Ribeirão Preto: UNESP. p.66.

SIMONETE, M.A., VAHL, L.C. \& FABRES, R.T. (1998). Capacidade de extração de potássio do solo por culturas forrageiras de inverno em Planossolo. In: Reunião Brasileira de Fertilidade do Solo e Nutrição de Plantas, 23., UFLA/SBCS/SBM. 520p.

SOUSA, D. M. G.; LOBATO, E. (2004). Correção da acidez do solo. In: SOUSA, D. M. G.; LOBATO, E. (Ed.). Cerrado: correção do solo e adubação. Brasília: Embrapa Informação Tecnológica. p. 81-96.

SPARKS, D.L. (1989). Kinetics of soil chemical processes. London: Academic Press. 210p.

SPOSITO, G. (1984). The surface chemistry of soils. New York: Oxford University Press: 231p.

STICHER, H. \& BACH, R. (1966). Fundamentals in the chemical weathering of silicates. Soils Fert., 29:321-325. 
STILLINGS, L.L. \& BRANTLEY, S.L. (1995). Feldspar dissolution at 25 $\square$ C and pH 3: Reaction stoichiometry and the effect at cations. Geochimica et Cosmochimica Acta, v.59, p.1483-1496.

STUMM, W. \& MORGAN, J.J. (1996). Aquatic chemistry. New York, John Wiley \& Sons, 1022p.

STUMM, W. (1987). Aquatic Surface Chemistry: Chemical processes at the particlewater interface. New York: Wiley Interscience. 520p.

SWIADER, J.M.; CHYAN, Y.; FREIJI, F.G. (1994). Genotypic differences in nitrate uptake and utilization efficiency in pumpkin hybrids. J. Plant Nut., v.17. p.1687-99.

TÁVVORA, J.E.M. (1982). Reservas minerais de potássio e suas explorações. In: YAMADA, T.; IGUE, K.; MUZILLI, O.; USHERWOOD, N.R. (Eds.). Potássio na agricultura brasileira: Anais... Piracicaba: Instituto da Potassa \& Fosfato: Instituto Internacional da Potassa. p.37-50.

THORNTHWAITE, C.W. (1948). An approach toward a rational classification of climate. Georg. Rev., v.38, p.55-94.

TISDALE, S.L. \& NELSON, W.L. (1993). Soil fertility and fertilizers. 5.ed. New York, Macmillan. 634p.

TOLEDO, M.C.M., OLIVEIRA, S.M.B. \& MELFI, A.J. (2008). Intemperismo e formação dos solos. In: TEIXEIRA, W., FAIRCHILD, T.R., TOLEDO, M.C.M. \& TAIOLI, F., Eds., Decifrando a Terra. 2ed. São Paulo: Companhia Editora Nacional. p.210-239.

TORRES, J. L. R.; PEREIRA, M. G. (2008). Dinâmica do potássio nos resíduos vegetais de plantas de cobertura no Cerrado. Revista Brasileira de Ciência do Solo, Viçosa, v. 32, n. 4, p. 1609-1618.

VAHL, L.C., SILVEIRA, R.J.C. \& NACHTIGALL, G. (1987). Disponibilidade de potássio para plantas em solos da região Sul do Rio Grande do Sul. Pelotas, Universidade Federal de Pelotas. Projeto FIPEC -Relatório Final.

VAHL, L.C.; ANGHINONI, I. \& VOLKWEISS, S.J. (1993). Cinética de absorção de potássio afetada por ferro, cálcio e magnésio em genótipos de arroz de diferentes sensibilidades à toxidez de ferro. R. Bras. Ci. Solo, 17:269-273.

VAN STRAATEN, P. (2002). Rocks for crops: Agrominerals of Sub-Saharan Africa. ICRAF, Nairobi, Kenya, 338p.

VAN STRAATEN, P. (2006). Farming with rocks and minerals: challenges and opportunities. Anais da Academia Brasileira de Ciência. 78(4): p.731-747.

VETTORI, L. (1969). Métodos de análises de solos. Rio de Janeiro: Ministério da Agricultura. 34 p. (Boletim Técnico, 7).

WHITE, A.F. (1995). Chemical weathering rates in soils. In: WHITE, A.F. \& BRANTLEY, S.L., eds., Chemical Weathering Rates of Silicate Minerals. Mineralogical Soc. Amer., vol. 31, pp. 407- 458.

WHITE, A.F., BLUM, A.E., BULLEN, T.D., VIVIT, D.V., SCHULZ, M. \& FITZPATRICK, J. (1999). The effect of temperature on experimental and natural chemical weathering rates of granitoid rocks. Geochimica et Cosmochimica Acta, v.58, p.2761-2775. 
WHITE. A.F. \& BRANTLEY, S.L. (2003). The effect of time on the weathering of silicate minerals: why do weathering rates differ in the laboratory and field? Chemical Geology, 202:479-506.

WIELAND, E., WEHRLI, B. \& STUMM, W. (1988). The coordination chemistry of weathering: III. A generalization on the dissolution rates of minerals. Geochimica at Cosmochimica Acta, v.52, p.1969-1981.

WINIWARTER, V. \& BLUM, W.E.H. (2008). From marl to rock powder: on the history of soil fertility management by rock materials. J. Plant Nutr. Soil Sci. 171, p.316-324.

WOLLAST, R. (1967). Kinetics of alteration of K-feldspar in buffered solutions at low temperature. Geochimica et Cosmochimica Acta, v.31, p.3113-3121.

WOLT, J. (1994). Soil solution chemistry: applications to environmental science and agriculture. New York, John Wiley \& Sons, 345p.

WOOD, S.; SEBASTIAN, K.; SCHERR, S.(2001). Soil resource condition. In: Pilot analysis of global ecosystems: agroecosystems. A joint study by the International Food Policy Research Institute and World Resources Institute, International Food Policy Research Institute and World Resources Institute, Washington DC, 2001. p. 45-54.

YAMADA, T. \& LOPES, A.S. (1999). Balanço de nutrientes na agricultura brasileira. In: SIQUEIRA, J.O.; MOREIRA, F.M.S.; LOPES, A.S.; GUILHERME, L.R.G.; FAQUIN, V.; FURTINI NETO, A.E. \& CARVALHO, J.G., eds. Inter-relação fertilidade, biologia do solo e nutrição de plantas. Viçosa, MG, Sociedade Brasileira de Ciência do Solo, Universidade Federal de Viçosa. p.143-161. 